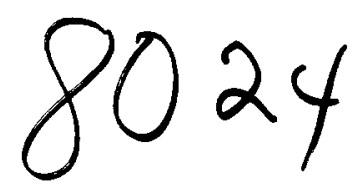

C.

$-8232-2 / 65511$
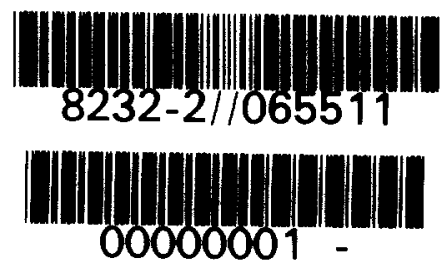

\title{
MELCOR Validation and Verification 1986 Papers
}

Christi D. Leigh, Editor

\section{Prepared by}

Sandia National Laboratories

Albuquerque, New Mexico 87185 and Livermore, California 94550

for the United States Department of Energy

under Contract DE-AC04-76DP00789

\section{Prepared for}

\section{U. S. NUCLEAR REGULATORY COMMISSION}




\section{NOTICE}

This report was prepared as an account of work sponsored by an agency of the United States Government. Neither the United States Government nor any agency thereof, or any of their employees, makes any warranty, expressed or implied, or assumes any legal liability or responsibility for any third party's use, or the results of such use, of any information, apparatus product or process disclosed in this report, or represents that its use by such third party would not infringe privately owned rights.

\section{Available from}

Superintendent of Documents

U.S. Government Printing Office

Post Office Box 37082

Washington, D.C. 20013-7082

and

National Technical Information Service Springfield, VA 22161 


\title{
NUREG/CR -4830 \\ SAND86-2689
}

R3

\section{MELCOR Validation and Verification 1986 Papers \\ Christi D. Leigh, Editor}

March 1987

\author{
Sandia National Laboratories \\ Albuquerque, New Mexico 87185 \\ Operated by \\ Sandia Corporation \\ for the \\ U.S. Department of Energy
}

Prepared for

Division of Reactor System Safety

Office of Nuclear Regulatory Research

U.S. Nuclear Regulatory Commission

Washington, D.C. 20555

Under Memorandum of Understanding DOE 40-550-75

NRC Fin No. A1369 

This report is a compilation of papers that documents the MELCOR validation and verification results obtained during 1986. It is intended that a report of this nature be published annually. The format used for this report follows that of a conference proceeding in that individual papers from various authors are combined into one report. This format was selected in part to encourage participation from MELCOR users outside Sandia. The format also has other advantages. One is that authors of individual papers can be properly credited. Another is that different reviewers can be selected for each test according to their expertise, and the review load can be distributed. Finally, each test report can be prepared, reviewed, and distributed individually before the composite report is published. 

MELCOR 1.6 Calculations for Adiabatic Expansion of Hydrogen, Two-cell Flow

C. D. Leigh and S. E. Dingman

MELCOR 1.6 Calculations for a Saturated Liquid Depressurization Test

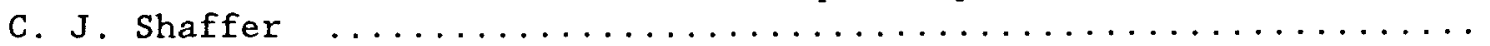

MELCOR 1.6 Calculations for the HDR Containment Experiment V44

C. J. Shaffer ................................ $3-1$

MELCOR 1.0 Calculations for the Battelle-Frankfurt Gas Mixing Tests

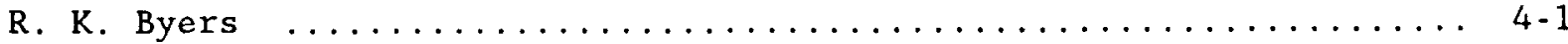

MELCOR 1.0 and HECTR 1.5 Calculations for Browns Ferry Reactor Building Burns

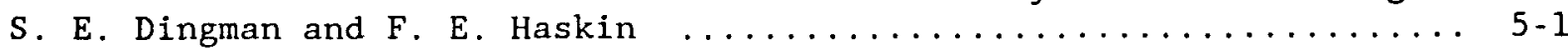

MELCOR 1.0 Calculations for Cooling of a Structure in a Fluid

P. N. Demmie ................................ $6-1$

MELCOR 1.0 Calculations for Radial Conduction in Annular Structures

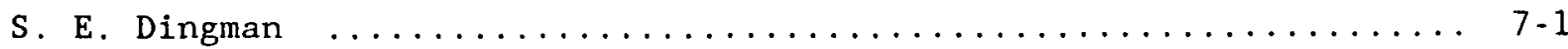

MELCOR 1.1 Calculations for a Semi-infinite Solid Heat Structure Test

C. J. Shaffer ............................... $8-1$

MELCOR 1.5 Calculations for ABCOVE Aerosol Experiments AB5, AB6, and AB7

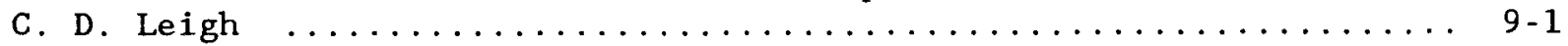

Appendix A: MELCOR standard Test Problems from $1986 \ldots \ldots \ldots \ldots \ldots \ldots$ A-1

Appendix B: Input Decks for MELCOR Standard Test Problems $\ldots \ldots \ldots \ldots \ldots$ B-1

ST001: Adiabatic Expansion of Hydrogen $\ldots \ldots \ldots \ldots \ldots \ldots \ldots \ldots \ldots \ldots$ B-1

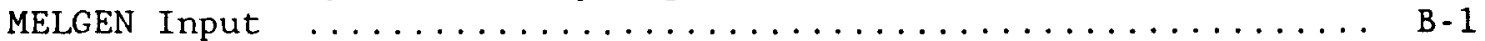

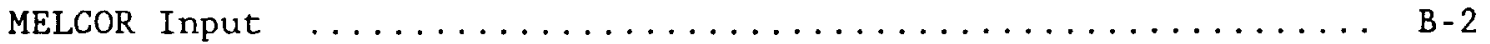

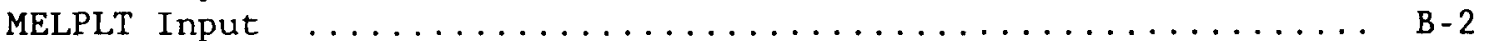

Analytical Data ........................ B 3

ST002: Radial Conduction in Annular structures $\ldots \ldots \ldots \ldots \ldots \ldots \ldots$ B-4

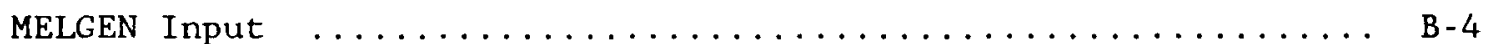

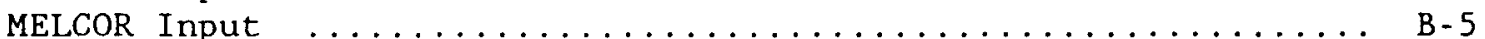

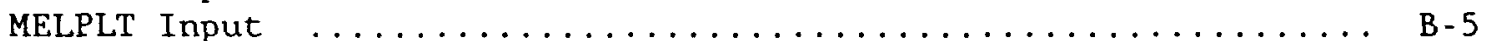

ST003: Cooling of a Structure in a Fluid $\ldots \ldots \ldots \ldots \ldots \ldots \ldots \ldots$ B-6

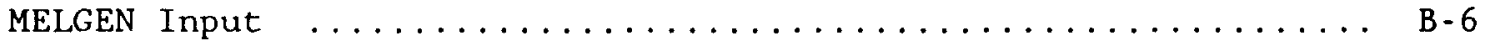

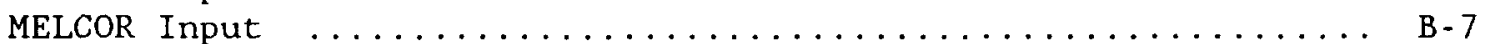

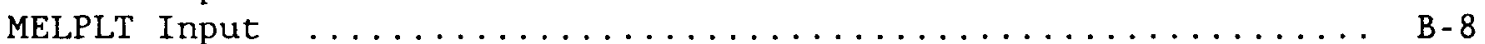

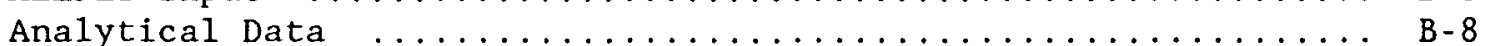

ST004: Semi-infinite Heat Structure Test $\ldots \ldots \ldots \ldots \ldots \ldots \ldots \ldots \ldots$ B-10

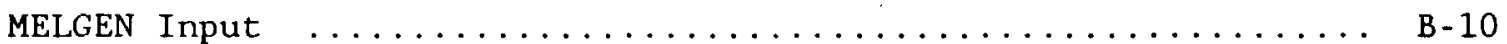




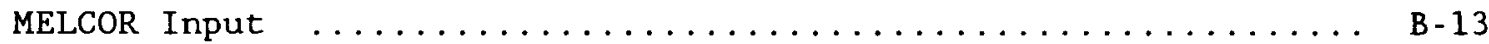

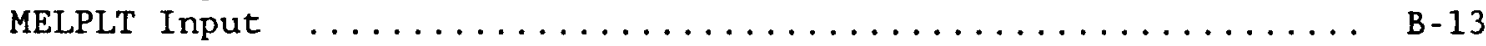

ST005: Saturated Liquid Depressurization Test $\ldots \ldots \ldots \ldots \ldots \ldots \ldots$ B 20

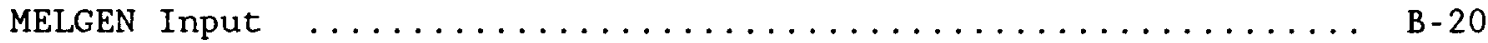

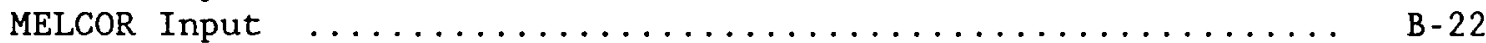

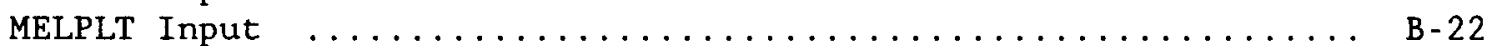

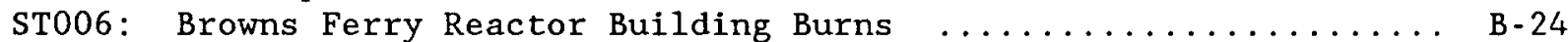

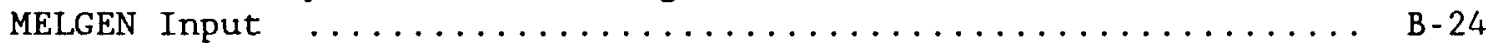

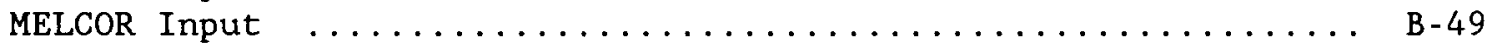

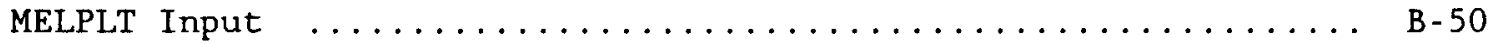

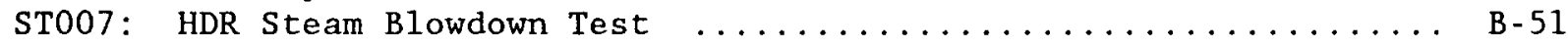

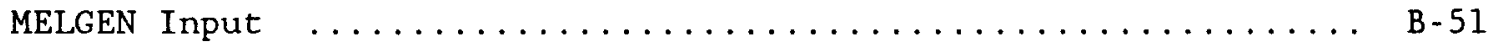

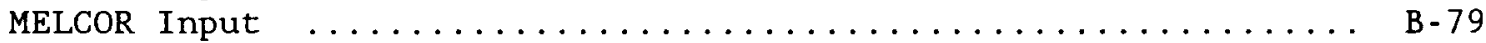

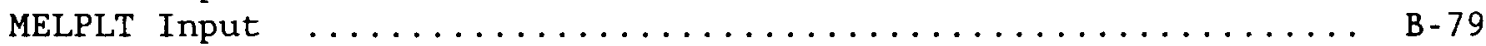

ST008: ABCOVE Aerosol Experiments Test AB6 ................ B-86

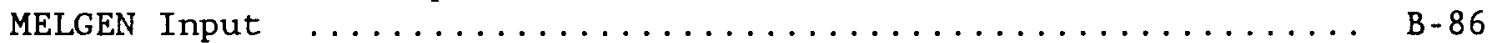

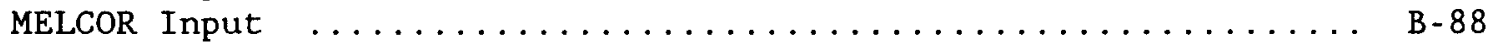

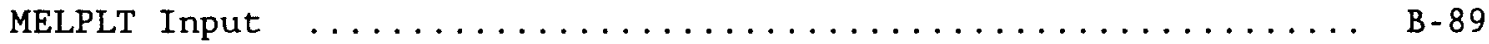

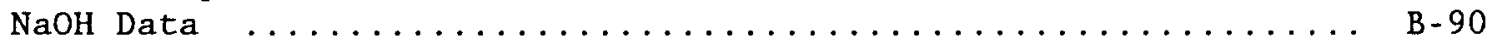

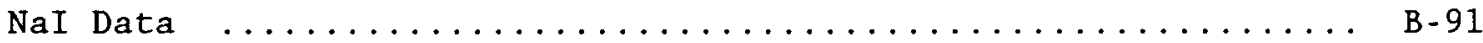

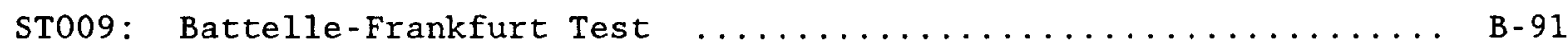

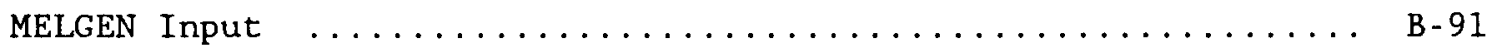

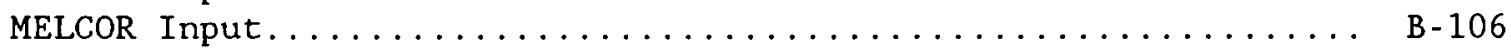

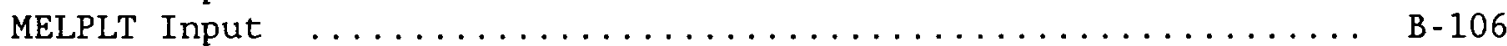

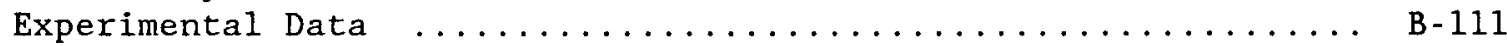

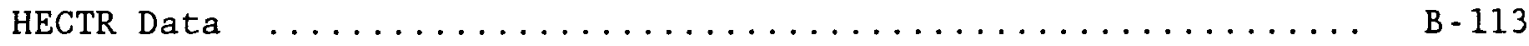

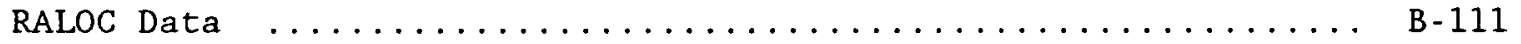

Appendix C: Comparison Plots for MELCOR Standard Test Problems $\ldots . \ldots$. C-1

Distributon $\quad$ Dist-1 
Preface

MELCOR is a fully integrated, relatively fast running code that models the progression of severe accidents in light water nuclear power plants (LWRs). An entire spectrum of severe accident phenomena is modeled in MELCOR.

Characteristics of severe accident progression that can be modeled in MELCOR include the thermal hydraulic response in the reactor coolant system, reactor cavity, containment, and confinement buildings; core heatup and degradation; hydrogen production, transport and combustion; core-concrete attack; heat structure response; radionuclide release and transport; and the impact of engineered safety features on thermal hydraulic and radionuclide behavior. MELCOR is being developed at Sandia National Laboratories for the United States Nuclear Regulatory Commission (NRC) to succeed the Source Term Code Package. MELCOR has been designed to facilitate sensitivity and uncertainty analyses and is currently being used to analyze severe-accident progression, source terms and associated sensitivities and uncertainties in several NRC-sponsored research programs.

The NRC in its report "Validation and Verification" [1], has established a multilevel approach to code validation. On the first level, past and near-term future experimental results that are suitable for code validation are identified. On the second level, specific comparisons to relevant experimental data with each of the detailed mechanistic codes are performed. On the third level, the SCTP and MELCOR calculations are compared to the detailed mechanistic code calculations. The cases for comparison, when possible, will be a subset of the same cases selected for data comparisons with the detailed mechanistic codes. This selection process will produce code-to-code as well as code-to-data comparisons for the integrated codes.

This report is a compilation of papers that documents the MELCOR validation and verification results obtained during 1986. It is intended that a report of this nature be published annually. The format used for this report follows that of a conference proceeding in that individual papers from various authors are combined into one report. This format was selected in part to ençourage participation from MELCOR users outside Sandia. The format also has other advantages. One is that authors of individual papers can be properly credited. Another is that different reviewers can be selected for each test according to their expertise, and the review load can be distributed. Finally, each test report can be prepared, reviewed, and distributed individually before the composite report is published.

Validation and verification loosely refer to the processes undertaken to achieve confidence in computer codes. Fairley [2] indicates that validation addresses the question, "Are we building the right product?" It is the "process that defines the domains wherein solutions generated by the software are acceptable representatives of physical processes." As a practical matter, we principally use the term validation to refer to the comparison of code predictions with experimental results. The experiments selected for comparison may examine separate effects or be integral in nature (i.e., several code modules must be exercised simultaneously in order to simulate integral experiments). 
According to Fairley, verification involves answering the question, "Are we building the product right?" He calls it the "process which demonstrates that the software correctly performs its stated capabilities." Verification is achieved via detailed inspections of coding and by performing tests specifically designed to identify defects that may exist in the various code modules. In this report, verification tests are frequently comparisons of MELCOR predictions to analytic solutions or to results obtained using other we11-established codes.

The terms test and testing are used herein to refer to comparisons of MELCOR predictions to results obtained from any other source-experimental, analytic, or other codes. The process of comparing one code's predictions to those obtained using other codes is referred to as benchmarking. Figure 1 depicts the conceptual overlap of the commonly used terms validation, verification, testing, inspection, and benchmarking.

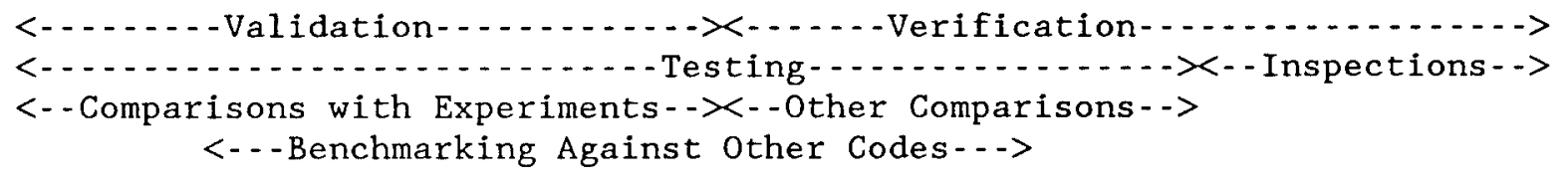

Figure 1. Definition of Terms Related to Validation

All of the tests that are included in this report were conducted at Sandia National Laboratories. We believe that on-site testing (testing at Sandia) is essential to the development of the code. Also, on-site testing is needed in order to establish a set of standard test problems that can be used to check revised versions of the code. However, for formal tests such as those documented in this report, we agree with G. J. Myers of IBM that, "It is impossible to test your own program." [3] Therefore, in no case is the developer of a module assigned the task of formally testing that module. In fact, it is expected that tests of MELCOR conducted outside of Sandia will be included as part of future MELCOR validation and verification reports.

Another important part of validation and verification philosophy is also taken from Myers [3], "Never alter the program to make testing easier." MELCOR has evolved substantially since our validation and verification efforts began. Although guided in part by the results of early validation and verification tests, the revisions that have been made to MELCOR over the last year were not done with any specific test in mind. Al1 of the tests were run on established versions of the code. The version of the code that was used to perform the test is given in the title of each paper.

MELCOR test problems are chosen on the basis of current technical and programmatic considerations. Such considerations include: 
1. MELCOR status and suitability of the current version for the test being considered

2. Availability of information required for preparation of the MELCOR input deck

3. Availability of results from other codes which would provide bases for comparison

4. Availability of resources required to perform the test

5. MELCOR models which would be invoked and their degree of testing to date

6. Usefulness of the input deck for future tests or applications

7. The risk significance of the phenomena or accident sequence modeled for the test

The structure that has been outlined for this program is designed to minimize duplication of effort, to select tests on the basis of well-defined priorities, and to document test results. At the same time, it is recognized that too much rigidity can be inhibitive, and excessive documentation requirements can be counterproductive. It is believed that with the current structure a balance is gained which maximizes the effectiveness of the overall validation and verification effort subject to resource constraints.

The tests that have been selected to date involve phenomena that take place in the containment of a light water reactor facility. This includes testing of the Burn Package, the Containment Spray Package, the Control Volume Hydrodynamics Package, the Heat Structure Package, and the Radionuclide Package. The focus has been primarily on containment phenomena because of the data available in that area and because the CONTAIN code developed at Sandia National Laboratories was available for comparison.

Some of the input decks used to develop the results presented in this report have been selected as standard test problems and run on the latest released version, MELCOR 1.6.0. A list of these standard test problems is given in Appendix A.

\section{References}

1. J. T. Larkins and M. A. Cunningham, Nuclear Power Plant Research Severe Accident Research Plan, U.S. Nuclear Regulatory Commission, Office of Regulatory Research, NUREG-0900, Revision 1 .

2. R. E. Fairley, Software Engineering Concepts, McGraw-Hill, New York, 1979.

3. G. J. Myers, Software Reliability, Wiley Interscience, NY, 1976. 

MELCOR 1.6 Calculations for Adiabatic Expansion of Hydrogen, Two-cel1 Flow

C. D. Leigh and S. E. Dingman Sandia National Laboratories Albuquerque, New Mexico 87185 United States of America

\begin{abstract}
MELCOR calculations for the adiabatic flow of hydrogen between two control volumes have been performed and compared to the closed form analytical solution. The MELCOR results differ only slightly from the analytical solution. The differences are caused by the use of a temperature dependent heat capacity in MELCOR, which introduces some deviation from the ideal gas as sumptions .
\end{abstract}

\title{
1. Introduction
}

This paper compares MELCOR predictions of the adiabatic flow of hydrogen between two control volumes to results obtained from an exact analytic solution for an ideal gas.

\section{Test Description}

Given two control volumes which are pressurized with hydrogen and the pressure in Control Volume 1 is greater than that in Control Volume 2, a flow path is opened between the two control volumes at time zero; hydrogen from the higher pressure control volume expands into the lower pressure control volume until the two pressures equilibrate. Assuming adiabatic flow and treating hydrogen as an ideal gas, analytic expressions for the control-volume temperatures and pressures as functions of the mass transferred are:

$$
\begin{aligned}
& \mathrm{T}_{1}=\mathrm{T}_{10}\left(\frac{\mathrm{m}_{1}}{\mathrm{~m}_{10}}\right)^{\gamma-1} \\
& \mathrm{P}_{1}=\mathrm{P}_{1 o}\left(\frac{\mathrm{m}_{1}}{\mathrm{~m}_{10}}\right)^{\gamma} \\
& \mathrm{T}_{2}=\frac{\mathrm{m}_{20} \mathrm{~T}_{2 o}}{\mathrm{~m}_{2}}+\frac{\mathrm{m}_{10} \mathrm{~T}_{1 o}}{\mathrm{~m}_{2}}\left[1-\left(\frac{\mathrm{m}_{1}}{\mathrm{~m}_{10}}\right)^{\gamma}\right]
\end{aligned}
$$




$$
\mathrm{P}_{2}=\mathrm{P}_{20}+\left(\frac{\mathrm{v}_{1}}{\mathrm{v}_{2}}\right) \mathrm{P}_{10}\left[1-\left(\frac{\mathrm{m}_{1}}{\mathrm{~m}_{10}}\right)^{\gamma}\right]
$$

where $\mathrm{T}_{1}, \mathrm{~T}_{10}, \mathrm{P}_{1}, \mathrm{P}_{10}, \mathrm{~m}_{1}$, and $\mathrm{m}_{10}$ are the temperature, initial

temperature, pressure, initial pressure, mass, and initial mass of the hydrogen in cell 1 and $\mathrm{T}_{2}, \mathrm{~T}_{20}, \mathrm{P}_{2}, \mathrm{P}_{20}, \mathrm{~m}_{2}$, and $\mathrm{m}_{20}$ are the temperature, initial temperature, pressure, initial pressure, mass, and initial mass of the

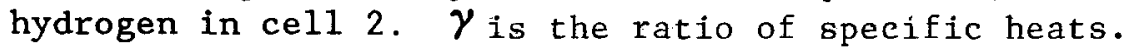

In this comparison, MELCOR is used to model the two-volume pressure equilibration. MELCOR results for the temperature and pressure in both control volumes (as a function of the mass remaining in the donor cell) are compared to values calculated with the closed form analytic solution.

\section{Model and Case Descriptions}

MELCOR was used to model the adiabatic flow of hydrogen between two control volumes as described in Section 2. The initial conditions, control volume sizes, and flow path parameters were varied over a wide range to provide a thorough test of the MELCOR packages. Six cases were run according to the specifications given in Table 1 .

Table 1. Specifications for MELCOR Runs

\begin{tabular}{|c|c|c|c|c|c|c|c|}
\hline \multirow{2}{*}{$\begin{array}{c}\text { Case } \\
\text { No. }\end{array}$} & \multirow{2}{*}{$\begin{array}{l}\operatorname{Vol}(1) \\
\left(\mathrm{m}^{3}\right)\end{array}$} & \multirow{2}{*}{$\begin{array}{l}\operatorname{Vol}(2) \\
\left(\mathrm{m}^{3}\right)\end{array}$} & \multicolumn{3}{|c|}{ Initial Conditions } & \multirow{2}{*}{$\begin{array}{l}\text { Flow } \\
\text { Area } \\
\left(\mathrm{m}^{2}\right)\end{array}$} & \multirow{2}{*}{$\begin{array}{l}\text { Loss } \\
\text { Coeff. } \\
(-)\end{array}$} \\
\hline & & & $\begin{array}{c}\mathrm{T}(1=2) \\
(\mathrm{K})\end{array}$ & $\begin{array}{l}\mathrm{P}(1) \\
(\mathrm{Pa})\end{array}$ & $\begin{array}{l}\mathrm{P}(2) \\
(\mathrm{Pa})\end{array}$ & & \\
\hline 1 & 1000 . & 1000. & 300 . & 2.E5 & 1.E5 & .05 & 2. \\
\hline 2 & 1000 & 1000 & 300. & $5 . \mathrm{E} 5$ & 1.E5 & .05 & 2. \\
\hline 3 & 100. & 1000 & 300 . & 2.E5 & 1.E5 & .05 & 2. \\
\hline 4 & 10000 & 1000 & 300. & 2.E5 & 1.E5 & .05 & 2. \\
\hline 5 & 1000 . & 1000 . & 300 . & 2. E5 & 1.E5 & 50. & 2. \\
\hline 6 & 1000. & 1000. & 300 . & 2.E5 & 1.E5 & .05 & .1 \\
\hline
\end{tabular}

\section{Results}

The analytic and MELCOR results for the six cases are compared in Figures 1 through 12. These figures show the temperatures and pressures for both cells as a function of the mass in Cell 1 . In all cases, the agreement is excellent. The slight differences are due in part to to using a temperature-dependent heat capacity in MELCOR which introduces some deviation from the gas assumption and in part to the time-step selection. 
In previous analyses of this test, oscillatory pressures and temperatures that diverged during the transient were calculated by MELCOR. The testers eliminated the oscillations in those calculations by forcing MELCOR to use a smaller time step (the maximum time step size was reduced from $10 \mathrm{~s}$ to $1 \mathrm{~s}$ ). The test has been repeated on a more recent version of MELCOR to determine whether or not this defect has been corrected and to examine a wider variation in parameters.

The oscillatory behavior that occurred when using an earlier version of MELCOR was not present in any of the cases examined here. As an example, plots of the transient temperatures, pressures, control volume masses, and system time step for Case 1 are included in Figure 13.

\section{Summary and Conclusions}

The previous MELCOR defect that produced oscillatory behavior for this test has been corrected. The current version of MELCOR (1.6) produces results that agree very well with the analytic solution. 


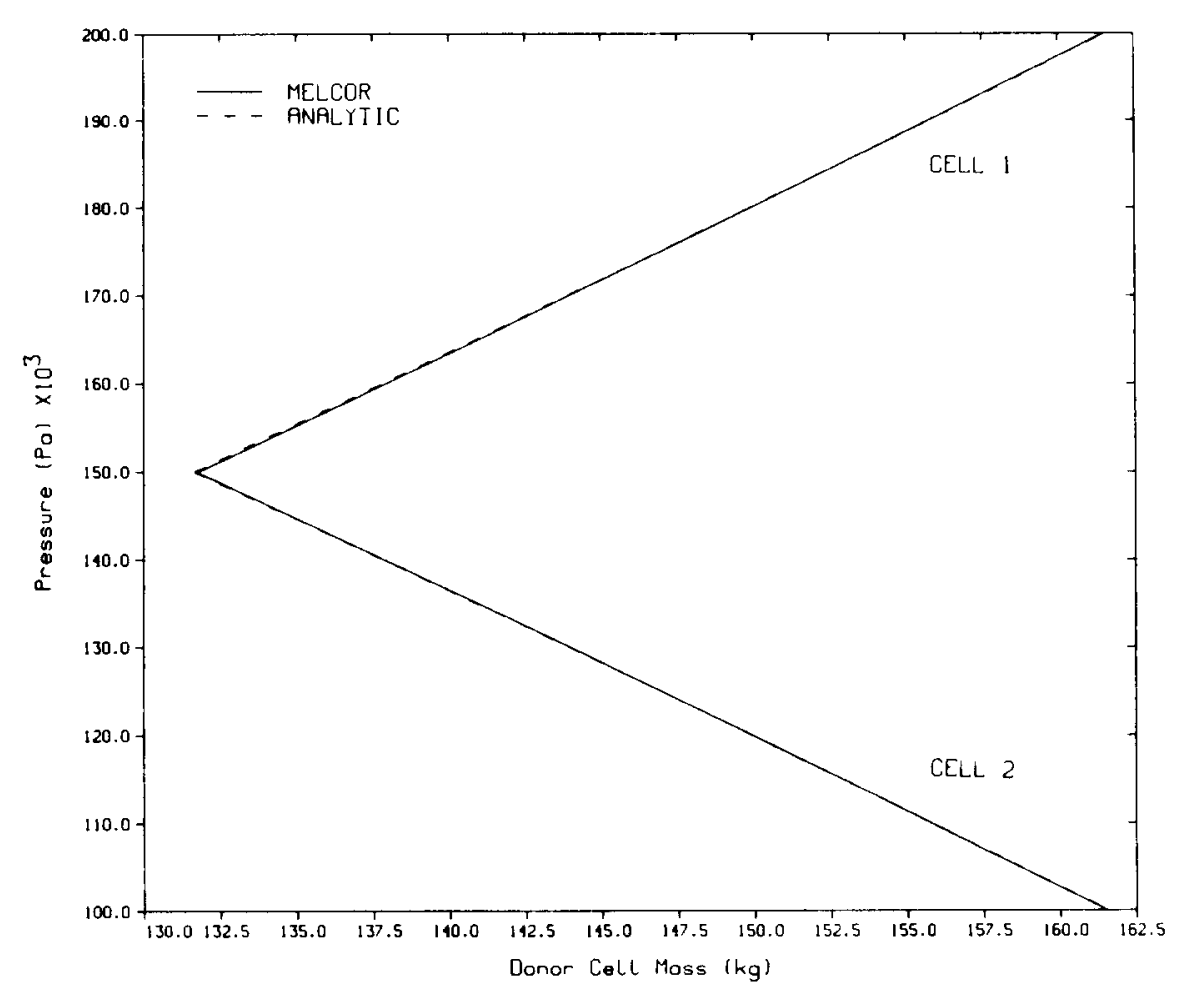

Figure 1. Pressure in Both Cells as a Function of Cel1 1 Mass for Case 1.

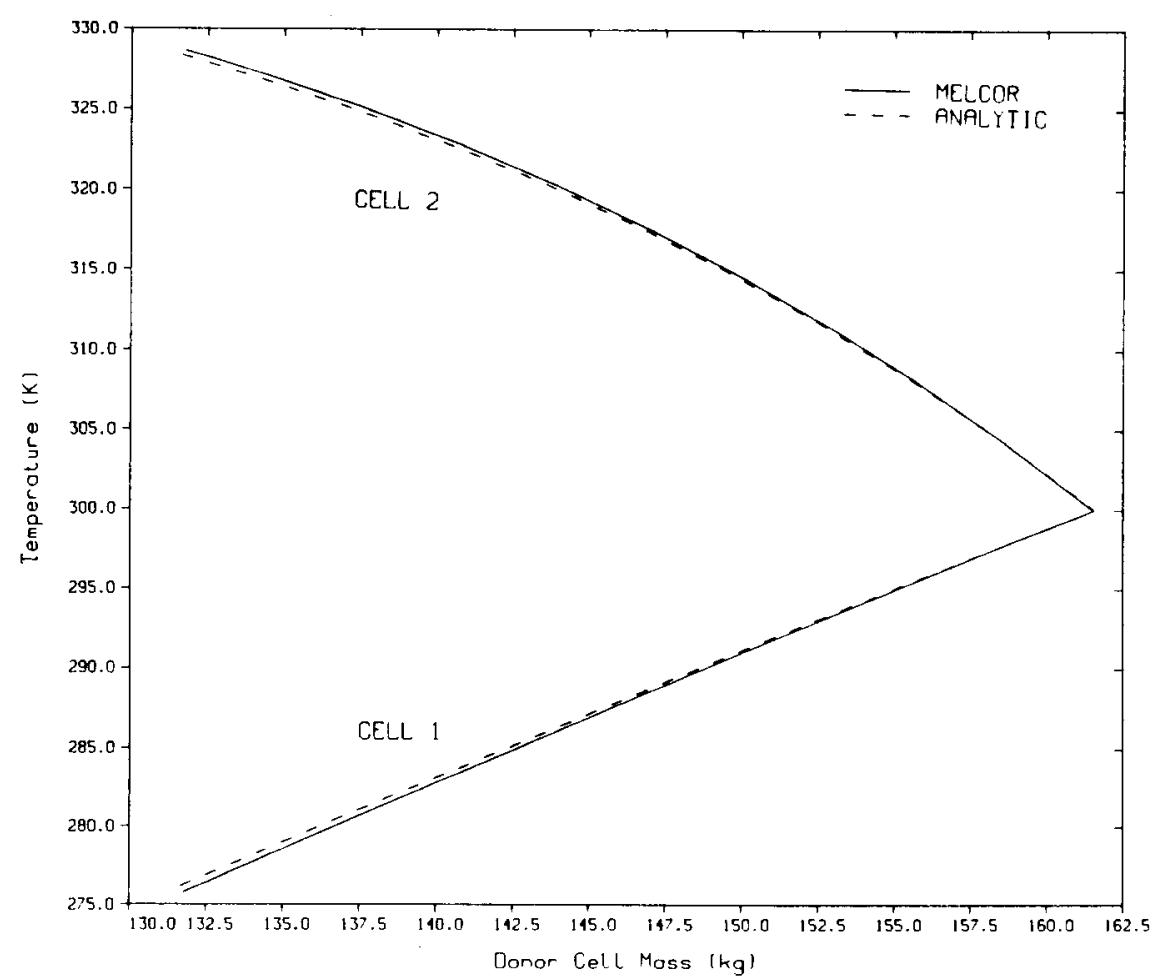

Figure 2. Temperature in Both Cells as a Function of Cell 1 Mass for Case 1. 


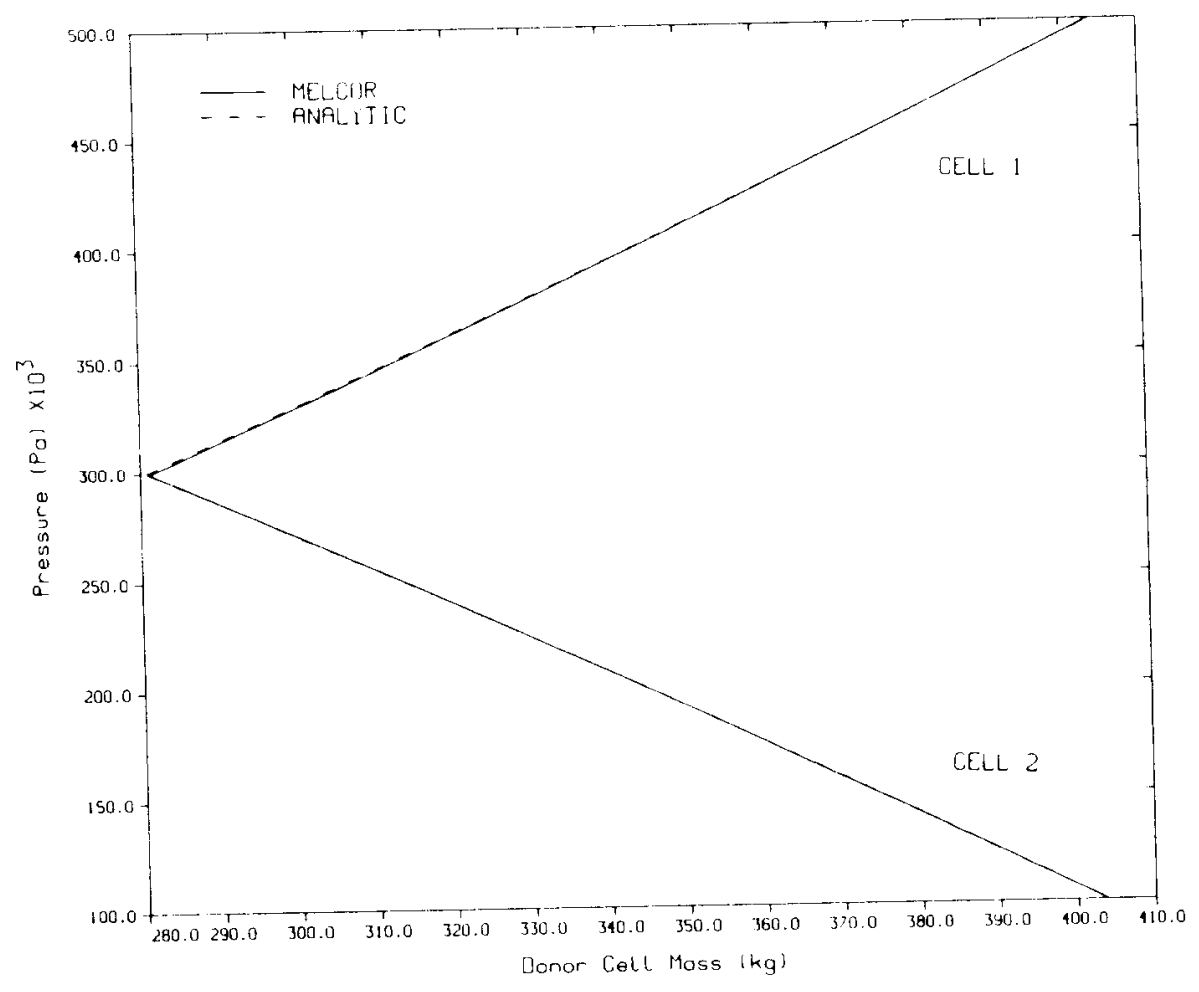

Figure 3. Pressure in Both Cells as a Function of Cell 1 Mass for Case 2.

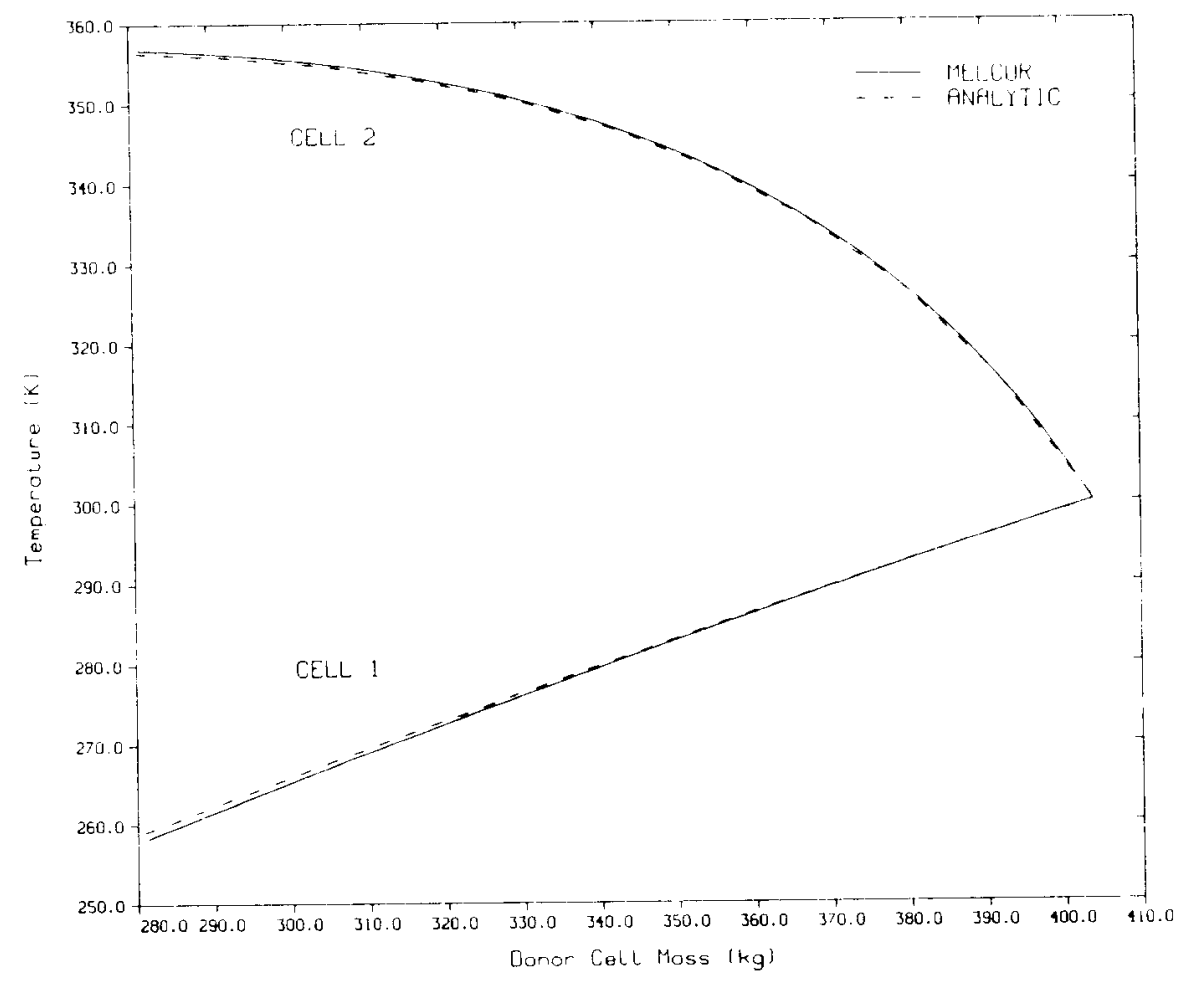

Figure 4. Temperature in Both Cells as a Function of Cell 1 Mass for Case 2. 


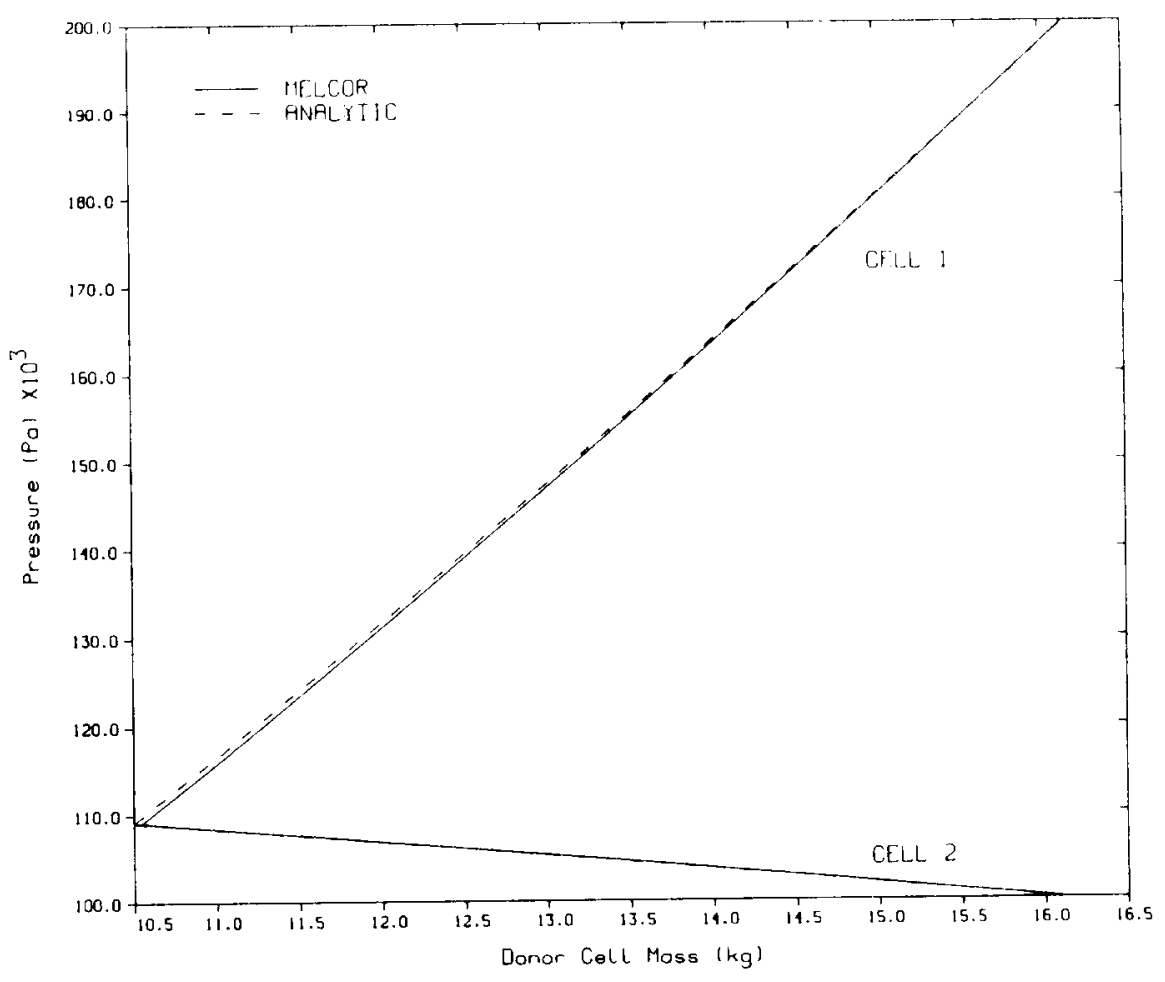

Figure 5. Pressure in Both Cells as a Function of Cell 1 Mass for Case 3.

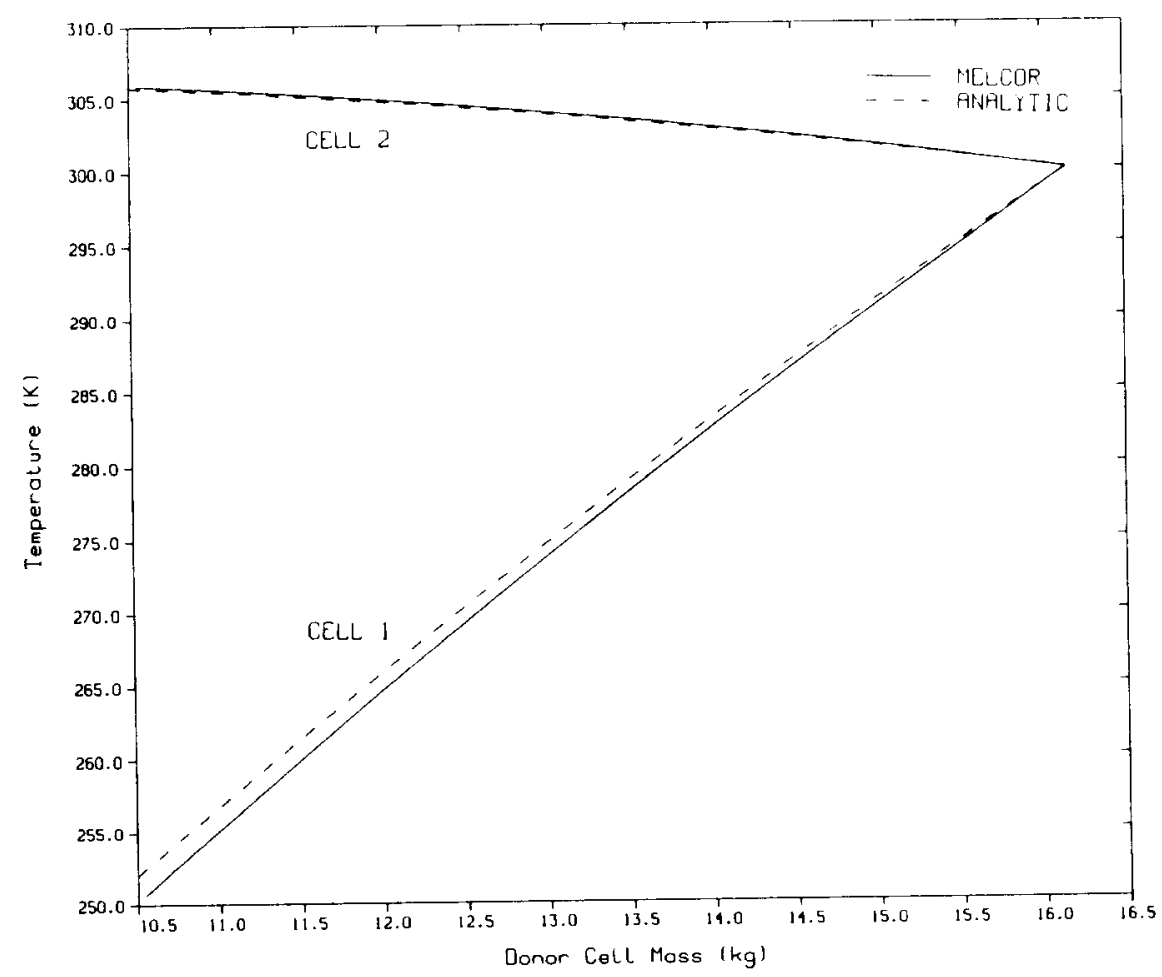

Figure 6. Temperature in Both Cells as a Function of Cell 1 Mass for Case 3. 


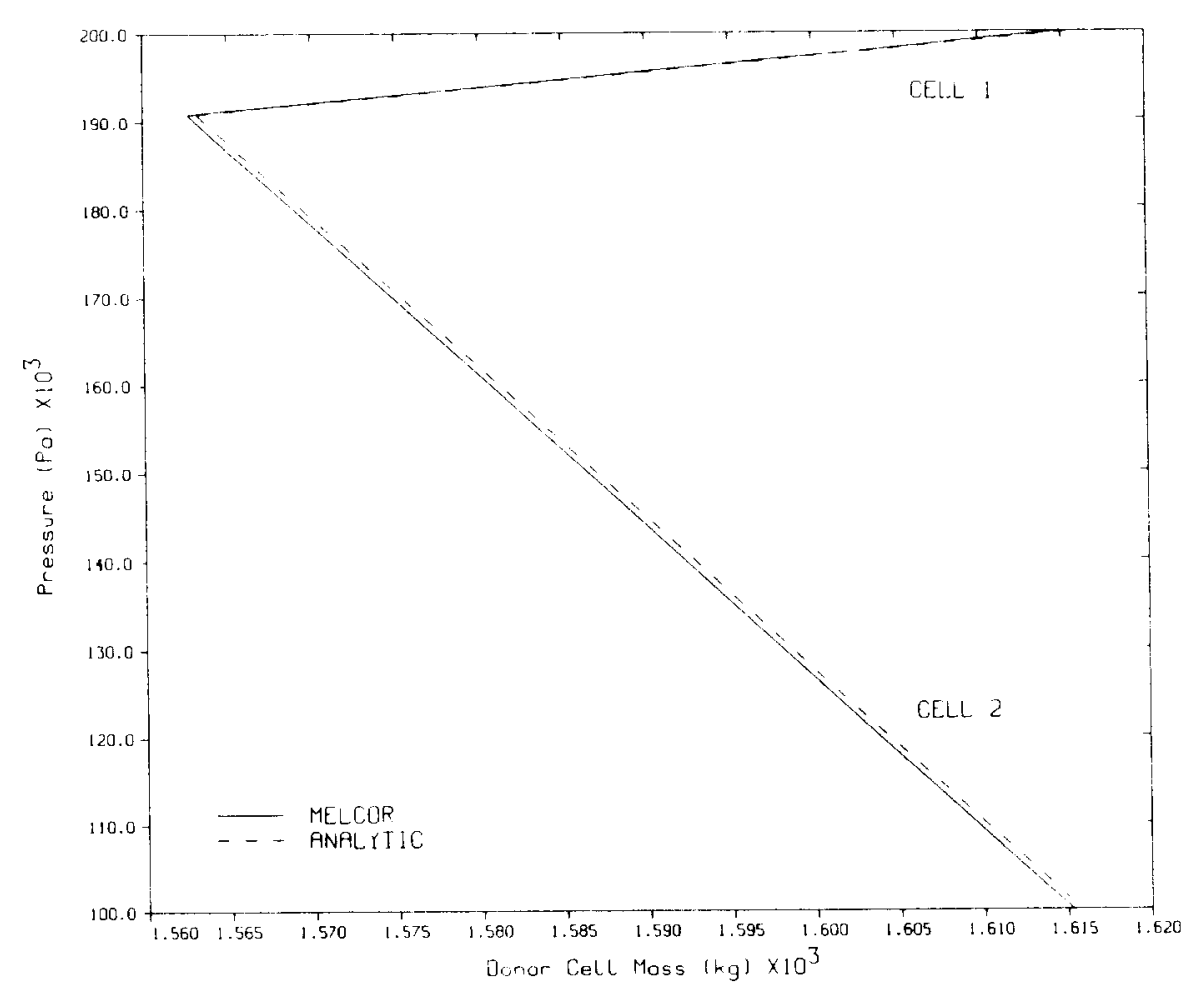

Figure 7. Pressure in Both Cells as a Function of Cell 1 Mass for Case 4.

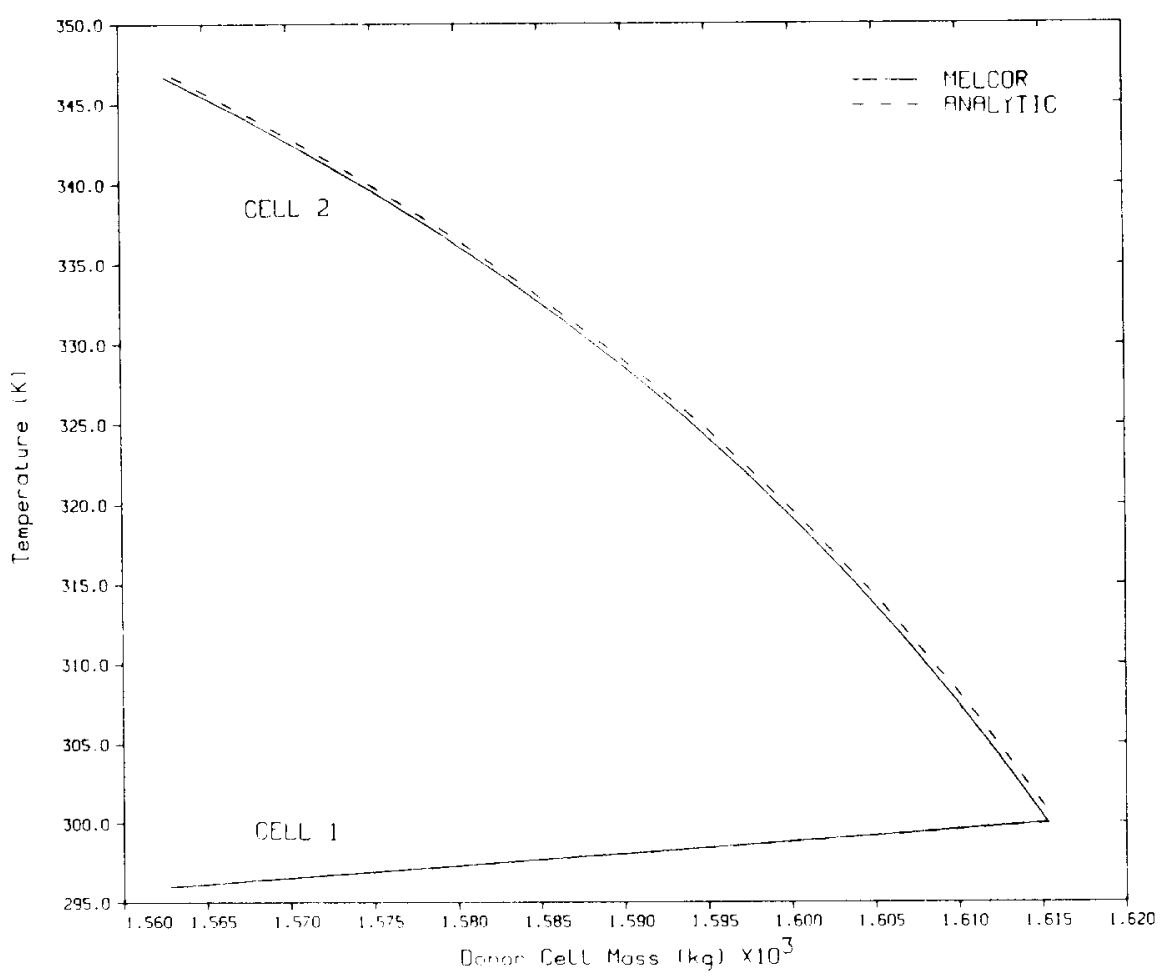

Figure 8. Temperature in Both Cells as a Function of Cel1 1 Mass Case 4. 


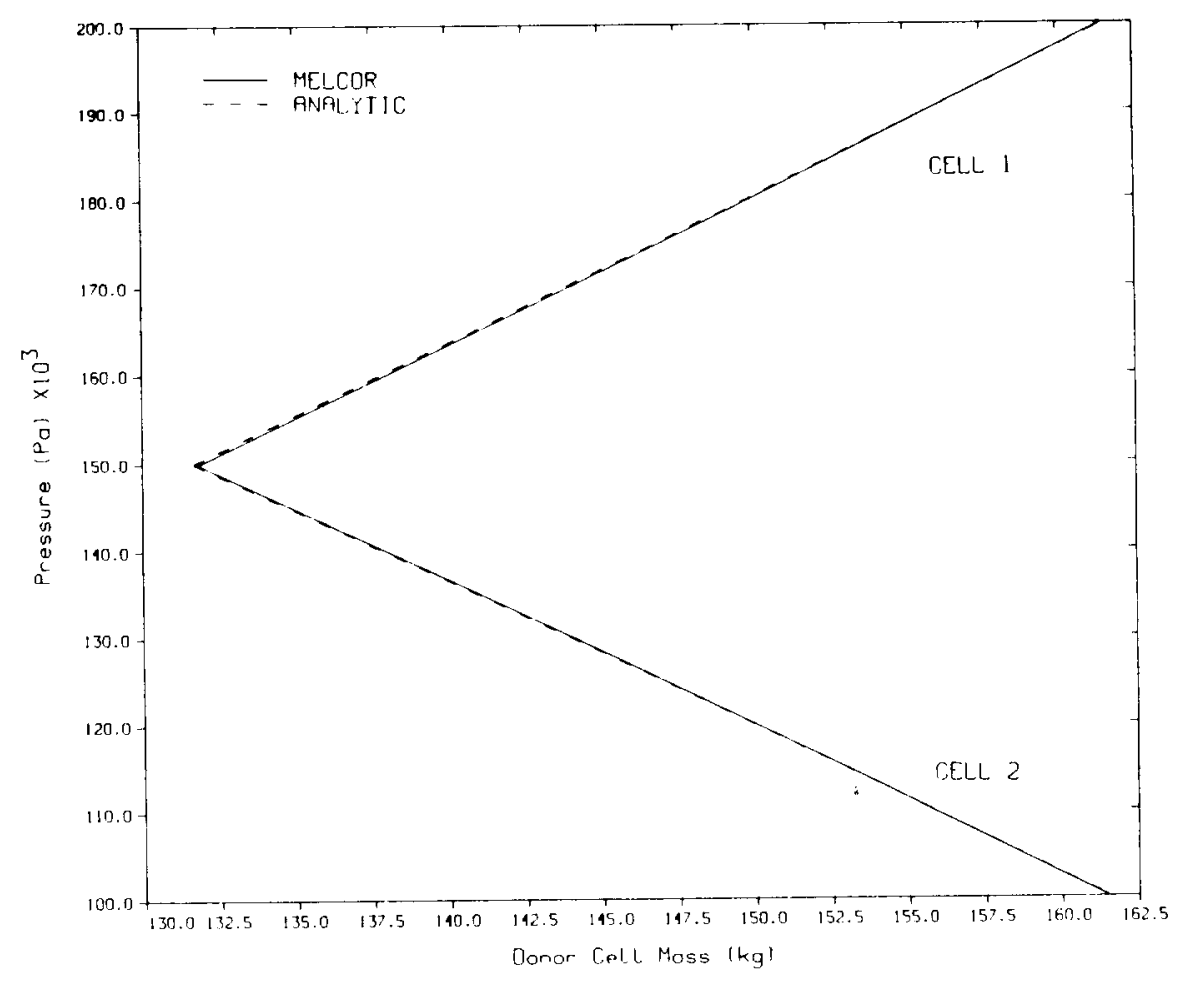

Figure 9. Pressure in Both Cells as a Function of Cell 1 Mass for Case 5.

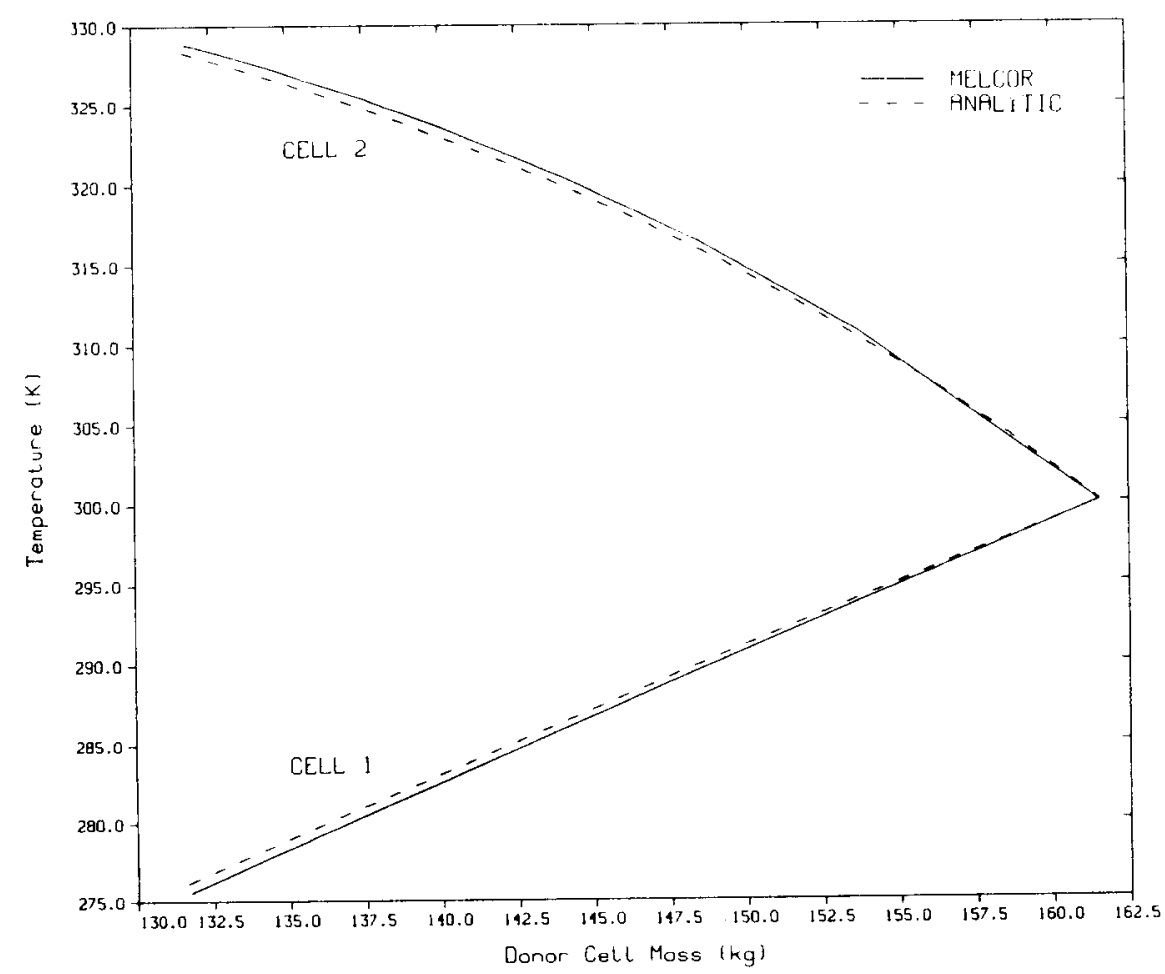

Figure 10. Temperature in Both Cells as a Function of Cel1 1 Mass Case 5. 


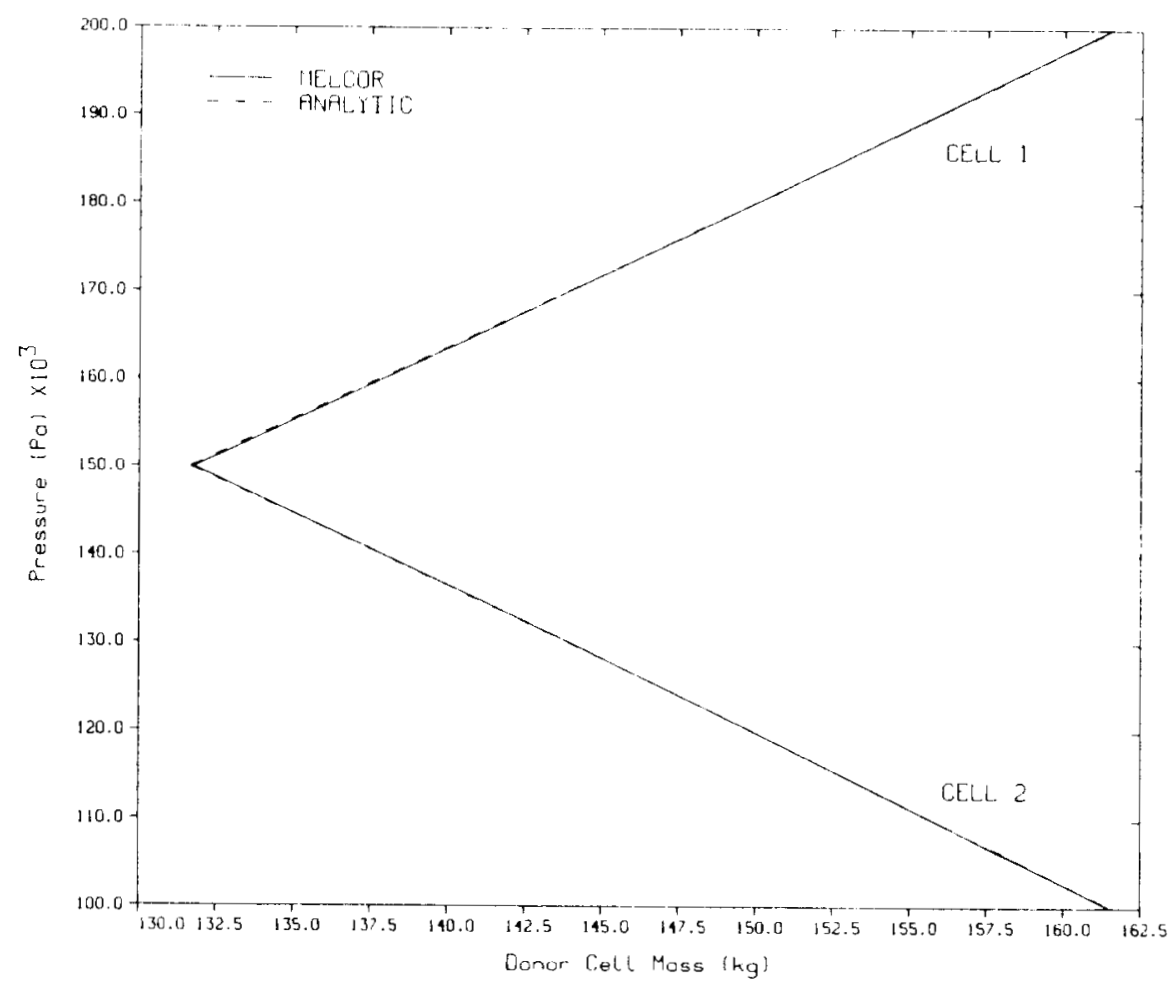

Figure 11. Pressure in Both Cells as a Function of Cell 1 Mass for Case 6.

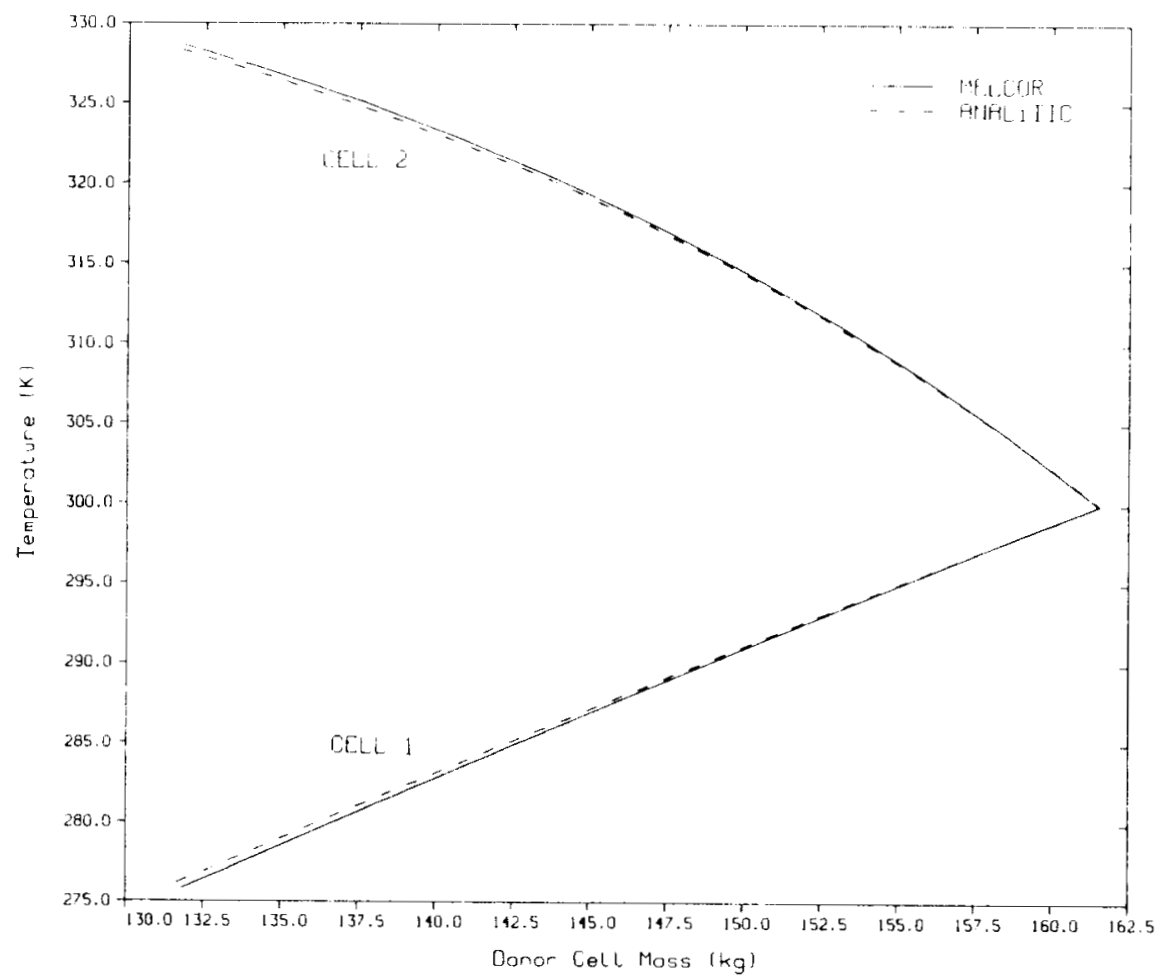

Figure 12. Temperature in Both Cells as a Function of Cel1 1 Mass Case 6. 

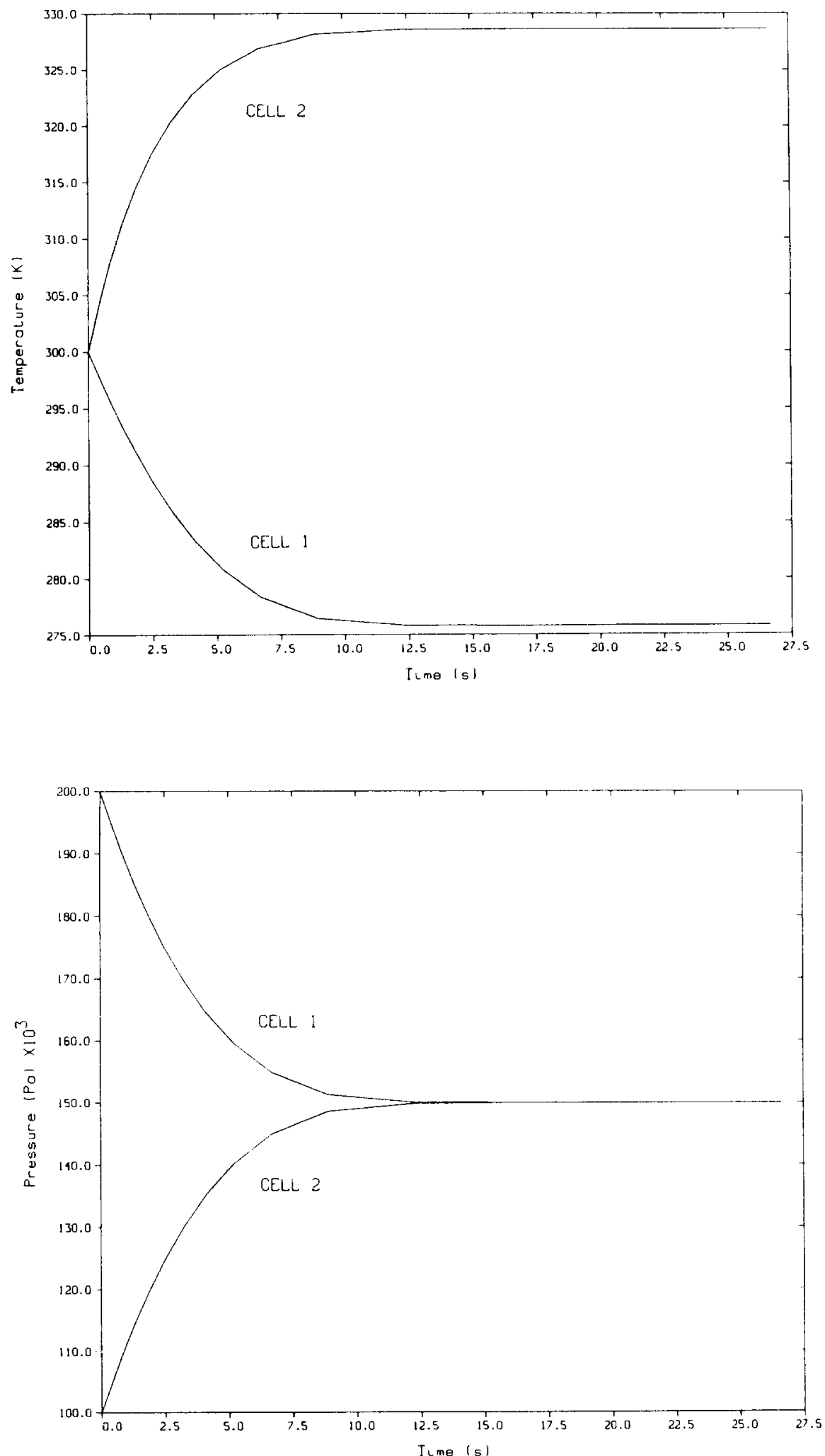

Figure 13. Time dependent Behavior for Case 1. 

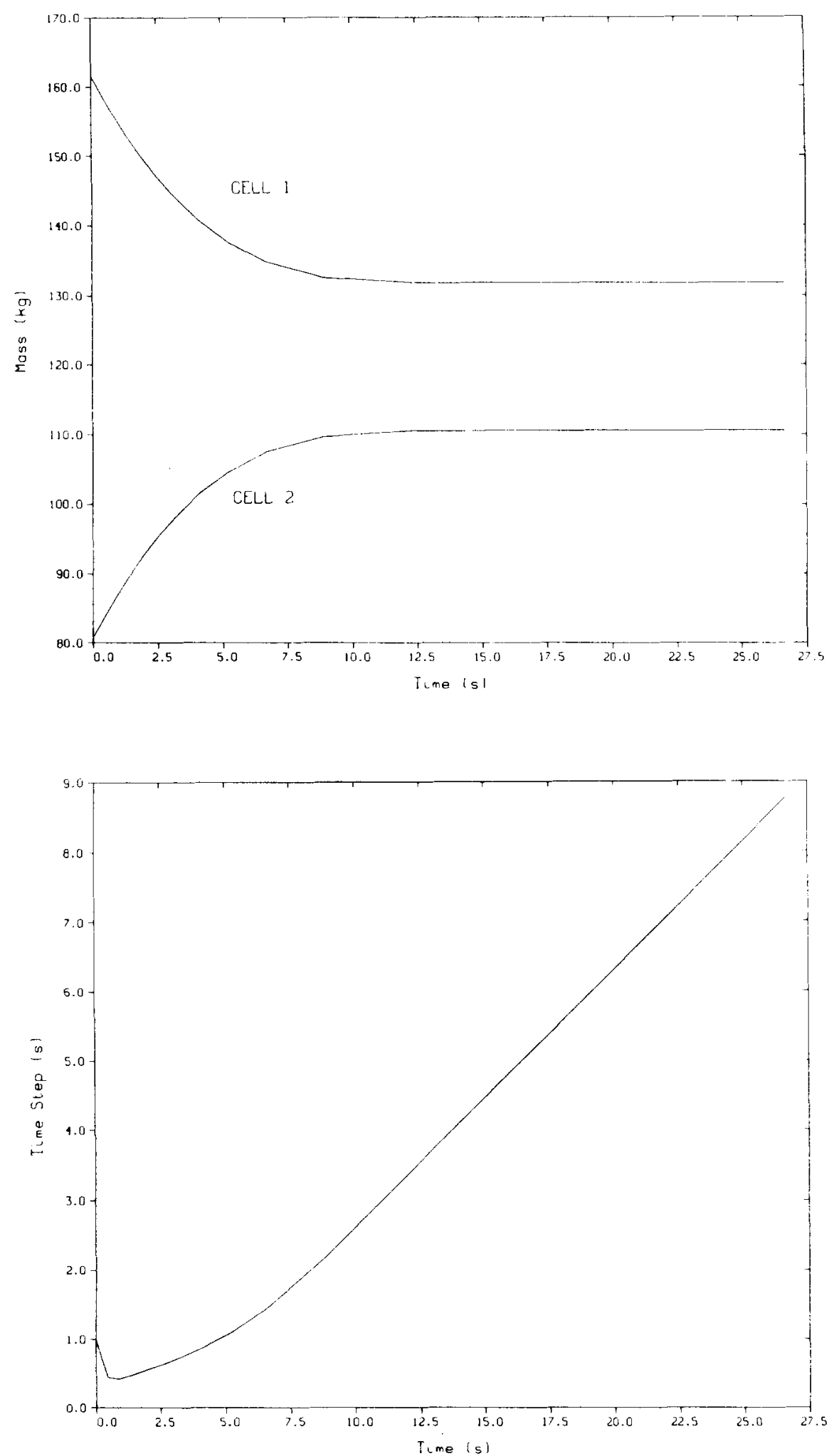

Figure 13 (cont.). Time dependent Behavior for Case 1. 

MELCOR 1.6 Calculations for a

Saturated Liquid Depressurization Test

C. J. Shaffer

Science and Engineering Associates

Albuquerque, New Mexico 87110

United States of America

\begin{abstract}
A simple test involving a volume containing saturated water at high pressure depressurizing into a second larger volume tests MELCOR's ability to predict the depressurization of a reactor vessel into its containment. The results show good agreement between the MELCOR and analytical solutions.
\end{abstract}

\title{
1. Introduction
}

The analysis of severe accidents involves predicting the depressurization of the reactor vessel into its containment. For some accident sequences, the reactor vessel contains significant quantities of high pressure, high temperature water which will undergo rapid flashing during depressurization. MELCOR's ability to predict this depressurization is tested using a simple model with an analytical solution.

\section{Test Description}

A volume containing saturated water at high pressure is connected to another volume containing only a low pressure steam atmosphere by a flow path and a heat structure. The flow path is opened at time zero and the system is allowed to come into pressure and thermal equilibrium. The heat structure which thermally equilibrates the two volumes is thin enough to be unimportant in the energy balances. The initial conditions are listed in Table 1 and the system is shown schematically in Figure 1.

Table 1. Initial Conditions for the Depressurization Test

\begin{tabular}{|l|c|c|}
\hline Initial Conditions & Volume 1 & Volume 2 \\
\hline Pressure (MPa) & 7.999 & 0.01 \\
Temperature (K) & 568.23 & 568.23 \\
Water Mass (kg) & 72240 & 0.0 \\
Steam Mass (kg) & 0.0 & 152.57 \\
Void Fraction & 0.0 & 1.0 \\
\hline
\end{tabular}




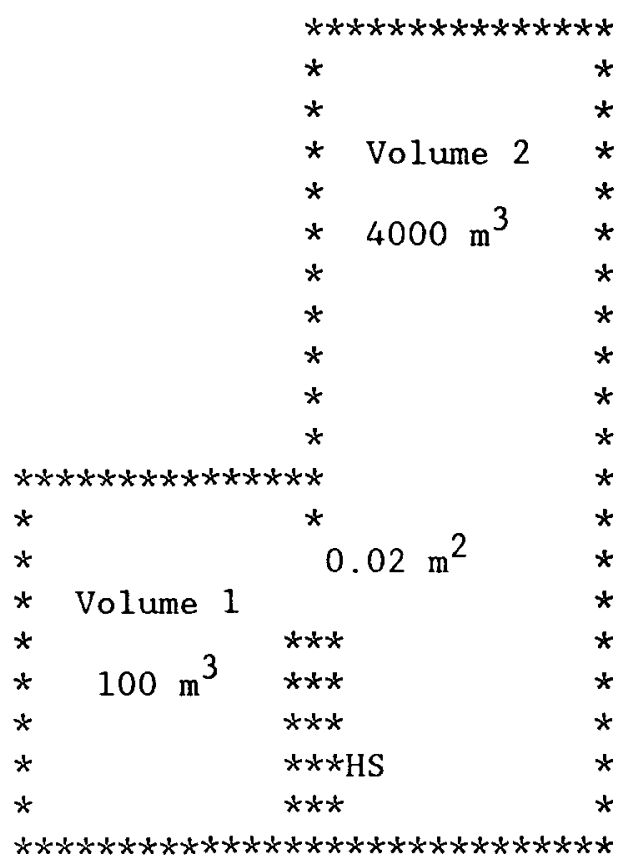

Figure 1: Mode1 Description

3. Analytical Solution

The analytical solution is obtained from mass and energy balances.

$$
\begin{aligned}
& u_{f}+x u_{f g}=\left(U_{o}+E_{s}\right) / M_{t} \\
& v_{f}+x v_{f g}=v / M_{t} \\
& u_{o}=M_{10} u_{10}+M_{20} u_{20} \\
& E_{s}=M_{S} C_{p}\left(T_{i}-T_{f}\right)
\end{aligned}
$$

where

$$
\begin{aligned}
& u_{f}=\text { specific internal energy of liquid } \\
& u_{f g}=\text { specific internal energy of evaporation } \\
& v_{f}=\text { specific volume of liquid } \\
& v_{f g}=\text { specific volume of evaporation } \\
& x=\text { steam quality at equilibrium } \\
& M_{t}=\text { total t20 mass } \\
& v=\text { total volume } \\
& M_{10}=\text { initial volume } 1 \text { mass } \\
& M_{20}=\text { initial volume } 2 \text { mass } \\
& u_{10}=\text { initial specific internal energy of volume } 1 \\
& u_{20}=\text { initial specific internal energy of volume } 2 \\
& M_{s}=\text { mass of structure }
\end{aligned}
$$


$C_{p}=$ structure specific heat

$T_{i}^{P}=$ initial structure temperature

$\mathrm{T}_{\mathrm{f}}=$ final structure temperature

This test was designed with $\mathrm{E}_{\mathbf{S}}$ about six orders of magnitude smaller than $\mathrm{U}_{\mathrm{o}}$ so the structure can be removed from the energy balance.

Using the Keenan and Keyes[1] steam tables and the initial conditions of Table 1 , the above equations reduce to the following.

$$
\begin{aligned}
& \mathrm{u}_{\mathrm{f}}+\mathrm{xu}_{\mathrm{fg}}=1.30886 \mathrm{E} 6 \quad(\mathrm{~J} / \mathrm{kg}) \\
& \mathrm{v}_{\mathrm{f}}+\mathrm{x} \mathrm{v}_{\mathrm{fg}}=0.0566356 \quad\left(\mathrm{~m}^{3} / \mathrm{kg}\right)
\end{aligned}
$$

Equations 5 and 6 are solved for the steam quality by iterating on pressure. The final values are $1.037 \mathrm{MPa}$ with a saturation temperature of $454.7 \mathrm{~K}$ and a quality of 0.297 .

\section{Results}

The MELCOR results are compared to the analytical solution in Table 2 . The MELCOR calculation was run using MELCOR 1.6 on a VAX and the results taken from the largest volume (volume 2). At the end of the calculation ( 3000 seconds), the pressures and temperatures of the two volumes differed by only $0.0003 \mathrm{MPa}$ and $0.28 \mathrm{~K}$.

\begin{tabular}{|c|c|c|c|c|}
\hline & & Analytical & MELCOR & Difference \\
\hline Pressure & $\begin{array}{l}\text { MPa } \\
\text { Psia }\end{array}$ & $\begin{array}{l}1.037 \\
150.6\end{array}$ & $\begin{array}{l}1.034 \\
150.0\end{array}$ & $\begin{array}{ll}0.003 & (0.38) \\
0.6 & \end{array}$ \\
\hline Temperature & $\begin{array}{l}\mathrm{K} \\
\mathrm{F}\end{array}$ & $\begin{array}{l}454.7 \\
358.8\end{array}$ & $\begin{array}{l}454.8 \\
359.0\end{array}$ & $\begin{array}{l}0.1 \\
0.2\end{array}$ \\
\hline Quality & - & 0.297 & 0.2964 & $0.0006(0.28)$ \\
\hline
\end{tabular}

Table 2. Comparison of Results

\section{Conclusions}

These results show good agreement between MELCOR predictions and the analytical solution. They demonstrate MELCOR's ability to predict the depressurization of a reactor vessel into its containment with the involvement of very rapid flashing of saturated water within the vessel. Even the small differences noted in Table 2 could be due to the slight non-equilibrium that exists at the end of the calculation. 
6. References

1. J.H. Keenan, F.G. Keyes, P.G. Hill, and J.G. Moore, Steam Tables:

Thermodynamic Properties of Water Including Vapor, Liquid, and Solid

Phases (International System of Units-S.I.), John Wiley and Sons, 1969. 
MELCOR 1.6 Calculations for the

HDR Containment Experiment V44

\author{
C. J. Shaffer \\ Science and Engineering Associates \\ Albuquerque, New Mexico 87110 \\ United States of America
}

\begin{abstract}
The MELCOR code has been used to simulate the HDR experiment V44. The HDR-V44 experiment is a reactor-scale steam blowdown experiment conducted in 1982 by Kernforschungszentrum Karlsruhe (KfK) at the decommissioned HDR reactor facility near Frankfurt, West Germany. The MELCOR predicted peak containment pressure is about 248 higher than measured but the longer term pressures are in good agreement. The MELCOR predicted main compartment temperature peaks about $20 \mathrm{~K}$ higher than measured with good long term agreement. Agreement between MELCOR predictions and the experimental results is similar to that obtained using the CONTAIN code.
\end{abstract}

\title{
1. Introduction
}

The containment of a nuclear power plant constitutes the final barrier against the accidental release of radioactive fission products to the environment. The reactor-scale steam blowdown experiments conducted at the HDR facility near Frankfurt, West Germany by Kernforschungszentrum Karlsruhe (KfK) in 1982 [1] contribute to the understanding of the physical processes taking place with: $n$ the containment after a loss-of-coolant accident and expand the data base of energy and mass transfer within a large and complex containment building. The HDR containment is enclosed by a cylindrical steel shell with an overall height of 60 meters, a diameter of 20 meters, and a total volume of 11,300 cubic meters. The primary containment is subdivided by concrete walls into 62 subcompartments containing a large amount of internal metallic structures.

Experiment V44 is one of a series of six water and steam blowdown experiments conducted to simulate full-scale loss-of-coolant accidents. Experiment V44 was initiated from saturated steam conditions, and had the highest reactor pressure vessel liquid level with the vessel nearly full. A MELCOR 1.6 calculation has been performed for the HDR-V44 experiment, and the results have been compared to the experimental data[2] and the CONTAIN calculation for HDR-V44[3]. 


\section{Test Description}

The HDR containment is enclosed by a cylindrical steel shell with an overall height of $60 \mathrm{~m}$, a diameter of $20 \mathrm{~m}$, and a total volume of $11,300 \mathrm{~m}^{3}$ as shown in Figures 1 and 2. An outer concrete containment surrounds the steel shell leaving an annular space between the primary and secondary containments. The primary containment is subdivided by concrete walls into 62 subcompartments with widely differing and complex shapes containing a large amount of internal metallic structure. The HDR containment in general has a high ratio of surface area to volume, a high steel to concrete surface area ratio, and complex interior geometries. The reactor pressure vessel which has a central stand pipe mounted inside for bottom discharge, blows down into the break subcompartment (room 1603) onto a jet impingement plate just downstream of the discharge pipe. The location of the break is a radius of $6.5 \mathrm{~m}$, an angle of 206 degrees, and an elevation of $14.5 \mathrm{~m}$ (bottom of the steel containment shell is at an elevation of $-10.0 \mathrm{~m}$ ). The experimental blowdown mass and energy flow rates are shown in Figures 3 and 4 . The test instrumentation includes about 230 pressure and temperature sensors. The sensors selected for comparison with MELCOR results are listed in Table 1.

Table 1: Sensors Selected for Comparison

\begin{tabular}{|c|c|c|c|c|}
\hline \multirow[b]{2}{*}{ Sensor } & \multirow[b]{2}{*}{ Type } & \multicolumn{3}{|c|}{ Location } \\
\hline & & $\begin{array}{l}\text { Radius } \\
\text { (m) }\end{array}$ & $\begin{array}{l}\text { Angle } \\
\text { (deg.) }\end{array}$ & $\begin{array}{l}\text { Elevation } \\
\text { (m) }\end{array}$ \\
\hline CP6202 & Pressure & 10.05 & 0 & 11.0 \\
\hline CP6311 & Pressure & 4.96 & 245 & 10.5 \\
\hline CT403 & Temperature & 0.00 & 0 & 50.0 \\
\hline CT404 & Temperature & 1.95 & 50 & 40.0 \\
\hline CT406 & Temperature & 1.10 & 50 & 45.0 \\
\hline CT410 & Temperature & 3.10 & 50 & 34.0 \\
\hline CT6303 & Temperature & 8.65 & 220 & 10.7 \\
\hline CT6605 & Temperature & 5.00 & 280 & 10.7 \\
\hline
\end{tabular}

\section{Computer Mode1}

The MELCOR calculation for HDR-V44 is patterned after a simulation that was performed with CONTAIN[3]. The MELCOR computer model consists of 5 volumes, 9 flow paths, and 41 heat structures. The heat structures are efther steel, concrete, or steel lined concrete.

The experimentally measured blowdown flow shown in Figures 3 and 4 is input as a fog source into volume 1 (break room) with tabular input. The reactor vesse1 is not modeled.

Volume descriptions are shown in Table 2. Volume 1 consists only of containment room 1603 where the vessel break occurs. Volumes 2 and 3 are relatively small 


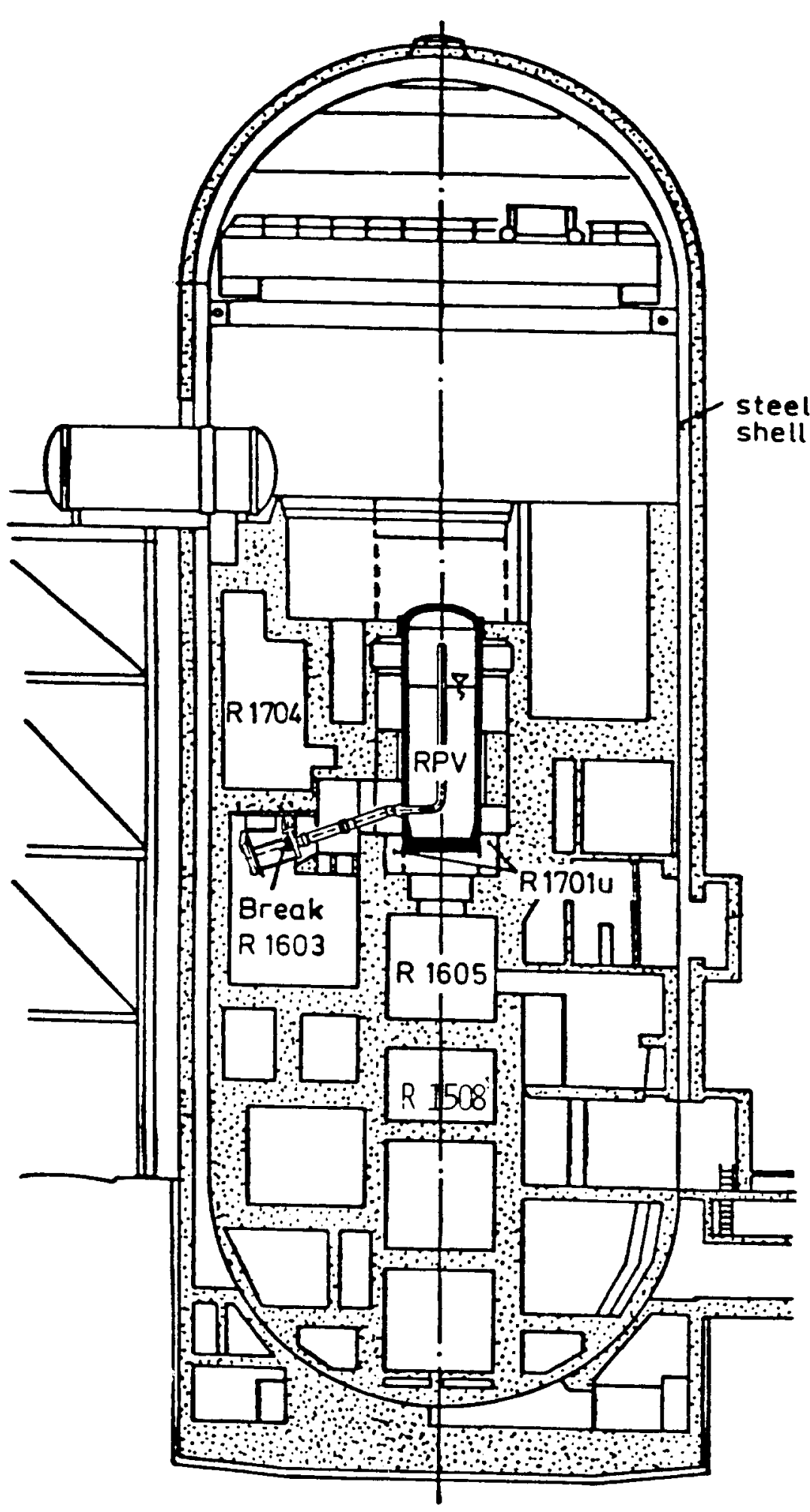

HDR containment data

Diameter: $\quad 20 \mathrm{~m}$

Height: $\quad 60 \mathrm{~m}$

Volume: $\quad 11.300 \mathrm{~m}^{3}$

Internal surface area: $30.000 \mathrm{~m}^{2}$ Number of

compartments: 62

steel

shell

Figure 1. The HDR Containment 


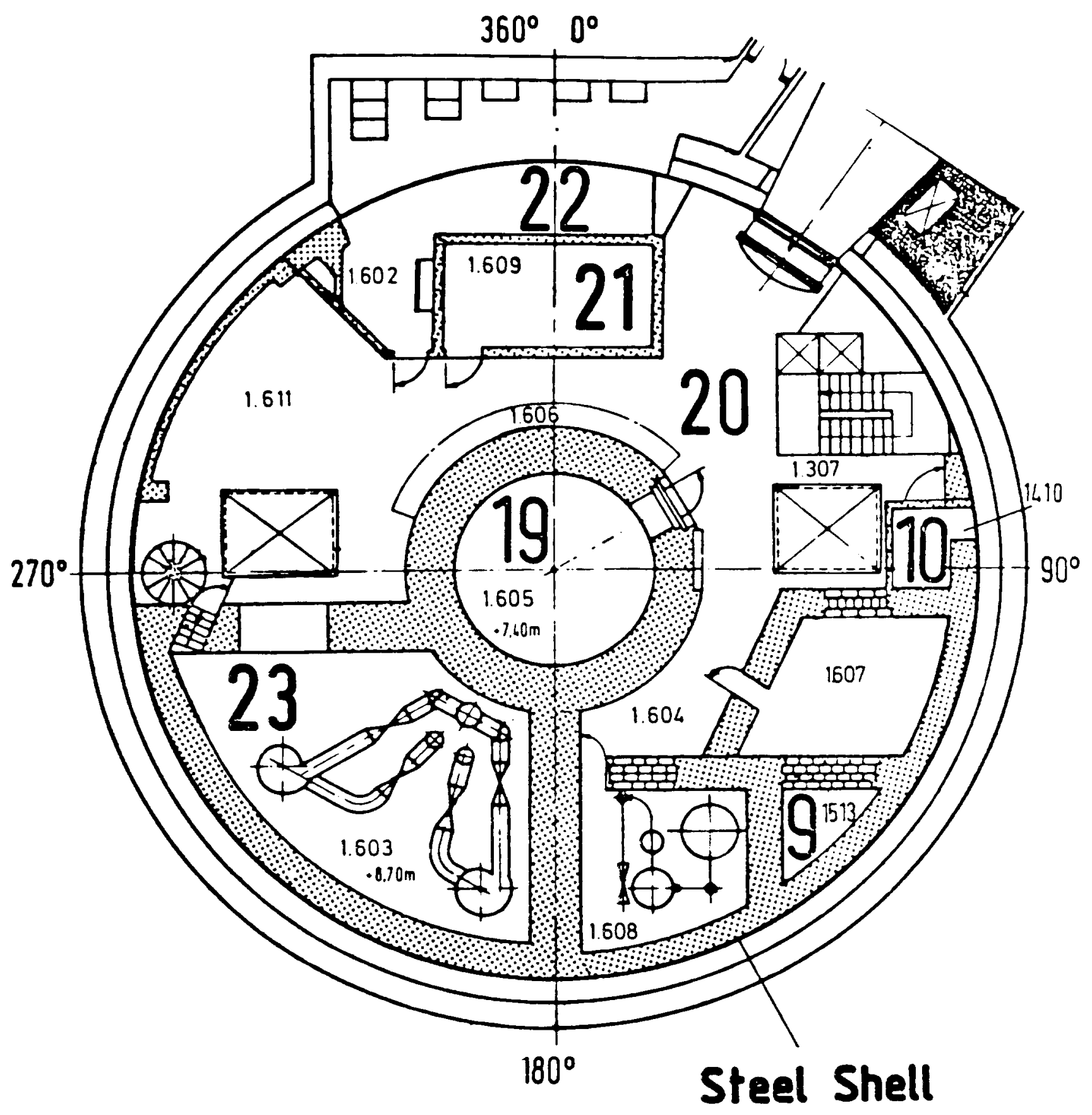

Figure 2. Plan View of the HDR Containment at the Break Room Level 


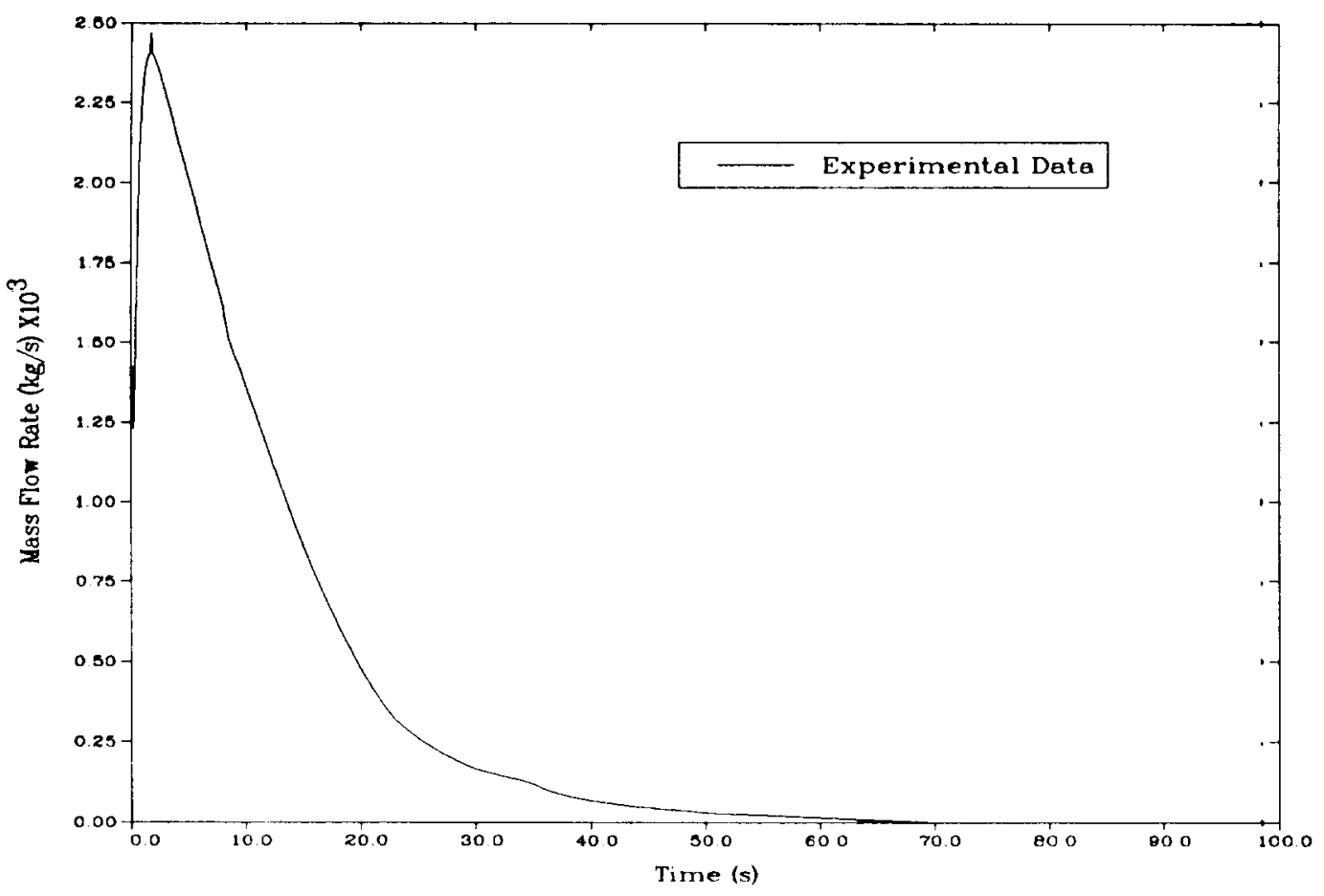

Figure 3. Blowdown Mass Flow Rate

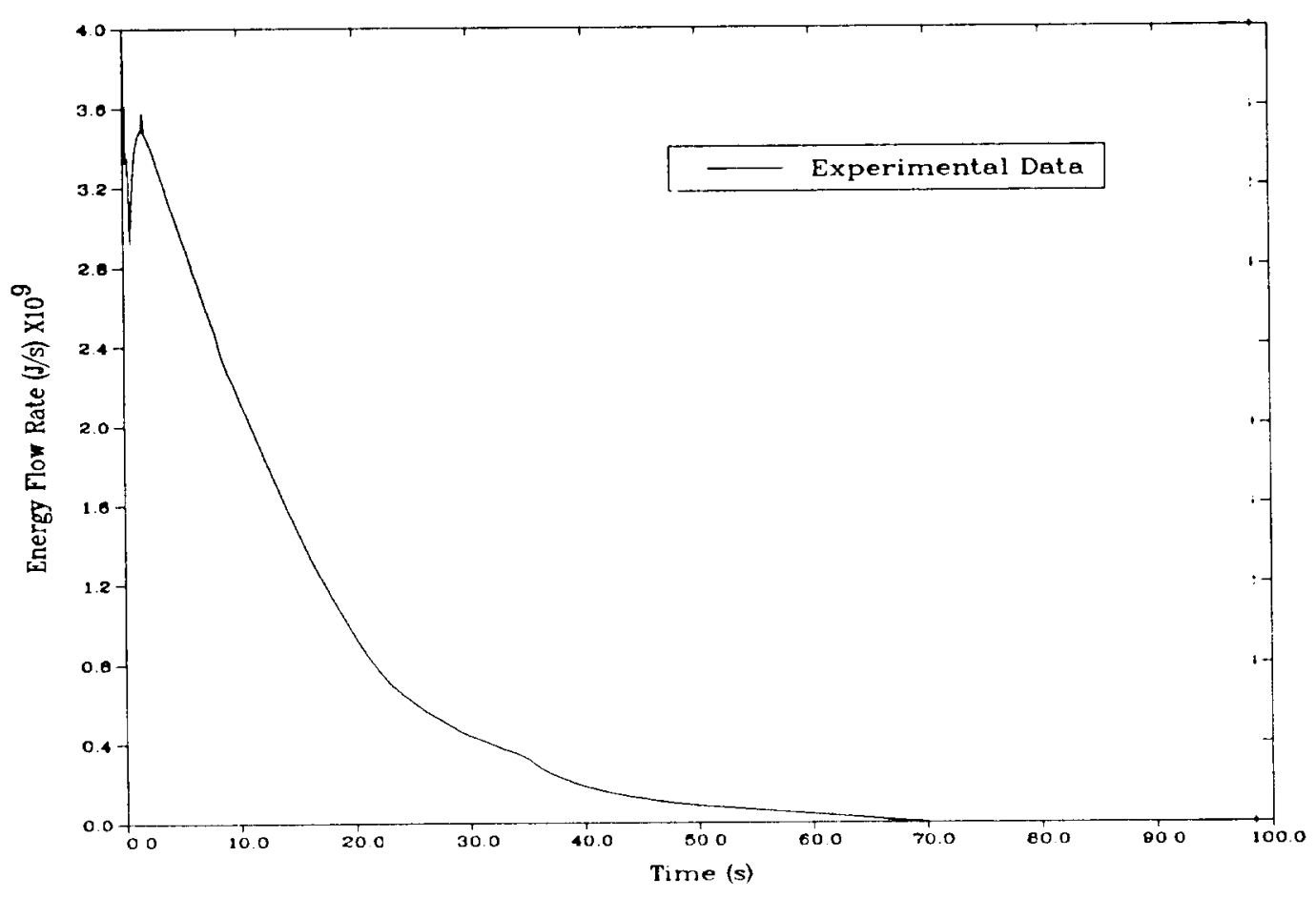

Figure 4. Blowdown Energy Flow Rate 
Table 2: Volume Descriptions

\begin{tabular}{|l|l|c|c|c|c|r|}
\hline No. & Description & $\begin{array}{c}\text { Volume } \\
\mathrm{m}^{3}\end{array}$ & $\begin{array}{c}\text { Lower } \\
\text { Elevation } \\
\mathrm{m}\end{array}$ & $\begin{array}{c}\text { Upper } \\
\text { Elevation } \\
\mathrm{m}\end{array}$ & $\begin{array}{c}\text { Floor } \\
\mathrm{m}\end{array}$ & $\begin{array}{c}\text { Height } \\
\mathrm{m}^{2}\end{array}$ \\
\hline & R1603 & 280 & 18.8 & 26.3 & 7.5 & 37.3 \\
2 & R1701u & 44 & 24.0 & 34.4 & 10.4 & 4.2 \\
3 & R17010,1704 & 912 & 27.6 & 35.9 & 8.3 & 109.9 \\
4 & R1201-1514 & 3003 & 4.0 & 18.0 & 14.0 & 214.5 \\
5 & R1602-11004 & 7102 & 35.4 & 63.5 & 28.1 & 252.7 \\
\hline
\end{tabular}

Table 3: Flow Path Descriptions

\begin{tabular}{|l|l|l|l|r|r|r|r|l|}
\hline No. & $\begin{array}{l}\text { From } \\
\text { Vol. }\end{array}$ & $\begin{array}{l}\text { To } \\
\text { Vol. }\end{array}$ & $\begin{array}{c}\text { From } \\
\text { Alt. } \\
\mathrm{m}\end{array}$ & $\begin{array}{c}\text { To } \\
\text { Alt. } \\
\mathrm{m}\end{array}$ & $\begin{array}{r}\text { Flow } \\
\text { Area } \\
\mathrm{m}^{2}\end{array}$ & $\begin{array}{l}\text { Flow } \\
\text { Diameter } \\
\mathrm{m}\end{array}$ & $\begin{array}{l}\text { Flow } \\
\text { Length } \\
\mathrm{m}\end{array}$ & $\begin{array}{l}\text { Loss } \\
\text { Coefficient }\end{array}$ \\
\hline 1 & 1 & 2 & 24 & 25 & 3.196 & 2.017 & 2.0 & 1.028 \\
2 & 1 & 3 & 26 & 28 & 2.593 & 1.817 & 3.0 & 0.866 \\
3 & 1 & 4 & 19 & 17 & 0.283 & 0.600 & 3.0 & 1.636 \\
4 & 1 & 5 & 26 & 36 & 2.128 & 1.646 & 11.0 & 1.116 \\
5 & 2 & 3 & 28 & 29 & 1.700 & 1.471 & 2.0 & 1.020 \\
6 & 2 & 5 & 34 & 36 & 1.374 & 1.323 & 3.0 & 1.389 \\
7 & 3 & 4 & 28 & 17 & 1.500 & 1.382 & 12.0 & 1.389 \\
8 & 3 & 5 & 35 & 36 & 15.014 & 4.372 & 12.0 & 0.782 \\
9 & 4 & 5 & 17 & 36 & 14.049 & 4.229 & 20.0 & 0.803 \\
\hline
\end{tabular}

volumes located next to the break room. Volume 4 consists of rooms numbered 1201 through 1514 which comprise the lower portion of the containment. Volume 5 consists of rooms numbered 1602 through 11004 which comprise the upper or dome portion of the containment. The sensors chosen for comparison with MELCOR are located in volumes 1 and 5 . All volumes were initialized at atmospheric pressure, a temperature of $300 \mathrm{~K}(80 \mathrm{~F}), 1008$ relative humidity, and with dry floors. Flow path descriptions are shown in Table 3. All volumes are directly interconnected except volumes 2 and 4.

Heat structure descriptions are shown in Table 4. Logarithmic spaced nodes were used for all structures. Three structures were steel lined concrete. Left surfaces are in the indicated volumes and right surfaces are adiabatic. Only MELCOR calculated heat transfer coefficients are used. The calculation was started at the initiation of reactor vessel blowdown and continued to 3600 seconds. 
Table 4: Heat Structure Descriptions

\begin{tabular}{|c|c|c|c|c|c|c|c|}
\hline No. & $\begin{array}{r}\text { Vo } \\
\text { Left }\end{array}$ & $\begin{array}{l}\text { me } \\
\text { ight }\end{array}$ & Type & Material & $\underset{\mathrm{m}^{2}}{\operatorname{Area}}$ & $\begin{array}{l}\text { Thickness } \\
\text { m }\end{array}$ & $\begin{array}{l}\text { No. } \\
\text { Nodes }\end{array}$ \\
\hline 1 & 1 & 1 & wall & steel & 196.8 & 0.001351 & 7 \\
\hline 2 & 1 & 1 & wall & steel & 287.0 & 0.006118 & 9 \\
\hline 3 & 1 & 1 & wa11 & steel & 144.2 & 0.02218 & 11 \\
\hline 4 & 1 & 1 & wall & steel & 1.5 & 0.02029 & 11 \\
\hline 5 & 1 & $A D^{*}$ & wal1 & concrete & 240.0 & 0.3048 & 16 \\
\hline 6 & 1 & $\mathrm{AD}$ & roof & concrete & 45.2 & 0.3048 & 16 \\
\hline 7 & 1 & $A D$ & floor & concrete & 45.2 & 0.3048 & 16 \\
\hline 8 & 2 & 2 & wa11 & steel & 93.0 & 0.001461 & 7 \\
\hline 9 & 2 & 2 & wa11 & stee 1 & 63.8 & 0.006746 & 9 \\
\hline 10 & 2 & 2 & wa11 & stee 1 & 20.9 & 0.02078 & 11 \\
\hline 11 & 2 & 2 & wal1 & steel & 28.3 & 0.1196 & 13 \\
\hline 12 & 2 & $\mathrm{AD}$ & wall & st/conc & 46.1 & 0.3302 & 22 \\
\hline 13 & 2 & $\mathrm{AD}$ & wa11 & concrete & 28.7 & 0.3048 & 16 \\
\hline 14 & 2 & $\mathrm{AD}$ & roof & concrete & 35.9 & 0.3048 & 16 \\
\hline 15 & 2 & $A D$ & floor & concrete & 35.9 & 0.3048 & 16 \\
\hline 16 & 3 & 3 & wa11 & steel & 1028.0 & 0.001169 & 7 \\
\hline 17 & 3 & 3 & wa11 & stee 1 & 87.5 & 0.005772 & 9 \\
\hline 18 & 3 & 3 & wa11 & steel & 28.4 & 0.01998 & 11 \\
\hline 19 & 3 & 3 & wa11 & steel & 12.4 & 0.04977 & 15 \\
\hline 20 & 3 & $\mathrm{AD}$ & wall & concrete & 730.5 & 0.3048 & 16 \\
\hline 21 & 3 & $\mathrm{AD}$ & wall & steel & 6.2 & 0.060 & 8 \\
\hline 22 & 3 & $\mathrm{AD}$ & wal1 & st/conc & 30.2 & 0.3302 & 22 \\
\hline 23 & 3 & $\mathrm{AD}$ & roof & concrete & 106.3 & 0.3048 & 16 \\
\hline 24 & 3 & $\mathrm{AD}$ & floor & concrete & 106.3 & 0.3048 & 16 \\
\hline 25 & 4 & 4 & wall & steel & 3253.0 & 0.0009542 & 7 \\
\hline 26 & 4 & 4 & wall & steel & 1967.0 & 0.006276 & 9 \\
\hline 27 & 4 & 4 & wall & stee 1 & 40.6 & 0.022295 & 11 \\
\hline 28 & 4 & 4 & wall & steel & 11.3 & 0.03628 & 11 \\
\hline 29 & 4 & $\mathrm{AD}$ & wall & concrete & 3370.4 & 0.3048 & 16 \\
\hline 30 & 4 & $\mathrm{AD}$ & wall & stee1 & 199.6 & 0.030 & 7 \\
\hline 31 & 4 & $\mathrm{AD}$ & roof & concrete & 624.8 & 0.3048 & 16 \\
\hline 32 & 4 & $\mathrm{AD}$ & floor & concrete & 624.8 & 0.3048 & 16 \\
\hline 33 & 5 & 5 & wall & steel & 3197.0 & 0.0009908 & 7 \\
\hline 34 & 5 & 5 & wall & steel & 3667.0 & 0.0059235 & 9 \\
\hline 35 & 5 & 5 & wall & stee 1 & 404.6 & 0.01402 & 11 \\
\hline 36 & 5 & 5 & wa11 & steel & 190.3 & 0.05196 & 13 \\
\hline 37 & 5 & $\mathrm{AD}$ & wall & concrete & 1896.5 & 0.3048 & 16 \\
\hline 38 & 5 & $\mathrm{AD}$ & wall & steel & 1605.3 & 0.027 & 7 \\
\hline 39 & 5 & $\mathrm{AD}$ & wall & st/conc & 599.9 & 0.3302 & 22 \\
\hline 40 & 5 & $\mathrm{AD}$ & roof & concrete & 595.9 & 0.3048 & 16 \\
\hline 41 & 5 & $A D$ & floor & concrete & 595.9 & 0.3048 & 16 \\
\hline
\end{tabular}

* AD indicates an adiabatic boundary is assumed. 


\section{Results}

The MELCOR results for the containment dome (volume 5) and the break room (volume 1) are compared to experimental data in Figures 5 through 8 . Figures 9 and 10 compare the MELCOR results to the corresponding CONTAIN results.

The containment dome pressure calculated by MELCOR is compared in Figure 5 to the data from pressure sensor CP6202 located near the bottom of control volume 5. MELCOR over predicts the peak pressure by about 248 but is in good agreement after about 1000 seconds.

The MELCOR calculated containment dome temperature is compared in Figure 6 to the data from sensors CT403, CT406, CT404, CT410, and CT6605 located at elevations $50.0,45.0,40.0,34.0$, and $10.7 \mathrm{~m}$, respectively, within control volume 5. The $50 \mathrm{~m}$ elevation is at the top of the dome. These sensors show a pronounced temperature gradient with the elevation within volume 5 . For example, the gradient at 2000 seconds is about $0.6 \mathrm{~K} / \mathrm{m}$. An experimental volume average temperature would probably be between the 34 and $40 \mathrm{~m}$ elevation temperatures. Therefore, MELCOR over predicts the peak temperature by about 20 $\mathrm{K}$ but again is in good agreement after about 1000 seconds.

The MELCOR break room results are compared in Figures 7 and 8 with pressure sensor CP6311 and temperature sensor CT6303 for the first 200 seconds. The break room with a volume of only $280 \mathrm{~m}^{3}$, experiences extremely dynamic fluid flow and heat transfer processes during the reactor vessel blowdown. MELCOR over predicts the peak break room pressure by about $22 \%$ and the peak temperature by only $6 \mathrm{~K}$.

The MELCOR and CONTAIN results are compared in Figures 9 and 10. CONTAIN results[3] are available for the containment dome pressure and temperature to 1500 seconds. These figures show that MELCOR and CONTAIN results are similar and in quite good agreement. The MELCOR predicted pressure is slightly lower and closer to the experimental data than CONTAIN. The MELCOR predicted temperature is slightly higher than CONTAIN and both are within the 34 and $40 \mathrm{~m}$ elevation experimental temperatures after about 900 seconds.

\section{Code Limitations Identified}

This investigation suggests that the MELCOR heat transfer coefficient correlations may not be adequate for dynamic heat transfer during blowdown. The MELCOR calculated heat transfer coefficients during the blowdown are generally less than $20 \mathrm{~W} / \mathrm{m}^{2} / \mathrm{K}$ but as high as $200 \mathrm{~W} / \mathrm{m}^{2} / \mathrm{K}$. The experimental data [1], [2], [4] shows heat transfer coefficients in room 1606 near the break room that range from about 6000 to $28000 \mathrm{~W} / \mathrm{m}^{2} / \mathrm{K}$ during blowdown. This same MELCOR calculation was run with a fixed heat transfer coefficient of 400 $\mathrm{W} / \mathrm{m}^{2} / \mathrm{K}$ for all heat structures. The result of this run was that the MELCOR calculated peak pressures and temperatures were reduced to the same general magnitude as the experimental data. In summary, MELCOR's heat transfer coefficient correlations, which are in keeping with currently accepted containment blowdown coefficient correlations, calculate coefficients too small to predict accurately the very dynamic containment heat transfer during blowdown. 


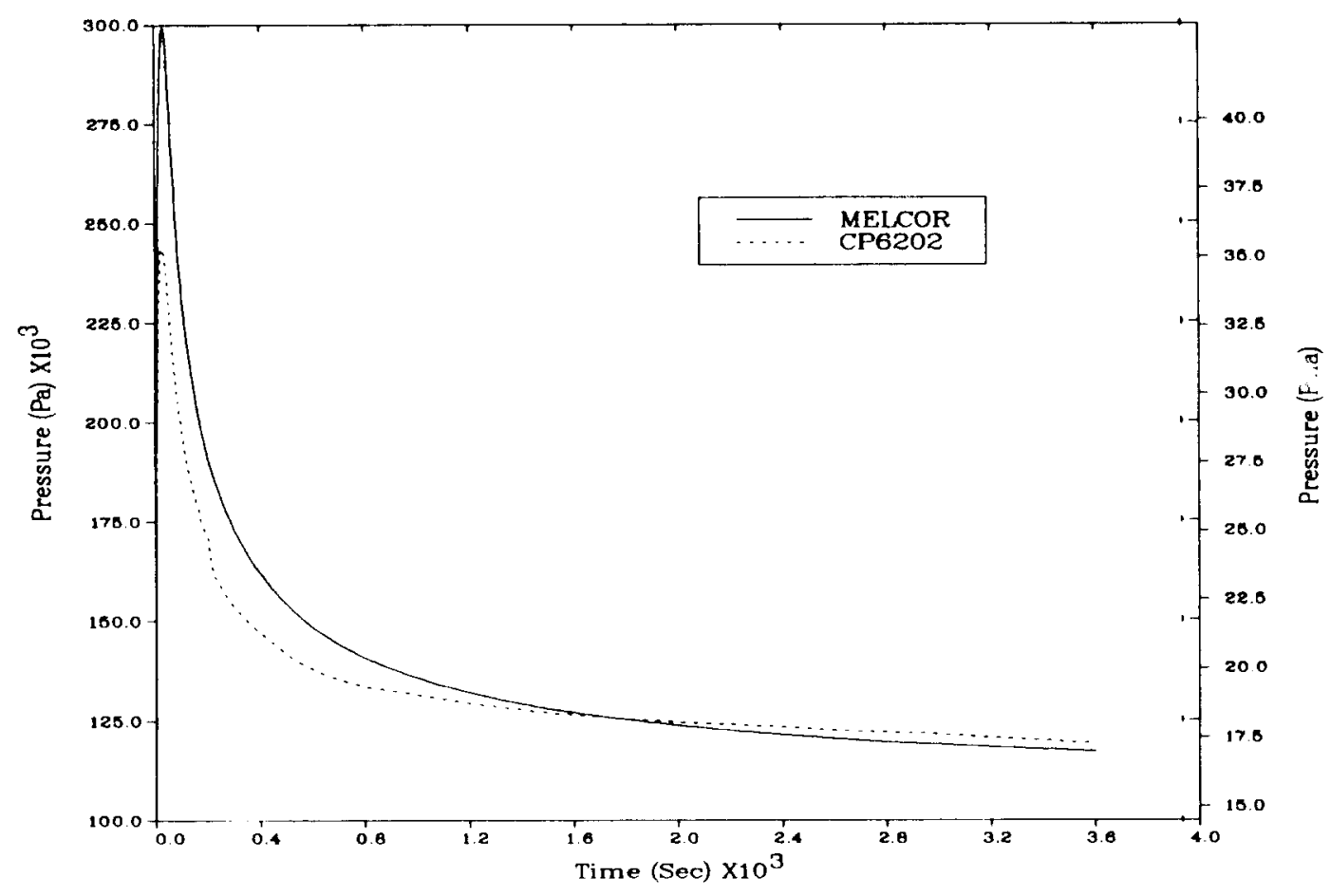

Figure 5. Containment Dome Pressure

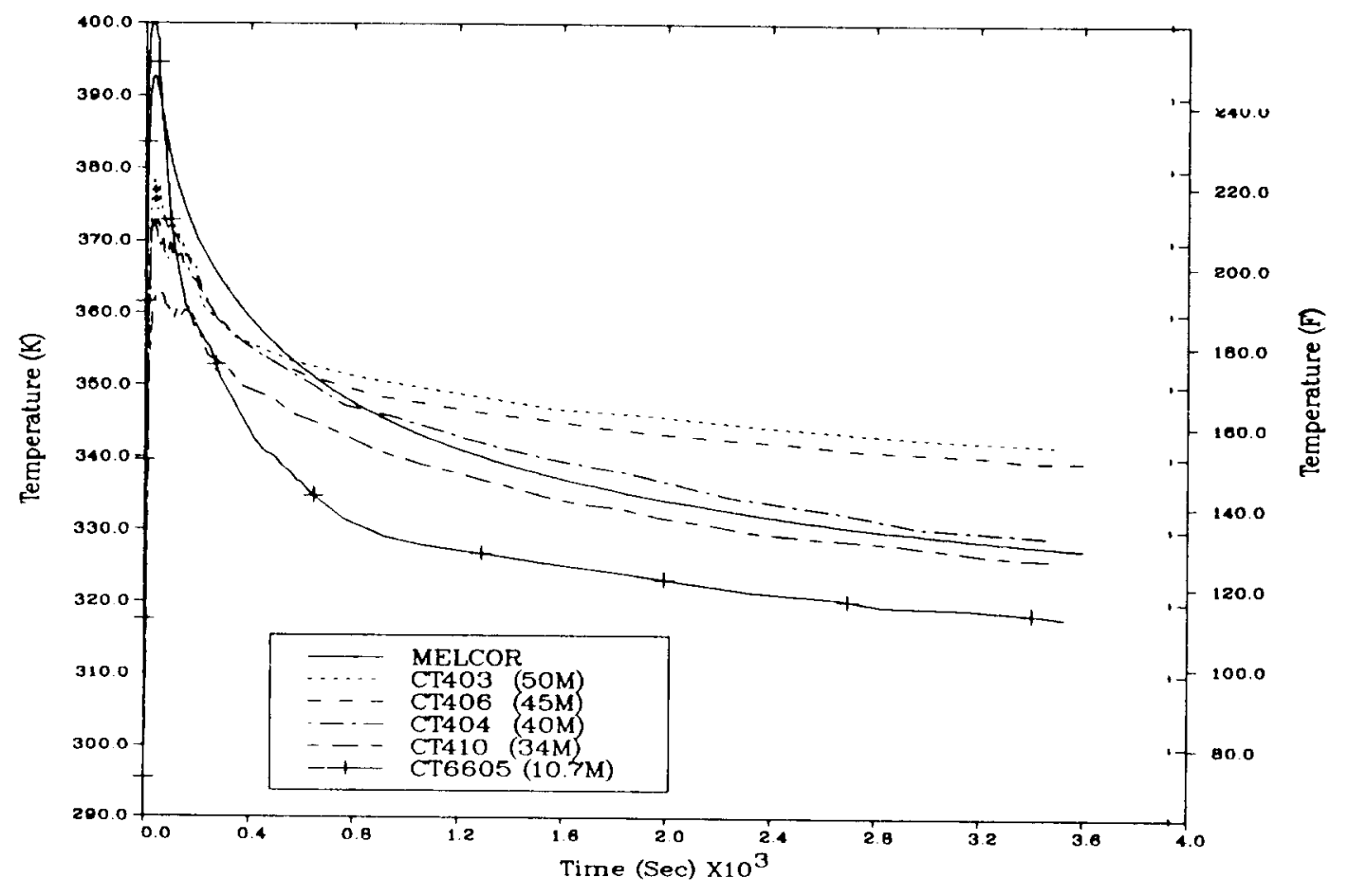

Figure 6. Containment Dome Temperature 


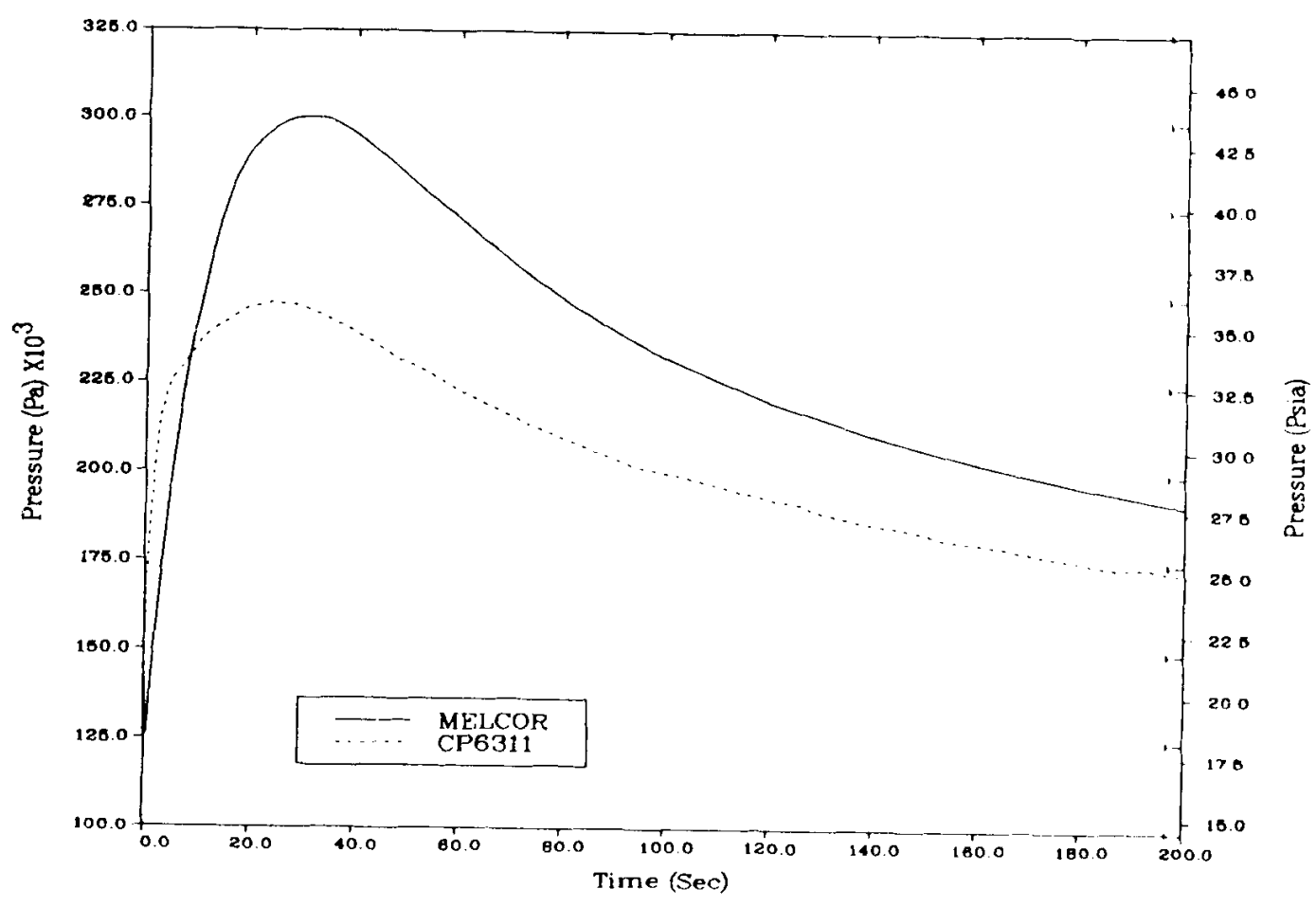

Figure 7. Break Room Pressure

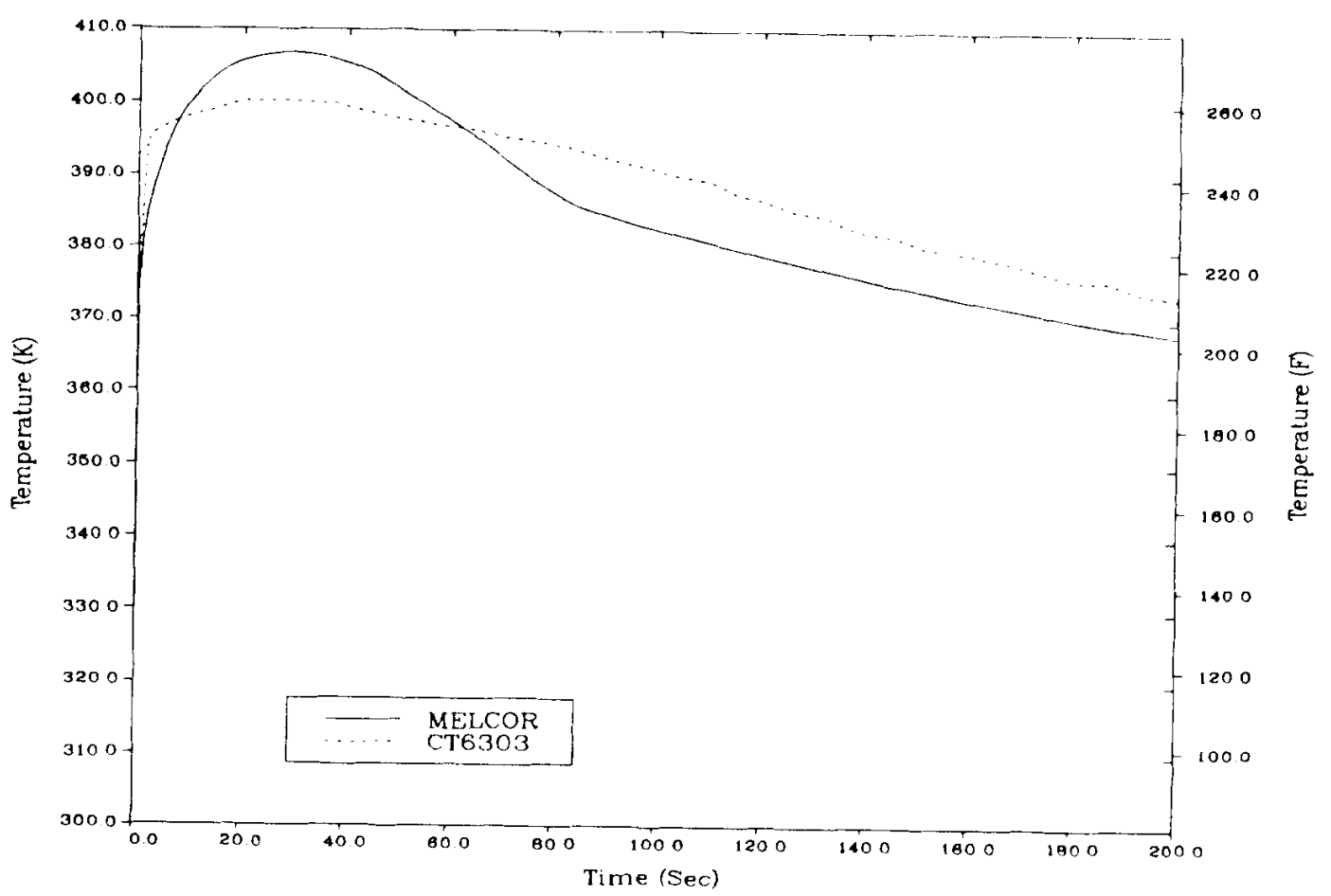

Figure 8. Break Room Temperature 


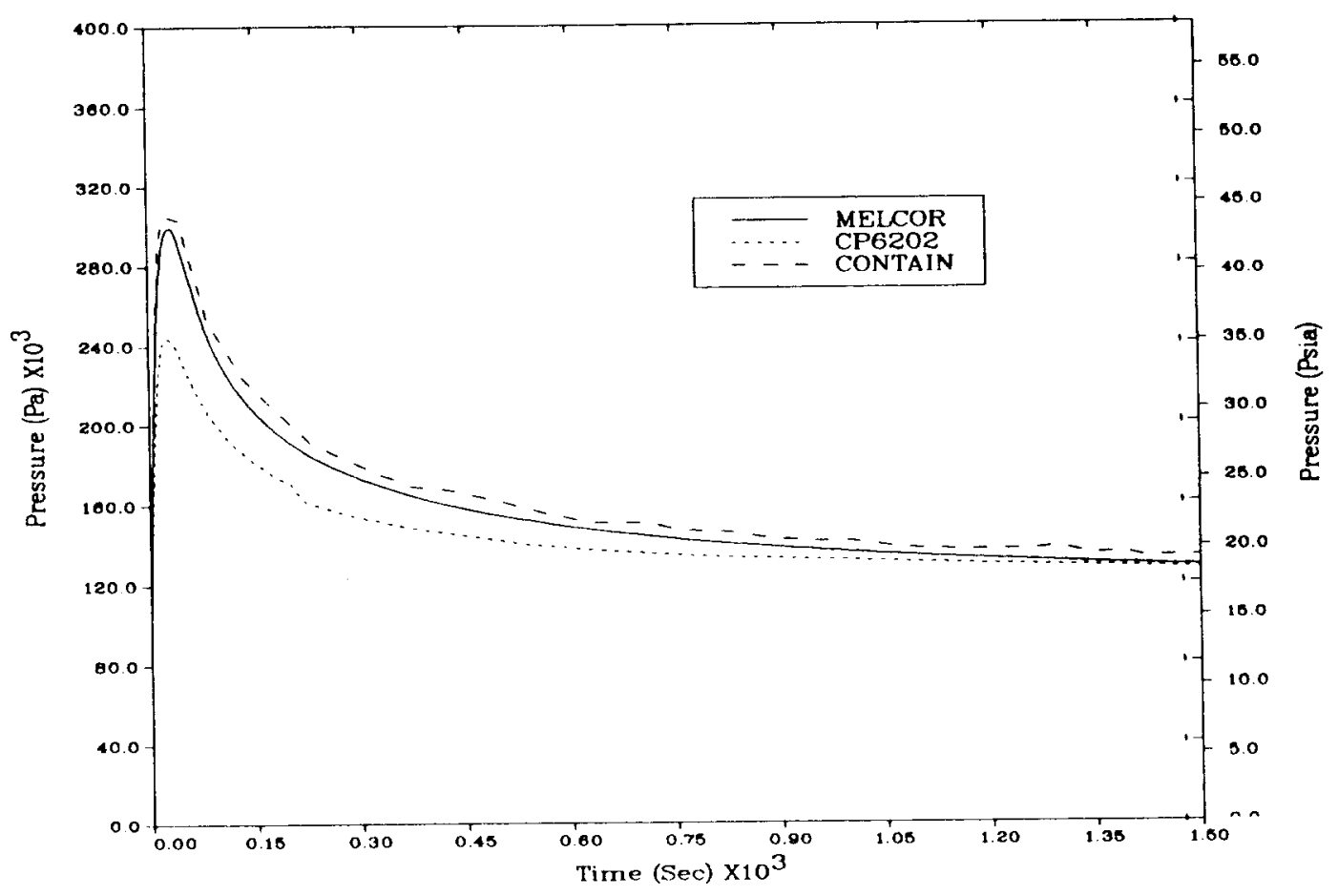

Figure 9. Containment Dome Pressure

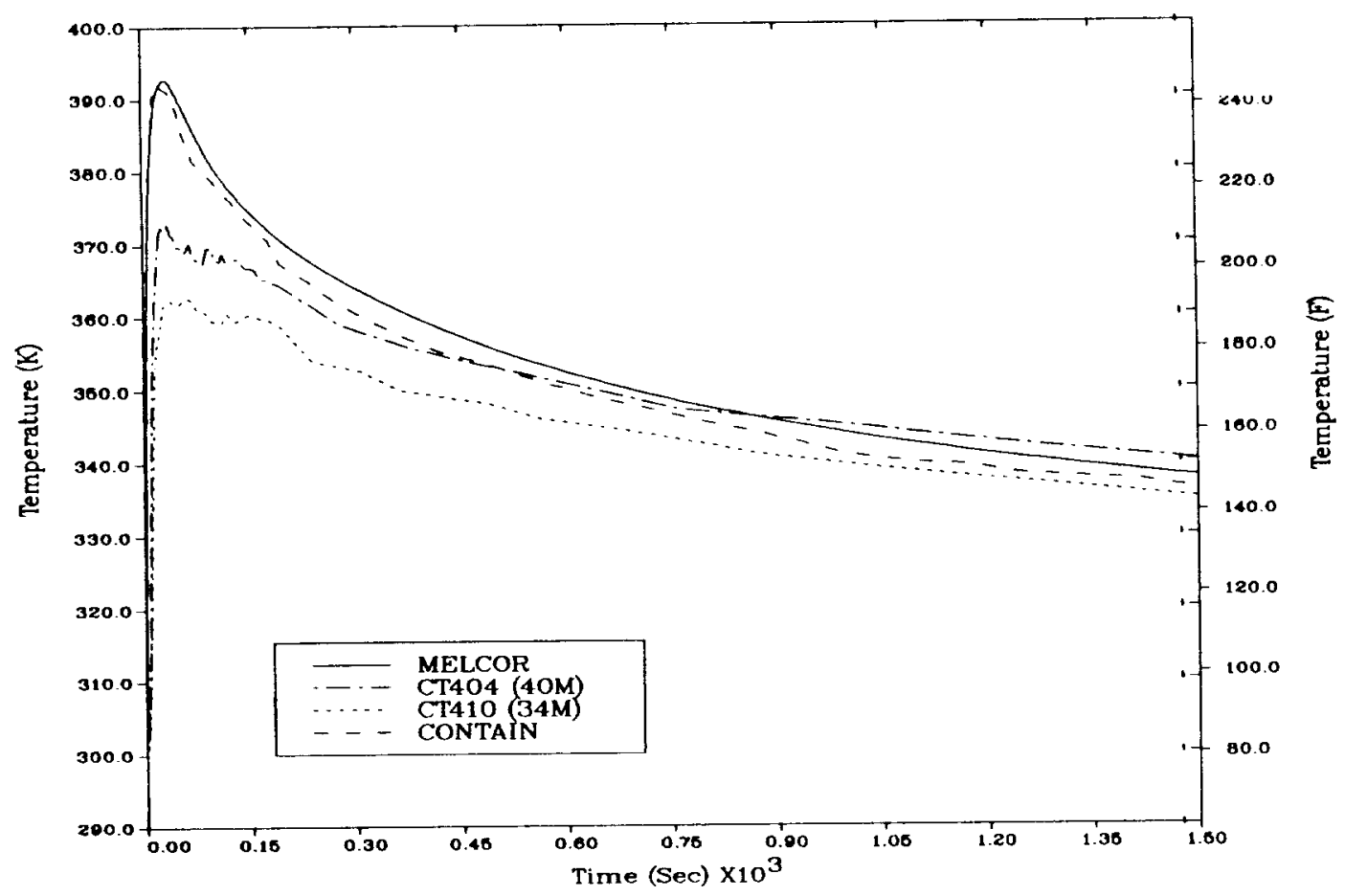

Figure 10. Containment Dome Temperature 

MELCOR 1.0 Calculations for the Battelle-Frankfurt Gas Mixing Tests

\author{
R.K. Byers
}

Sandia National Laboratories

Albuquerque, New Mexico 87185

United States of America

\begin{abstract}
Recent comparisons of MELCOR predictions to the BattelleFrankfurt Gas Mixing Experiments are presented. These predictions are for a hydrogen-nitrogen gas mixture that is injected into a model containment. The MELCOR results are compared to the experimental data, the results obtained using the HECTR code, and the results obtained using the RALOC code. This comparison provides critical testing of the MELCOR control volume hydrodynamics package and the flow path package.
\end{abstract}

\title{
1. Introduction
}

The Battelle-Frankfurt Mixing Tests were comprised of a series of experiments in which hydrogen-nitrogen mixtures were injected into a model containment at the Battelle Institut e.V. Frankfurt [1],[2]. The containment mode1 was a concrete structure with cylindrical central regions which could be isolated from the upper and asymmetric outer compartments.

\section{Test Description}

In the experiments considered here, the injected gas was two parts hydrogen by volume, introduced at nominally constant rates of $1-2 \mathrm{~m}^{3} / \mathrm{hr}(0.15-0.3$ $\mathrm{g} / \mathrm{s})$ until the hydrogen amounted to about four percent of the total containment volume. Pressures and temperatures of the mixture were very close to those in the injection region, so the distribution of the injected mixture was governed principally by buoyancy forces. The reported experimental data included variations in the hydrogen concentrations with time and location.

\section{Mode1 Description}

MELCOR calculations were performed for tests BF- 2 and BF-6, where only the inner regions of the containment were used (the first sixteen cells in Figure 1a) and for tests $\mathrm{BF}-10$ and $\mathrm{BF}-19$, in which the inner regions could communicate with the outer compartments (using all twenty-eight cells in Figure 1a). The gas injection was modeled as a source in Cell 15 for all four tests. In Tests 
2 and 10 uniform initial temperatures in all cells were imposed, while in Tests 6 and 19, the initial temperatures in the upper portion of the containment were approximately 20 and $30 \mathrm{~K}$ higher than at the bottom, respectively. These four tests had also been simulated with the RALOC[3] and HECTR [4] codes. The nodalizations used in the MELCOR calculations were, with a few exceptions, the same as those used with RALOC and HECTR and are shown in Figure 1b.. The HECTR nodalization for $B F-10$ and BF-19 involved twenty-two compartments and is shown in Figure 1b. Using a similar twenty-two compartment nodalization with MELCOR proved inadequate, however. In a calculation performed on a VAX computer with no injection, uniform temperature, and an initial pressure distribution corresponding to zero flow in a gravity field, mass flows were observed which were more than three orders of magnitude larger than the specified injection rate for the transient analysis. There are two reasons for these flows of that order of magnitude. First, in the twenty-two volume model shown in Figure $1 \mathrm{~b}$ there are discontinuities in the bottom elevations of the volumes. When a cell is connected to adjacent cells with differing bottom elevations, there will be a flow generated due to the acceleration of gravity. In addition, when there is no liquid present (as in these calculations), the pressure gradients driving the flow should be very small. The second reason for the magnitude of the flows seen in the steady-state problem has to do with the repeated application of the numerical methods used in MELCOR. In particular, the 32 -bit word length used on the VAX might produce unacceptable round-off in long calculations.

Therefore, the twenty-eight volume MELCOR model was developed. This model has fewer discontinuities in cell bottom elevations. In a short calculation with the CRAY version of MELCOR, the initial temperature for Test 10 was specified, and injection was started after 400 seconds of "steady state". The same boundary and initial conditions were used for a calculation on a VAX with the 22-volume model. The 64-bit word length and more uniform elevations in the CRAY calculation combined to produce much smaller mass flows during the steady-state period. In addition, the CRAY and VAX calculations produced significantly different results for the mass distribution of hydrogen (percentage differences were between thirty and forty percent for most locations). For this reason, all subsequent calculations were performed with the CRAY version, and the 28-volume nodalization was used for Tests 10 and 19.

\section{Results}

Calculated results for Tests 2 and 10 (the tests with uniform initial temperatures) showed good agreement with both experimental data and with the available output from RALOC and HECTR analyses. The calculations with the three codes all used slightly different nodalizations and injection rates, but the calculated results for all three codes were similar as may be seen in Figures 2 and 3 . Local hydrogen concentrations increased at almost constant rates until the end of the injection period, and rapidly achieved values corresponding to uniform distribution of the injected hydrogen. RALOC results could only be obtained for about the first 10,000 seconds of Test 10; however, the three codes are so similar in the context of these analyses that no significantly different predictions should be obtained.

In Tests 6 and 19, the initial temperatures in the upper portion of the containment were approximately 20 and $30 \mathrm{~K}$ higher than at the bottom, 

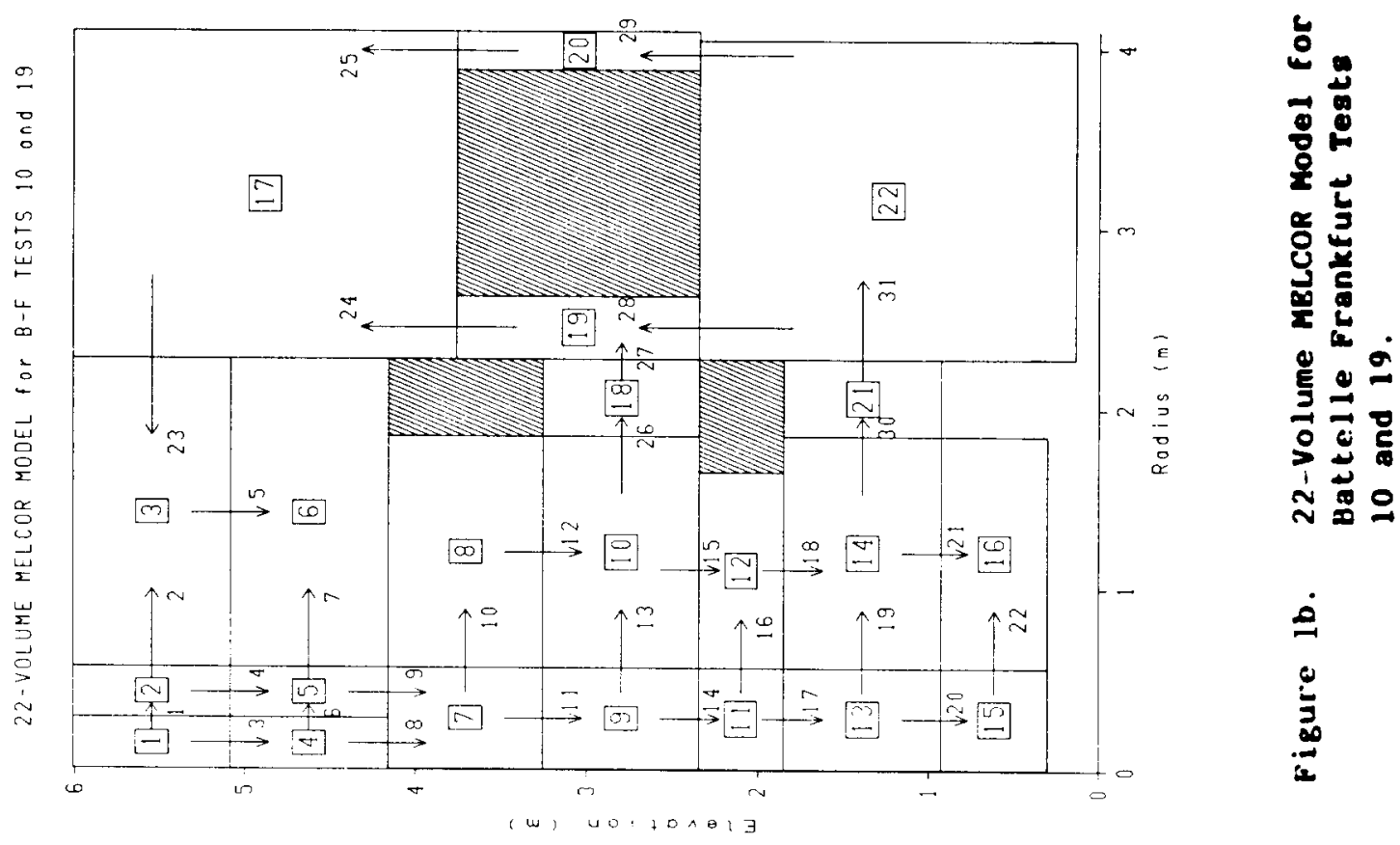

$\stackrel{0}{0}$

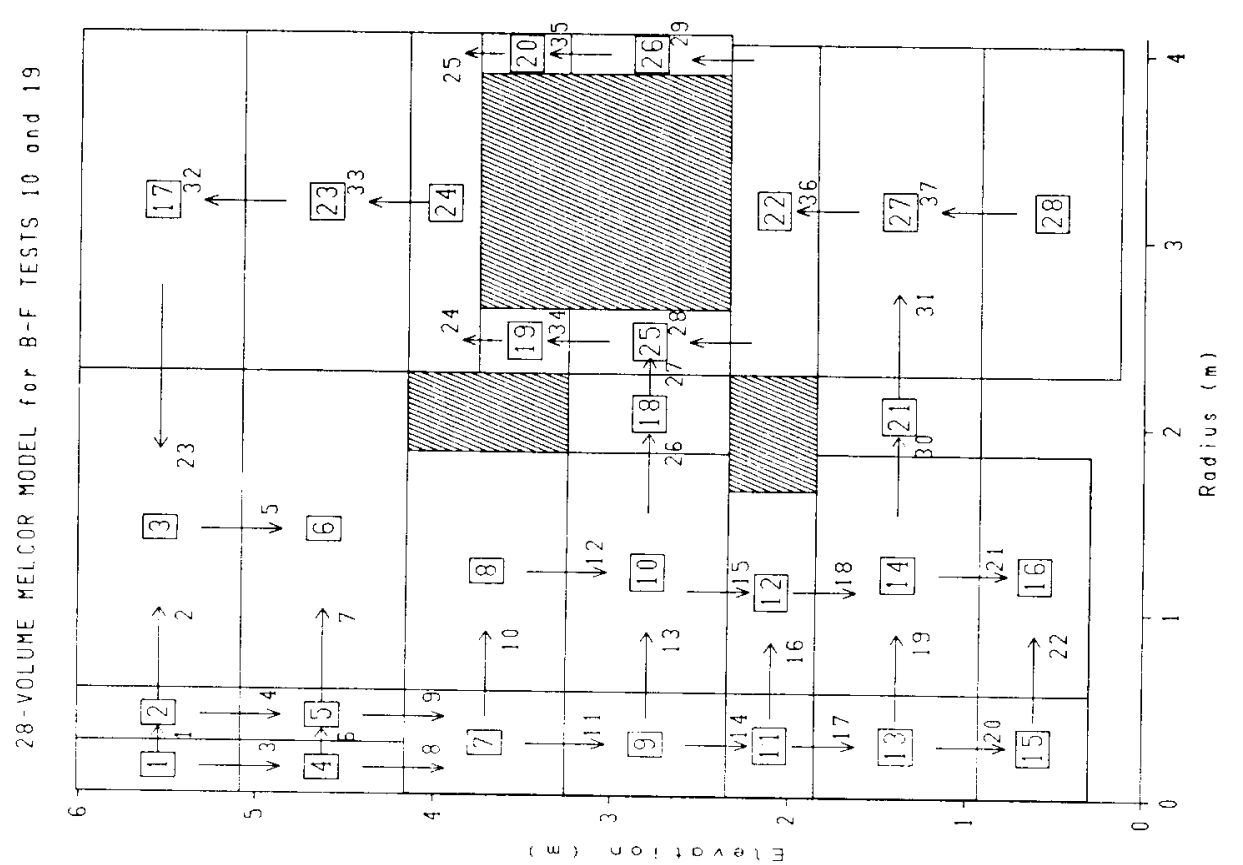

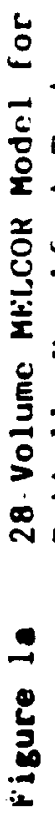




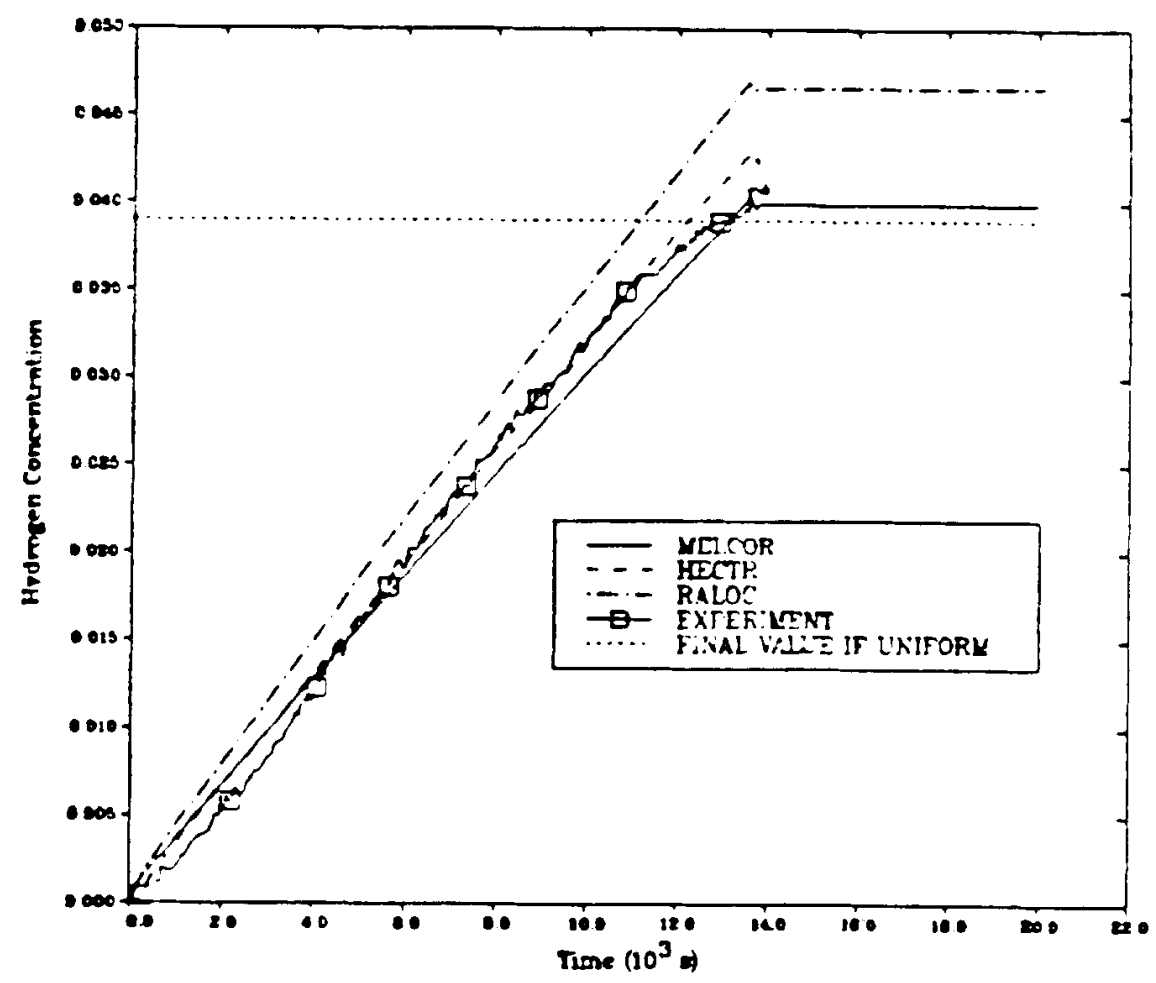

Figure 2. Hydrogen Concentration in Cell 1 for Battelle-Frankfurt Test 2

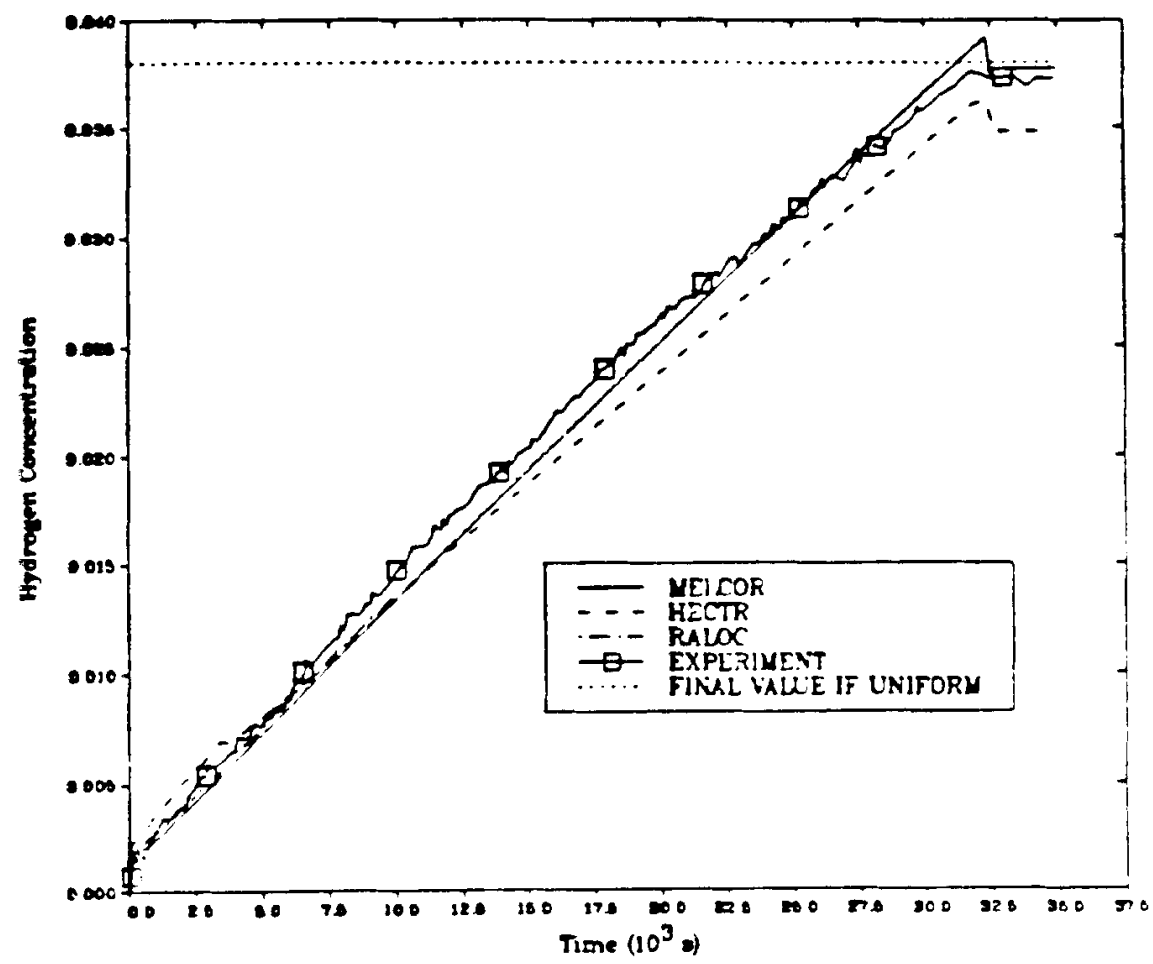

Figure 3. Hydrogen Concentration in Cell 13 for Battelle-Frankfurt Test 10 
respectively. The choice of initial temperatures for each cell in the model was a matter of some ambiguity, and a number of such choices were made in attempting to obtain good agreement between HECTR and experimental results. [5] In those calculations, both the initial temperature distribution and heat transfer between the containment walls and the atmosphere were shown to have profound effects on the computed hydrogen distributions. A limited number of similar variations were carried out with MELCOR, but none of the results compared very well with the experimental data at all locations.

Calculated and experimental hydrogen concentrations near the injection point for Test 6 are shown in Figure 4. Until slightly before the end of injection at 8000 seconds, both MELCOR and HECTR agree reasonably well with data, although the HECTR result is somewhat smoother than MELCOR's. A decrease in the concentration in both calculations occurs at about the same time as in the measured data, and all three curves reach maxima well above the value at which the total injected hydrogen would be uniformly distributed. Figure 5 presents results at the top center of the containment (Cell 1), and only the HECTR prediction seems to capture at least the character of the data over its available duration. Because the initial temperatures in the upper region are higher, upward flow is delayed until the buoyancy of the lower density of the injected gas can overcome the initial density gradient. The rapid increase in the HECTR result at about 8500 seconds clearly shows this phenomenon. Earlier behavior in the RALOC and MELCOR curves might also be partly attributable to this effect. Unfortunately, the data do not extend to a late enough time that this "thermal breakthrough" could be experimentally confirmed or denied.

In Test 19, MELCOR seemed to agree best with data for the lower of the outer compartments (Cell 27), as shown in Figure 6, while the HECTR results were closest to the somewhat questionable measurement in the upper, outer region (Cel1 23), as shown in Figure 7 . For concentrations just above the injection source (Cell 13), neither RALOC, HECTR, nor MELCOR could be said to agree well with the data, as shown in Figure 8 . That none of the codes was obviously superior in comparing with data at all locations was also true of the other nonisothermal test, Test 6.

\section{Summary and Conclusions}

In summary, we found MELCOR to be capable of producing very good agreement with Battelle-Frankfurt hydrogen mixing tests, when initial temperatures were assumed to be uniform and very nearly equal to the temperature of the injected gas. We also found that relatively large flows could be calculated for what should be a zero-flow steady state, and that these flows can be substantially reduced by careful selection of initial pressures, by eliminating elevation discontinuities where possible, and by taking advantage of a large computer-word length. Finally, it appears that a fairly large number of sensitivity studies would be required to obtain good agreement between MELCOR and experiment when the initial temperatures are not uniform; this is also true of at least two other codes, HECTR and RALOC, which are suitable for modeling this type of mixing test. 


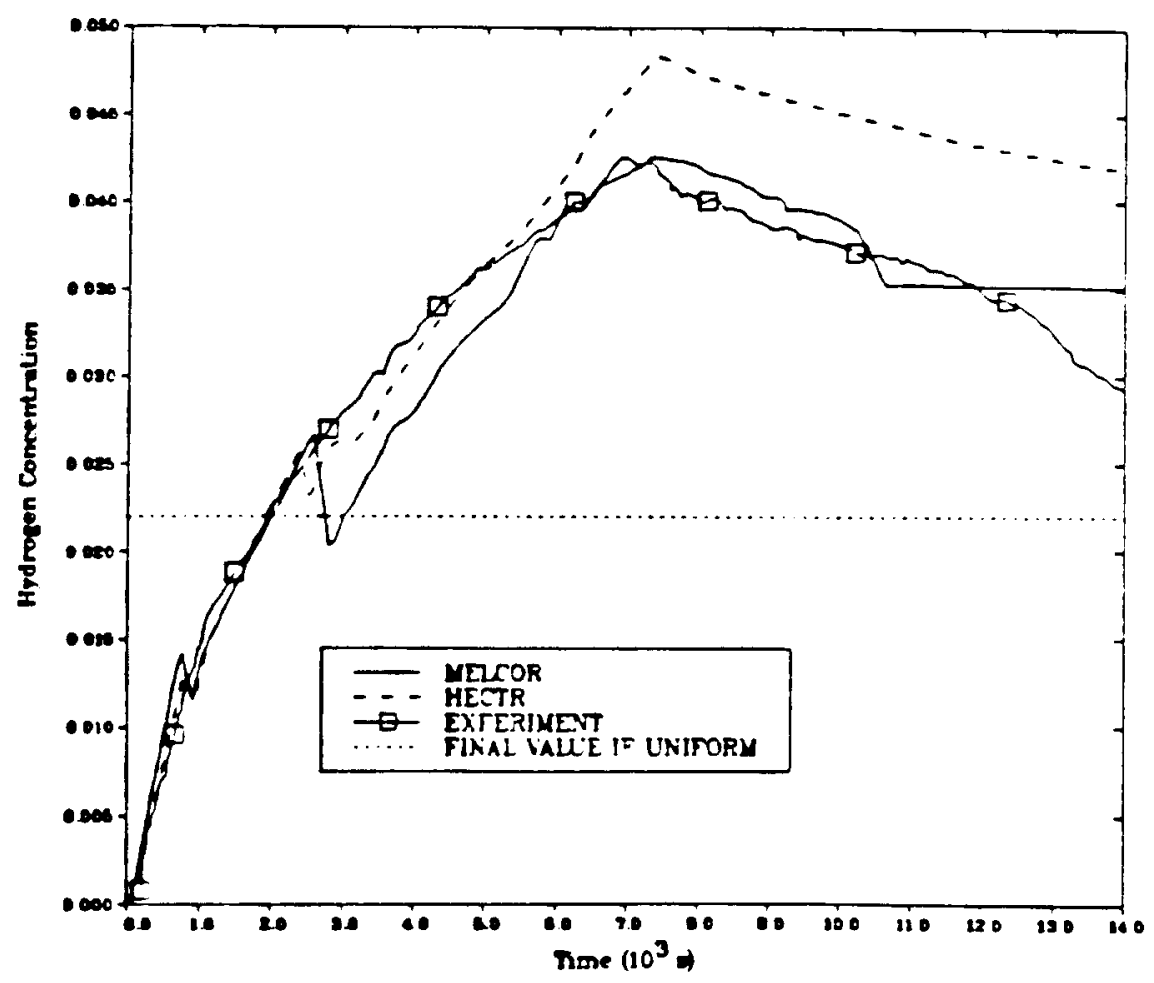

Figure 4. Hydrogen Concentration in Cell 13 for Battelle-Frankfurt Test 6

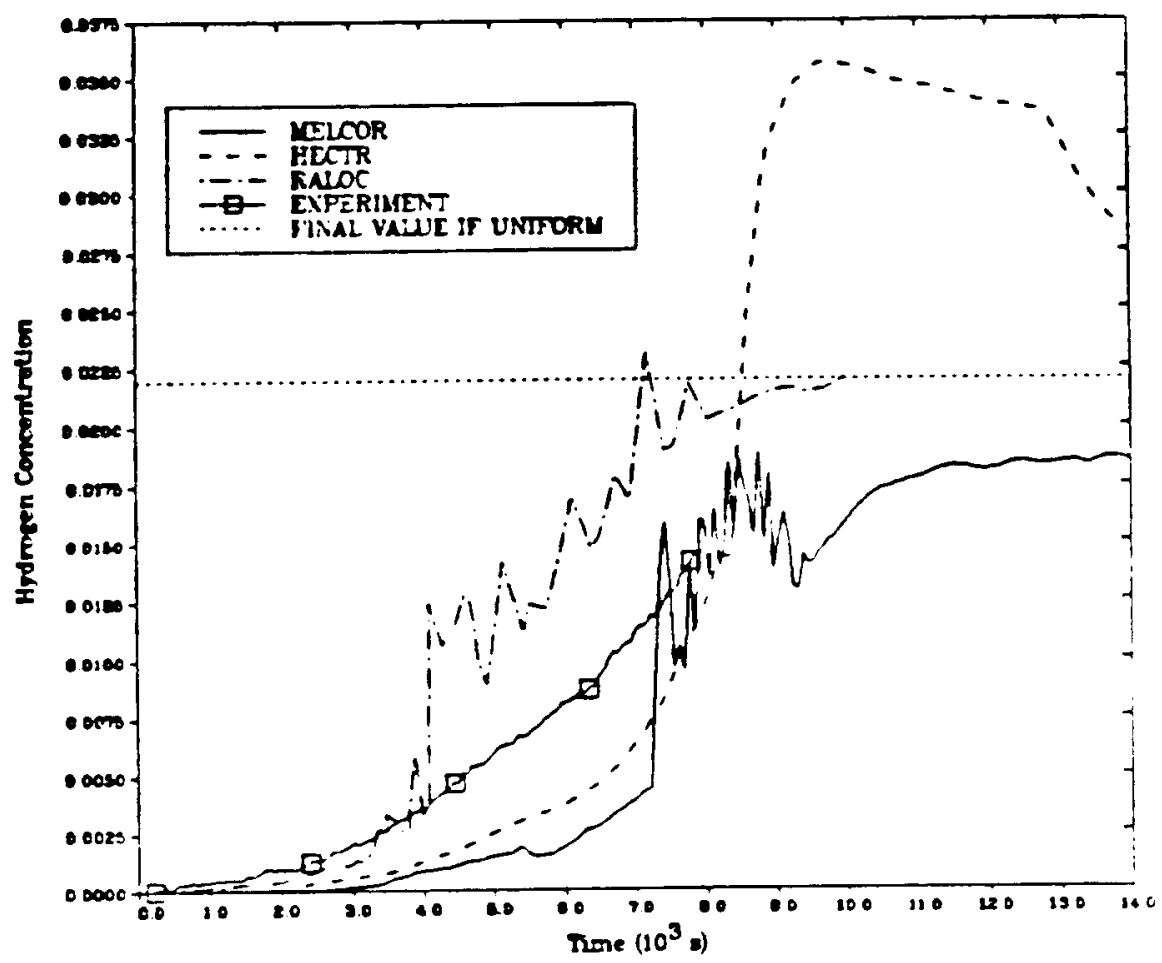

Figure 5. Hydrogen Concentration in Cell 1 for Battelle-Frankfurt Test 6 


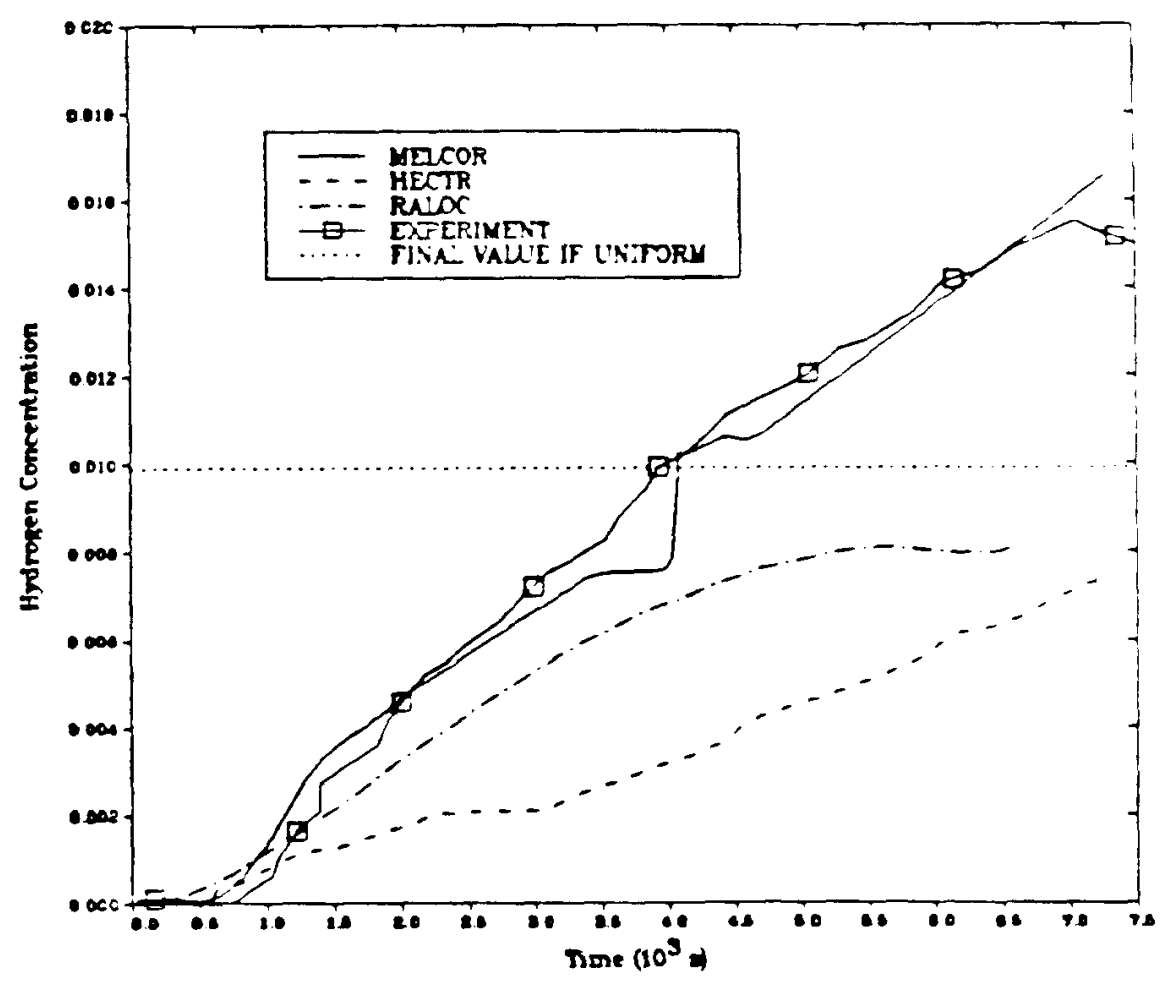

Figure 6. Hydrogen Concentration in Cell 27 for Battelle-Frankfurt Test 19

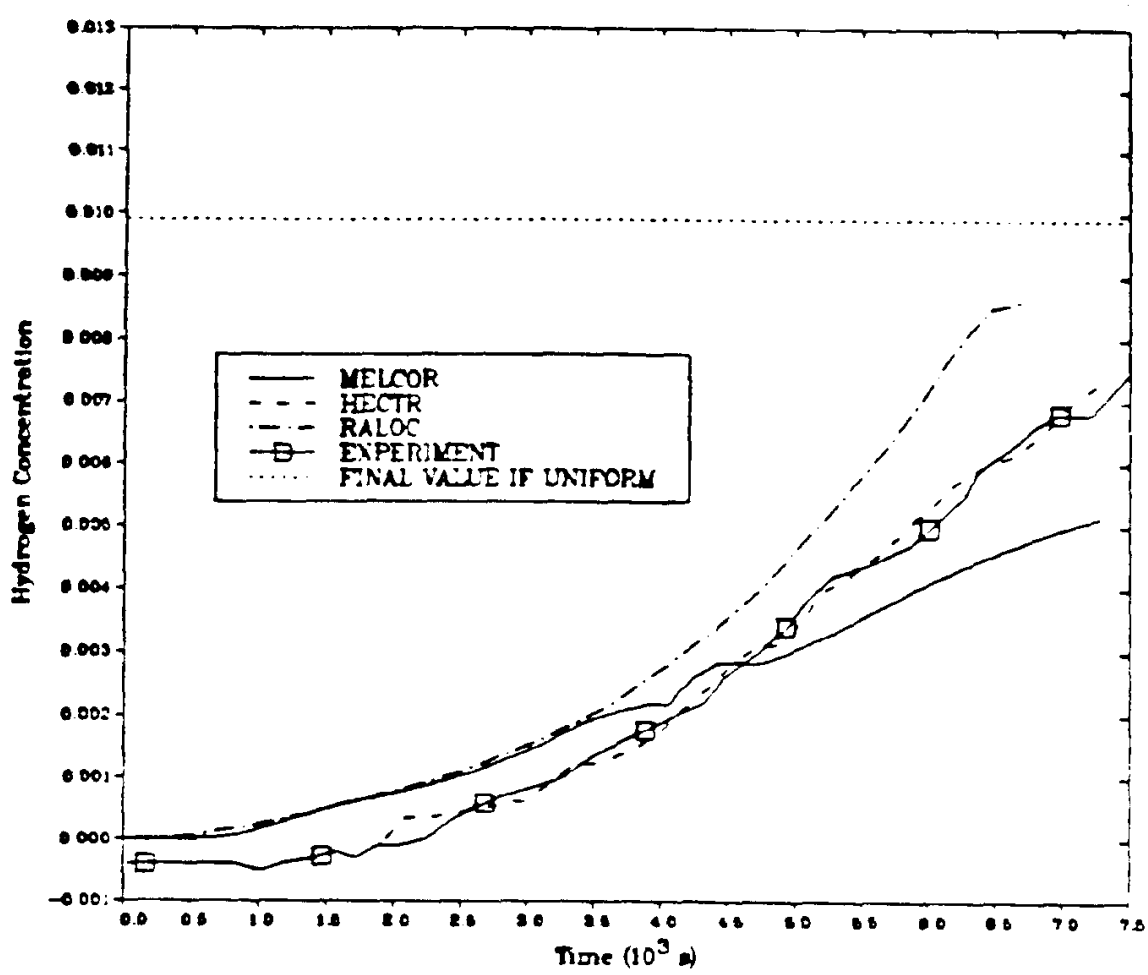

Figure 7. Hydrogen Concentration in Cell 23 for Battelle-Frankfurt Test 19 


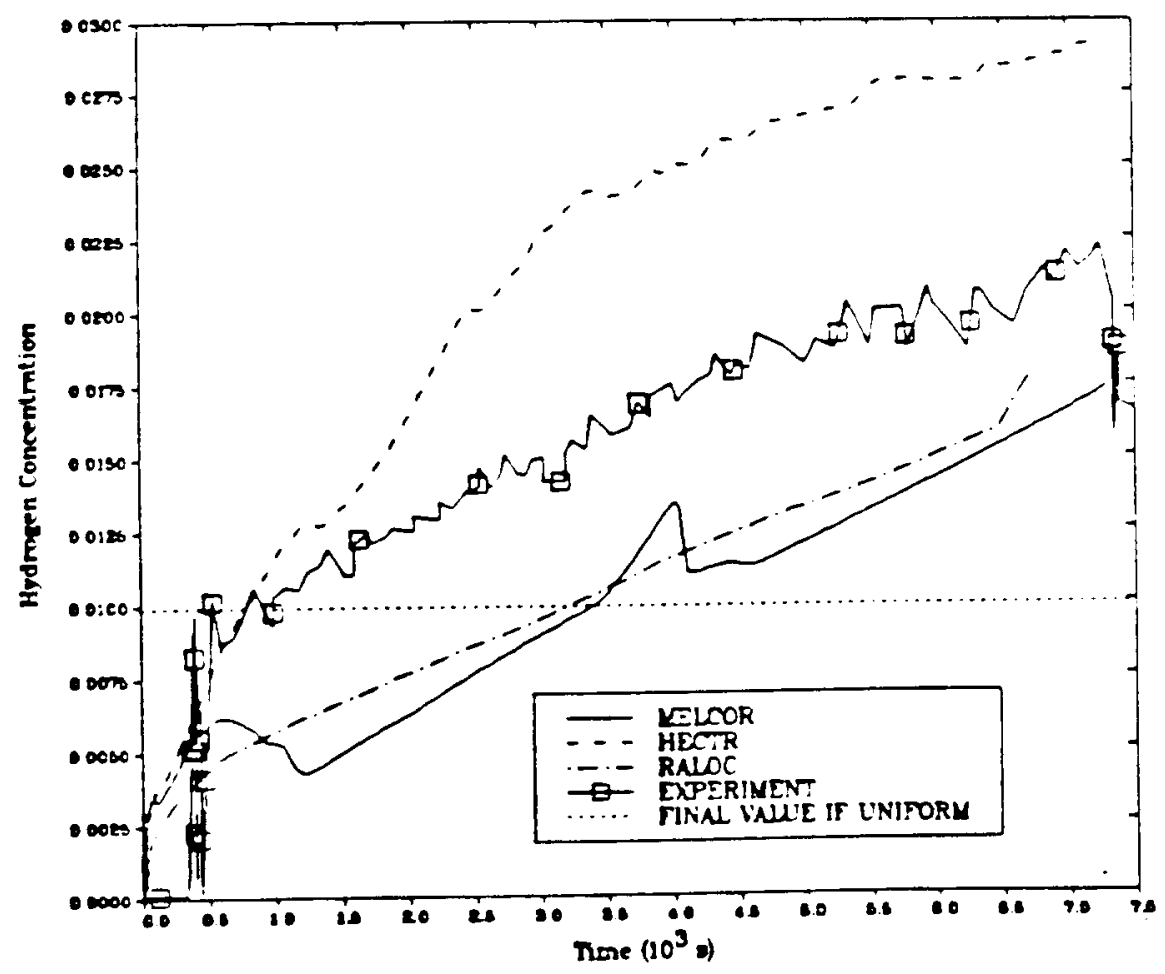

Figure 8. Hydrogen Concentration in Cell 13 for Battelle-Frankfurt Test 19

\section{References}

1. G. Langer, R. Jenior, and H. G. Wentlandt, Experimental Investigation of the Hydrogen Distribution in the Containment of a Light Water Reactor Following a Coolant Loss Accident, NRC Translation 801, BF-F-63.363-3, Battelle Institut e.V. Frankfurt, Federal Republic of Germany, October 1980 .

2. Research Project 150.375, Experimental Investigation of the Hydrogen Distribution in a Model Containment (Preliminary Experiments II), NRC Translation 1065, BF-R-64.036-1, Battelle Institut e.V. Frankfurt, Federal Republic of Germany, May 1982.

3. L. D. Buxton, D. Tomasko, and G. C. Padilla, An Evaluation of the RALOC Computer Code, NUREG/CR-2764, SAND82-1054, Sandia National Laboratories, Albuquerque, New Mexico, August 1982.

4. M. J. Wester and A. L. Camp, An Evaluation of HECTR Predictions of Hydrogen Transport, NUREG/CR-3463, SAND83-1814, Sandia National Laboratories, Albuquerque, New Mexico, September 1983.

5. A. L. Camp, Private Communication, Sandia National Laboratories. 
MELCOR 1.0 and HECTR 1.5 Calculations for
Browns Ferry Reactor Building Burns

S.E. Dingman and F.E. Haskin

Sandia National Laboratories

Albuquerque, New Mexico 87185

United States of America

\begin{abstract}
Following drywell failure in postulated severe accidents at Browns Ferry, hydrogen burns could occur in the reactor building. MELCOR and HECTR calculations for such burns have been performed. When using the same flame speed, the two codes predict similar pressure responses. However, the magnitude of the pressure rises differs somewhat because the preburn conditions are slightly different. These differences are due to different treatments of the control volume gravity head and heat transfer/ condensation in the two codes. Some MELCOR improvements are suggested.
\end{abstract}

\title{
1. Introduction
}

This paper compares MELCOR and HECTR [1] calculations of the Brown's Ferry secondary containment response to hydrogen burns that occur when hydrogen is released to the reactor building following drywell failure. Results from both codes are discussed, including calculations using HECTR models that are not currently available in MELCOR. These additional HECTR calculations are discussed in this report because they show how the models affect the calculated results, indicating a need for new MELCOR models. The input decks for these calculations were based on a CONTAIN [2] input deck provided by S. R. Greene of ORNL. Gas source rates were also provided by S. R. Greene.

\section{Test Description}

This test examines the response of the Browns Ferry reactor building, shown in Figure 1, following failure of the drywell steel shell. Initially, the reactor building is at atmospheric conditions. Following drywell failure, hydrogen from the drywell is pushed into the reactor building, such that a hydrogen burn (or series of hydrogen burns) is possible. The pressure rises during these burns will affect the release to the environment. There is also the potential for equipment failure due to temperature rises during the burns. Since there are no igniters in the reactor building, the threshold for burning cannot be reliably predicted. For the calculations presented herein, it is postulated that ignition occurs whenever the hydrogen mole fraction exceeds 88 . The corresponding pressure and temperature rises for the burns for various flame 


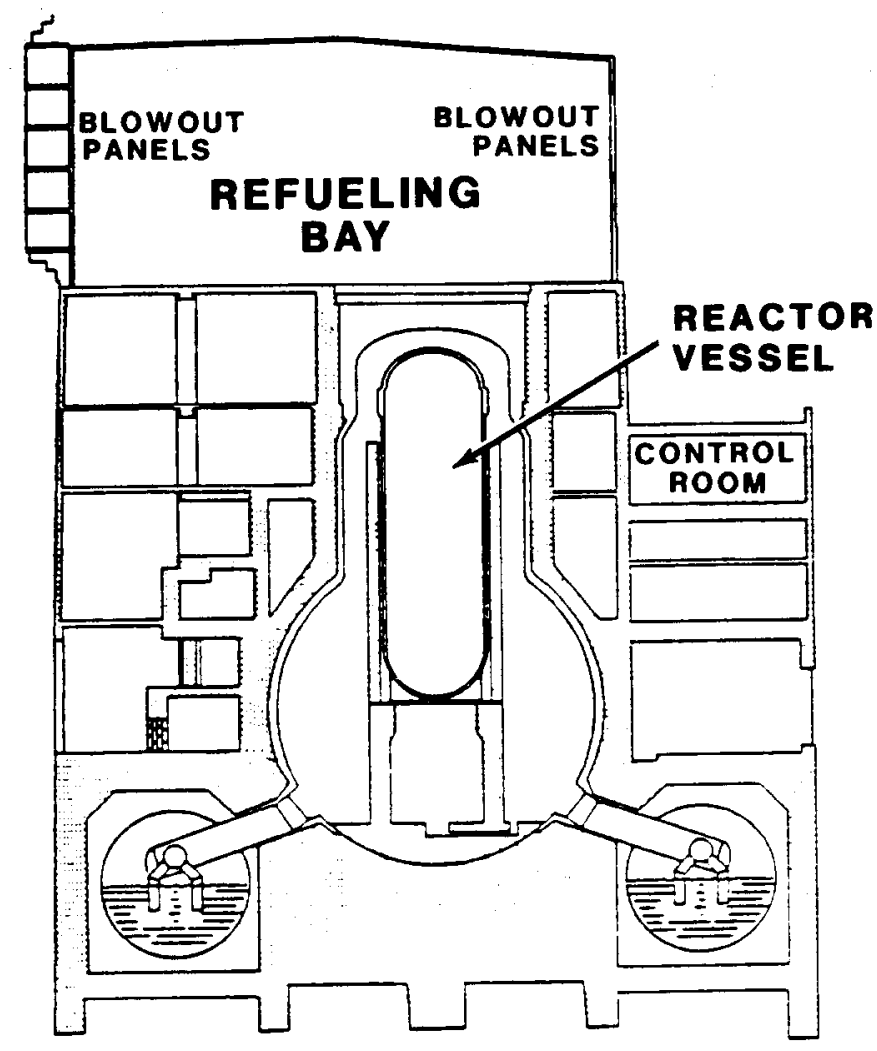

Figure 1. Browns Ferry Reactor Building

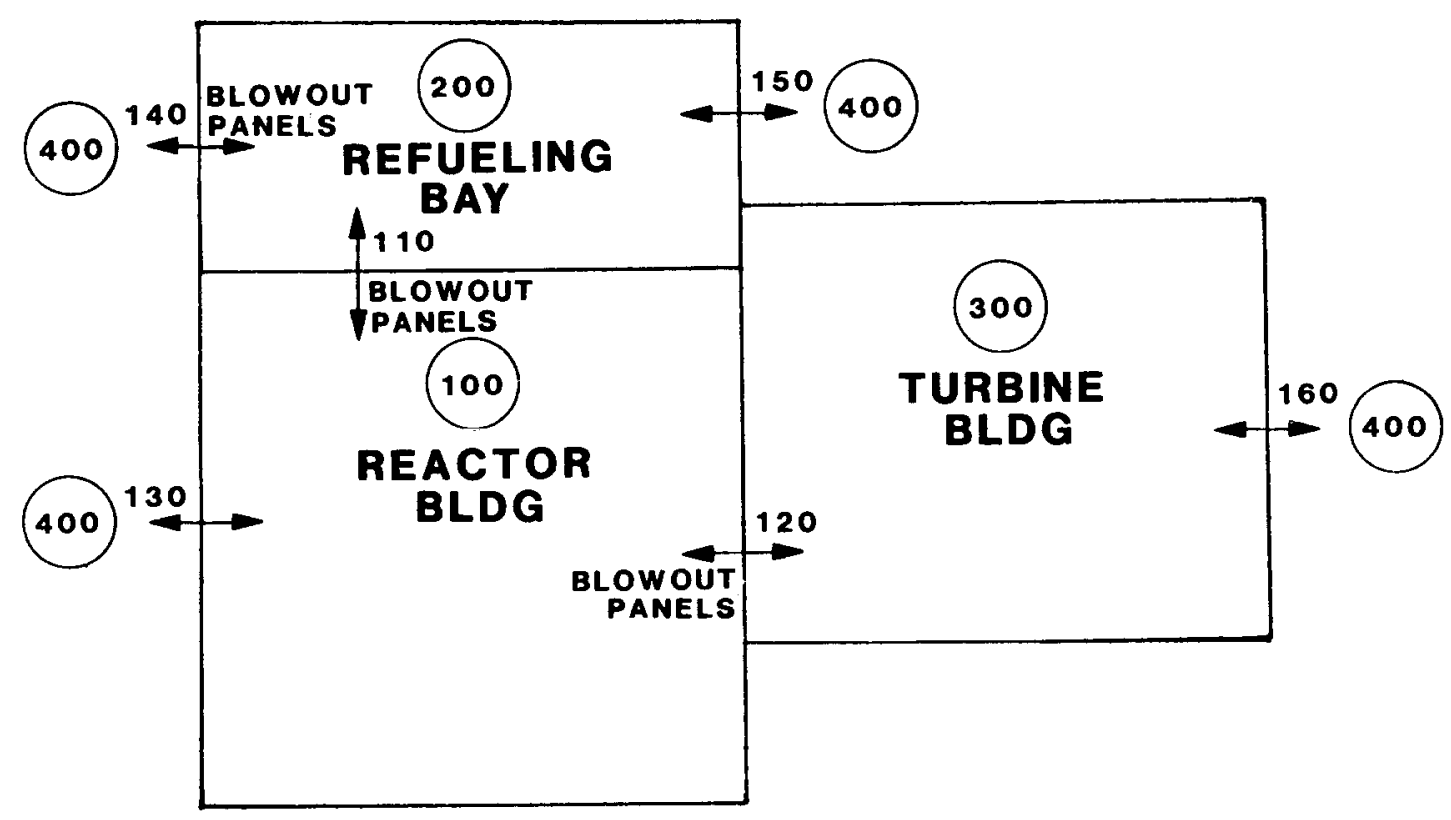

Figure 2. MELCOR Nodalization for the Browns Ferry Secondary Containment 
speeds are examined. The effects of radiative heat transfer and fire sprays, which are not currently available in MELCOR 1.0 are examined.

\section{Model and Case Descriptions}

Both MELCOR and HECTR were used to model the thermal-hydraulic response of the Brown's Ferry secondary containment as described in Section 2. The nodalization used for MELCOR is shown in Figure 2. The MELCOR input model consists of four compartments, six flow junctions, and 29 heat structures. The compartments represent the reactor building, refueling bay, turbine building, and the environment. Three flow junctions are included to model blowout panels and the remaining three junctions are included to model leakage to (or infiltration from) the environment. The heat structures are used to model the floors, walls, and ceilings of the reactor building, refueling bay, and turbine building. The HECTR nodalization was as similar as possible to the MELCOR nodalization.

Preliminary calculations showed that the MELCOR and HECTR default flame speed correlations gave sufficiently different values when significant quantities of steam were present that direct comparison of the calculated results were not meaningful. The variation in the flame speeds in high steam environments is so large that neither of the default correlations can be strongly supported. Therefore, rather than using the default correlations, the flame speed was varied from 1 to $10 \mathrm{~m} / \mathrm{s}$ in both the MELCOR and HECTR calculations. This also allowed us to examine the sensitivity of the results to the flame speed. Two additional sets of HECTR calculations were run that included effects of reactor building sprays and radiative heat transfer from the gases to passive heat sinks. The cases considered are listed in Tables 1 and 2 .

\section{Results}

The pressures calculated by MELCOR and HECTR during the first burn for Case 2 ( $5 \mathrm{~m} / \mathrm{s}$, no radiation, no sprays) are compared in Figure 3. Although the burns begin at slightly different times in the transient, the codes calculate similar pressure responses after the burns begin. The difference in burn timing will be discussed below.

The peak pressures as a function of the flame speed for the remaining MELCOR and HECTR calculations are shown in Figure 4. For both codes, the peak pressure increases as the flame speed increases, as expected. Differences in the magnitudes of the increases are due to different treatments of the control volume gravity head and heat transfer/ condensation in the two codes. These contributors are discussed in the following paragraphs.

\section{Gravity Head Treatment}

MELCOR defines the control volume pressure at the pool/ atmosphere interface (which is basically the bottom of the control volume for these calculations) whereas HECTR defines the control volume pressure at its vertical midpoint. When performing flow calculations, both codes account for the pressure 
Table 1. MELCOR Cases

\begin{tabular}{|c|c|c|c|}
\hline Case & $\begin{array}{c}\text { Flame Speed } \\
(\mathrm{m} / \mathrm{s})\end{array}$ & Radiation & Sprays \\
\hline 1 & 10. & No & No \\
2 & 5. & No & No \\
3 & 1. & No & No \\
\hline
\end{tabular}

Table 2. HECTR Cases

\begin{tabular}{|c|c|c|l|}
\hline Case & $\begin{array}{c}\text { Flame Speed } \\
(\mathrm{m} / \mathrm{s})\end{array}$ & Radiation & Sprays \\
\hline 1 & 10. & No & No \\
2 & 5. & No & No \\
3 & 1. & No & No \\
4 & 10. & Yes & No \\
5 & 5. & Yes & No \\
6 & 1. & Yes & No \\
7 & 10. & Yes & Yes \\
8 & 5. & Yes & Yes \\
9 & 1. & Yes & Yes \\
\hline
\end{tabular}

variation due to differences in the control volume and flow junction elevations that result from the gravity head. Thus, the initial pressures specified for the two codes can be adjusted such that flow rate calculations are not affected by this modeling difference. However, since the number of moles in a control volume is defined by its pressure and temperature, adjusting the pressure to match the gravity head, will yield a different initial mole content in the two codes. We chose to match the gravity head rather than mole content.

When these calculations were performed, it was not possible in either MELCOR or HECTR to account for the gravity head between the control volume and junction elevations when calculating pressure differences for blowout panels. Since MELCOR and HECTR use different references for the control volume elevations, it was not possible to match the blowout panel performance. In MELCOR, the blowout panels between the reactor building and turbine building were blown out before the first burn, but in HECTR they did not blow out until the burn started. As a result, the preburn temperature in the reactor building was lower in MELCOR than in HECTR. With a lower temperature, more moles of hydrogen were required to accumulate in the reactor building to yield the 88 ignition limit. Thus, the first burn occurred later in MELCOR and it resulted in a larger pressure rise. 


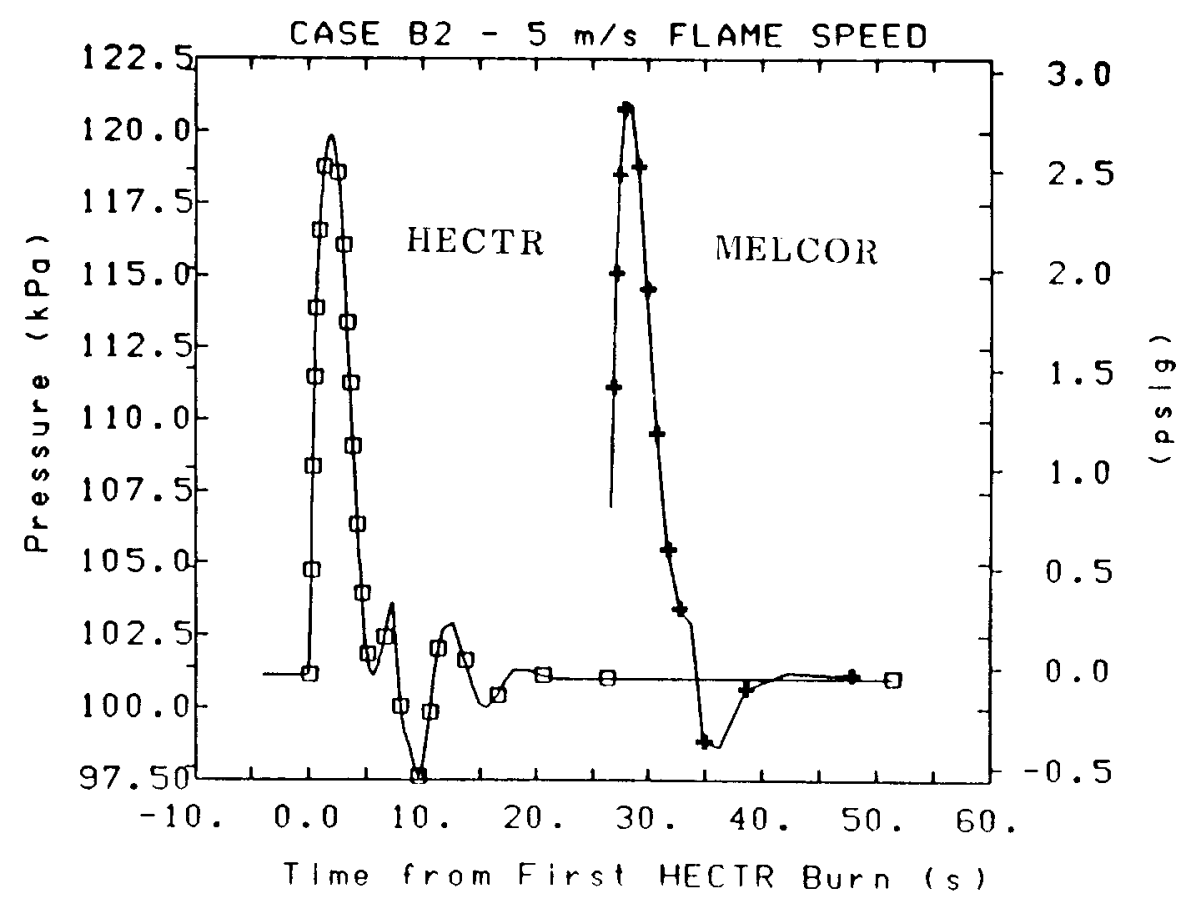

Figure 3. Pressure Comparison for the First Burn in Case 2.

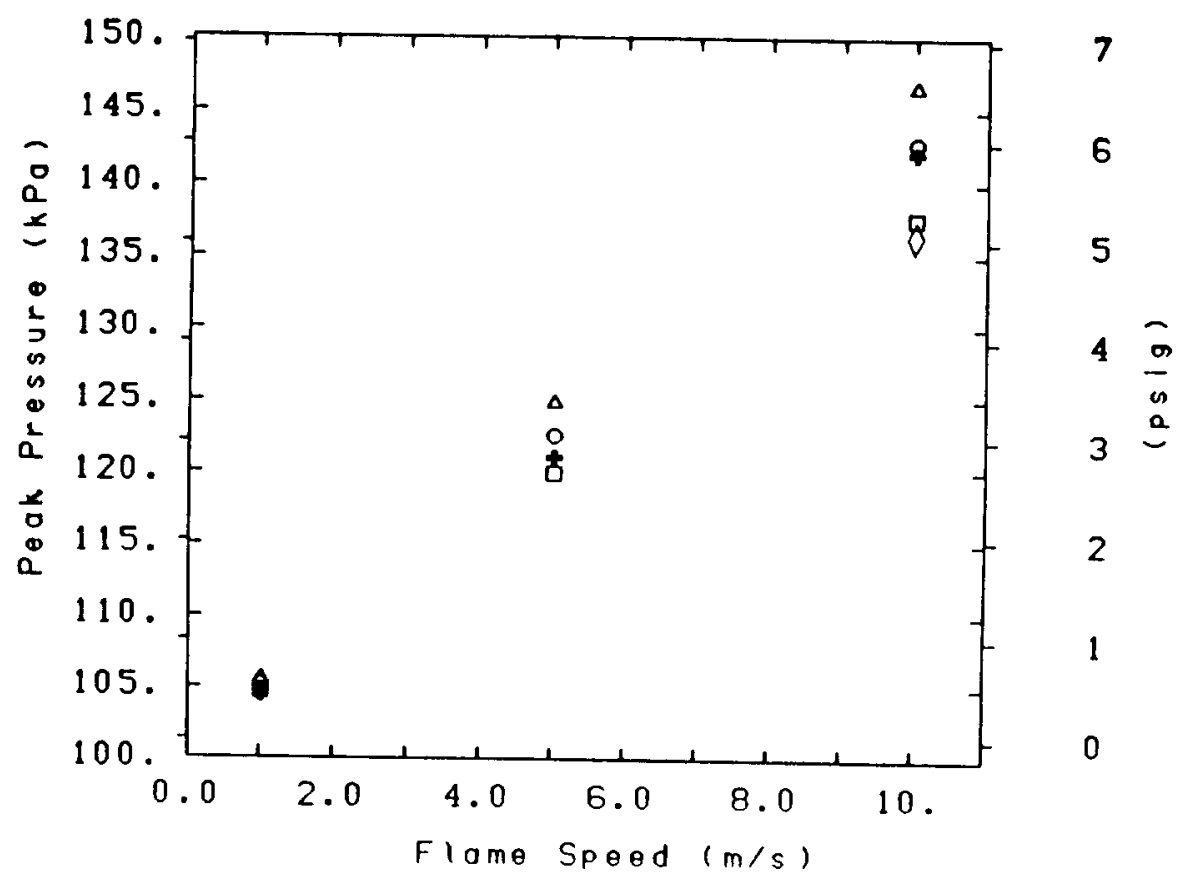

Figure 4. Peak Pressure Versus Flame Speed. $\triangle$ HECTR with radiation and sprays; OHECTR with radiation and no sprays; + MELCOR without radiation and sprays; $\square$ HECTR without radiation and sprays; $\triangle$ MELCOR 1.6. 


\section{Heat Transfer / Condensation}

The heat flux to surfaces in the reactor building was generally lower in MELCOR than in HECTR. This is mainly due to differences in heat transfer correlations; an internal flow type of convective heat transfer correlation (Dittus-Boelter) is used in MELCOR, whereas an external flow correlation [1] is used in HECTR. The MELCOR correlation is appropriate for control volumes such as the reactor vesse1, but an external flow correlation should be added for containment surfaces.

MELCOR and HECTR also use different methods to determine the convective velocity for heat transfer calculations. In MELCOR, the user inputs a control volume area which is used in conjunction with an average control volume flow rate to define a velocity. In HECTR, the user specifies a constant velocity, which is used during portions of the calculation in which burns are not occurring. During burns, HECTR uses the flame speed as the convective velocity. There are problems with both approaches. Using a constant velocity does not allow for variations during the transient, but using average inflows and outflows from a control volume to determine the velocity may not give an accurate representation of conditions within the control volume. For this test problem, we specified the MELCOR area and HECTR velocity such that the velocities used were approximately the same.

Although the condensation/evaporation rates were much smaller than the convective heat transfer rates for these calculations, modeling differences between HECTR and MELCOR could affect results in other comparisons, so they will be briefly discussed here.

The condensation rates in MELCOR are calculated using

$$
\mathrm{Sh}=\mathrm{Nu}(\mathrm{Sc} / \mathrm{Pr})^{1 / 3}
$$

whereas at the time these calculations were performed HECTR used

$$
\mathrm{Sh}=\mathrm{Nu}(\mathrm{Pr} / \mathrm{Sc})^{2 / 3} \text {. }
$$

To resolve this discrepancy, several different heat transfer texts were reviewed, and it was concluded that the MELCOR treatment is correct. The error in HECTR has been reported and is being corrected.

The heat flux to surfaces in the reactor building was generally lower in MELCOR than in HECTR, but the surface temperature increases during the burns were higher in MELCOR. There are too many differences in this calculation to determine the exact cause of this discrepancy. Possible causes include differences in nodalization of the structures and different treatments of liquid films in the two codes.

\section{Effect of Radiation and Sprays}

The HECTR calculations that included radiative heat transfer and sprays were significantly different from the calculations discussed above (See Figure 4). 


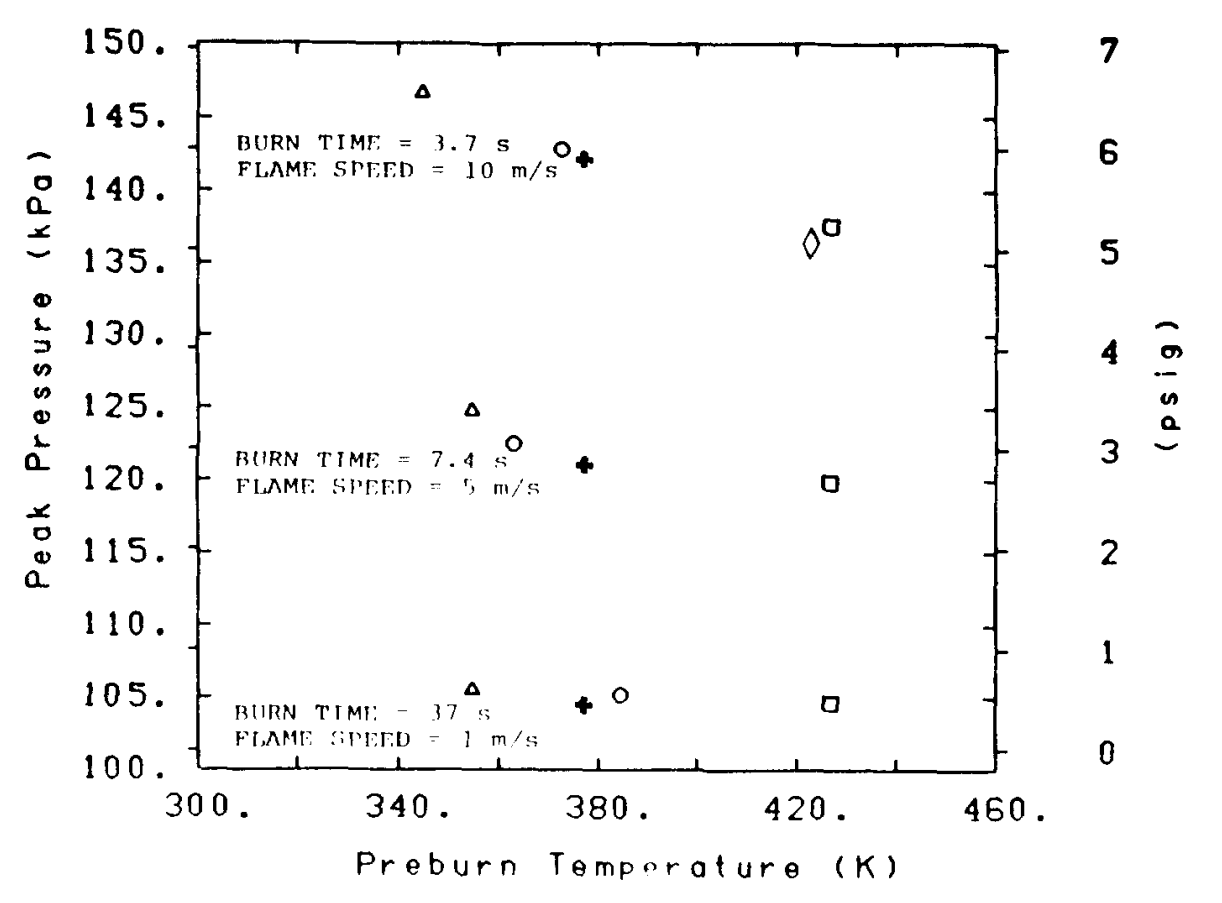

Figure 5. Peak Pressure as a Function of the Preburn Temperature. $\triangle$ HECTR with radiation and sprays; O HECTR with radiation and no sprays; + MELCOR without radiation and sprays; $\square$ HECTR without radiation and sprays; $\triangle$ MELCOR 1.6 .

Including radiative heat transfer resulted in lower temperatures at the initiation of the burn. Thus, there were more moles of hydrogen in the reactor building prior to the first burn than in the cases without radiation, giving larger pressure rises. The peak pressure is plotted as a function of the preburn temperature in Figure 5 to illustrate this effect. When spray injection was included, the reactor building was cooled even further prior to the first burn, giving a still larger pressure rise.

\section{MELCOR 1.6 Calculations}

A calculation for case 3 was performed using MELCOR 1.6. The heat structure package was revised substantially for MELCOR 1.6. The MELCOR 1.6 results indicate that the preburn temperature in MELCOR was closer to that of HECTR without radiation and sprays, and therefore, the peak pressure is closer to the HECTR calculation. These results are shown on Figure 4 and Figure 5.

\section{Summary and Conclusions}

The calculations showed good agreement between HECTR and MELCOR results. However, the need for additional test problems that compare results from MELCOR and HECTR has been identified. Suggested problems are listed below: 
(1) Comparison of pressure and temperature rises during burns starting at the same initial conditions, including propagation into adjoining

compartments. The ignition limit and flame speed should be varied over a reasonable range.

(2) Comparison of heat transfer rates (with and without condensation) for a wide range of temperatures, convective velocities, and steam concentrations. The same nodalization should be used for the structures in both codes. Structure surface temperatures should also be compared.

The HECTR calculations that included radiative heat transfer and sprays showed that these effects can be important. Radiative heat transfer from gas to surfaces should be included in MELCOR. A spray model is currently available in MELCOR, but the capability to turn on the sprays based on pressure and/or temperature is not currently available. This should be added such that spray actuation can be correctly modeled.

\section{References}

1. S.E. Dingman, et a1., HECTR Version 1.5 User's Manual, NUREG/CR-4507, SAND86-0101, Sandia National Laboratories, April 1986.

2. K.D. Bergeron, et al., User's Manual for CONTAIN 1.0, NUREG/CR-4085, SAND84-1204, Sandia National Laboratories, May 1985. 


\author{
MELCOR 1.0 Calculations \\ for Cooling of Structures in a Fluid
}

\author{
P. N. Demmie \\ Sandia National Laboratories \\ Albuquerque, New Mexico 87185 \\ United States of America
}

\begin{abstract}
MELCOR calculations were performed for the cooling of two uniform structures (rectangular and cylindrical) with constant thermal properties and heat transfer coefficients. The temperatures as a function of time for the structures are compared in this paper to the exact analytical solution and to SCDAP results. The good agreement between the MELCOR results, the SCDAP results, and the exact analytical solution show that the finite-difference methods used in the MELCOR Heat Structure Package produce accurate results.
\end{abstract}

\title{
1. Introduction
}

This paper presents a MELCOR calculation for the cooling of two structures in a fluid and compares the results of this calculation to both an analytic solution and the results of the calculation of the same transient using the SCDAP Code[1]. The purpose of this calculation is to test the implementation of the internal heat conduction methodology of the MELCOR Heat Structure Package (HSP) without internal or surface power sources.

\section{Test Description}

MELCOR calculations were performed for two uniform solid structures (rectangular and cylindrical) with constant thermal properties and constant surface heat transfer coefficients. These structures, which were initially at $1000 \mathrm{~K}$, were immersed in a fluid at $500 \mathrm{~K}$. Table 1 contains the values of the thermal properties of the material in these structures as well as the other parameters that were used for the calculation. The material in these structures does not correspond to any known material but was chosen to permit comparison of the results of a MELCOR calculation with an analytic solution and the results of a SCDAP calculation [1] of the same transient.

It is well documented in heat transfer texts that lumped-heat-capacity (LHC) methods are adequate for transient heat conduction calculations for a structure if its Biot Number is less than 0.1 [2]. The Biot Number for a structure is 
where

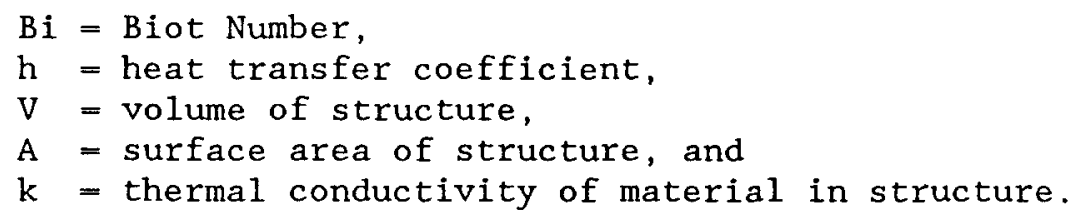

A low Biot Number implies that the transfer of energy within the structure is rapid relative to the transfer of energy from the structure to the fluid. Thus, the temperature within a structure with a low Biot Number can be assumed to be uniform.

The analytic solution for the temperature of a LHC structure which is immersed in a fluid is [2]:

$$
T=T_{f}+\left(T_{i}-T_{f}\right) \quad[\exp (-h A t / \alpha V)]
$$

where

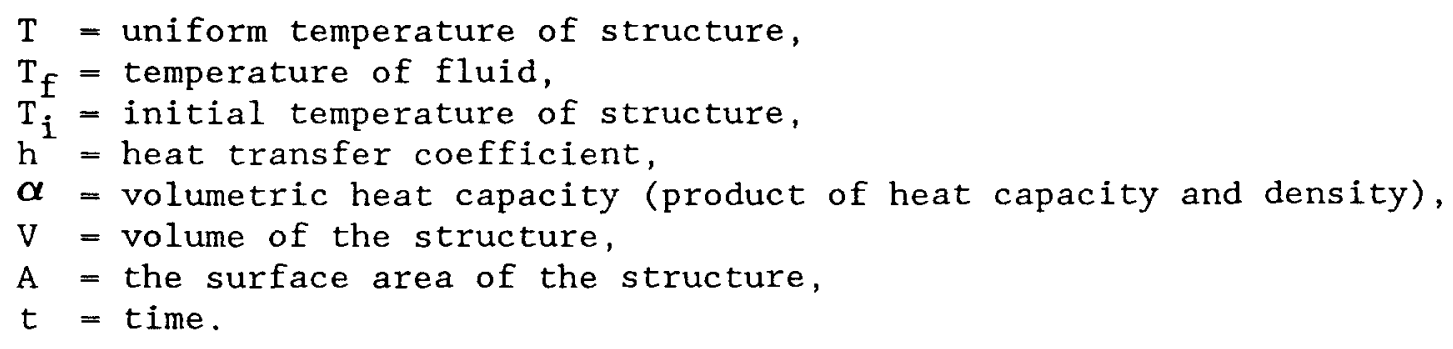

This solution is obtained by solving the first order linear differential equation that follows from the global energy balance between the structure and the fluid under the assumption of a uniform temperature throughout the solid (i.e., the LHC method).

The Biot Number is 0.05 for both rectangular and cylindrical structures with parameters from Table 1 . Hence, the temperatures that are calculated by MELCOR should be close to the analytic solution which is given by Equation 2 .

\section{Model and Calculation Description}

The MELCOR code was run for a rectangular and cylindrical heat structure each with a Biot Number of 0.05 and a control volume boundary which models a temperature reservoir at $500.0 \mathrm{~K}$. All parameters were chosen to permit an exact comparison of the MELCOR results with the SCDAP results. Since the SCDAP calculation used a constant time step of $0.0029 \mathrm{~s}$, the MELCOR calculation also used this value. 


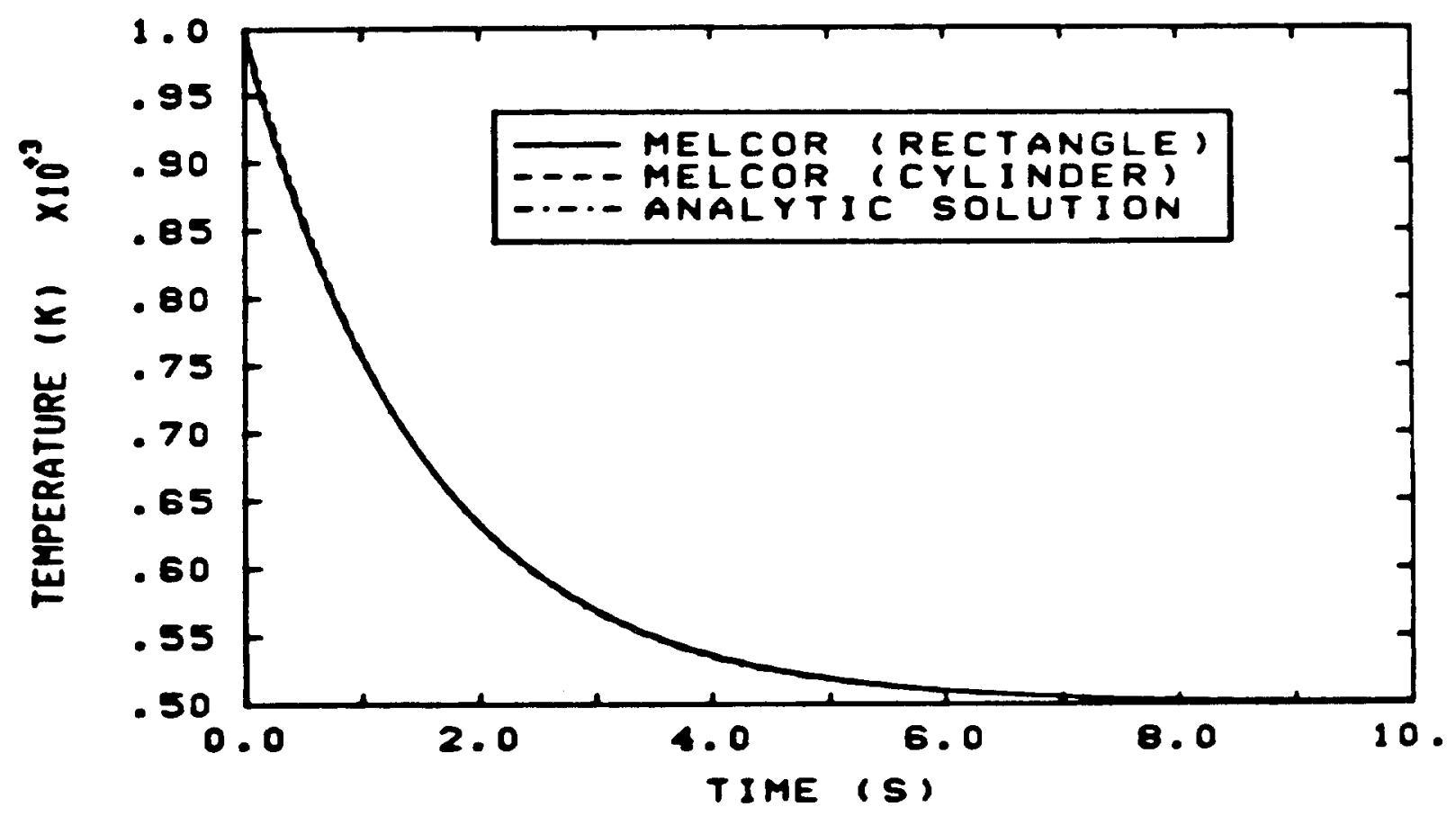

Figure 1. MELCOR Calculated Temperatures and Analytic solution.

Table 1. Parameter Values For Calculation

\begin{tabular}{|c|l|}
\hline \multicolumn{1}{|c|}{ Parameter } & \multicolumn{1}{|c|}{ Value } \\
\hline & \\
Thermal Conductivity of Material in Structures & $50.0 \mathrm{~W} / \mathrm{m} / \mathrm{K}$ \\
Density of Material in Structures & $1.0 \mathrm{~kg} / \mathrm{m}^{-}$ \\
Heat Capacity of Material in Structures & $1500.0 \mathrm{~J} / \mathrm{kg} / \mathrm{K}$ \\
Heat Transfer Coefficient at Surfaces & $50.0 \mathrm{~W} / \mathrm{m}^{2} / \mathrm{K}$ \\
Initial Temperature of Structures & $1000.0 \mathrm{~K}$ \\
Fluid Temperature & $500.0 \mathrm{~K}$ \\
Thickness of Rectangular Structure & $0.1 \mathrm{~m}$ \\
Area of Each Surface of Rectangular Structure & $1.0 \mathrm{~m}$ \\
Radius of Cylindrical Structure & $0.1 \mathrm{~m}$ \\
Height of Cylindrical Structure & $1.0 \mathrm{~m}$ \\
\hline
\end{tabular}


Table 2. Surface Temperature Versus Time

\begin{tabular}{|l|c|c|c|c|}
\hline \multirow{2}{*}{ Time (s) } & \multicolumn{4}{|c|}{ Temperature (K) } \\
\cline { 2 - 5 } & $\begin{array}{c}\text { MELCOR } \\
\text { (rectangle) }\end{array}$ & $\begin{array}{c}\text { MELCOR } \\
\text { (cylinder) }\end{array}$ & $\begin{array}{c}\text { SCDAP } \\
\text { (cylinder) }\end{array}$ & Analytic \\
\hline 0.0 & 1000.00 & 1000.00 & 1000.00 & 1000.00 \\
1.0 & 755.196 & 754.410 & 754.642 & 756.692 \\
2.0 & 632.419 & 632.725 & 632.978 & 631.782 \\
3.0 & 568.715 & 569.243 & 569.443 & 567.655 \\
4.0 & 535.661 & 536.125 & 536.264 & 534.733 \\
5.0 & 518.510 & 518.848 & 518.938 & 517.831 \\
6.0 & 509.630 & 509.853 & 509.890 & 509.154 \\
7.0 & 505.003 & 505.142 & 505.164 & 504.700 \\
8.0 & 502.603 & 502.685 & 502.697 & 502.413 \\
9.0 & 501.358 & 501.402 & 501.408 & 501.239 \\
10.0 & 500.711 & 500.734 & 500.735 & 500.636 \\
\hline
\end{tabular}

\section{Discussion of Results}

The results of the MELCOR calculation are compared to the SCDAP results and the analytic solution. The comparison with the SCDAP results shows the similarity between results which are obtained using the finite-difference methodology of the MELCOR HSP and the finite-element heat conduction methodology in SCDAP; the comparison with the analytic solution shows the accuracy of the MELCOR heat conduction methodology.

Figure 1 shows the temperatures for a rectangular and cylindrical structure which were calculated by MELCOR and the analytic solution which is given by Equation 2. This figure shows excellent agreement between the MELCOR results and the analytic solution. All structures are cooled as expected and have surface temperatures at the end of this 10-second calculation that are nearly equal to the fluid temperature of $500.0 \mathrm{~K}$.

A comparison of the MELCOR results to the SCDAP results is given in Table 2 . Results are given at 1 -second intervals in the table. Excellent agreement is shown between the MELCOR results, the SCDAP results, and the analytic solution.

\section{References}

1. G. A. Berna, "Finite Element Method for SCDAP", EGG-CDD-5697, December 1981.

2. J. P. Holman, Heat Transfer, 4th Edition, McGraw-Hill Book Company, 1976. 
MELCOR 1.0 Calculations for Radial Conduction in Annular Structures

S. E. Dingman

Sandia National Laboratories

Albuquerque, New Mexico 87185

United States of America

\begin{abstract}
MELCOR predictions of the steady state temperature distributions resulting from radial heat conduction in annular structures have been compared to the exact analytical solutions for two sets of boundary conditions and two cylinder sizes. The agreement between MELCOR results and the analytic solution is excellent in all cases.
\end{abstract}

\title{
1. Introduction
}

This paper compares MELCOR predictions of the steady state temperature distributions resulting from radial heat conduction in annular structures to results obtained from exact analytic solutions. Two sets of boundary conditions and two cylinder sizes are considered. In addition, a transient calculation is performed for a structure with an initially uniform temperature profile to test whether MELCOR achieves the correct steady-state temperature profile.

\section{Test Description}

The analytic solution for the temperature profile resulting from radial, steady state heat conduction in an annular structure given the inner and outer surface temperatures is:[1]

$$
\mathrm{T}=\mathrm{T}_{\mathrm{i}}-\ln \left(\mathrm{r} / \mathrm{r}_{\mathbf{i}}\right)\left[\frac{\left(\mathrm{T}_{\mathrm{i}}-\mathrm{T}_{\mathrm{o}}\right)}{\ln \left(\mathrm{r}_{\mathrm{o}} / \mathrm{r}_{\mathrm{i}}\right)}\right]
$$

where

$$
\begin{aligned}
& \mathrm{T}=\text { The temperature at radius } \mathrm{r}(\mathrm{K}) \\
& \mathrm{T}_{\mathrm{i}}=\text { Inner surface tube temperature }(\mathrm{K}) \\
& \mathrm{T}_{0}=\text { Outer surface tube temperature }(\mathrm{K}) \\
& \mathrm{r}_{\mathrm{i}}=\text { Inner tube radius }(\mathrm{m}) \\
& \mathrm{r}_{0}=\text { Outer tube radius }(\mathrm{m})
\end{aligned}
$$


Given specified heat transfer coefficients and control volume temperatures at the inner and outer surfaces, the analytic solution is[1]:

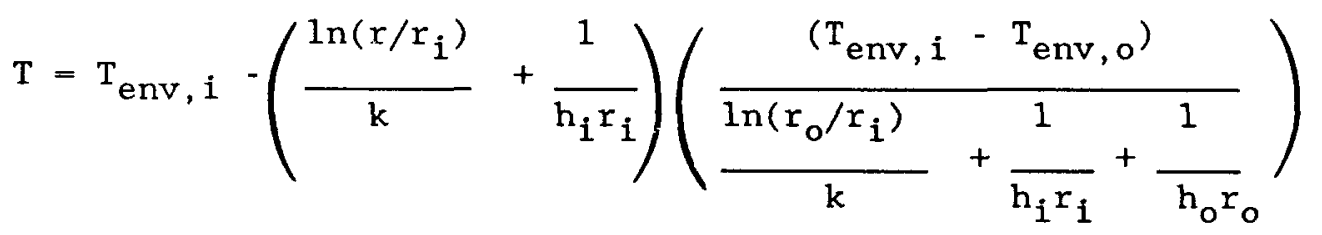

where

$$
\begin{aligned}
\mathrm{k}= & \text { The thermal conductivity of the structure }(\mathrm{W} / \mathrm{m} / \mathrm{K}) \\
\mathrm{T}_{\text {env, } \mathrm{i}}= & \text { The temperature of the control volume adjacent to the inner } \\
& \text { surface } \\
\mathrm{T}_{\text {env, } \mathrm{o}=} & \begin{array}{l}
\text { The temperature of the control volume adjacent to the outer } \\
\text { surface }
\end{array}
\end{aligned}
$$

\begin{tabular}{|c|c|c|c|c|c|}
\hline \multirow[t]{2}{*}{$\begin{array}{l}\text { Case } \\
\text { No. }\end{array}$} & \multirow[t]{2}{*}{$\begin{array}{l}\text { Transient } \\
\quad \text { or SS }\end{array}$} & \multicolumn{2}{|c|}{$\begin{array}{c}\text { Boundary Conditions } \\
\left(\mathrm{K} \text { or } \mathrm{W} / \mathrm{m}^{2} \angle \mathrm{K}\right)\end{array}$} & \multicolumn{2}{|c|}{$\begin{array}{c}\text { Radius } \\
(\mathrm{m})\end{array}$} \\
\hline & & Left & Right & Inner & Outer \\
\hline $\begin{array}{l}1 \\
2 \\
3 \\
4\end{array}$ & $\begin{array}{l}\text { Steady } \\
\text { Steady } \\
\text { Steady } \\
\text { Transient }\end{array}$ & $\begin{array}{l}\mathrm{T}=600 \\
\mathrm{~T}=600, \mathrm{~h}=1000 \\
\mathrm{~T}=600, \mathrm{~h}=1000 \\
\mathrm{~T}=600\end{array}$ & $\begin{array}{l}\mathrm{T}=550 \\
\mathrm{~T}=550, \mathrm{~h}=5 \\
\mathrm{~T}=550, \mathrm{~h}=500 \\
\mathrm{~T}=550\end{array}$ & $\begin{array}{l}3.1856 \\
3.1856 \\
.00843 \\
3.1856\end{array}$ & $\begin{array}{l}3.3412 \\
3.3412 \\
.00953 \\
3.3412\end{array}$ \\
\hline
\end{tabular}

In this paper comparisons of the results obtained using the MELCOR Heat Structure Package to these two analytic solutions are presented.

\section{Model and Case Descriptions}

Four cases are considered according to the following specifications:

Table 1. Specifications for MELCOR Calculations

Two cylinder sizes are considered. One (Cases 1, 2, and 4) is typical of a BWR reactor vessel. The second (Case 3 ) is typical of a PWR steam generator tube. Case 4 is a transient calculation (starting with a uniform temperature across the cylinder) which tests for the correct approach to the steady state temperature profile. 


\section{Results}

The analytic and MELCOR results for the four cases are compared in Figures 1 through 4. The steady state temperature profile calculated by MELGEN is plotted for the first three cases, and the temperature profile after reaching a steady state condition in MELCOR is plotted for case 4. The agreement between the MELCOR results and the analytic results is excellent in all cases.

\section{References}

1. J. P. Holman, Heat Transfer, pp. 25 - 30, McGraw-Hill Book Company, 1976. 


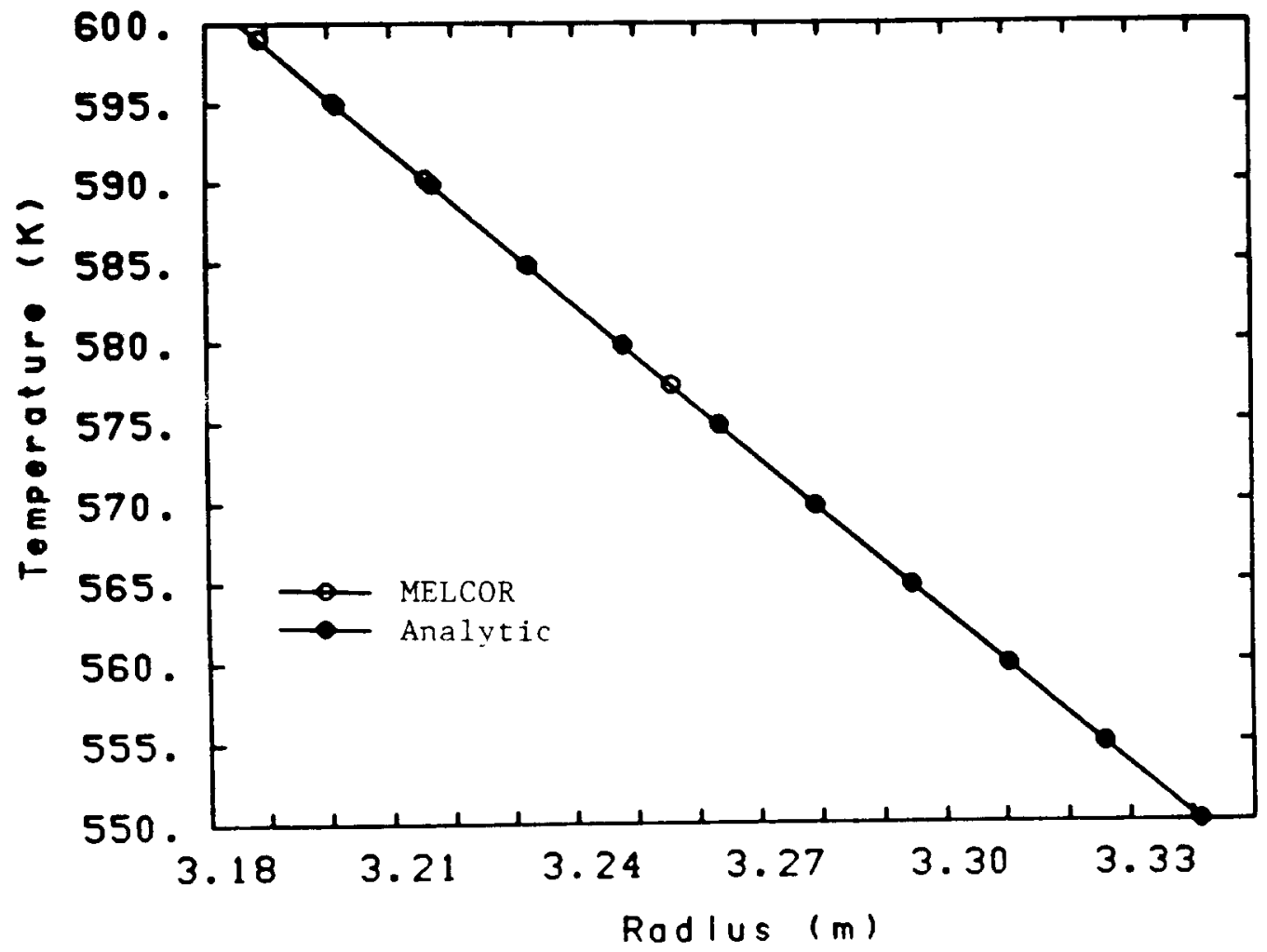

Figure 1. Temperature in the Cylinder as a Function of Radius for Case 1

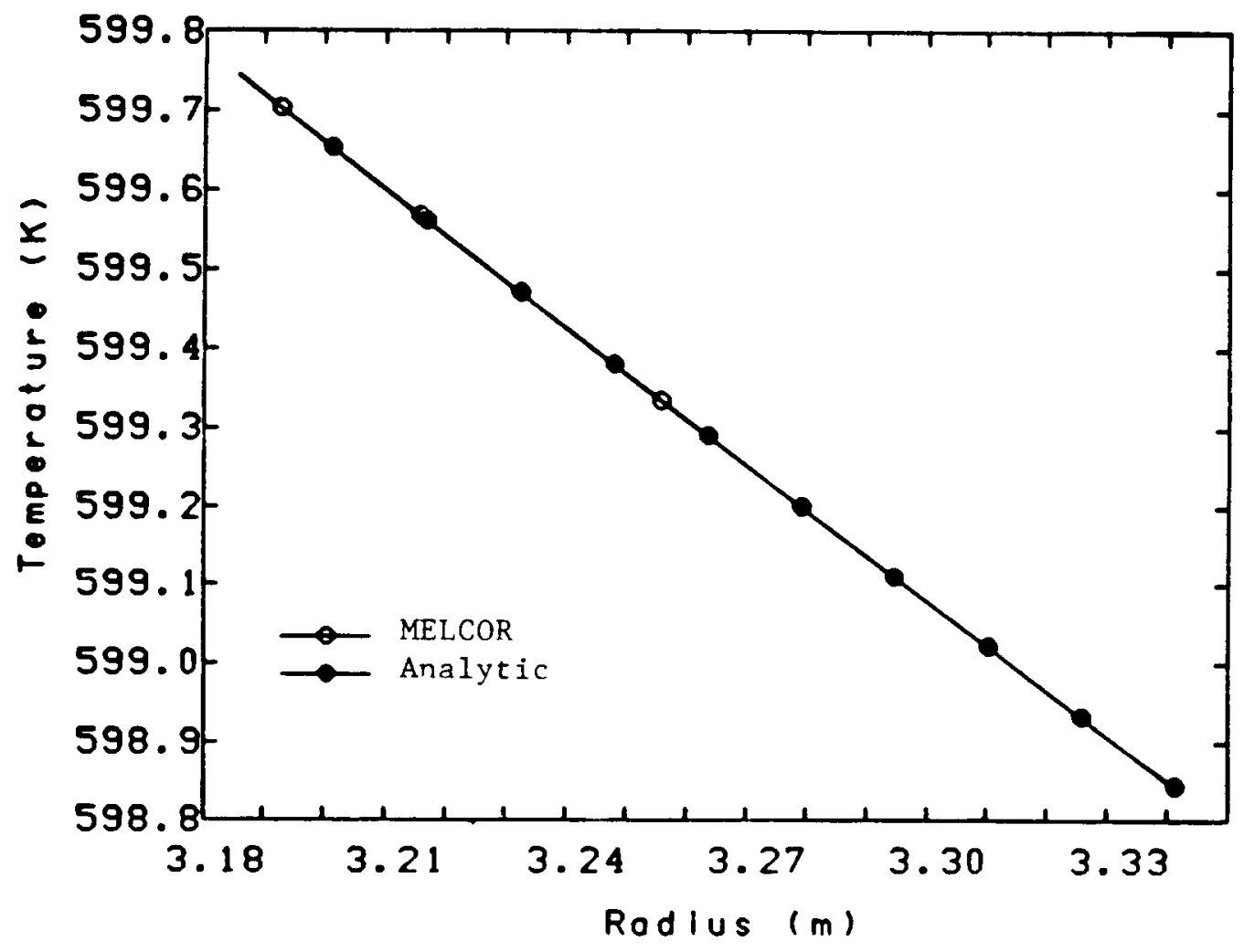

Figure 2. Temperature in the Cylinder as a Function of Radius for Case 2 


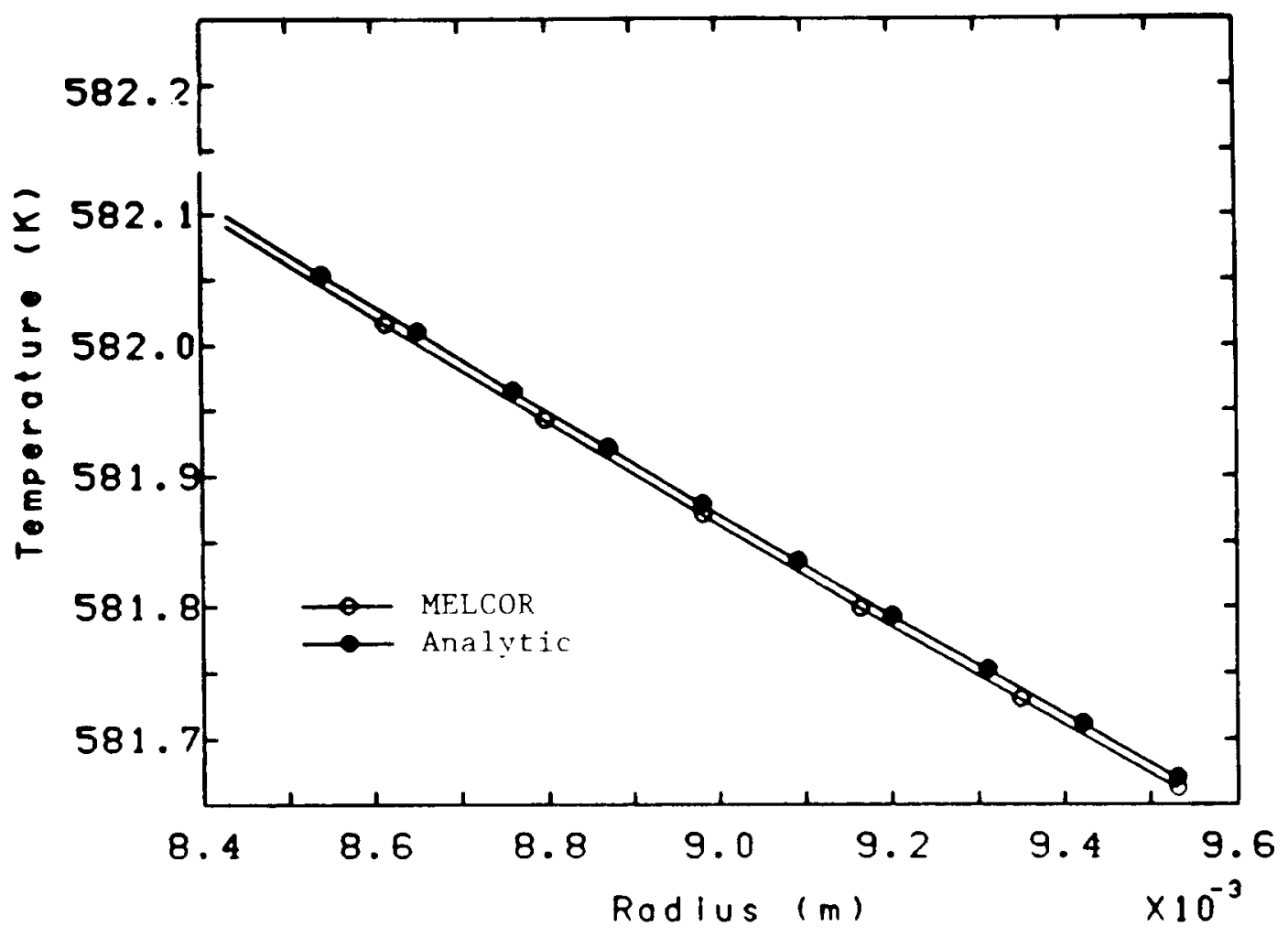

Figure 3. Temperature in the Cylinder as a Function of Radius for Case 3

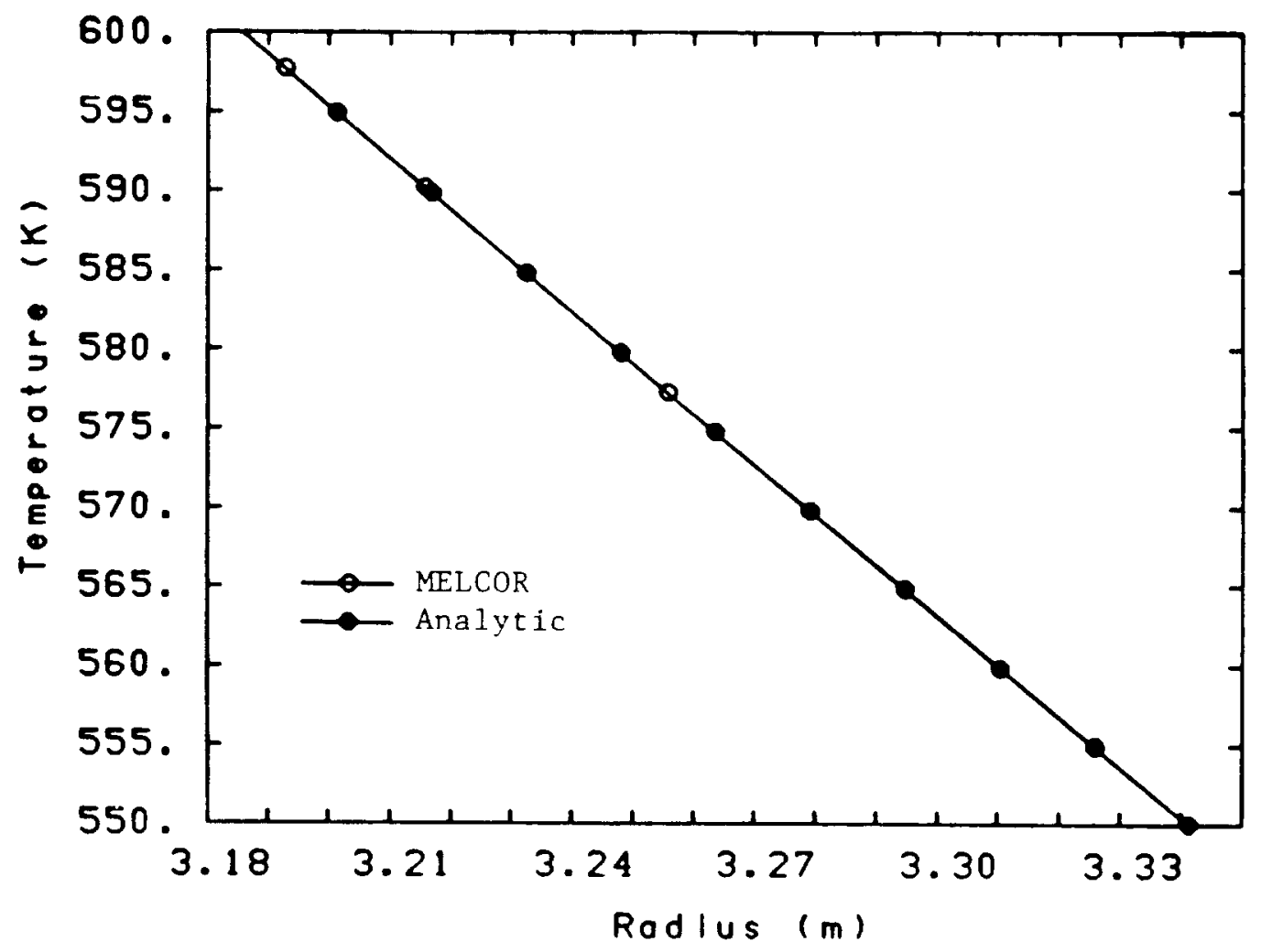

Figure 4. Temperature in the Cylinder as a Function of Radius for Case 4 



\author{
MELCOR 1.1 Calculations for a \\ Semi-infinite Solid Heat Structure Test \\ C. J. Shaffer \\ Science and Engineering Associates \\ Albuquerque, New Mexico 87110 \\ United States of America
}

\begin{abstract}
Predictions of the MELCOR heat structure package have been compared to the exact analytical solution for transient heat flow in a semi-infinite solid with convective boundary conditions. Comparisons have been made for steel and concrete, various thermal conductivities, atmospheric temperatures, node structures and time steps. MELCOR results appear to be more accurate for cases involving materials with low thermal conductivities like concrete rather than high thermal conductivities like steel, although in either case the accuracy of the MELCOR results is quite good (. 38 error in the integrated heat flux for concrete and .68 error in the integrated heat flux for steel). Guidelines regarding node spacings in typical concrete containment walls have been developed.
\end{abstract}

1. Introduction

In order to test the MELCOR heat conduction models, MELCOR predictions for heat conduction in a solid are compared to the exact analytical solution for transient heat flow in a semi-infinite solid with convective boundary conditions. This test best simulates the conduction heat transfer in thick walls, in particular, the concrete containment walls of a nuclear power plant during a severe accident. This test demonstrates the accuracy of the MELCOR heat conduction models and provides guidelines for node spacing and time step sizes for concrete containment walls.

\title{
2. The Analytical Solution
}

Transient heat flow in a semi-infinite solid with convective boundary conditions is modeled in MELCOR using a finite slab heat structure of sufficient thickness to approximate a semi-infinite solid. The analytical solution for transient heat flow in a semi-infinite slab is given in Holman[1] as a function of the time and the position from the surface given the initial slab temperature, the fluid temperature, the convective heat transfer coefficient, and the thermal properties of the solid (thermal conductivity, specific heat, and density) which are all assumed constant. The solution is given by the following equation. 


$$
\frac{T-T_{i}}{T_{0}-T_{i}}=1-\operatorname{erf}\left[\frac{x}{2 \sqrt{\alpha t}}\right]-\exp \left[\frac{h x}{k}+\frac{h^{2} \alpha t}{k^{2}}\right]\left[1-\operatorname{erf}\left(\frac{x}{2 \sqrt{\alpha t}}+\frac{h \sqrt{\alpha t}}{k}\right]\right]
$$

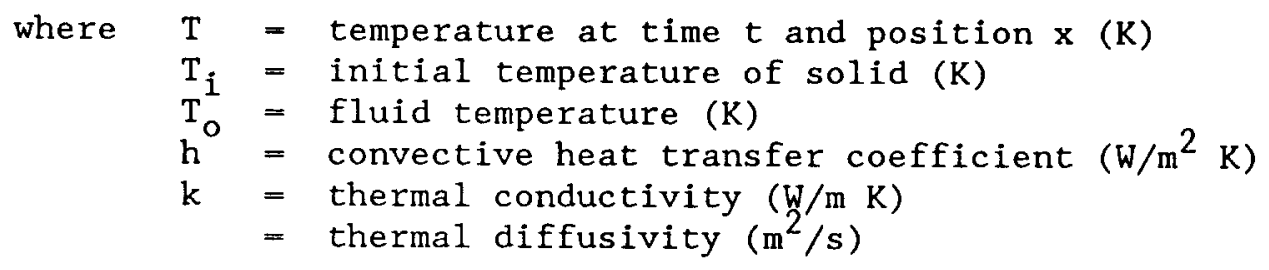

The time integrated surface heat flux was obtained from solving Equation 1 for the surface temperature and numerically integrating Equation 2 .

$$
Q=\int_{0}^{100,000} h\left(T_{0}-T_{S}\right) d t
$$

where $\mathrm{T}_{\mathbf{S}}$ is the temperature of the surface.

\section{Test Descriptions}

In the MELCOR calculations for this test, a 10 meter thick heat structure with logarithmic node spacing is assumed. The smallest node spacing is on the left side of the heat slab which is adjacent to a very large control volume. On the left side of the heat slab, a convective heat transfer boundary condition is specified with a heat transfer coefficient of $10 \mathrm{~W} / \mathrm{m}^{2} \mathrm{~K}$. An adiabatic boundary condition is specified for the right side of the heat slab.

MELCOR calculations were performed for two different materials (steel and concrete) and two different fluid temperatures to test MELCOR's ability to predict the analytical solution. Table 1 summarizes the specifications for the first three tests. These cases were run with 69 nodes within the first meter of thickness and with 10 second time steps. Case 1 is considered the base case for this report. The parameters for this case simulate the concrete wall of a containment building during a severe acciderit. Then, the number of nodes used and the time step sizes were varied to examine the effect on the accuracy of the results and to recommend node spacing and time step sizes for severe accident analyses.

Six different node structures were tested to survey the effect of the node spacing on calculation results. These node structures were designed to include 69 (base case) $, 35,18,11,8$, and 5 nodes in the first meter. Nodes between 0.0 and .001 meters were equally spaced while the nodes between 0.001 and 10.0 meters were logarithmically spaced according to Equation 3. 
Table 1. MELCOR Specifications Cases 1, 2 and 3

\begin{tabular}{|c|c|c|c|c|c|c|c|}
\hline $\begin{array}{c}\text { Case } \\
\text { No. }\end{array}$ & $\begin{array}{l}\text { Initial } \\
\text { Temp. } \\
\text { (K) }\end{array}$ & $\begin{array}{l}\text { Fluid } \\
\text { Temp. } \\
\text { (K) }\end{array}$ & Material & $\begin{array}{l}\text { Density } \\
\left(\mathrm{kg} / \mathrm{m}^{3}\right)\end{array}$ & $\begin{array}{c}\text { Specific } \\
\text { Heat } \\
(\mathrm{J} / \mathrm{kg} \mathrm{K})\end{array}$ & $\begin{array}{l}\text { Thermal } \\
\text { Conduc. } \\
(\mathrm{W} / \mathrm{m} \mathrm{K})\end{array}$ & $\begin{array}{c}\text { Thermal } \\
\text { Diff. } \\
\left(\mathrm{m}^{2} / \mathrm{s}\right)\end{array}$ \\
\hline $\begin{array}{l}1 \\
2 \\
3\end{array}$ & $\begin{array}{l}300.0 \\
300.0 \\
300.0\end{array}$ & $\begin{array}{l}450.0 \\
450.0 \\
600.0\end{array}$ & $\begin{array}{l}\text { Concrete } \\
\text { Steel } \\
\text { Concrete }\end{array}$ & $\begin{array}{l}2300.0 \\
7850.0 \\
2300.0\end{array}$ & $\begin{array}{l}650.0 \\
500.0 \\
650.0\end{array}$ & $\begin{array}{r}1.6 \\
47.0 \\
1.6\end{array}$ & $\begin{array}{l}1.07 E-6 \\
1.20 E-5 \\
1.07 E-6\end{array}$ \\
\hline
\end{tabular}

$$
\frac{x_{i}}{x_{i-1}}=(10)^{1 / N}
$$

where $x_{i} / X_{i-1}$ is the ratio of adjacent node positions and $N$ is the number of nodes desired per order of magnitude (i.e. between $1 \mathrm{~mm}$ and $1 \mathrm{~cm}$ ). A graphical representation of the node locations for the six cases is given in Table 2 .

Nine different time step sizes $(10,20,30,60,120,250,500,1000,2000$, and 5000 seconds) were run for both the 69 and 18 node structures. The 10 second and 69 node base case does the most detailed calculation and the 30 second and 18 node calculation represents more realistic parameters for a severe accident calculation.

\section{Results}

The MELCOR results are compared to the exact solution as plots of temperatures versus time and as time integrated surface heat fluxes. All analytical results from Equations 1 and 2 were calculated with double precision on the CRAY computer. The solutions were not calculated beyond 100,000 seconds to avoid round-off errors involving the use of the error function (erf) in Equation 1. Al1 MELCOR test cases were run out to 100,000 seconds and all surface heat fluxes were numerically integrated to 100,000 seconds. A summary of the results for the integrated heat fluxes for all the test cases is given in Table 3 .

\subsection{The Base Case}

Temperature comparison plots for 6 nodes are shown in Figure 1 for the base case (Case 1 in Table 1). The integrated surface heat flux error is $0.30 \%$. The error is defined as the integrated flux calculated by MELCOR minus the flux from the analytical solution divided by the analytical flux. From the results shown in Figure 1, it is difficult to distinguish the differences between the 
Table 2. Node Locations for MELCOR Calculations

$\begin{array}{llcccccc}\text { Node } & \text { Location } & \text { Number of } & \text { Nodes } & \text { in } & \text { First Meter } \\ \text { Number } & \text { (meters) } & 69 & 35 & 18 & 11 & 8 & 5\end{array}$

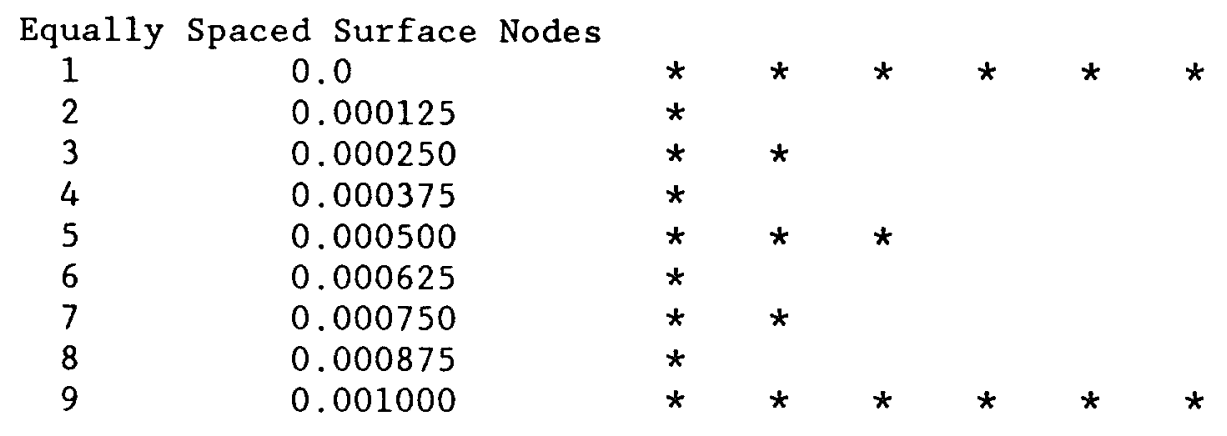

Logarithmic Spaced Interior Nodes

\begin{tabular}{|c|c|c|c|c|c|c|c|}
\hline 10 & 0.001122 & * & & & & & \\
\hline 11 & 0.001259 & * & * & & & & \\
\hline 12 & 0.001413 & * & & & & & \\
\hline 13 & 0.001585 & * & * & * & & & \\
\hline 14 & 0.001778 & * & & & & & \\
\hline 15 & 0.001995 & * & * & & & & \\
\hline 16 & 0.002239 & * & & & & & \\
\hline 17 & 0.002519 & * & * & * & * & * & \\
\hline 18 & 0.002818 & * & & & & & \\
\hline 19 & 0.003162 & * & * & & & & \\
\hline 20 & 0.003548 & * & & & & & \\
\hline 21 & 0.003981 & * & * & * & & & \\
\hline 22 & 0.004467 & * & & & & & \\
\hline 23 & 0.005012 & $*$ & * & & & & \\
\hline 24 & 0.005623 & * & & & & & \\
\hline 25 & 0.006310 & * & * & * & * & & \\
\hline 26 & 0.007079 & * & & & & & \\
\hline 27 & 0.007943 & * & * & & & & \\
\hline 28 & 0.008913 & * & & & & & \\
\hline 29 & 0.010000 & * & * & * & * & * & * \\
\hline$\cdots$ & . & & & & & & \\
\hline 49 & 0.10000 & * & * & * & * & * & * \\
\hline . & $\cdots$ & & & & & & \\
\hline$\ddot{69}$ & 1.00 & * & * & * & * & * & * \\
\hline - & & & & & & & \\
\hline 89 & 10.0 & $*$ & * & * & * & * & * \\
\hline
\end{tabular}


MELCOR and analytical solutions, so blowup plots are provided in Figures 2 and 3. Figure 2 shows the MELCOR predicted surface temperature lagging behind the analytical temperature by about $0.2 \mathrm{~K}$. This temperature difference is relatively constant throughout the calculation and is the right order of magnitude to cause the error in the integrated heat flux. Figure 3 shows the temperature at 1 meter into the slab. Other than the $0.2 \mathrm{~K}$ surface temperature difference, the MELCOR and analytical results compare extremely well.

\subsection{Steel Thermal Properties}

The steel thermal properties test case (Case 2 in Table 1 ) is the same as the base case except that the thermal properties represent steel instead of concrete. The results of this test case are shown in Figure 4. The integrated surface heat flux error is 0.648 . The MELCOR surface temperature lags the analytical temperature by about 0.5 to $1.0 \mathrm{~K}$, and the temperature at 1 meter lags by about $0.5 \mathrm{~K}$. MELCOR results for this case are not as accurate as for the base case involving concrete thermal properties. Perhaps a finer node spacing further in for steel due to the higher thermal diffusivity might produce better accuracy.

\subsection{High Temperature Test Case}

The high temperature case (Case 3 in Table 1 ) is the same as the base case except that the fluid temperature was $600 \mathrm{~K}$ instead of $450 \mathrm{~K}$. The results of this case are shown in Figure 5. The integrated surface heat flux error is $0.21 \%$. The MELCOR surface temperature lags the analytical temperature by about 0.2 to $0.3 \mathrm{~K}$. MELCOR results for this case are slightly more accurate than for the base case.

\subsection{Node Spacing Cases}

The results obtained using different nodalizations $(69,35,18,11$, and 8 nodes) are shown in Figures 6 through 9. The 69 node case is the base case and all of the cases were run with 10 second time steps. The node locations are shown in Table 2. The 5 node case yielded large errors (about 258) and was not included in the figures.

The integrated surface heat flux errors for these tests are shown in Figure 6 as a function of the number of nodes in the first meter of the slab. The errors are large for the cases with few nodes and become more or less asymptotic for the finer node spacings. Actually the 35 node case has a slightly smaller error than the 69 node base case. Cases with less than about 18 nodes give errors in excess of 18 .

The surface temperatures are shown in Figures 7 and 8 . The surface temperatures for the 35 and 69 node cases are practically identical. It appears that a higher degree of accuracy cannot be obtained by adding more than about 35 nodes. The 18 node case calculates reasonable results ( $0.88 \%$ error). The 8 node case and the 11 node case have 7.28 and 3.38 errors in the surface temperature, respectively. 
Table 3. Summary of MELCOR Results for Integrated Heat Flux

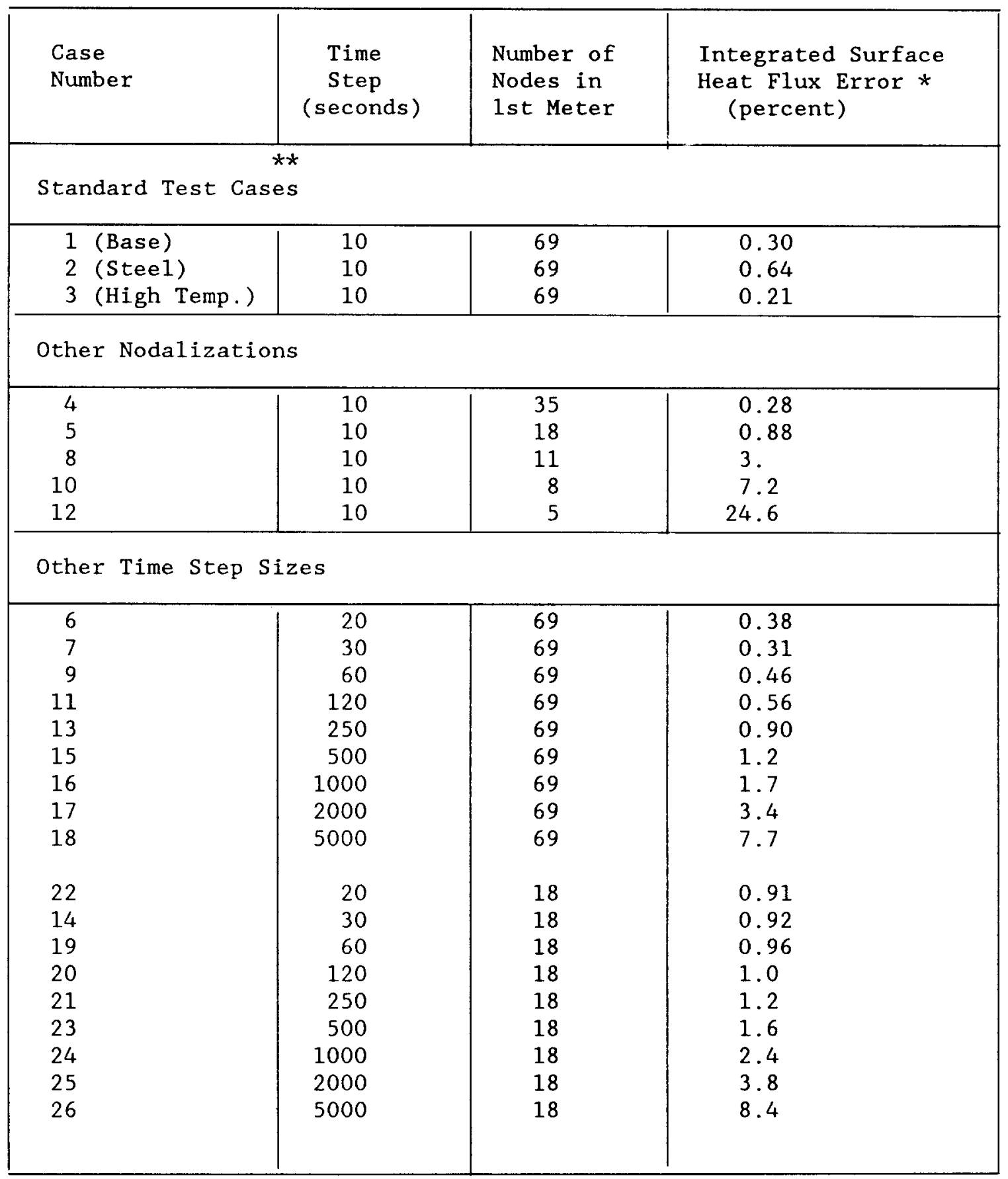

* (MELCOR-Analytica1)/Analytica1 X 100

$* *$ Analytical Time Integrated Surface Heat Flux $=5.5896 \mathrm{E} 7$ (Case 1), $=1.2729 \mathrm{E} 8$ (Case 2), $=1.1179 \mathrm{E} 8$ (Case 3), $[\mathrm{J} / \mathrm{m} * * 2]$ 


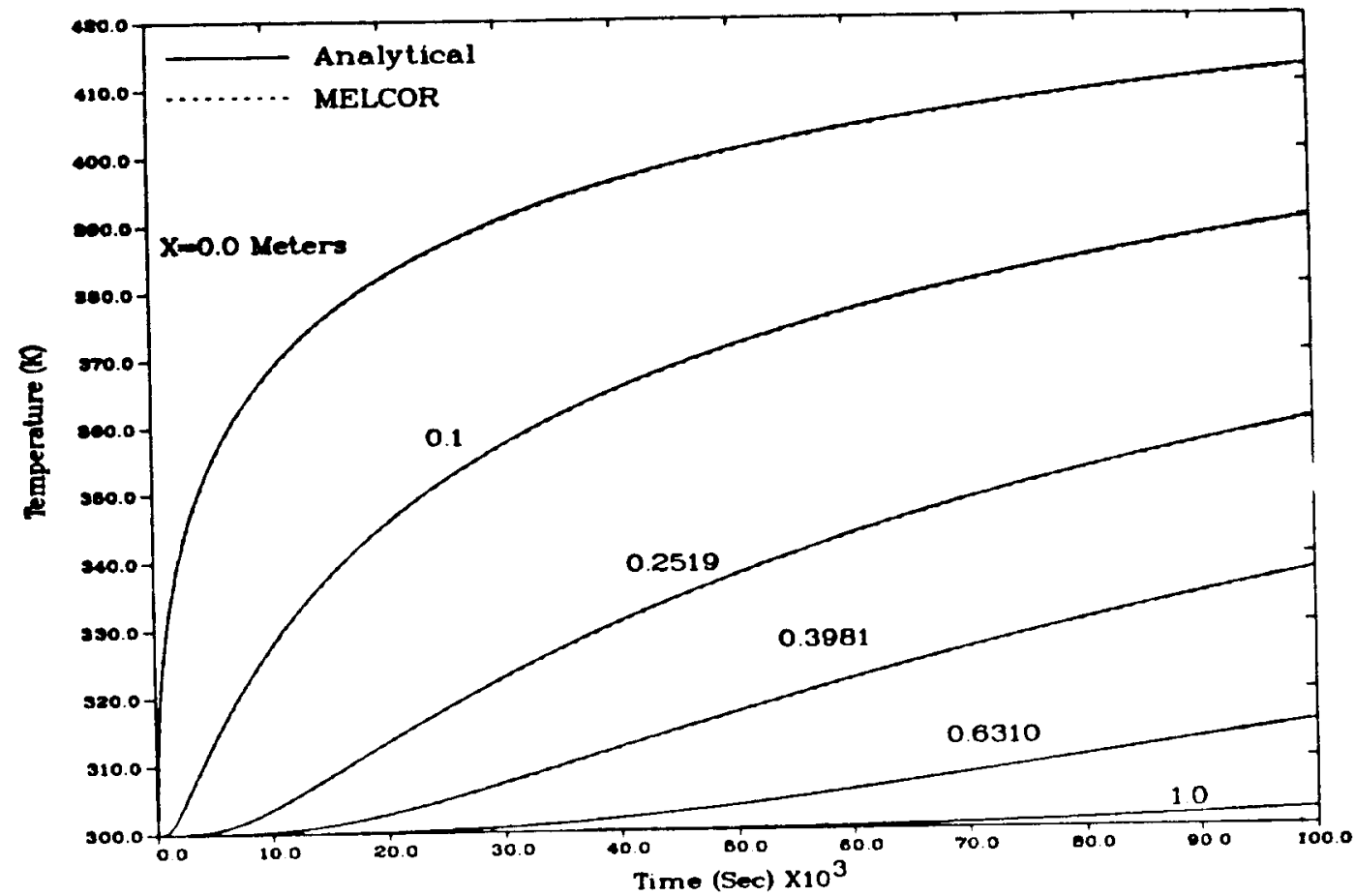

Figure 1. Time Temperature Results at Six Positions within the Slab for the Base Case (Case 1 Table 1).

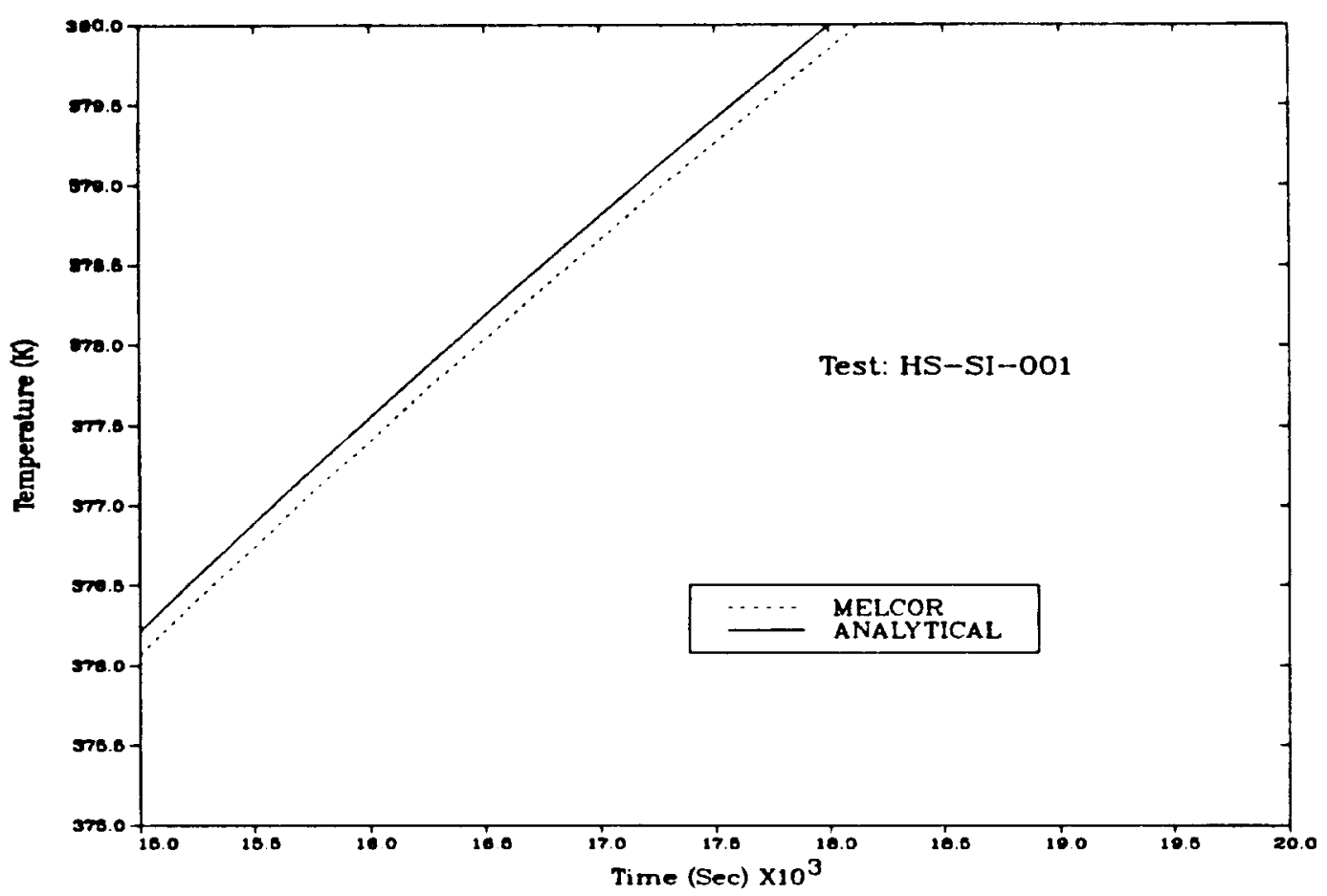

Figure 2. Surface Temperature Versus Time on an Expanded Scale for the Base Case (Case 1 from Table 1). 


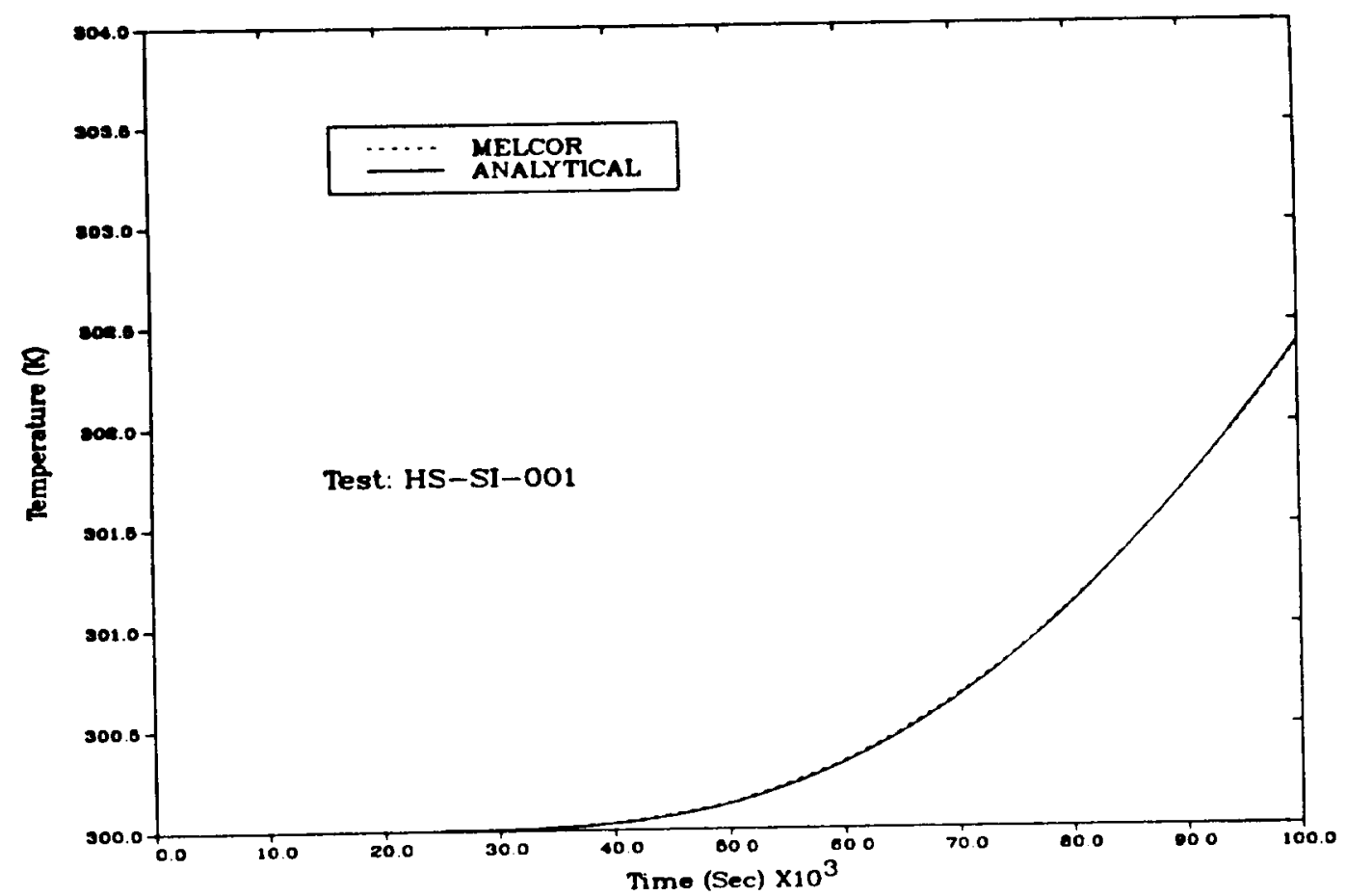

Figure 3. Slab Temperature at 1 Meter Versus Time on an Expanded Scale for the Base Case (Case 1 Table 1).

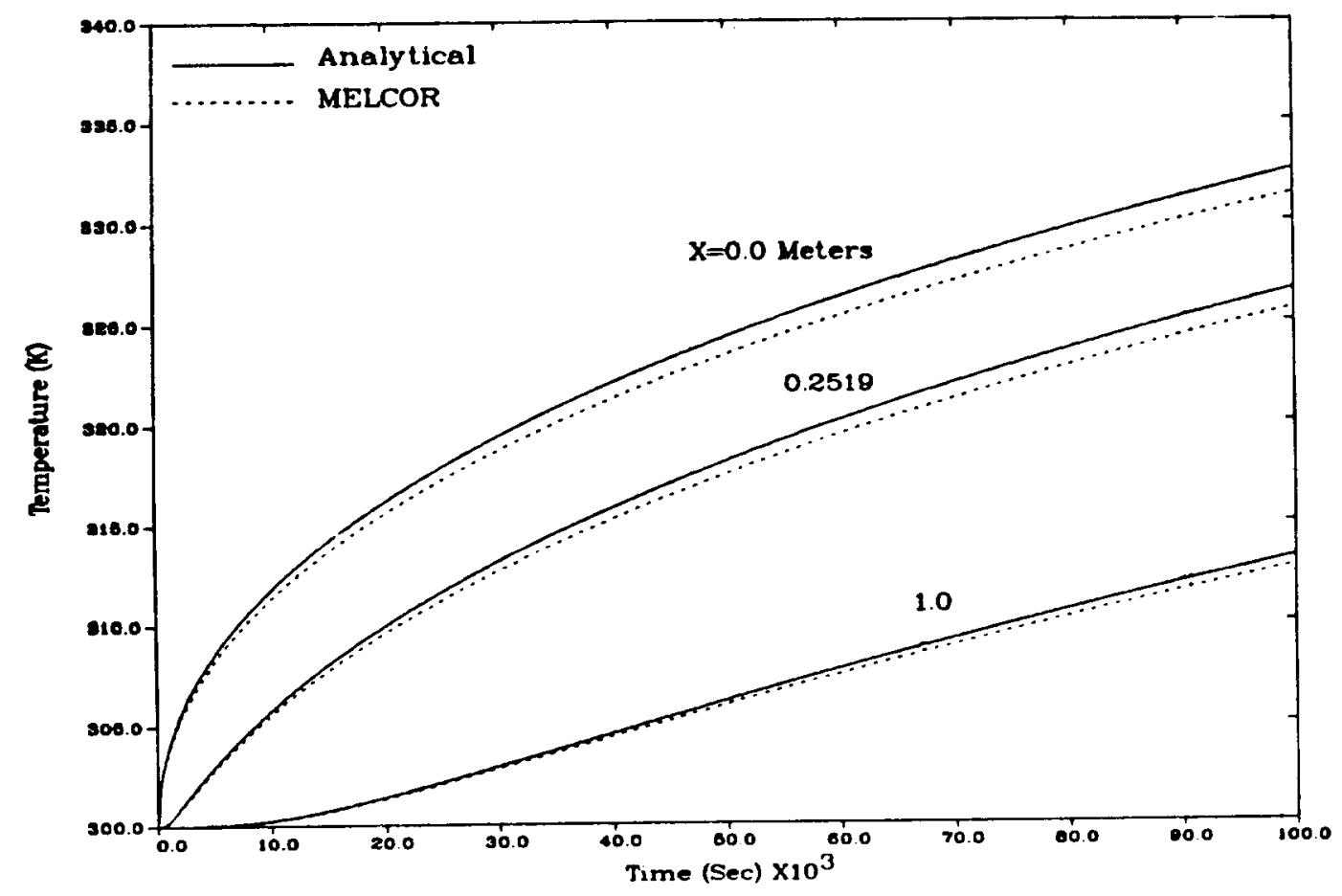

Figure 4. Time Temperature Results at Three Positions within the Slab for the Steel Properties Case (Case 2 from Table 1). 


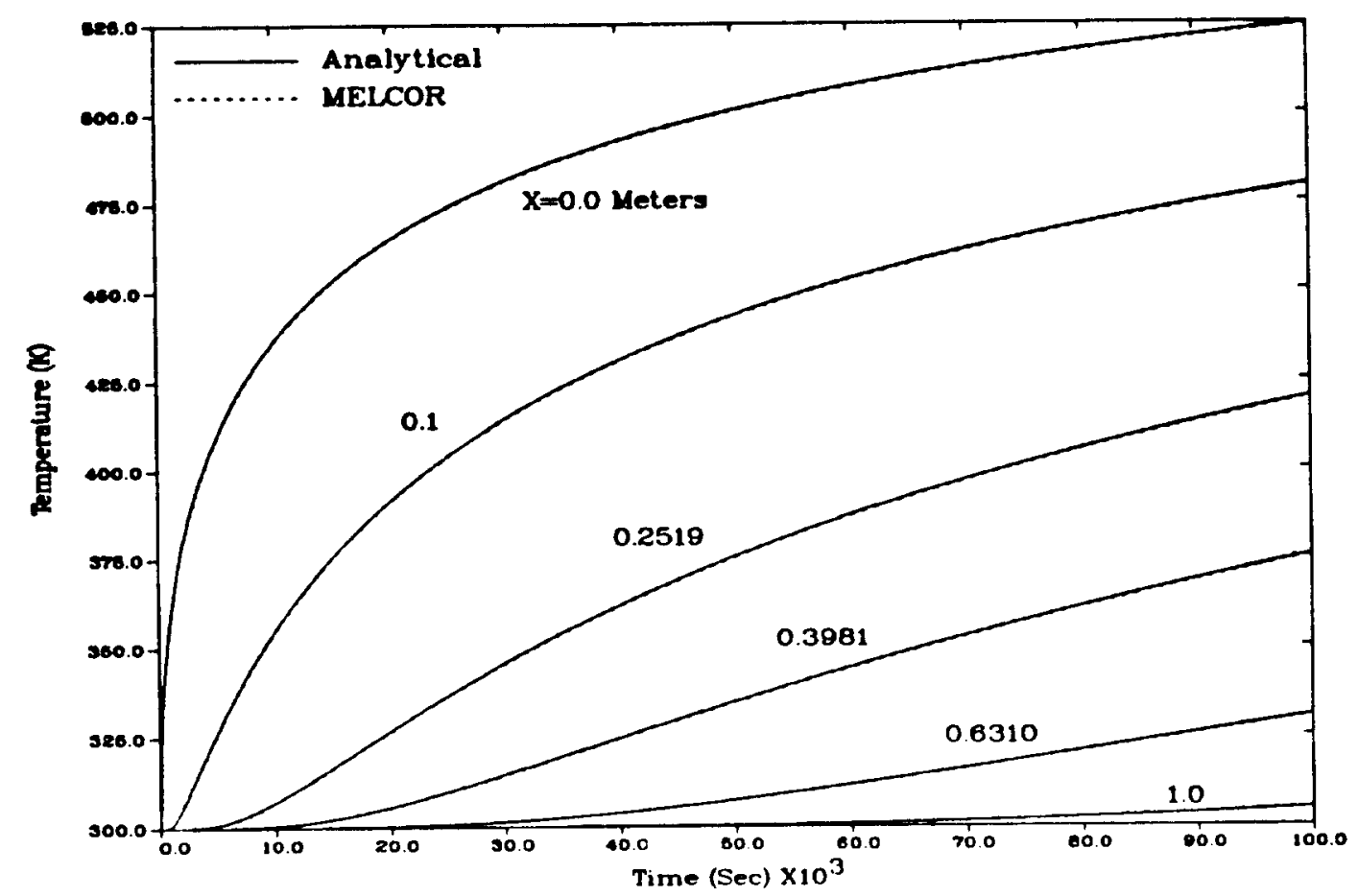

Figure 5. Time Temperature Results at Six Positions within the Slab for the High Temperature Case (Case 3 Table 1).

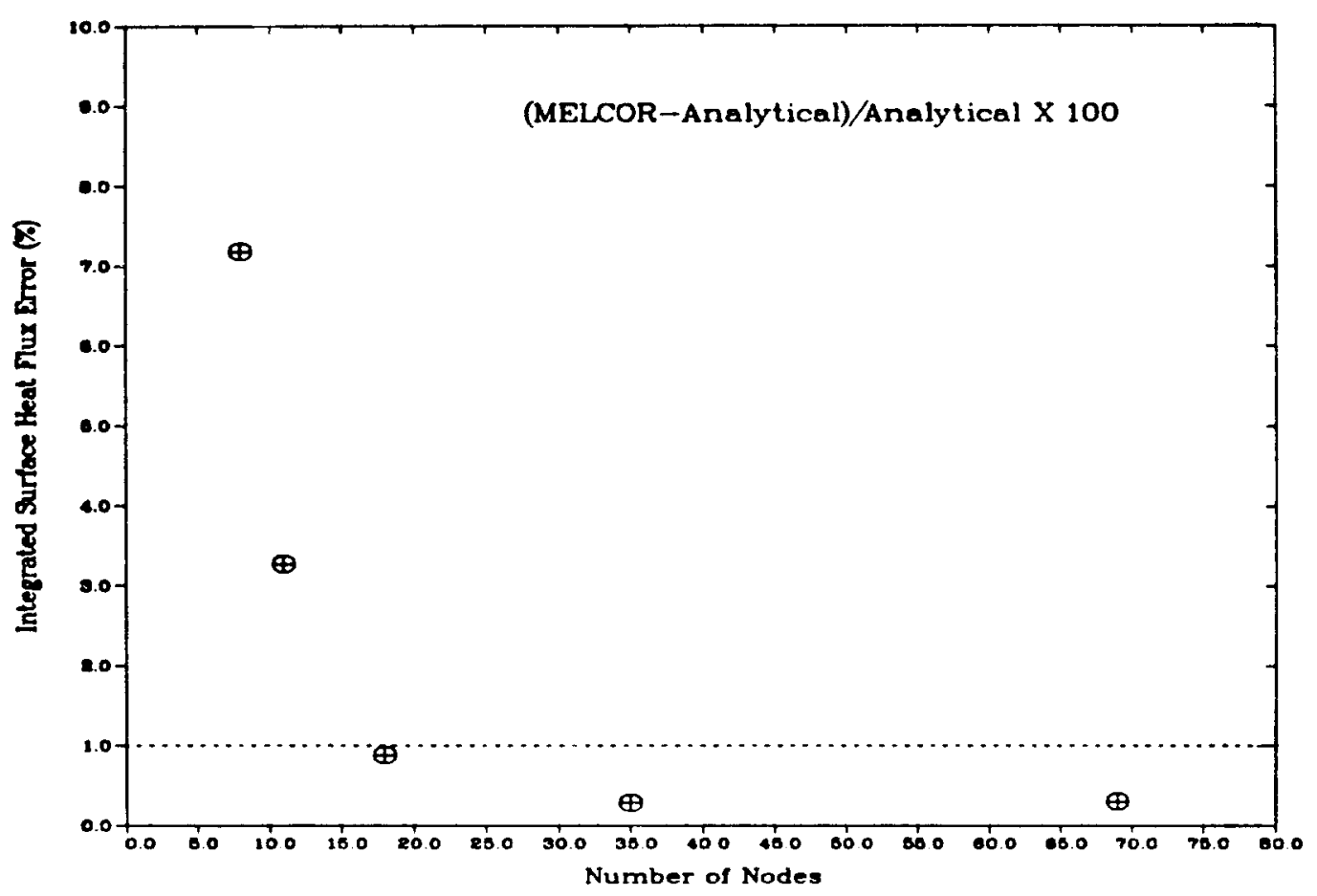

Figure 6. Node Spacing Test Errors 
The temperatures at 1 meter are shown in Figure 9. The temperature is very accurately predicted for the 69 node case, but the other cases deviate somewhat from the exact solution.

\subsection{Time Step Size Test Cases}

Test cases were run for time step sizes of $10,20,30,60,120,250,500,1000$, 2000 , and 5000 seconds for both the 18 and 69 node structures. The results are shown in Figures 10 through 13.

The integrated surface heat flux errors for these 18 test cases are shown in Figure 10 as a function of time step size. The errors for both node structures remain within 18 for time steps less than about 100 seconds. Severe accident calculations usually use time steps of less than 60 seconds.

The surface temperature results for the 69 node cases using 10, 20,30,60, and 120 second time steps are shown in Figures 11 and 12 . In Figure 11, the curves cannot be distinguished from one another, but Figure 12 shows an expanded section. The expanded plot shows "oscillations" in the surface temperatures which increase in amplitude with increasing time step size. These oscillations are somewhat smaller for the 18 node cases than for the the 69 node cases. For the 69 node cases, only the 10 second time step case is without observable oscillations whereas for the 18 node cases, the 10, 20, and 30 second time step cases are without oscillations. These oscillations do not seem to have much effect upon the integrated surface heat fluxes for the time step sizes of practical interest but could become important in calculations with convective heat transfer correlations that are sensitive to the surface temperature.

Figure 13 shows the temperatures at 1 meter into the slab. These temperatures are predicted reasonably well with time step sizes up to 120 seconds. The 69 node cases show better agreement with the analytical results than the 18 node cases.

\subsection{Practical Parameters}

The base case calculation with 69 nodes and a 10 second time step size was chosen to give a very accurate prediction of the exact solution. In the interest of keeping computer run times reasonable (around $200 \mathrm{CPU}$ ), realistic severe accident analysis calculations are more likely to use something like the 18 nodes and 30 second time step size case for predicting the heat transfer into the containment walls. Figure 14 compares both of these cases with the analytical solution for an expanded section of the surface temperature. The integrated surface heat flux errors for these two cases are 0.308 and 0.928 for the 69 and 18 node cases, respectively. The surface temperatures of both of these calculations are apparently free of the oscillations shown in the previous section.

User judgement must be exercised in selecting the node spacing and time step sizes for a particular calculation. The need for accuracy must be balanced against the cost of the run. Consideration must be given to the accuracy of the overall heat transfer and the sensitivity of the convective heat transfer 


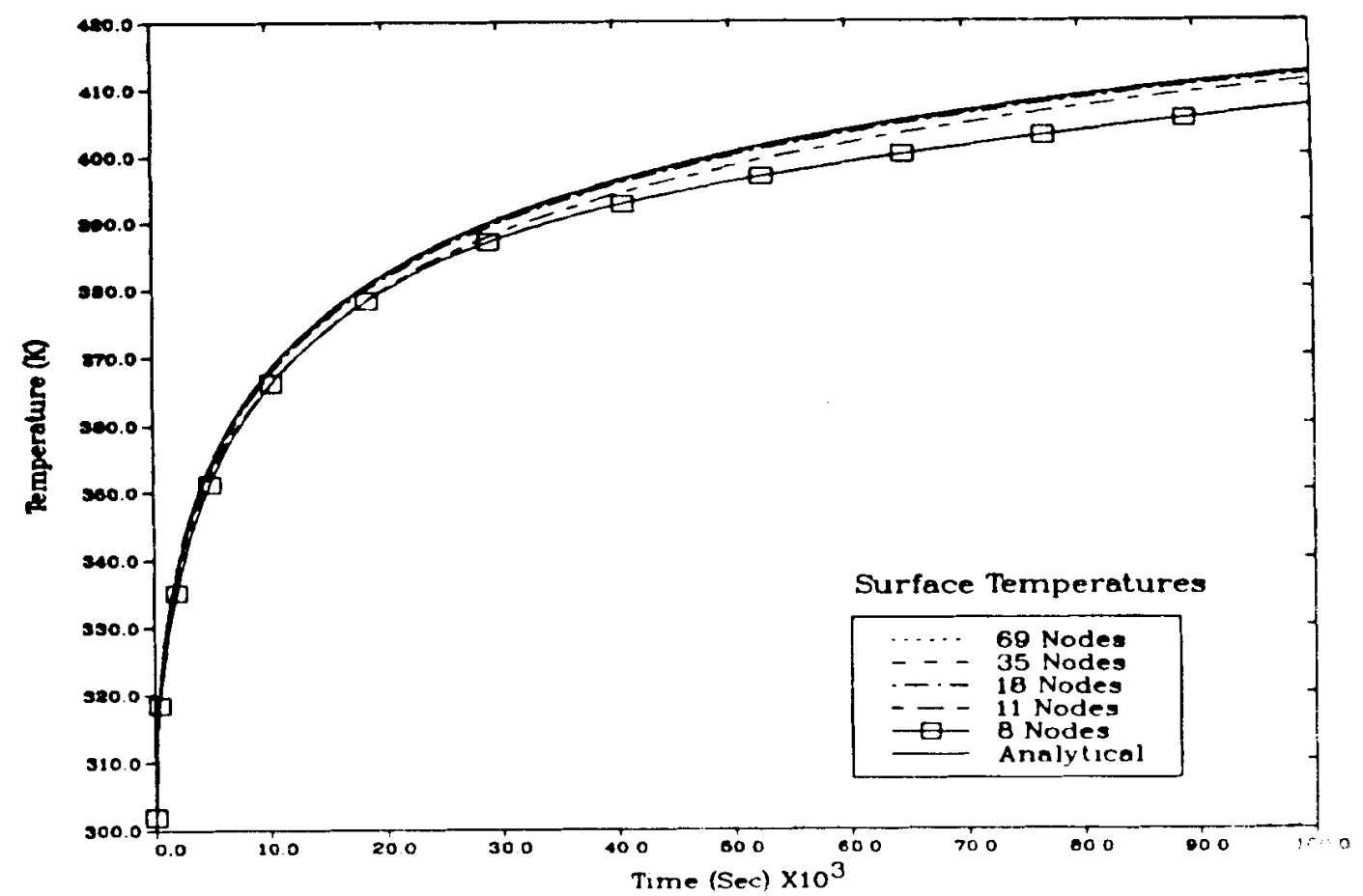

Figure 7. Surface Temperature Versus Time For Six Different Node Spacings

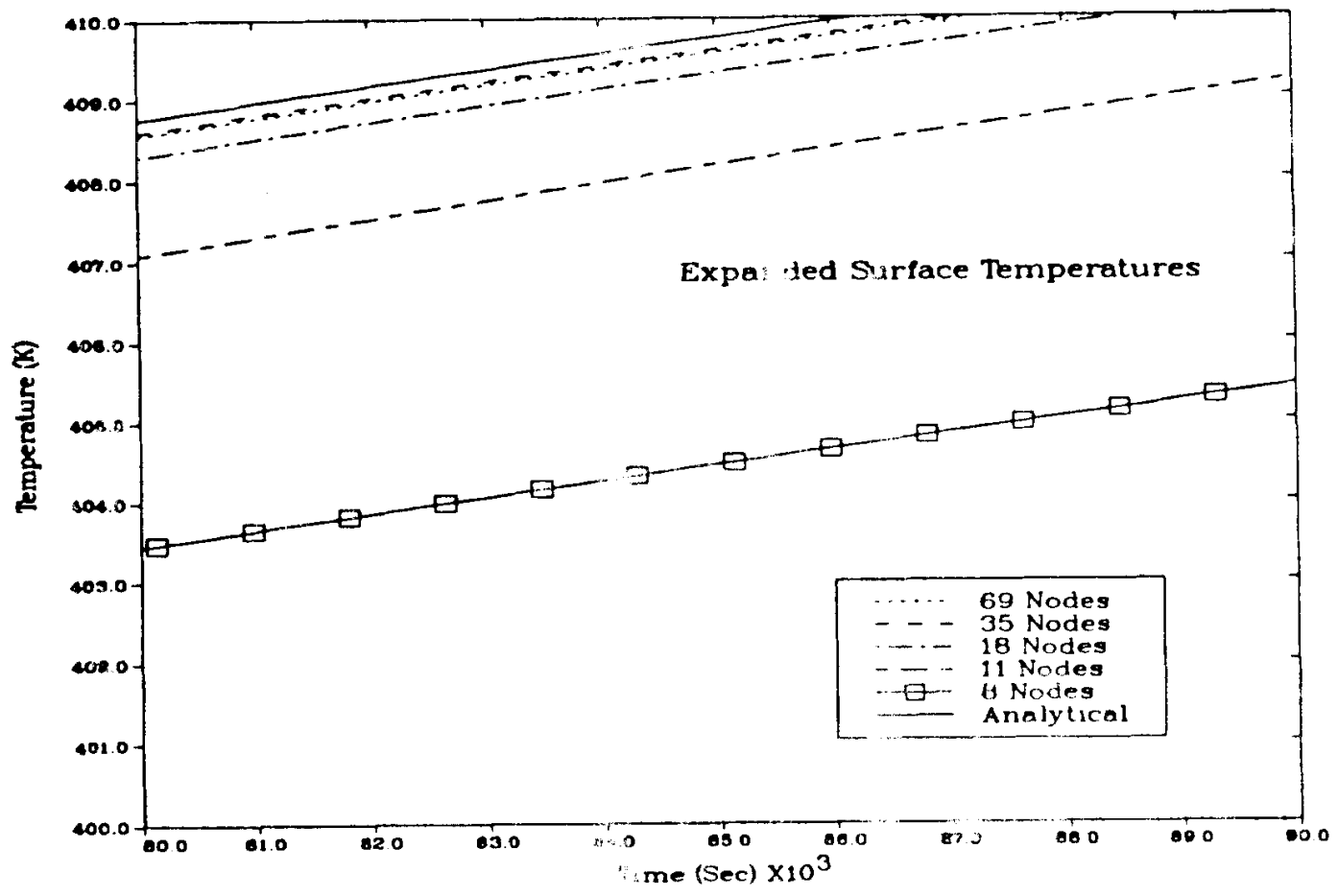

Figure 8. Surface Temperature Versus Time on an Expanded Scale for Six Different Node Spacings 


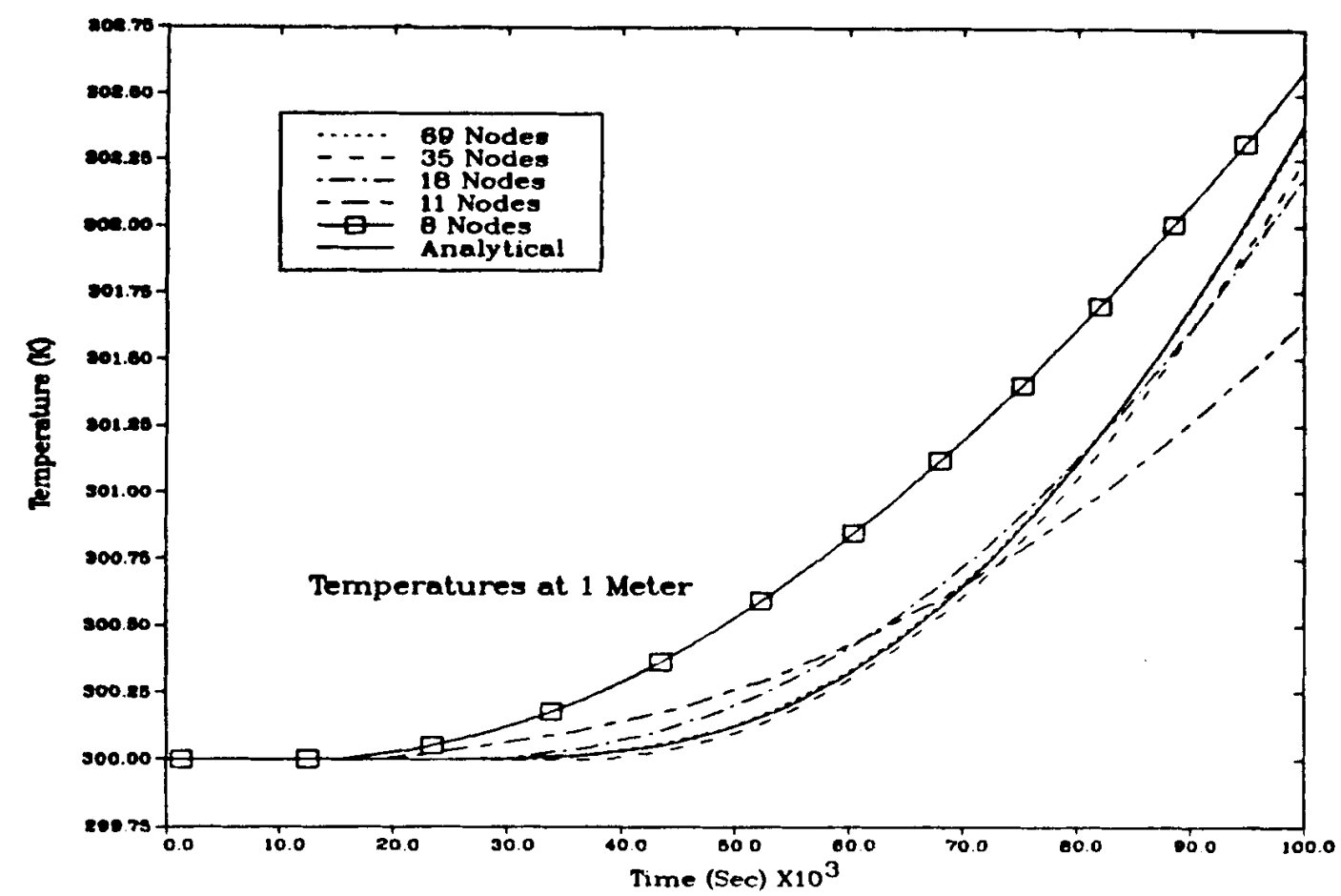

Figure 9. Temperature at 1 Meter Versus Time For Six Different Node Spacings

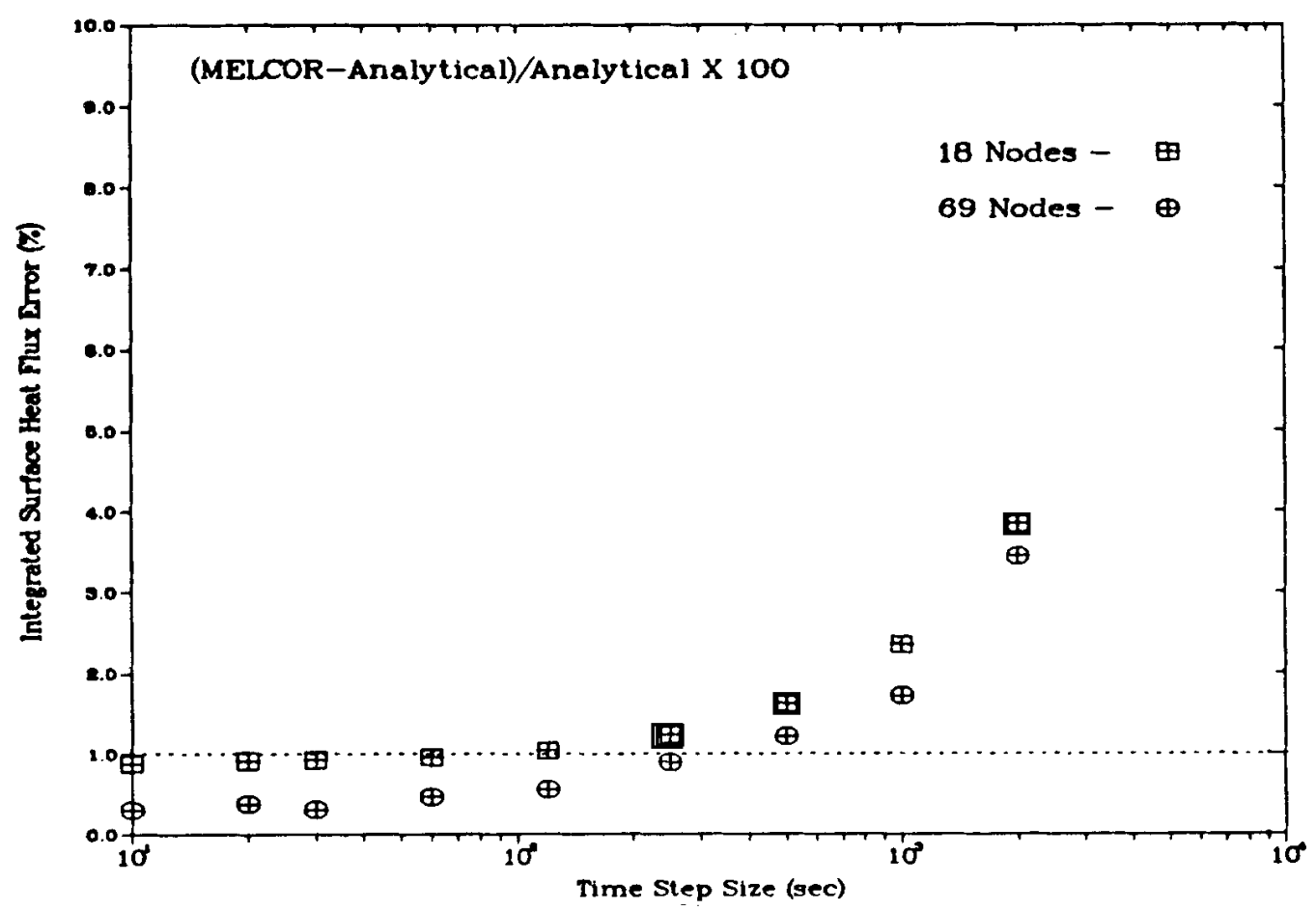

Figure 10. Variation in Integrated Surface Heat Flux with Time Step Size 


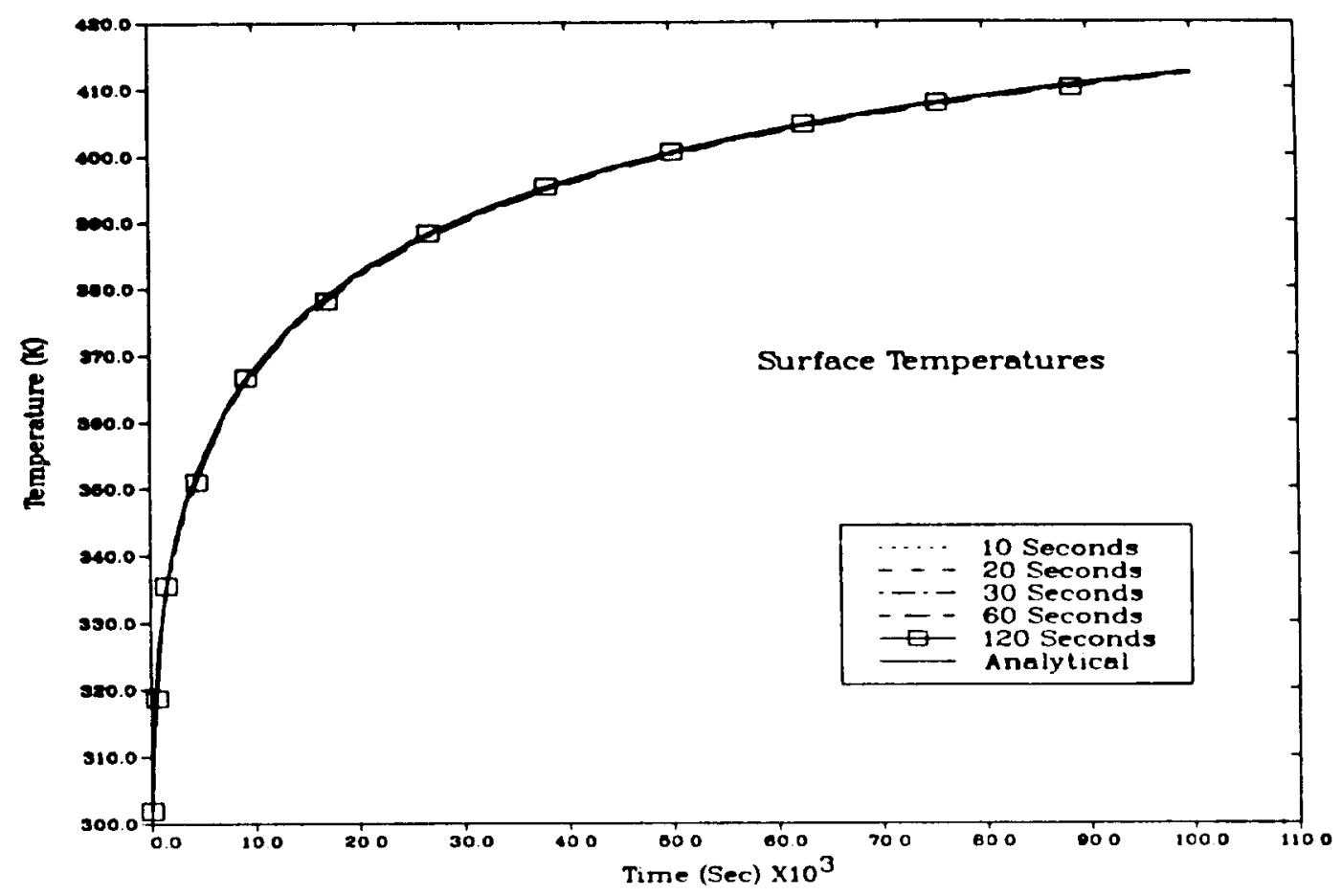

Figure 11. Surface Temperature Versus Time For Different Time Steps

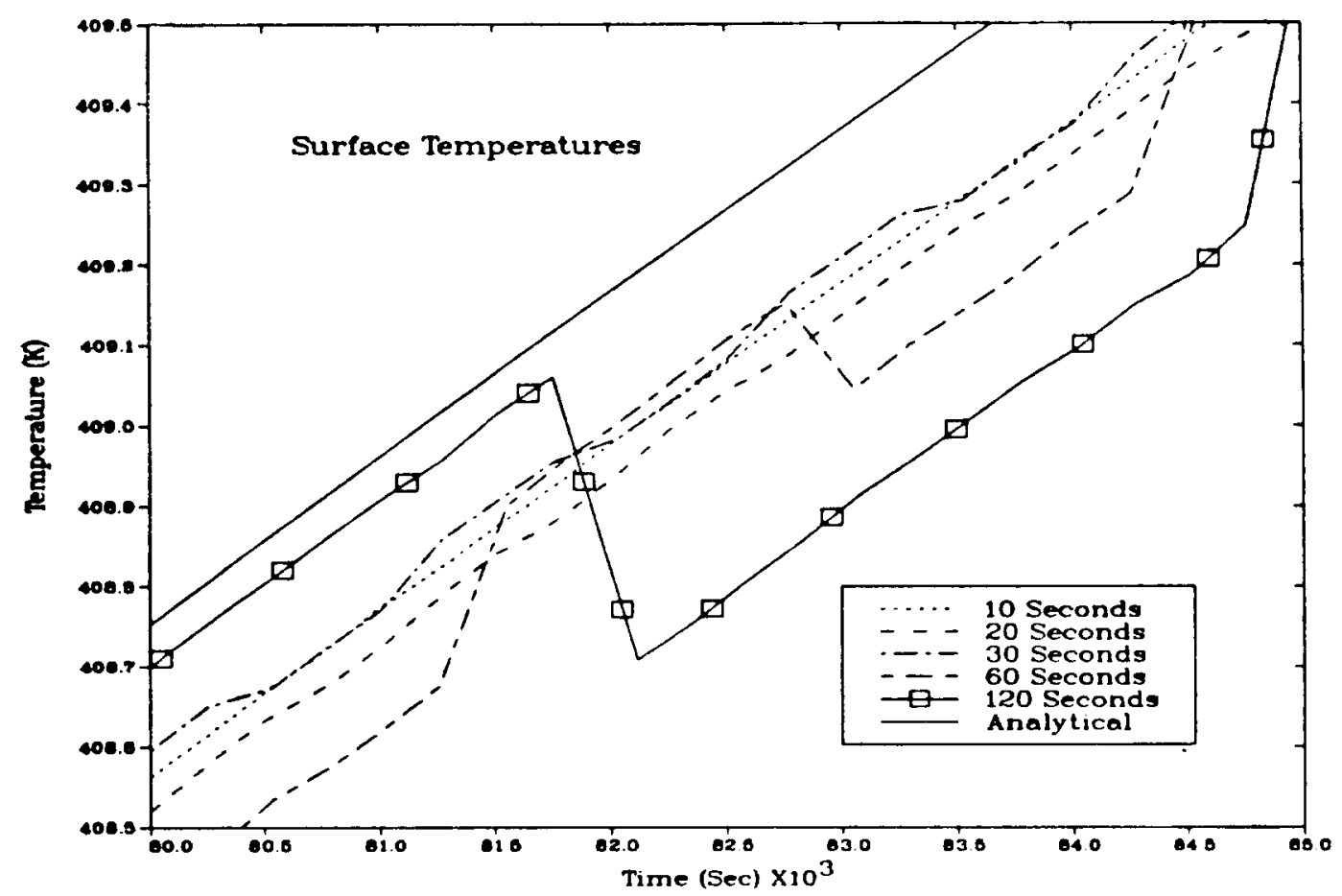

Figure 12. Surface Temperature Versus Time on an Expanded Scale for Different Time Steps 


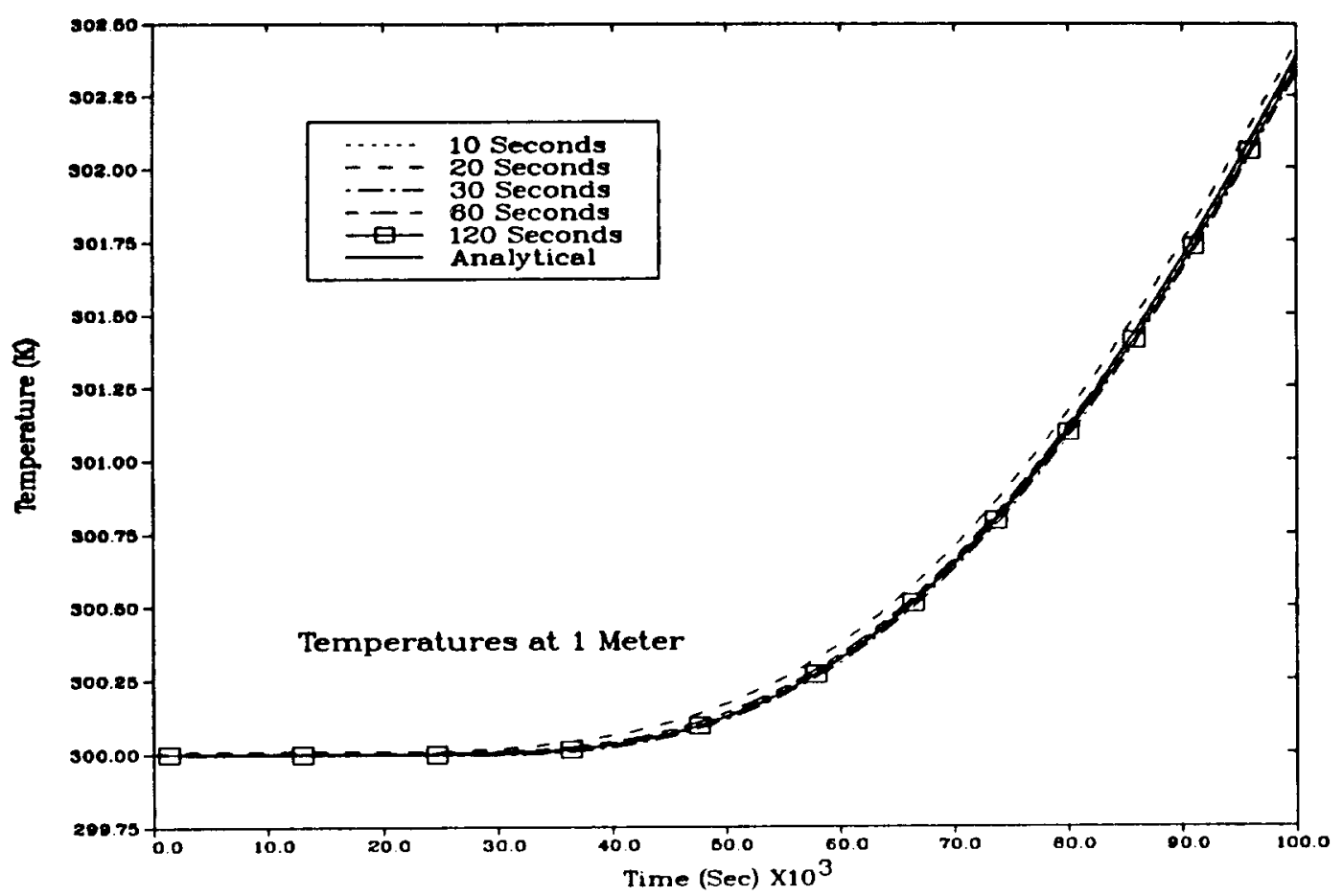

Figure 13. Temperature at 1 Meter Versus Time For Different Time Steps

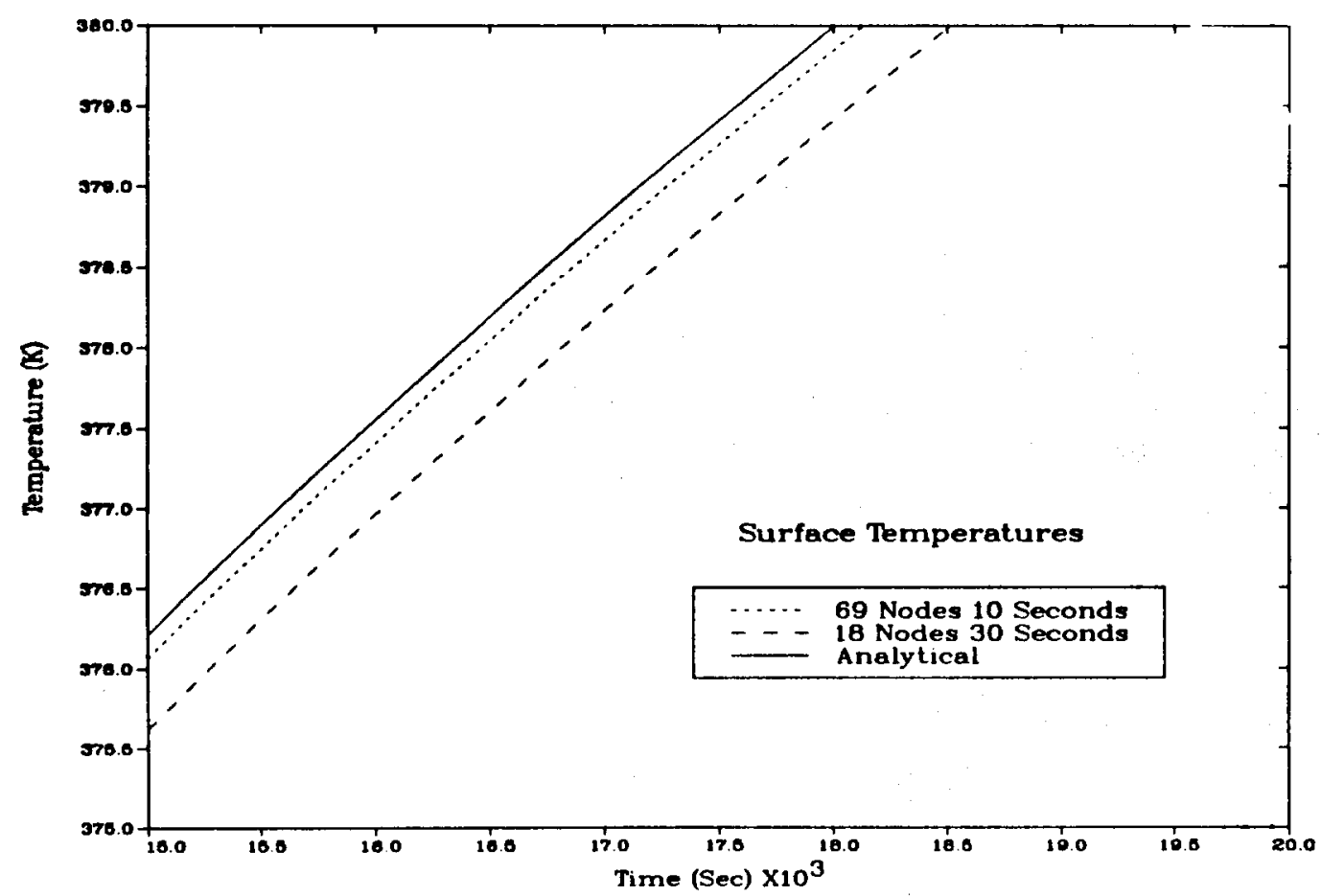

Figure 14. Surface Temperature Versus Time on an Expanded Scale for the 69 node:10 second Case and the 18 node:30 second Case 
coefficient to the surface temperature. For instance, if the convective heat transfer coefficient is a function of a small temperature differential between the fluid and the wall temperatures then a relatively small error in the surface temperature might yield a much larger error in the resulting coefficient and heat flux.

\section{Summary}

Predictions of the MELCOR heat structures package heat conduction models are compared to the exact analytical solution for transient heat flow in a semi-infinite solid with convective boundary conditions. The semi-infinite solid is modeled in MELCOR as a 10 meter thick heat slab with logarithmic node spacing. The accuracy of the heat conduction models is demonstrated and node spacing and time step sizes are recommended for the modeling of the concrete containment walls in a severe accident analysis calculation of a nuclear power plant.

The results of three standard test cases compared relatively well with the analytical solution. Cases modeling concrete compared more closely than the case modeling steel. The best MELCOR predicted surface temperature for concrete lags the exact solution by about $0.2 \mathrm{~K}$ resulting in an error of about 0.38 in the time integrated surface heat flux. The temperature lag for steel was about 0.5 to $1.0 \mathrm{~K}$ resulting in an error of about 0.68 .

Node structures ranging from 5 to 69 nodes in the first meter of the wall were tested to survey the effect of node spacings on calculational results. The calculational errors are unacceptably large for the cases with few nodes and become more or less asymptotic for the finer node spacings. Cases with less than about 18 nodes in the first meter of the wall predict errors in excess of 18 .

Test cases were run for time step sizes ranging from 10 to 5000 seconds for both the 18 and 69 node structures. The errors in the integrated surface heat fluxes for both node structures remain within 18 for time step sizes below about 100 seconds. Most severe accident calculations use time step sizes o.' less than 60 seconds. The surface temperatures for runs up to about 120 seconds follow the analytical solution fairly closely (within about $0.5 \mathrm{~K}$ ), however, small oscillations do occur and the amplitude of the oscillations increases with the size of the time step. The oscillations are somewhat smaller for the 18 node cases than for the 69 node cases indicating a relationship between the time step size and the size of the surface nodes. These oscillations appear to have little effect upon the integrated surface heat fluxes for the time step sizes of practical interest, but could become important in calculations with convective heat transfer correlations sensitive to the surface temperature.

The ability of MELCOR to predict the exact solution depends on the fineness of the node spacing and the time steps, and the precision of the computer. The inaccuracies in the standard test cases are stable and uniform throughout the calculations indicating the soundness of the MELCOR numerical models. The node spacing and time steps have been reduced to a fineness such that additional fineness does not increase the accuracy. The remaining inaccuracies then are 
probably caused by computer round-off errors. In fact, the 35 node case results were slightly more accurate than the 69 node case implying that a use of more than 69 nodes will increase the round-off errors. A computer with more precision should calculate even better results.

While the exact analytical solution was predicted reasonably accurately with the case using 69 nodes and 10 second time steps (the CPU time is about 1500 seconds for these runs), realistic severe accident analysis calculations are more likely to use something like the 18 nodes and 30 second time steps for predicting the heat transfer into the containment walls (the CPU time is about 200 seconds for these runs). The integrated surface heat flux errors for the 69 and 18 node cases are 0.30 and 0.928 , respectively, and both are apparently free of the oscillations.

Cases 1 and 14 were rerun on MELCOR 1.6 with no significant differences from the results presented here.

\section{References}

1. J. P. Holman, Heat Transfer, 2nd Edition, McGraw-Hill Book Company, 1968 . 
MELCOR 1.5 Calculations

for $A B C O V E$ Aerosol Experiments $A B 5, A B 6$, and $A B 7$

\author{
C. D. Leigh \\ Sandia National Laboratories \\ Albuquerque, New Mexico 87185 \\ United States of America
}

\begin{abstract}
The MELCOR code was used to simulate the ABCOVE Aerosol experiments $A B 5, A B 6$, and $A B 7$. In these tests, a dry sodium aerosol was introduced into an $850 \mathrm{~m}^{3}$ vessel and the aerosol behavior was monitored. Single and double component aerosols were used. Other codes have been used to simulate these tests including the CONTAIN[1] code at Sandia National Laboratories. Results from MELCOR were compared both to the experimental data and to the CONTAIN results. MELCOR results were nearly identical to the CONTAIN results. Code predictions for the suspended mass of aerosol track the experimental data to the end of the experiment to within a factor of two or three. Final predictions of the mass deposited by settling agree within an 118 error for all tests. In AB5, code predictions for the mass of material deposited by plating agree with the experimental data with a 128 error. However, in the other tests, the codes do not give accurate results for the amount of material deposited on the walls at the end of the test. These errors are probably related to the turbulence in the vessel which may cause inertial impaction. Impaction is not modeled in either of the codes.
\end{abstract}

\title{
1. Introduction
}

The Aerosol Behavior Code Validation and Evaluation (ABCOVE) program was a cooperative effort between the USDOE and the USNRC to validate aerosol behavior codes under the conditions found in an LMFBR containment during a severe accident. The expected aerosol suspended mass concentrations in an LMFBR accident exceed that expected of particulates in an LWR accident. Nevertheless, the ABCOVE experiments are also of interest for LWR modeling. The spherical cluster structure of the sodium oxide aerosols is similar to that expected of particulate aerosols in a steam environment. A series of validation experiments was conducted at the Containment Systems Test Facility (CSTF) at Hanford Engineering Development Laboratory (HEDL). Six codes were involved in a code comparison to these experiments including the CONTAIN[1] code run at Sandia National Laboratories. This test is a comparison of MELCOR results for the $A B C O V E$ tests, $A B 5, A B 6$, and $A B 7$ to both the experimental results and to the results from the CONTAIN code calculations. Both MELCOR and CONTAIN 
CONTAIN incorporate MAEROS[2] in order to model aerosol behavior. However, the thermal hydraulic coupling is different in the two codes. The primary difference being that CONTAIN (at the time) used a user-specified thermal gradient when calculating the thermophoretic deposition, whereas MELCOR uses a thermal gradient calculated internally from the structure heat flux and the gas thermal conductivity. (CONTAIN has since been modified and follows the MELCOR approach). The input deck for these calculations is based on a CONTAIN input deck provided by K.K. Murata of Sandia National Laboratories (SNL). These calculations were most recently run on MELCOR 1.5.[3]

\section{Test Descriptions}

In all three tests, $A B 5, A B 6$ and $A B 7$, the behavior of aerosols injected into a closed $850 \mathrm{~m}^{3}$ vessel was examined. In Figure 1 , a schematic diagram of the vessel is given. $A B 5$ was a single component aerosol test while $A B 6$ and $A B 7$ were multicomponent aerosol tests. In the $A B 5$ test, sodium oxide aerosols were generated from a sodium spray fire at a rate of $445 \mathrm{~g} / \mathrm{s}$ for 885 seconds. In the AB6 test, two aerosol sources were provided to the vessel. One source, a simulated fission product aerosol, NaI, was generated by an ex-vessel vaporizercondenser. The other source, $\mathrm{NaOx}$, was generated by a sodium spray fire. The release rate of $\mathrm{NaOx}$ from the spray fire was approximately five hundred times that of the $\mathrm{NaI}$, and the $\mathrm{NaOx}$ source was continued well past the $\mathrm{NaI}$ source cutoff. This overlap in the source rates was used in order to demonstrate the "washout" of the $\mathrm{NaI}$ by the continuing $\mathrm{NaOx}$ aerosol. The $\mathrm{AB} 7$ test was also a two component aerosol test; the $\mathrm{NaI}$ was generated by an ex-vessel vaporizercondenser, and the sodium oxide was provided by a sodium pool fire. In the $A B 7$ test, the quantity of $\mathrm{NaOx}$ released during the sodium pool fire was low, and all of the $\mathrm{NaOx}$ was reacted to sodium hydroxide, $\mathrm{NaOH}$, by moisture in the vessel atmosphere. The $\mathrm{NaI}$ was released into the vessel atmosphere after the end of the sodium pool fire so that there was no overlap in the sources.

\section{Computer Modeling of the ABCOVE Tests}

The MELCOR calculations for $A B 5, A B 6$, and $A B 7$ are based on the simulation that was originally performed with CONTAIN[3]. The aerosol sources were modeled by specifying lognormal source rates into the volume as indicated in Table 1.

For these three tests, the plating area and settling area used were about 750 $\mathrm{m}^{2}$ and $88 \mathrm{~m}^{2}$ respectively. For the CONTAIN calculations, a fitting procedure using the results of earlier experiments ( $A B 1, A B 2$, and $A B 3$ ) was used to obtain values for the agglomeration and dynamic shape factors[3]. The values obtained were 1.5 for the dynamic shape factor and 2.25 for the agglomeration shape factor. These values were used for the MELCOR calculations. A material density of $2500 \mathrm{~kg} / \mathrm{m}^{3}$ was assumed in $A B 5$ and $A B 6$, and $2130 \mathrm{~kg} / \mathrm{m}^{3}$ was assumed in $\mathrm{AB} 7$. The turbulent agglomeration coefficient was set at $1.0 \mathrm{E}-03 \mathrm{~m}^{2} / \mathrm{s}^{3}$ for all three tests and the diffusional boundary layer thickness was set at $1.0 \mathrm{E}-5 \mathrm{~m}$. A summary of these values is given in Table 2 . 


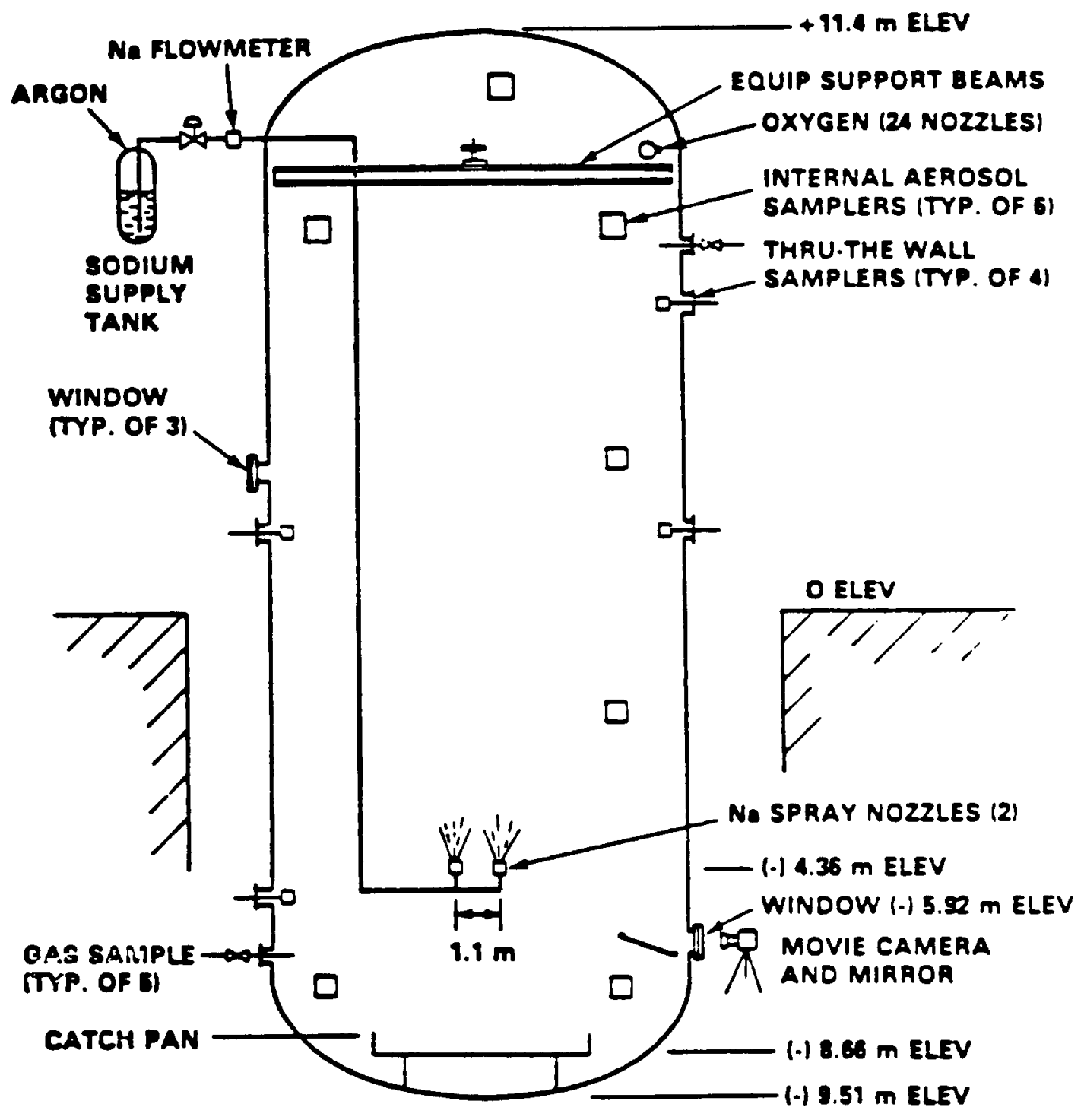

Figure 1. Schematic Diagram of the Aerosol Test Facility 
Table 1. Aerosol Sources for Tests AB5, AB6, and AB7.

\begin{tabular}{|c|c|c|c|c|c|}
\hline Aerosol & $\begin{array}{c}\text { Source } \\
\text { Rate } \\
(\mathrm{kg} / \mathrm{s})\end{array}$ & $\begin{array}{c}\text { Time } \\
\text { On } \\
(\mathrm{s})\end{array}$ & $\begin{array}{c}\text { Time } \\
\text { Off } \\
(\mathrm{s})\end{array}$ & $\begin{array}{c}\text { Mass Median } \\
\text { Diameter } \\
(\mathrm{m})\end{array}$ & $\begin{array}{c}\text { Standard } \\
\text { Deviation }\end{array}$ \\
\hline $\mathrm{AB} 5-\mathrm{NaOx}$ & $4.45 \mathrm{E}-01$ & 13 & 885 & $0.50 \mathrm{E}-06$ & 1.50 \\
\hline $\mathrm{AB} 6-\mathrm{NaOx}$ & $7.79 \mathrm{E}-02$ & 620 & 5400 & $0.50 \mathrm{E}-06$ & 2.00 \\
\hline $\mathrm{AB} 6-\mathrm{NaI}$ & $1.40 \mathrm{E}-04$ & 0. & 300 & $0.54 \mathrm{E}-06$ & 1.55 \\
\hline $\mathrm{AB} 7-\mathrm{NaOH}$ & $5.03 \mathrm{E}-03$ & 0. & 600. & $0.50 \mathrm{E}-06$ & 2.00 \\
\hline $\mathrm{AB} 7-\mathrm{NaI}$ & $1.97 \mathrm{E}-04$ & 600 & 1800. & $0.54 \mathrm{E}-06$ & 1.55 \\
\hline
\end{tabular}

Table 2. Parameter Values for MELCOR and CONTAIN Calculations for AB5, $\mathrm{AB} 6$, and $\mathrm{AB} 7$

\begin{tabular}{|c|c|c|c|}
\hline Parameter & AB5 & AB6 & $\mathrm{AB} 7$ \\
\hline Plating Area $\left(\mathrm{m}^{2}\right)$ & 88.40 & 88.40 & 88.40 \\
\hline Settling Area $\left(\mathrm{m}^{2}\right)$ & 749.7 & 750.5 & 750.5 \\
\hline Agglomeration Shape Factor & 2.25 & 2.25 & 2.25 \\
\hline Dynamic Shape Factor & 1.5 & 1.5 & 1.5 \\
\hline Material Density $\left(\mathrm{kg} / \mathrm{m}^{3}\right)$ & 2500 . & 2500 . & 2130 \\
\hline Turb. Agg1. Coefficient $\left(\mathrm{m}^{2} / \mathrm{s}^{3}\right)$ & .001 & .001 & .001 \\
\hline Diff. Boundary Layer Thickness (m) & $1 . E-5$ & $1 . E-5$ & $1 . E-5$ \\
\hline
\end{tabular}


One control volume and two heat structures (one representing vertical surfaces and one representing horizontal surfaces) were specified in the MELCOR simulation of these tests. In the experiments, the vessel temperature and pressure were monitored through time at approximately forty locations. For the calculations performed with the CONTAIN code, there was no attempt made to simulate the experimental temperature and pressure profiles. $A B 5$ and $A B 7$ were modeled with a constant temperature and pressure assumption, and AB6 was modeled with a series of step jumps in temperature.

To achieve a step temperature profile with MELCOR for AB6, heat was added incrementally to the vessel. The heat, $Q$, necessary to achieve a step jump, $\triangle \mathrm{T}$, in the vessel temperature is:

$$
\mathrm{Q}(\Delta \mathrm{T})=\mathrm{c}_{\mathrm{v}} \mathrm{V} \Delta \mathrm{T}
$$

where $c_{v}$ is the constant volume specific heat of the gas (assumed constant in this calculation), $V$ is the vessel volume, and $p$ is the density of the gas.

In CONTAIN (as in the stand-alone version of MAEROS), the thermal gradient used to calculate the thermophoretic deposition rate is an input quantity, whereas in MELCOR it is not. In order to obtain a constant thermal gradient at a surface in MELCOR, one must specify a constant heat flux boundary condition that will result in the appropriate thermal gradient according to the equation:

$$
\nabla \mathrm{T} k=-\mathrm{q}
$$

where $\nabla \mathrm{T}$ is the thermal gradient at the surface $(\mathrm{K} / \mathrm{m}), \mathrm{k}$ is the gas thermal conductivity $(\mathrm{W} / \mathrm{m} \mathrm{K})$, and $\mathrm{q}$ is the heat flux at the surface $\left(\mathrm{W} / \mathrm{m}^{2}\right)$. The value of $k$ used in the MELCOR radionuclide package is the thermal conductivity of air provided by the material properties package as a function of temperature. To maintain the energy content of the control volume and heat structure, an equal heat flux must be specified at the other side of the heat structure to transfer the energy back into the control volume.

\section{Results}

Figures 2 through 7 show the time dependent results of the MELCOR and CONTAIN calculations as well as available experimental data for experiments $A B 5$, $A B 6$, and $A B 7$ respectively. Results are shown for the suspended aerosol mass, the mass deposited (settled) on the floor, and the mass deposited (plated) on the walls. End of experiment values for the deposited masses for MELCOR, CONTAIN, and the stand-alone version of MAEROS are compared to the experimental results in Table 3 .

For AB5, CONTAIN and MELCOR are very close in their predictions of the suspended mass. Excellent agreement is apparent during the source and up to the time when the concentrations are reduced by a factor of $10^{-2}$. Agreement with experimental data to the end of the experiment where concentrations are 
Table 3. Comparisons for Settled and Plated Masses

\begin{tabular}{|c|c|c|c|c|c|}
\hline & MELCOR & CONTAIN & Hilliard [5] & MAEROS & $\begin{array}{l}\text { MELCOR* } \\
\text { \& Error }\end{array}$ \\
\hline \multicolumn{6}{|l|}{$\mathrm{AB} 5$} \\
\hline Settled Mass (kg) & 370.5 & 370.5 & 382.0 & 370.1 & 38 \\
\hline Plated Mass $(\mathrm{kg})$ & 16.1 & 17.0 & 18.3 & 17.4 & 128 \\
\hline \multicolumn{6}{|l|}{$A B 6$} \\
\hline Settled Mass (kg) & 371.1 & 362.8 & 335.0 & 365.5 & 118 \\
\hline Plated Mass (kg) & 6.7 & 9.0 & 38.0 & 7.1 & 838 \\
\hline \multicolumn{6}{|l|}{$\mathrm{AB} 7$} \\
\hline Settled Mass (kg) & 3.2 & 3.3 & 3.3 & 3.3 & 38 \\
\hline Plated Mass $(\mathrm{kg})$ & .02 & .02 & .24 & .02 & 908 \\
\hline
\end{tabular}

* Calculated as 100x(MELCOR - Hilliard)/Hilliard

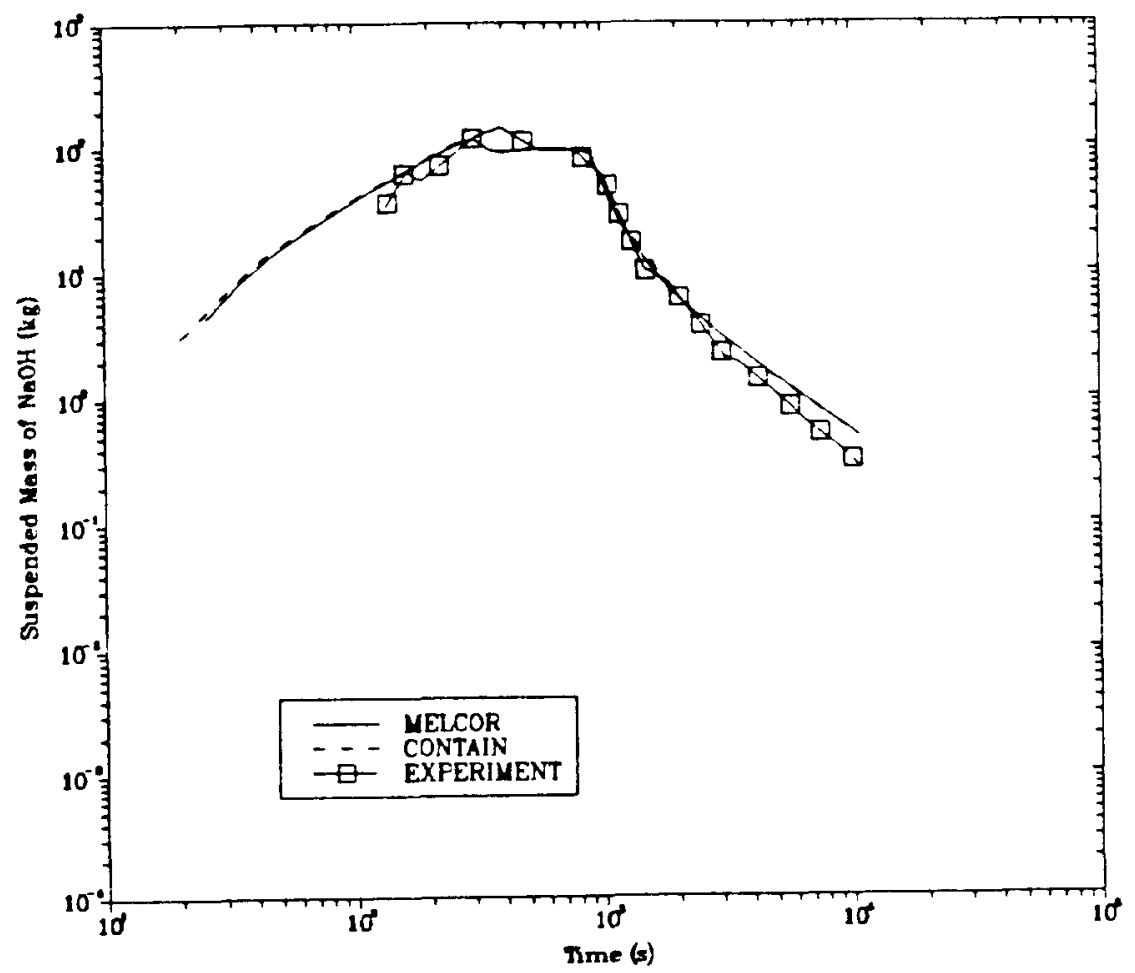

Figure 2 . Suspended Mass of Aerosol Predicted by CONTAIN and MELCOR for AB5 

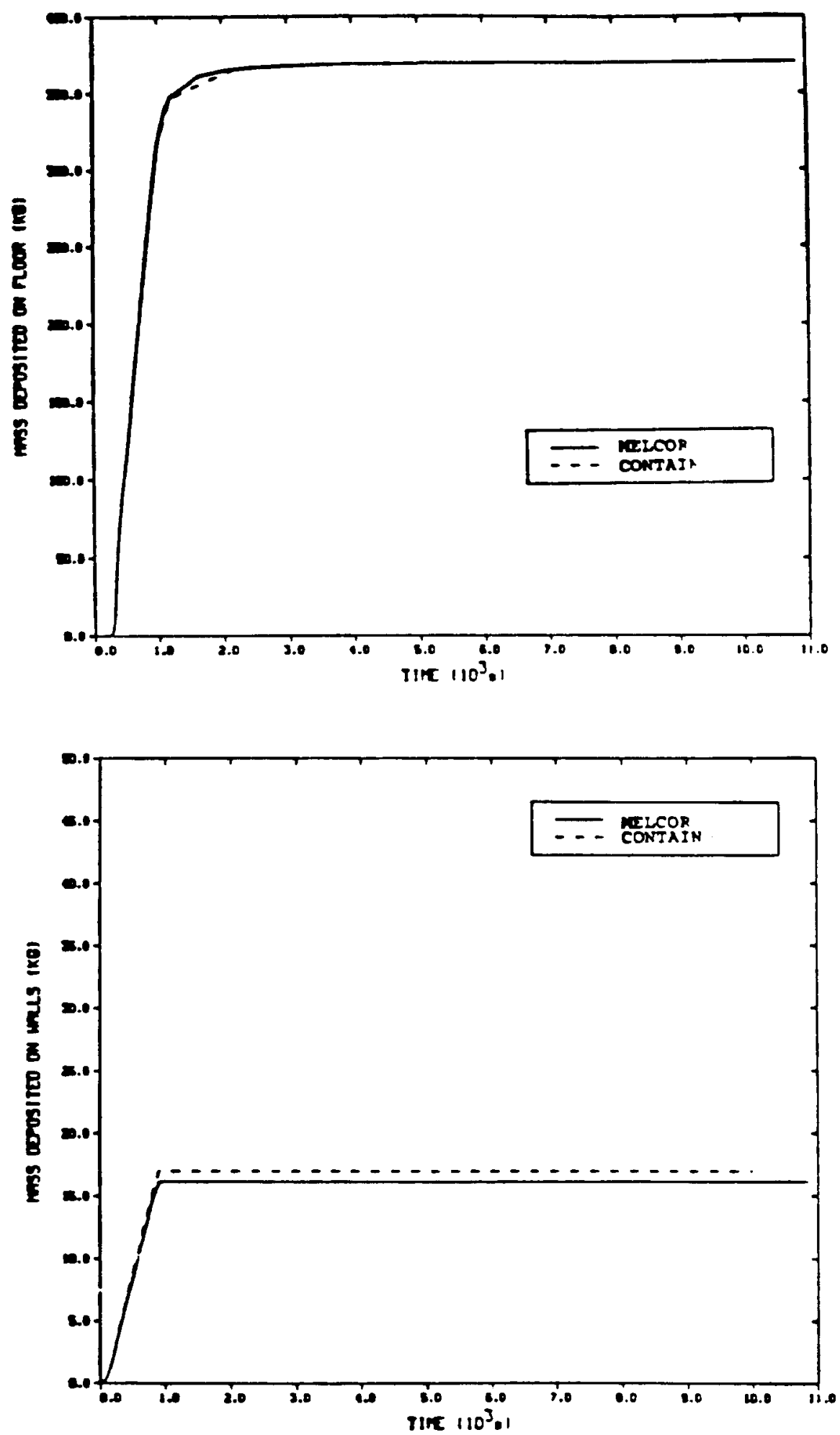

Figure 3. Deposited Mass Predicted by CONTAIN and MELCOR For AB5 

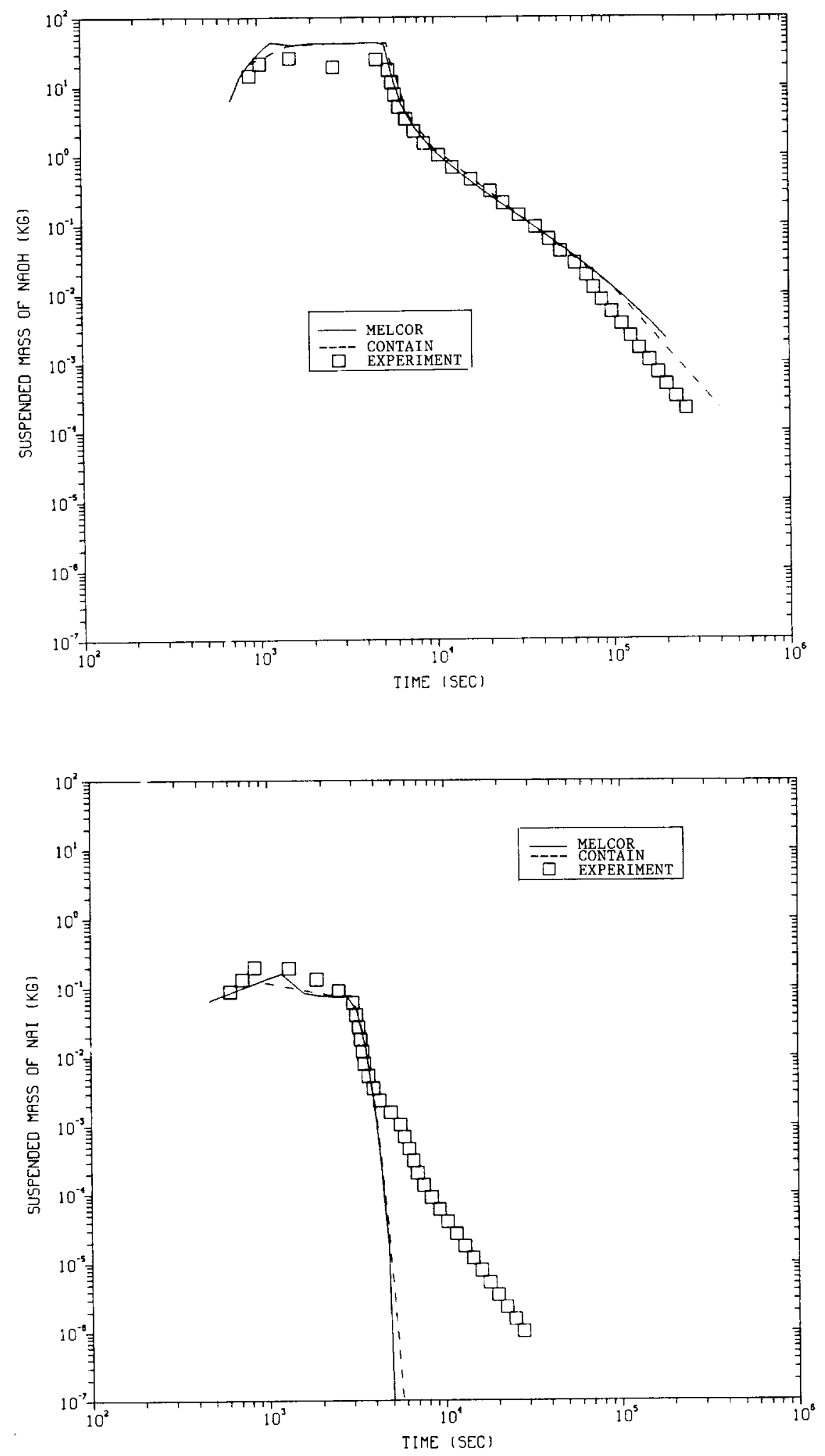

Figure 4. Suspended Aerosol Mass Predicted by CONTAIN and MELCOR for AB6 

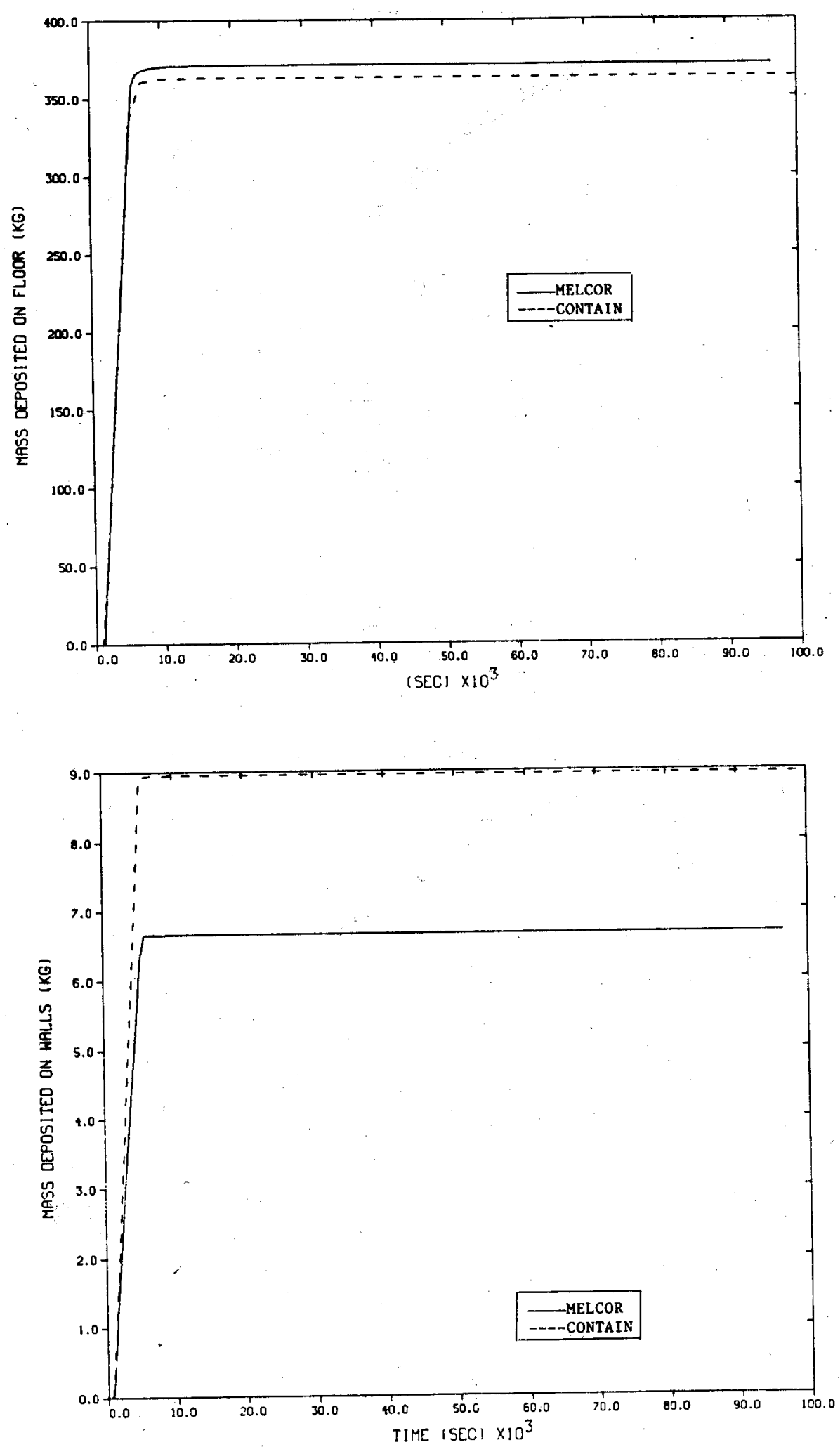

Figure 5. Deposited Aerosol Mass Predicted by CONTAIN and MELCOR for AB6 

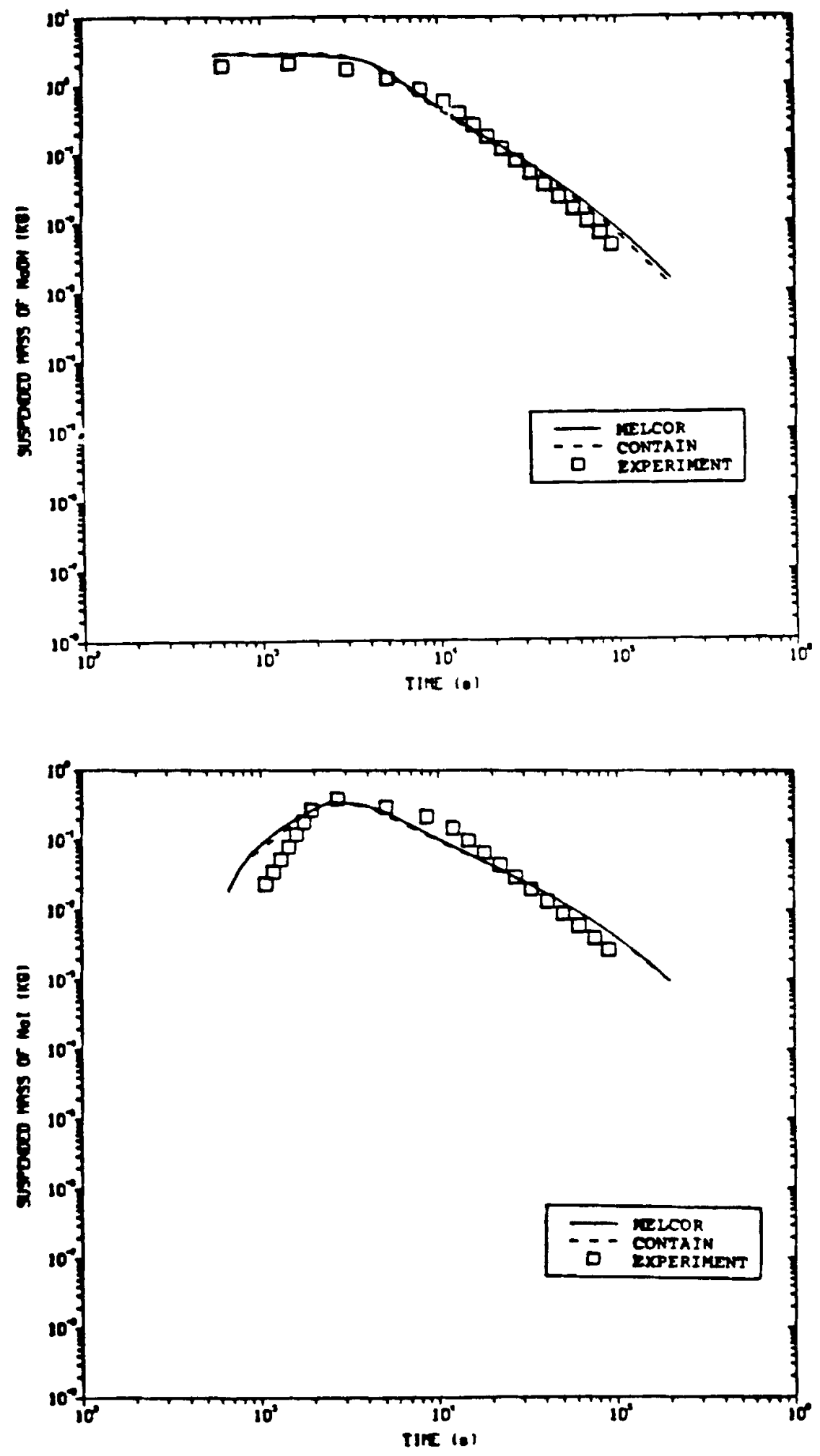

Figure 6. Suspended Aerosol Mass Predicted by CONTAIN and MELCOR for AB7 

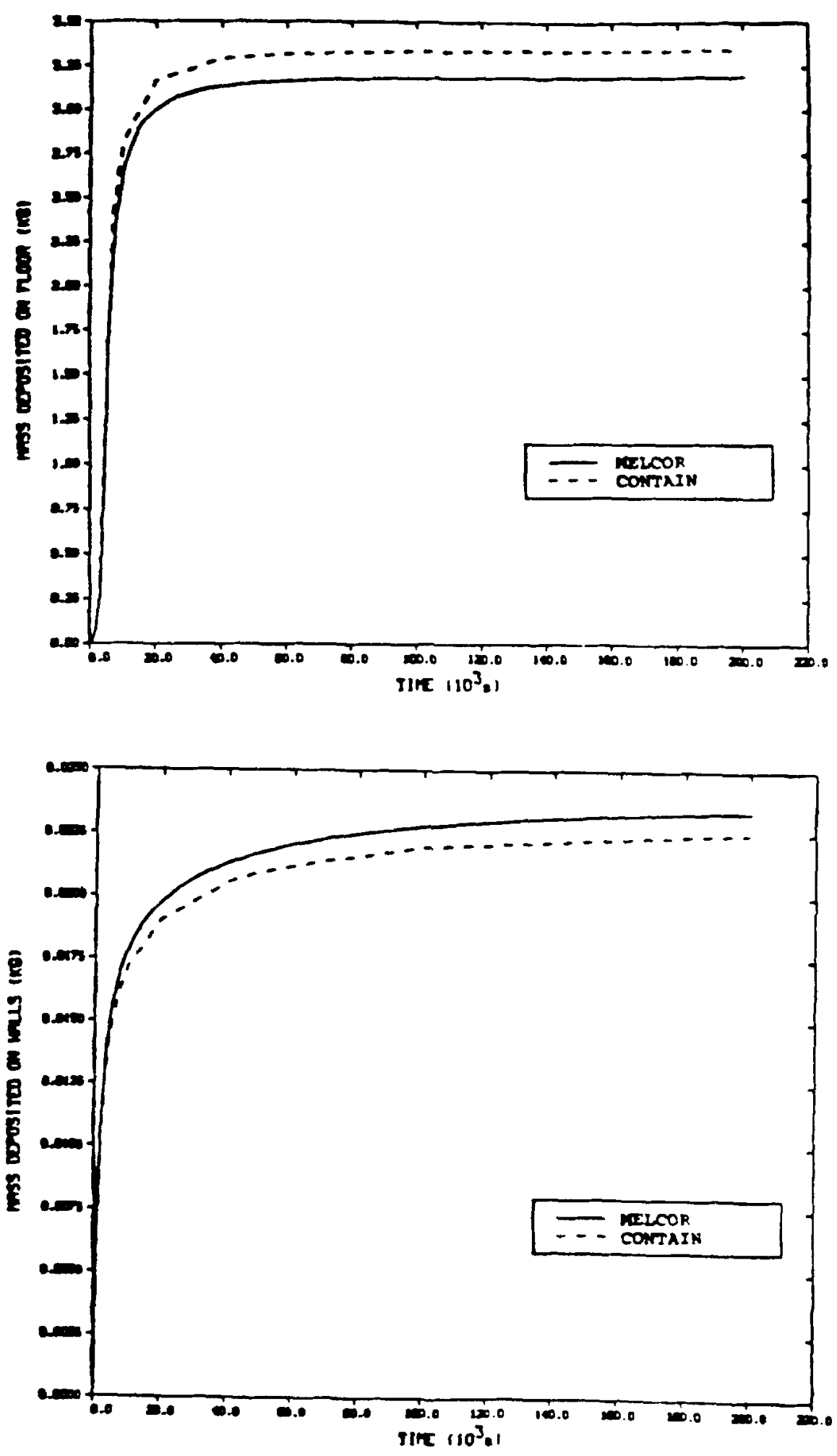

Figure 7. Deposited Aerosol Mass Predicted by CONTAIN and MELCOR for AB? 
reduced by $10^{-6}$ are within a factor of two to three. MELCOR and CONTAIN predictions of the settled mass also agree. Time dependent experimental results are not available for the settled mass. However, the total deposition on horizontal surfaces was measured at the end of the test and was 382.0 $\mathrm{kg}[5]$. CONTAIN and MELCOR predict a settled mass of aerosol deposited on the floor of $370.5 \mathrm{~kg}$. The percentage error in the MELCOR calculation for the settled mass in AB5 is 3\%. The amount of material deposited on the walls in $A B 5$ is $17.0 \mathrm{~kg}$ in the CONTAIN calculation and $16.1 \mathrm{~kg}$ in the MELCOR calculation. $18.3 \mathrm{~kg}$ of aerosol measured on vertical surfaces at the end of the experiment is reported by Hilliard et al.[5]. The MELCOR code predicts the mass deposited on the wall in AB5 with about a 128 error when compared to the experimental results and a 78 error when compared to the stand-alone MAEROS.

In AB6, CONTAIN and MELCOR are very close in their predictions of the NaOx suspended mass. Both codes slightly overpredict the NaOx suspended mass during the source and at later times when the suspended concentration has been significantly reduced. Code predictions are in excellent agreement with the experimental results between $1.0 \mathrm{E} 4$ and $1.0 \mathrm{E} 5$ seconds. The behavior of the suspended mass of NaI in AB6 differs significantly from the code predictions at late times. Both MELCOR and CONTAIN predict a rapid, continuous decay in the NaI concentration after the source has been cut off. The experimental results show that the rapid decay lasts only a short while before slowing down to a rate that is approximated by uniform coagglomeration[6]. Hilliard[6] suggests that phenomena not modeled by any of the codes may have caused this behavior. He suggests two possibilities: resuspension of previously deposited material or vaporization of the $\mathrm{NaI}$ (since the spray fire continues throughout the test) followed by condensation on the smaller NaOx particles (which causes a shift in the particle size distribution to smaller sizes that remain suspended longer). In addition, two mixing cells developed in the containment atmosphere during the test which are not modeled in any of the calculations. Once again, the two codes agree in their predictions of the settled and plated masses. Time dependent experimental results are not available for these quantities. However, Hilliard[6] reports a settled mass of $335.0 \mathrm{~kg}$. MELCOR predicts a settled mass of $371.1 \mathrm{~kg}$ and CONTAIN predicts $362.8 \mathrm{~kg}$. The MELCOR result has an 118 error. The experimental results indicate that $38.0 \mathrm{~kg}$ of aerosol were plated on vertical surfaces during the test. MELCOR predicts a plated mass of $6.7 \mathrm{~kg}$ and CONTAIN predicts $9.0 \mathrm{~kg}$. The MELCOR value represents an 838 error when compared to experimental results and a 68 error when compared to the stand-alone MAEROS. None of the codes involved in the comparison were able to adequately predict the plated mass for this test. The testers conclude that the primary plating mechanism in this test was impaction, not thermophoresis, which is a phenomenon that none of the codes can predict.

For AB7, CONTAIN and MELCOR are very close in their predictions of the suspended aerosol masses and show good agreement with the experimental data. During the source and at later times when the concentrations have been significantly reduced, the codes slightly overpredict the suspended masses of both components. Both MELCOR and CONTAIN predict higher values $(3.3 \mathrm{~kg}$ by CONTAIN and 3.2 by MELCOR) for the settled mass than Hilliard [5] who reports that a total of $3.1 \mathrm{~kg}$ is deposited on upward facing horizontal surfaces. The MELCOR prediction has a 38 error. Both MELCOR and CONTAIN predict a mass deposited on the wall of $.02 \mathrm{~kg}$. It is apparent that neither CONTAIN nor MELCOR adequately predicts deposition on the wall for this test since Hilliard [5] reports that $.24 \mathrm{~kg}$ of aerosol is deposited on vertical surfaces in this 
test. This is a $90 \%$ error, however, the MELCOR results do agree with stand-alone MAEROS predictions. None of the codes involved in the comparison was able to adequately predict the plated mass. The testers suggest that these errors may be caused by inertial impaction in the vessel.

\section{Code Limitations Identified}

Currently in MELCOR, the suspended mass of an individual component is not available as an output variable although the MELCOR calculation is multicomponent. It is extremely important for LWR applications that the aerosol calculations be multicomponent [9], and $A B 6$ and $A B 7$ are ideal tests of the multicomponent nature of the MELCOR code. However, the comparison is very difficult because the suspended mass of each component is not available as an output variable. Since MELCOR does provide the suspended radioactive mass as an output variable, for $A B 6$ and $A B 7$, MELCOR was run first by specifying that all of the $\mathrm{NaOx}$ (component 1 ) was radioactive, and the radioactive mass (the mass of $\mathrm{NaOx}$ ) was plotted. Then MELCOR was rerun specifying that all of the $\mathrm{NaI}$ was radioactive, and the radioactive mass (the mass of $\mathrm{NaI}$ ) was plotted. This was a cumbersome process, and the need to output the suspended mass of individual components has been reported to the code developers.

While performing these calculations with the MELCOR code several defects were identified. First, instabilities in the heat structure package were identified and corrected. Second, the need for providing the diffusional boundary layer thickness as a user input was identified and the input parameter was added. Third, a defect in the logarithmic plotting option was identified and corrected. Finally, it was reported that the mass median diameter of the aerosol size distribution is a variable of interest in aerosol tests, and it should be made available as an output variable. This option has not yet been added.

\section{Summary and Conclusions}

These MELCOR calculations showed good agreement with CONTAIN predictions for the $A B C O V E$ aerosol tests $A B 5, A B 6$, and $A B 7$. All quantities predicted by the two codes agreed very well although neither code adequately predicted the plated masses in $A B 6$ and $A B 7$.

In the future, it would be interesting to compare the time dependent behavior of the mass median diameter of the aerosol size distribution. However, this is not an output variable that is available in MELCOR at this time. 
6. References

1. K.D. Bergeron et a1., User's Manual for CONTAIN 1.0, NUREG/CR-4085, SAND84-1204, Sandia National Laboratories, May 1985.

2. F. Gelbard, MAEROS User's Manual, NUREG/CR-1391, SAND80-0822, Sandia National Laboratories, December 1982.

3 MELCOR 1.5 was released although not officially published.

4. K.K. Murata, et al., "CONTAIN: Recent Highlights in Code Testing and Validation, Proceedings from the International Meeting on Light Water Reactor Severe Accident Evaluation, Cambridge, Massachusetts, September 1983 .

5. R.K. Hilliard, J.D. McCormack, and A.K. Postma, Results and Code Predictions for ABCOVE Aerosol Code Validation .. Test AB5, HEDL-TME 83-16, Hanford Engineering Laboratory, 1983.

6. R.K. Hilliard, J.D. McCormack, and L.D. Muhlestein, Results and Code Predictions for ABCOVE Aerosol Code Validation -- Test AB6 with Two Aerosol Species, HEDL-TME 84-19, Hanford Engineering Laboratory, December 1984.

7. R.K. Hilliard, J.D. McCormack, and L.D. Muhlestein, Results and Code Predictions for ABCOVE Aerosol Code Validation with Low Concentration $\mathrm{NaOH}$ and $\mathrm{NaI}$ Aerosol, HEDL-TME 85-1, Hanford Engineering Laboratory, October 1985.

9. R.J. Lipinski et al., Uncertainty in Radionuclide Release Under Specific LWR Accident Conditions: Volume II: TMLB' Analysis, SAND84-0410, Sandia National Laboratories, February 1986. 
Appendix A

MELCOR Standard Test Problems from 1986

This appendix contains brief descriptions of the standard tests that have been developed in association with this report. One standard test has been developed from each paper. Appendix B contains copies of the input files for the tests, and Appendix C contains copies of the comparison plots. Requests for additional information should be directed to the editor of this report.

\section{ST001: Adiabatic Expansion of Hydrogen, Two-Cell Flow}

This test is Case 5 from the paper, "MELCOR 1.6 Calculations for Adiabatic Expansion of Hydrogen, Two-cell Flow". Two control volumes are pressurized with hydrogen. The pressure in control volume 1 is 2 . E5 $\mathrm{Pa}$ and the pressure in control volume 2 is 1 .E5 Pa. Both volumes are $1000 \mathrm{~m}^{3}$ and at $300 \mathrm{~K}$. A 50 $\mathrm{m}^{2}$ flow path is opened between the volumes at time zero and they are allowed to equilibrate.

\section{ST002: Radial Conduction in Annular Structures}

This test is Case 4 from the paper, "MELCOR 1.0 Calculations for Radial Conduction in Annular structures". An annular structure initially at $600 \mathrm{~K}$ is exposed to a $550 \mathrm{~K}$ environment on its outer surface and a $600 \mathrm{~K}$ environment on its inner surface. The structure is allowed to reach its steady state temperature distribution.

\section{ST003: Cooling of a Structure in a Fluid}

This test is taken from the paper, "MELCOR 1.0 Calculations for Coolirg 01 Structures in a Fluid". Two uniform structures, a rectangular slab and a cylinder, are submersed in a fluid that is at $500 \mathrm{~K}$. Both structures are initially at $1000 \mathrm{~K}$ and have constant thermal properties and constant surface heat transfer coefficients. The temperature of each solid as a function of time is noted.

\section{ST004A and ST004B: Semi-Infinite Heat Structure Test}

This test is Case 1 from the paper, "MELCOR 1.1 Calculations for a Semi-infinite solid Heat structure lest". This is a test of transient heat flow in a semi-infinite solid with convective boundary conditions. This case involves a $10 \mathrm{~m}$ thick concrete structure. The fluid temperature is $450 \mathrm{~K}$, and the initial temperature of the structure is $300 \mathrm{~K}$. For ST004A, there are 18 nodes in the first meter of the structure, and it is run with 30 second time steps. For ST004B, there are 69 nodes in the first meter of the structure, and it is run with 10 second time steps. 
This test is taken from the paper, "MELCOR 1.6 Calculations for a Saturated Liquid Depressurization Test". A volume containing saturated water at high pressure is depressurized into a second larger volume. The two volumes are connected by a flow path and a heat structure.

\section{ST006: Browns Ferry Reactor Building Burns}

This test was taken from the paper, "MELCOR 1.0 and HECTR 1.5 Calculations for Browns Ferry Reactor Building Burns". It is a test of the reactor building response to hydrogen burns that occur when hydrogen is released to the building. This is an integrated test that involves three control volumes and six flow paths.

\section{ST007: HDR Steam Blowdown Test}

This test was taken from the paper, "MELCOR 1.6 Calculations for the HDR Containment Experiment V44". It is a test of the containment response to the depressurization of a reactor pressure vessel. This is an integrated test that involves five control volumes and nine flow paths.

\section{ST008: ABCOVE Aerosol Experiment Test AB6}

This is Case 2 from the paper, "MELCOR 1.5 Calculations for ABCOVE Aerosol Experiments $A B 5, A B 6$, and $A B 7 "$ " Two aerosol sources are introduced into an 850 $\mathrm{m}^{3}$ volume. The two aerosols are $\mathrm{NaI}$ and $\mathrm{NaOH}$. The $\mathrm{NaI}$ is introduced first with a small source rate. Following that, the $\mathrm{NaOH}$ is introduced with a large source rate. The $\mathrm{NaOH}$ source is continued well after the $\mathrm{NaI}$ source is discontinued. This is a dry aerosol problem.

ST009A and ST009B: Battelle-Frankfurt Gas Mixing Experiments

These are Case 2 and Case 19 from the paper, "MELCOR 1.0 Calculations for the Battelle-Frankfurt Mixing Tests". In both tests a hydrogen-nitrogen mixture is injected into a model containment. The containment in Case 2 is a sixteen compartment mode1; the containment in Case 19 is a twenty-eight volume model. Calculations for this test are normally run on the Cray. 
Appendix B

Input Decks for MELCOR Standard Test Problems

In this appendix the input decks for the standard test problems are given. Three files are needed in order to run MELCOR. The first file is the input file for MELGEN. The second is the input file for MELCOR, and the third is the input file for MELPLT. All three decks for the standard test are given here. In addition, if there is experimental data or data generated by another computer code for the comparison, those files are given here. The MELGEN run produces two output files, MEGOUT.DAT and MEGDIA.DAT. These contain the MELGEN output and MELGEN diagnostics, respectively. The MELCOR run produces four files: MELOUT.DAT, MELDIA.DAT, MELRST.DAT, and MELPTF.DAT. These are the MELCOR output, the MELCOR diagnostics, the MELCOR restart file, and the plot data file respectively.

ST001: Adiabatic Expansion of Hydrogen

MELGEN Input

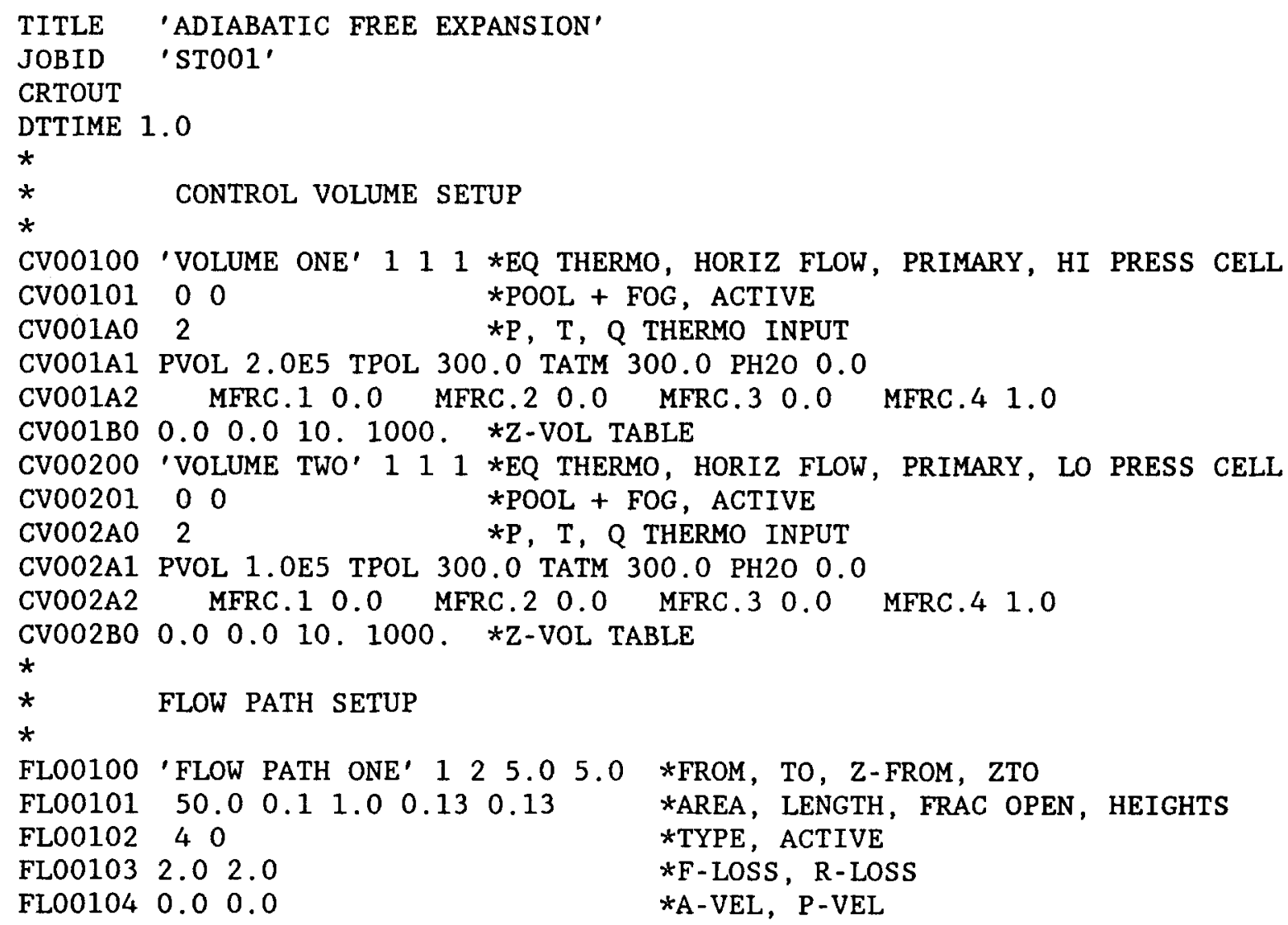


FL001S1 50. $0.1 \quad 0.13 \quad 5 . E-5 \quad 0.0$

*SEG AREA, L, D, ROUGH, LAM FL COEF

*

$*$

*

NCGOOO H2 4

ST001: Adiabatic Expansion of Hydrogen

MELCOR Input

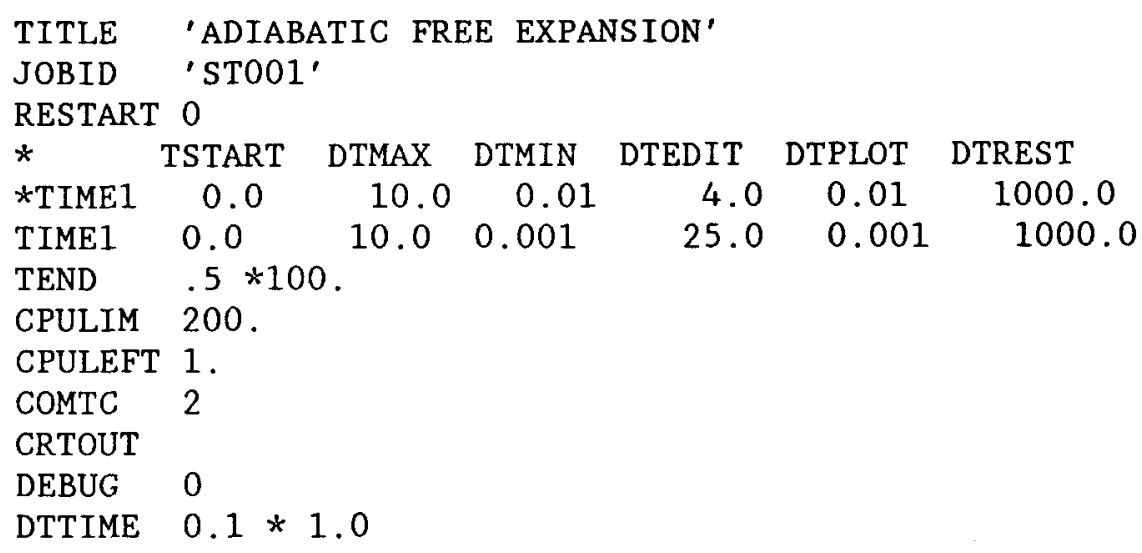

ST001: Adiabatic Expansion of Hydrogen

MELPLT Input

FILE1 MELPTF.DAT

TITLE CASE ST001

XLABEL Donor Ce11 Mass ( $\mathrm{kg}$ )

YLABEL Pressure ( $\mathrm{Pa}$ )

*XLIMITS 270.0430 .0

*YLIMITS 100000 . 500000 .

LEGEND CELL 1

PLOT CVH-P.1 CVH-MASS. 1

LEGEND MELCOR

CPLOT CVH-P. 2 CVH-MASS. 1

LEGEND ANALYTIC

DATAI PI CFOIANAL.DAT

LEGEND CELL 2

DATA1 P2 CF01ANAL.DAT

XLABEL Donor Ce11 Mass (kg)

YLABEL Temperature (K)

*XLIMITS 270.0430 .0

*YLIMITS 240.360.

LEGEND CELL 1

PLOT CVH-TVAP. 1 CVH-MASS 1 


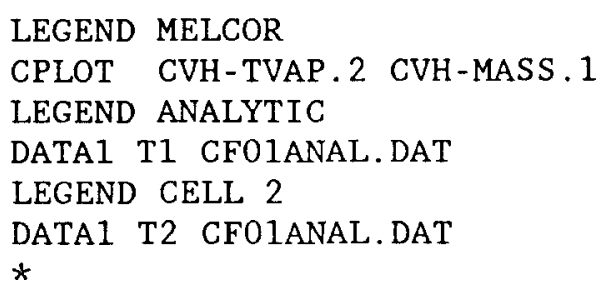

ST001: Adiabatic Expansion of Hydrogen

$<\mathrm{T} 1$ Analytical Data

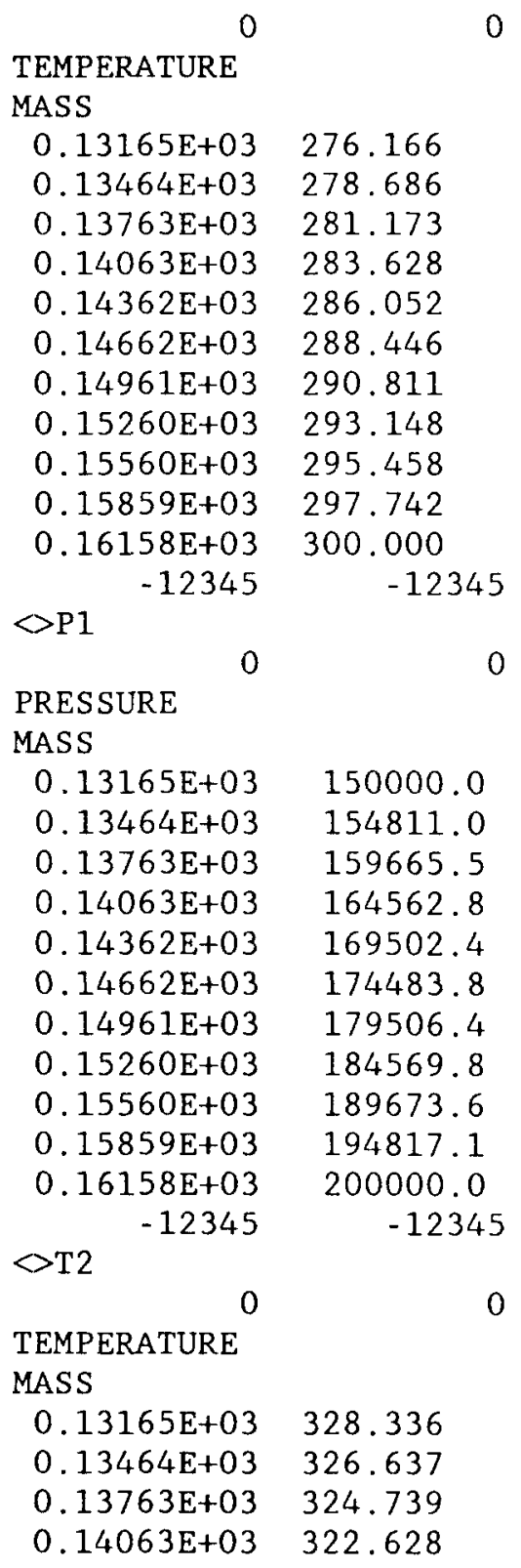




\begin{tabular}{|c|c|}
\hline $0.14362 \mathrm{E}+03$ & 320.285 \\
\hline $0.14662 \mathrm{E}+03$ & 317.689 \\
\hline $0.14961 E+03$ & 314.819 \\
\hline $0.15260 \mathrm{E}+03$ & 311.647 \\
\hline $0.15560 \mathrm{E}+03$ & 308.143 \\
\hline $0.15859 \mathrm{E}+03$ & 304.274 \\
\hline $0.16158 \mathrm{E}+03$ & 300.000 \\
\hline-12345 & -12345 \\
\hline
\end{tabular}

PRESSURE

MASS
$0.13165 \mathrm{E}+03$
150000.0
$0.13464 \mathrm{E}+03$
145189.0
$0.13763 \mathrm{E}+03$
140334.5
$0.14063 \mathrm{E}+03$
135437.2
130497.6
125516.2
120493.6
115430.2
110326.4
105182.9
100000.0
$0.15859 \mathrm{E}+03$
$0.16158 \mathrm{E}+03$
$-12345$
$-12345$

ST002: Radial Conduction in Annular Structures

MELGEN Input

TITLE ST002

JOBID 'STO02'

CRTOUT

*

* HEAT SLAB InPUT

$*$

HS00001000 72000

HS00001001 'TEST SLAB'

HSO0001002 0. 1.

HS00001100 $-1 \quad 1 \quad 3.1856$

HS00001101 $3.1886 \quad 2$

* NO. NODES, TYPE, SS INIT, TRANS ITER

*

* BOTTOM ALTITUDE, ORIENTATION

* NODALIZATION FLAGS, INSIDE RADIUS

* LOCATION, NODE NO.

HS00001102 $3.1926 \quad 3$

HS00001103 $3.2006 \quad 4$

HSO0001104 $3.2156 \quad 5$

HS00001105 $3.2556 \quad 6$

HS00001106 $3.3412 \quad 7$

HS00001201 STEEL 6

HS00001300 0

HS00001400 $2001-1$

HS00001600 $2002 \quad-1$

HSO0001801 600.7

* MATERIAL TYPE, MESH INTERVAL

* SOURCE TYPE, FLAG, SOURCE MULTIPLIER

* LHS BC TYPE, ASSOC CV

* RHS BC TYPE, ASSOC CV

* initial temperature, NODE No. 


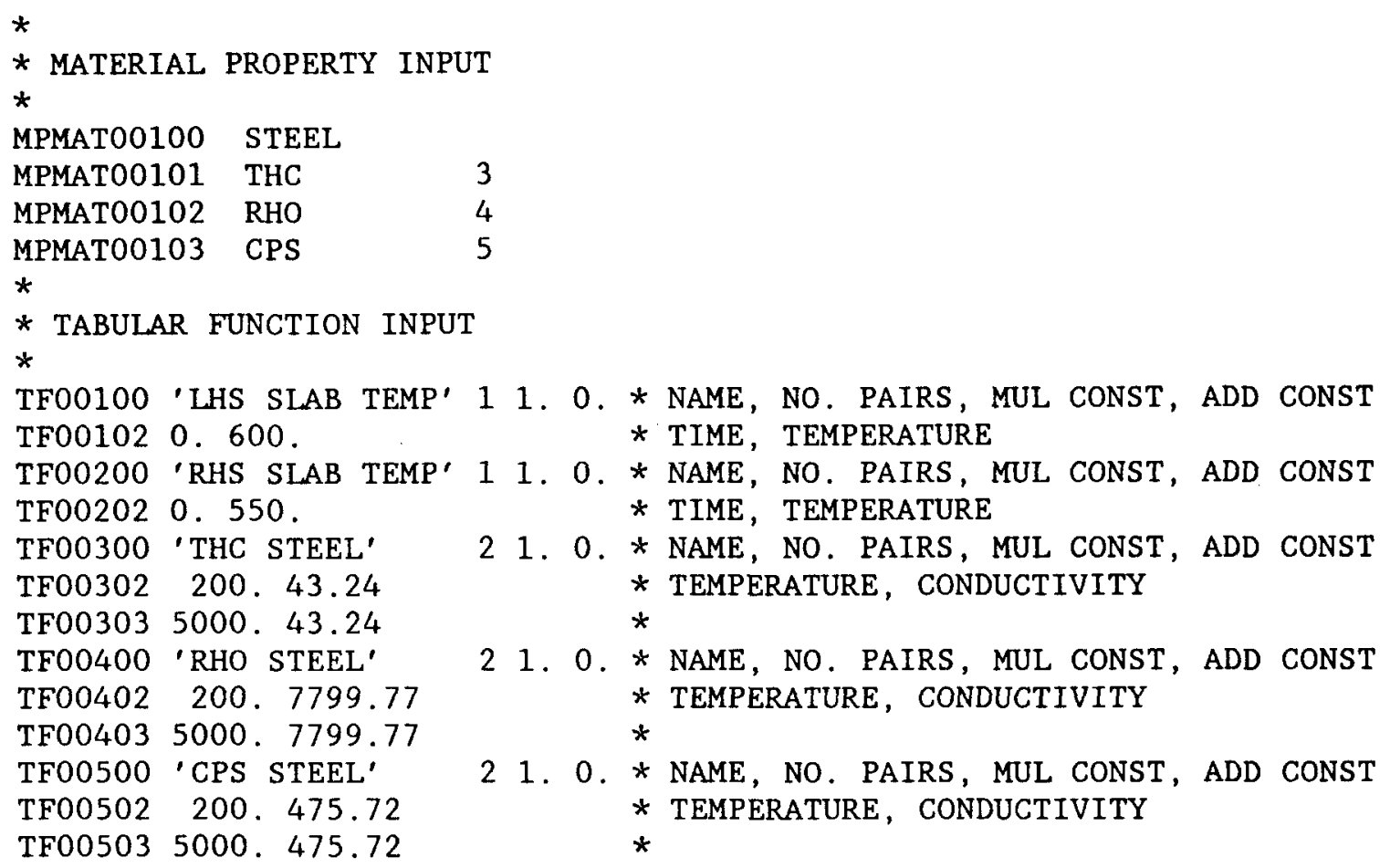

ST002: Radial Conduction in Annular Structures

MELCOR Input

TITLE ST002

JOBID 'STO02'

CRTOUT

COMTC 2

DEBUG 0

RESTART 0

* TSTART DTMAX DTMin DTEDit DTPlot DTREsT

$\begin{array}{lllllll}\text { TIME1 } & 0 . & 30 . & .01 & 4 . & .01 & 1000 .\end{array}$

$\begin{array}{lllllll}\text { TIME2 } & 100 . & 30 . & .01 & 200 . & .01 & 1000 .\end{array}$

TEND 2500.

CPULIM 200.

CPULEFT 1.

ST002: Radial Conduction in Annular Structures

MELPLT Input

TITLE HEAT SLAB TEST CASE STO02

XLABEL RADIUS (M) 
YLABEL TEMPERATURE (K)

DATA - 5 T-MELCOR - 04

00

TEMPERATURE ( $\mathrm{K}$ )

RADIUS ( $M$ )

3.1856600 .

3.1886599 .013

$3.1926 \quad 597.698$

3.2006595 .075

$3.2156 \quad 590.172$

3.2556577 .210

3.3412550

$-12345 .-12345$.

DATAB T-ANAL-04 HS06ANAL. DAT

ST003: Cooling of a Structure in a Fluid

MELGEN Input

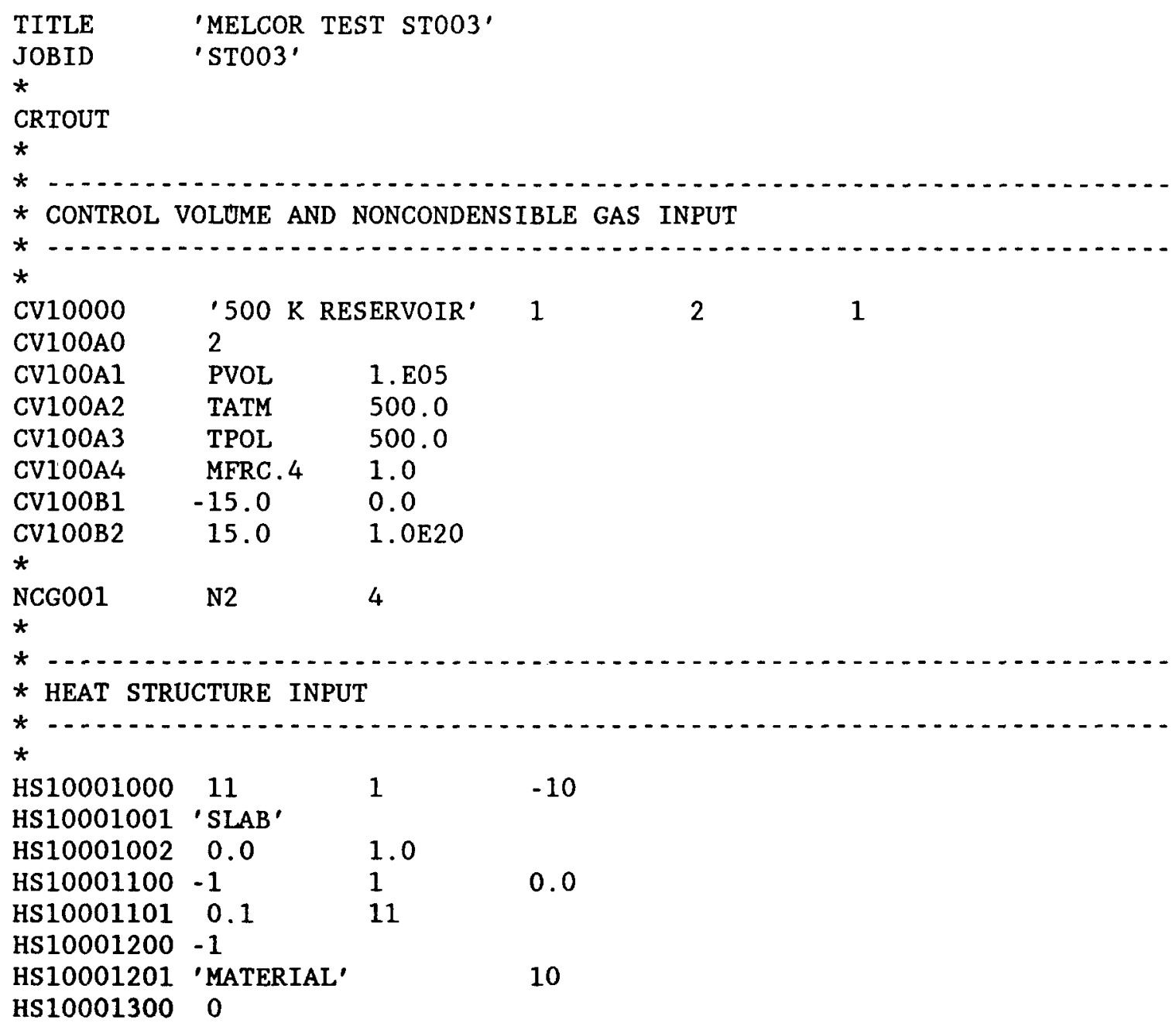




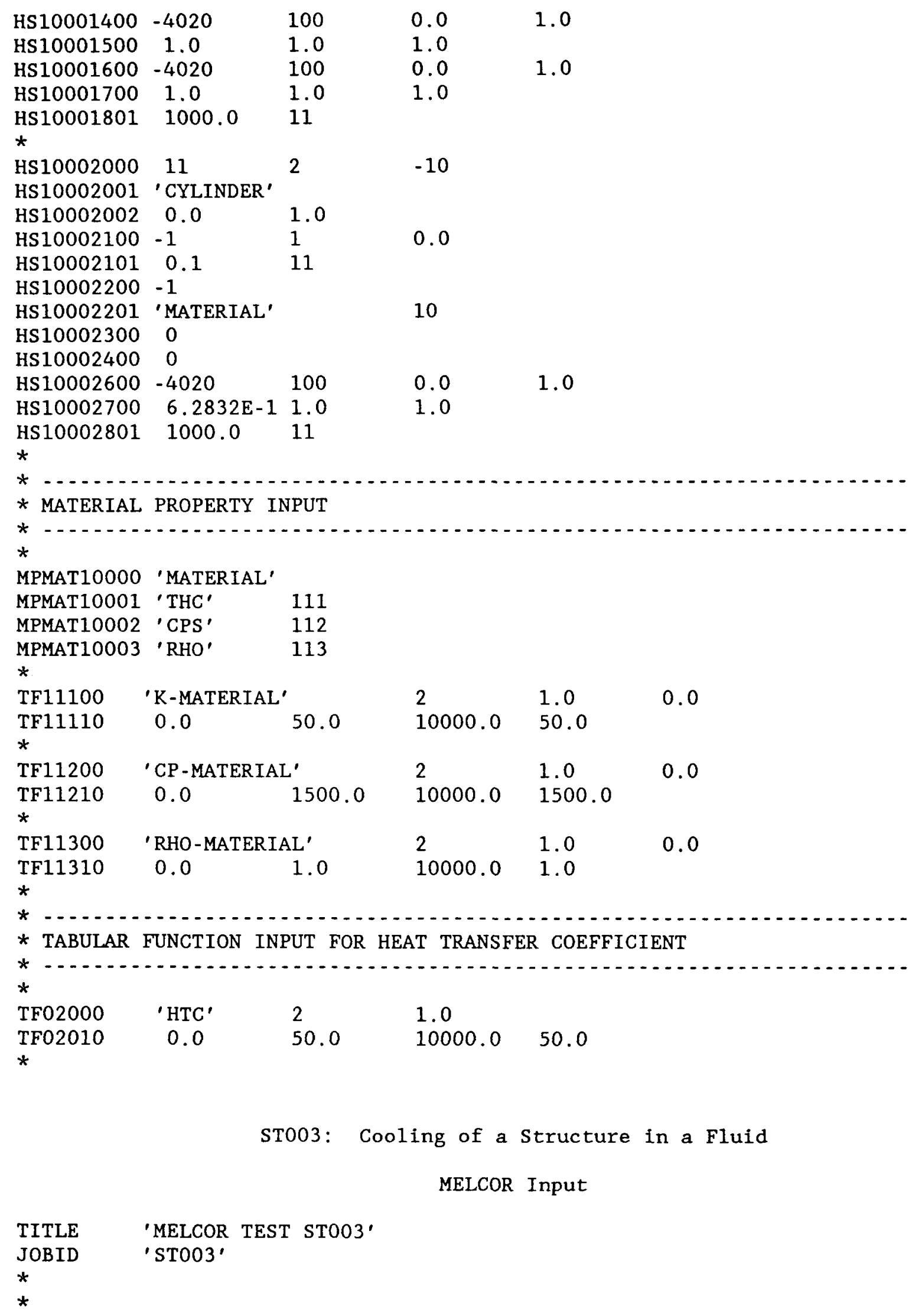




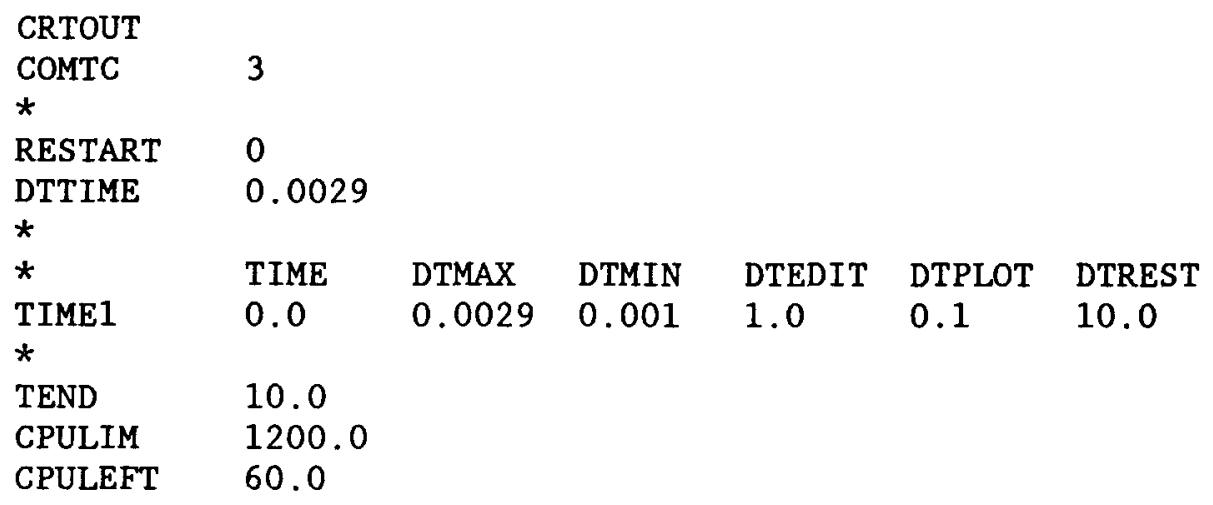

ST003: Cooling of a Structure in a Fluid MELPLT Input

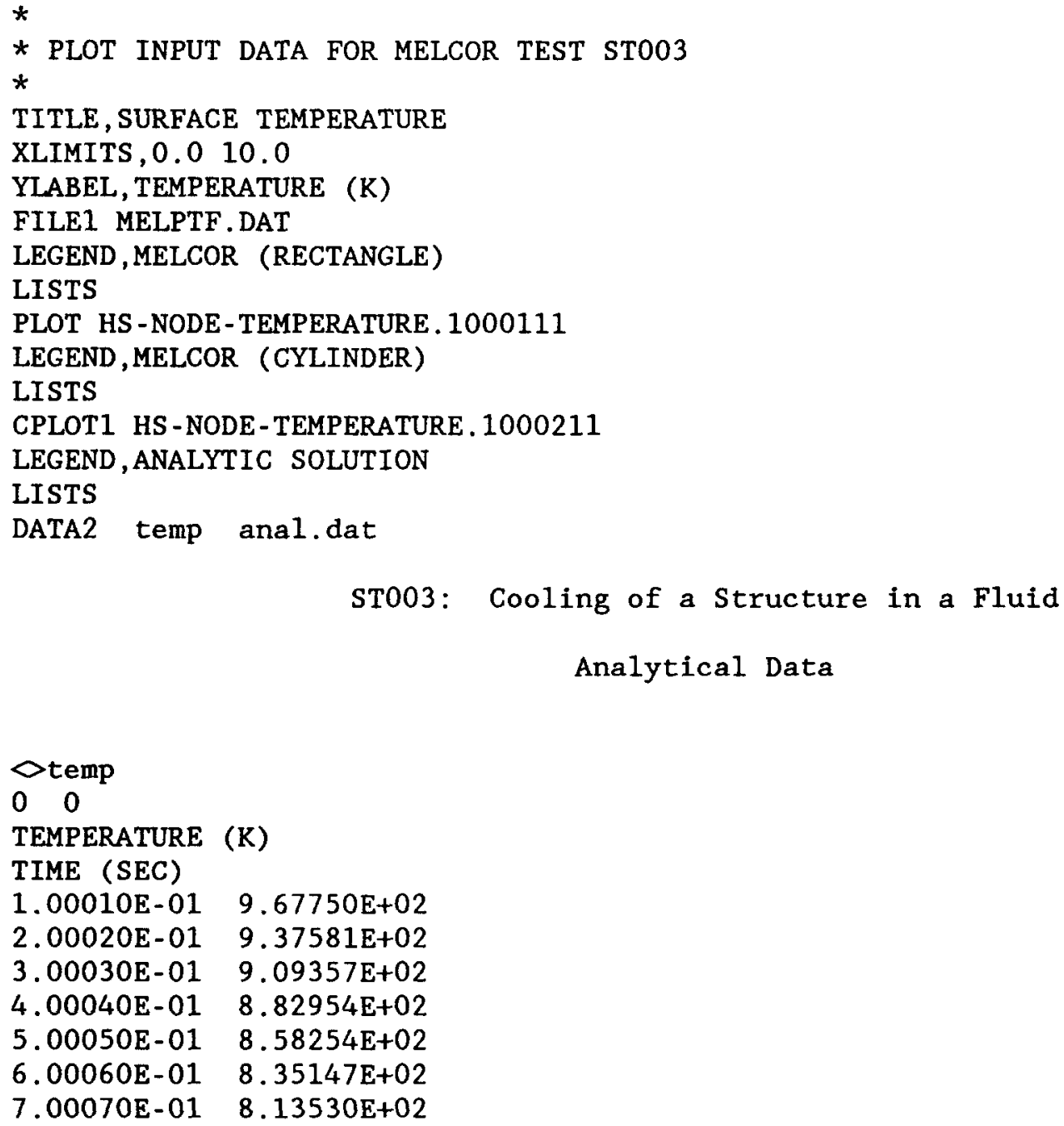



$8.00080 \mathrm{E}-01$
$7.93308 \mathrm{E}+02$
9. $00090 \mathrm{E}-01$
$7.74390 \mathrm{E}+02$
$1.00010 \mathrm{E}+00$
$7.56692 \mathrm{E}+02$
1. $10011 \mathrm{E}+00$
$7.40136 \mathrm{E}+02$
1. $20012 \mathrm{E}+00$
7. $24647 \mathrm{E}+02$
1. $30013 \mathrm{E}+00$
$1.40014 \mathrm{E}+00$
7. $10158 \mathrm{E}+02$
1. $50015 \mathrm{E}+00$
$6.96603 \mathrm{E}+02$
1. $60016 \mathrm{E}+00$
1. $70017 \mathrm{E}+00$
1. $80018 \mathrm{E}+00$
1. $90019 \mathrm{E}+00$
$6.83922 \mathrm{E}+02$
$6.72059 \mathrm{E}+02$
$6.60962 \mathrm{E}+02$
6. $50580 \mathrm{E}+02$
$6.40867 \mathrm{E}+02$
$2.00020 \mathrm{E}+00$
6. $31782 \mathrm{E}+02$
2. $10021 \mathrm{E}+00$
6. $23282 \mathrm{E}+02$
2. $20022 \mathrm{E}+00$
$6.15330 \mathrm{E}+02$
2. $30023 \mathrm{E}+00$
$6.07892 \mathrm{E}+02$
$2.40024 \mathrm{E}+00$
2. $50025 \mathrm{E}+00$
2. $60026 \mathrm{E}+00$
2. $70027 \mathrm{E}+00$
2. $80028 \mathrm{E}+00$
$6.00933 \mathrm{E}+02$
5. $94423 \mathrm{E}+02$
5. $88332 \mathrm{E}+02$
5. $82635 \mathrm{E}+02$
5. $77305 \mathrm{E}+02$
2. $90029 \mathrm{E}+00$
5. $72319 E+02$
3. $00030 \mathrm{E}+00$
$5.67655 \mathrm{E}+02$
3. $10031 \mathrm{E}+00$
$5.63291 \mathrm{E}+02$
3. $20032 \mathrm{E}+00$
5. $59209 \mathrm{E}+02$
3. $30033 \mathrm{E}+00$
5. $55390 \mathrm{E}+02$
3. $40034 \mathrm{E}+00$
5. $51817 \mathrm{E}+02$
3. $50035 \mathrm{E}+00$
$5.48475 \mathrm{E}+02$
3. $60036 \mathrm{E}+00$
$5.45348 \mathrm{E}+02$
3. $70037 \mathrm{E}+00$
$5.42424 \mathrm{E}+02$
3. $80038 \mathrm{E}+00$
5. $39687 \mathrm{E}+02$
$3.90039 \mathrm{E}+00$
4. $00040 \mathrm{E}+00$
5. $37127 \mathrm{E}+02$
5. $34733 \mathrm{E}+02$
4. $10041 \mathrm{E}+00$
5. $32493 \mathrm{E}+02$
4. $20042 E+00$
5. $30397 \mathrm{E}+02$
4. $30043 \mathrm{E}+00$
5. $28436 \mathrm{E}+02$
4. $40044 \mathrm{E}+00$
5. $26602 \mathrm{E}+02$
$4.50045 \mathrm{E}+00$
5. $24886 \mathrm{E}+02$
4. $60046 \mathrm{E}+00$
5. $23281 \mathrm{E}+02$
4. $70047 \mathrm{E}+00$
5. $21780 \mathrm{E}+02$
4. $80048 \mathrm{E}+00$
5. $20375 \mathrm{E}+02$
$5.00050 \mathrm{E}+00$
5. $17831 \mathrm{E}+02$
$5.10051 \mathrm{E}+00$
5. $16681 \mathrm{E}+02$
5. $20052 \mathrm{E}+00$
5. $15605 \mathrm{E}+02$
$5.30053 \mathrm{E}+00$
5. $14599 \mathrm{E}+02$
$5.40054 \mathrm{E}+00$
5. $13657 \mathrm{E}+02$
$5.50055 \mathrm{E}+00$
$5.12776 \mathrm{E}+02$
5. $60056 \mathrm{E}+00$
5. $11952 \mathrm{E}+02$
$5.70057 \mathrm{E}+00$
5. $11181 \mathrm{E}+02$
$5.80058 \mathrm{E}+00$
$5.10460 \mathrm{E}+02$
$5.90059 \mathrm{E}+00$
$5.09785 \mathrm{E}+02$
$6.00060 \mathrm{E}+00$
$5.09154 \mathrm{E}+02$
$6.10061 \mathrm{E}+00 \quad 5.08564 \mathrm{E}+02$
$6.20062 \mathrm{E}+00$
$5.08011 \mathrm{E}+02$ 

$6.30063 E+00$
$5.07495 E+02$
$6.40064 E+00$
$5.07011 \mathrm{E}+02$
$6.50065 E+00$
$5.06559 \mathrm{E}+02$
$6.60066 \mathrm{E}+00$
$5.06136 \mathrm{E}+02$
$6.70067 \mathrm{E}+00$
$5.05740 \mathrm{E}+02$
$6.80068 \mathrm{E}+00$
$5.05370 \mathrm{E}+02$
$7.00070 \mathrm{E}+00$
$7.10071 \mathrm{E}+00$
$5.04700 \mathrm{E}+02$
7. $20072 \mathrm{E}+00$
$5.04397 \mathrm{E}+02$
7. $30073 \mathrm{E}+00$
$5.04113 \mathrm{E}+02$
$7.40074 \mathrm{E}+00$
$5.03848 \mathrm{E}+02$
$7.50075 \mathrm{E}+00$
$5.03600 \mathrm{E}+02$
$7.60076 \mathrm{E}+00$
$5.03367 \mathrm{E}+02$
7. $70077 \mathrm{E}+00$
$5.03150 \mathrm{E}+02$
$7.80078 \mathrm{E}+00$
$5.02947 \mathrm{E}+02$
7. $90079 \mathrm{E}+00$
$5.02757 \mathrm{E}+02$
$8.00080 \mathrm{E}+00$
$5.02579 \mathrm{E}+02$
8. $10081 \mathrm{E}+00$
$5.02413 E+02$
8. $20082 \mathrm{E}+00$
$5.02257 \mathrm{E}+02$
8. $30083 \mathrm{E}+00$
$5.02112 E+02$
$8.40084 \mathrm{E}+00$
5. $01975 \mathrm{E}+02$
$8.50085 \mathrm{E}+00$
$5.01848 \mathrm{E}+02$
$8.60086 \mathrm{E}+00$
$5.01729 E+02$
$8.70087 \mathrm{E}+00$
5. $01617 \mathrm{E}+02$
$8.80088 \mathrm{E}+00$
$5.01513 E+02$
$9.00090 \mathrm{E}+00$
$5.01415 E+02$
9. $10091 \mathrm{E}+00$
$5.01239 E+02$
9. $20092 \mathrm{E}+00$
$5.01159 \mathrm{E}+02$
9. $30093 \mathrm{E}+00$
$5.01084 \mathrm{E}+02$
9. $40094 \mathrm{E}+00$
$5.01014 \mathrm{E}+02$
$9.50095 \mathrm{E}+00$
$5.00949 E+02$
$9.70097 \mathrm{E}+00$
$5.00888 \mathrm{E}+02$
$9.80098 \mathrm{E}+00$
$5.00777 \mathrm{E}+02$
$9.90099 \mathrm{E}+00$
$5.00727 \mathrm{E}+02$
$1.00010 \mathrm{E}+01 \quad 5.00636 \mathrm{E}+02$
$-12345 .-12345$.

ST004A: Semi-infinite Solid Heat Structure Test

Note: The input data for ST004B is not included here. The input data for ST004B can be obtained from the editor of this report.

MELGEN Input

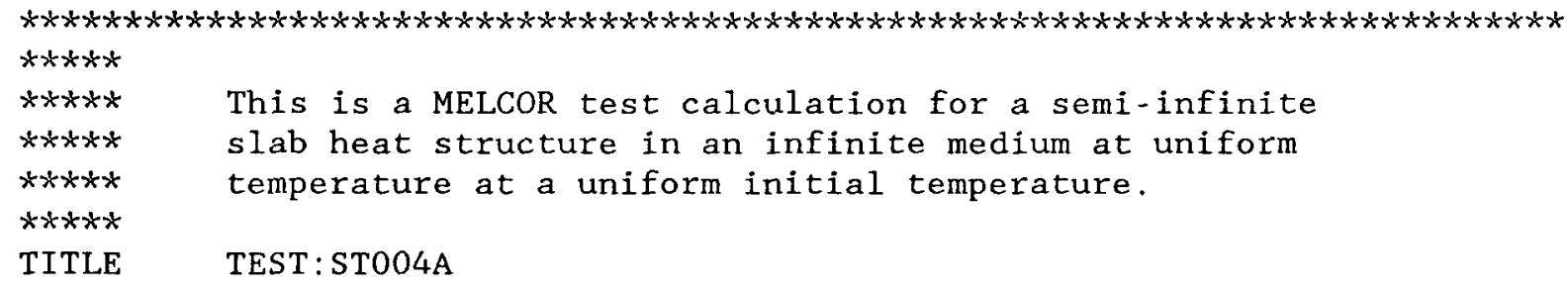




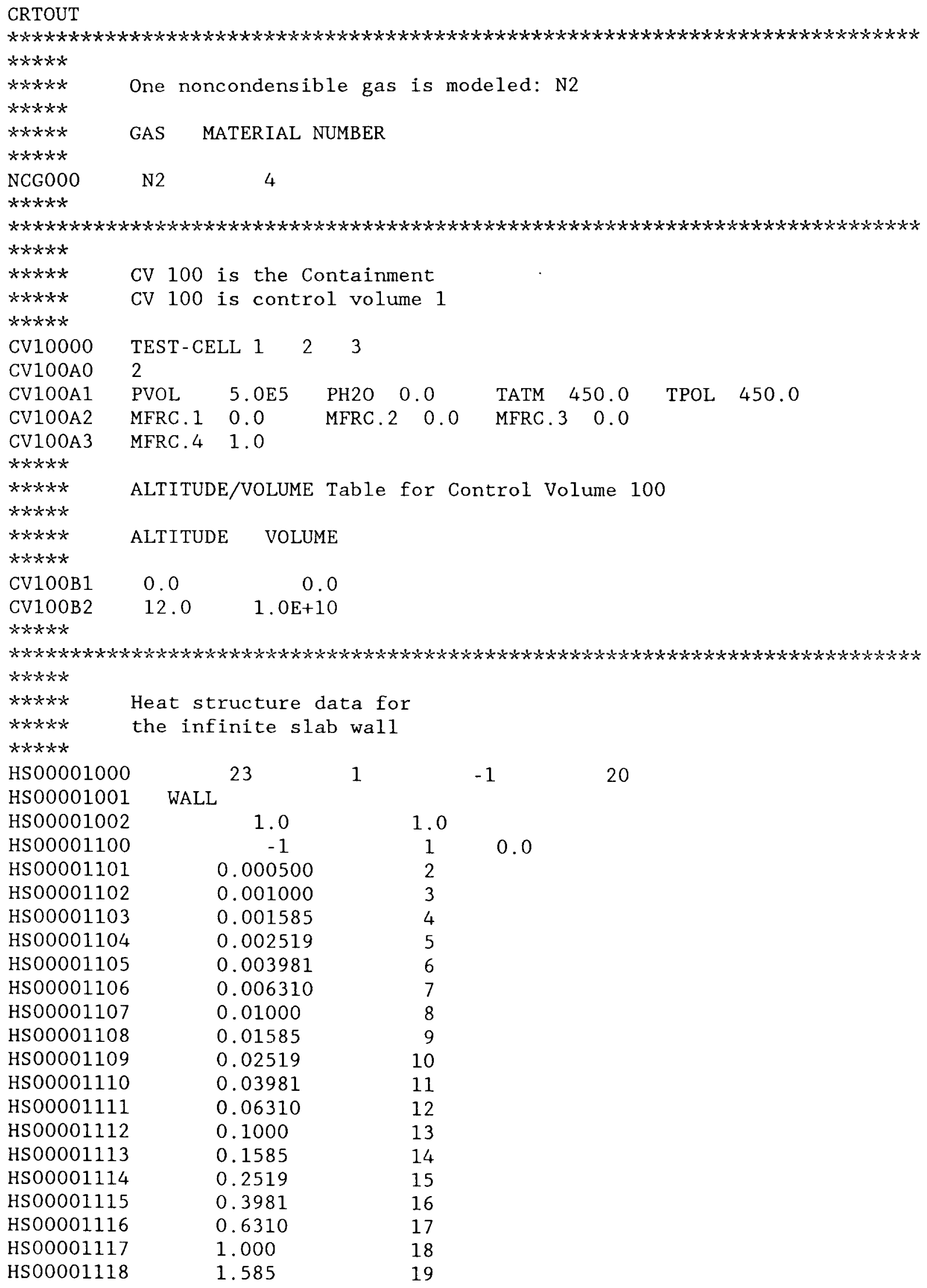

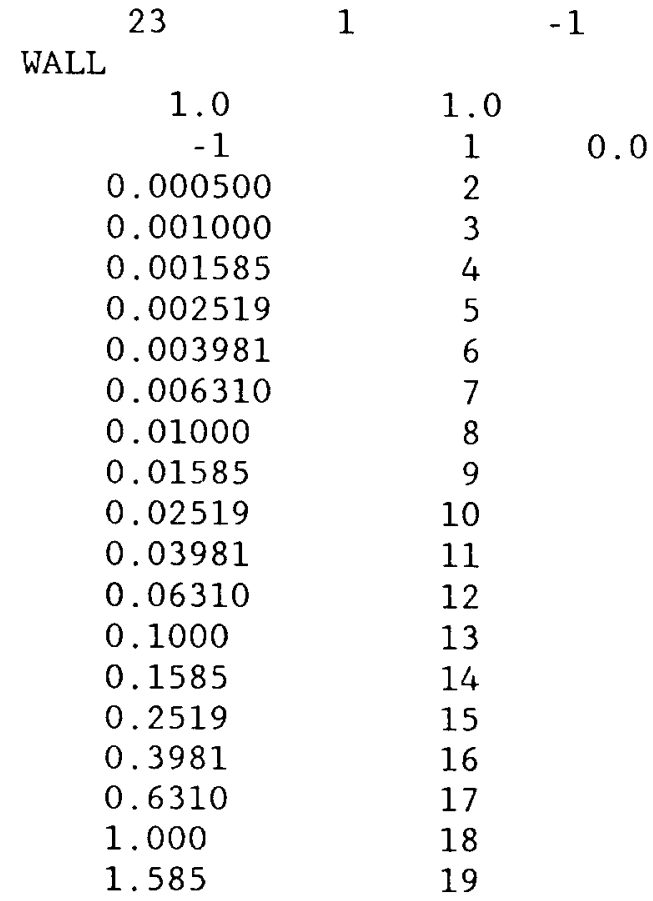




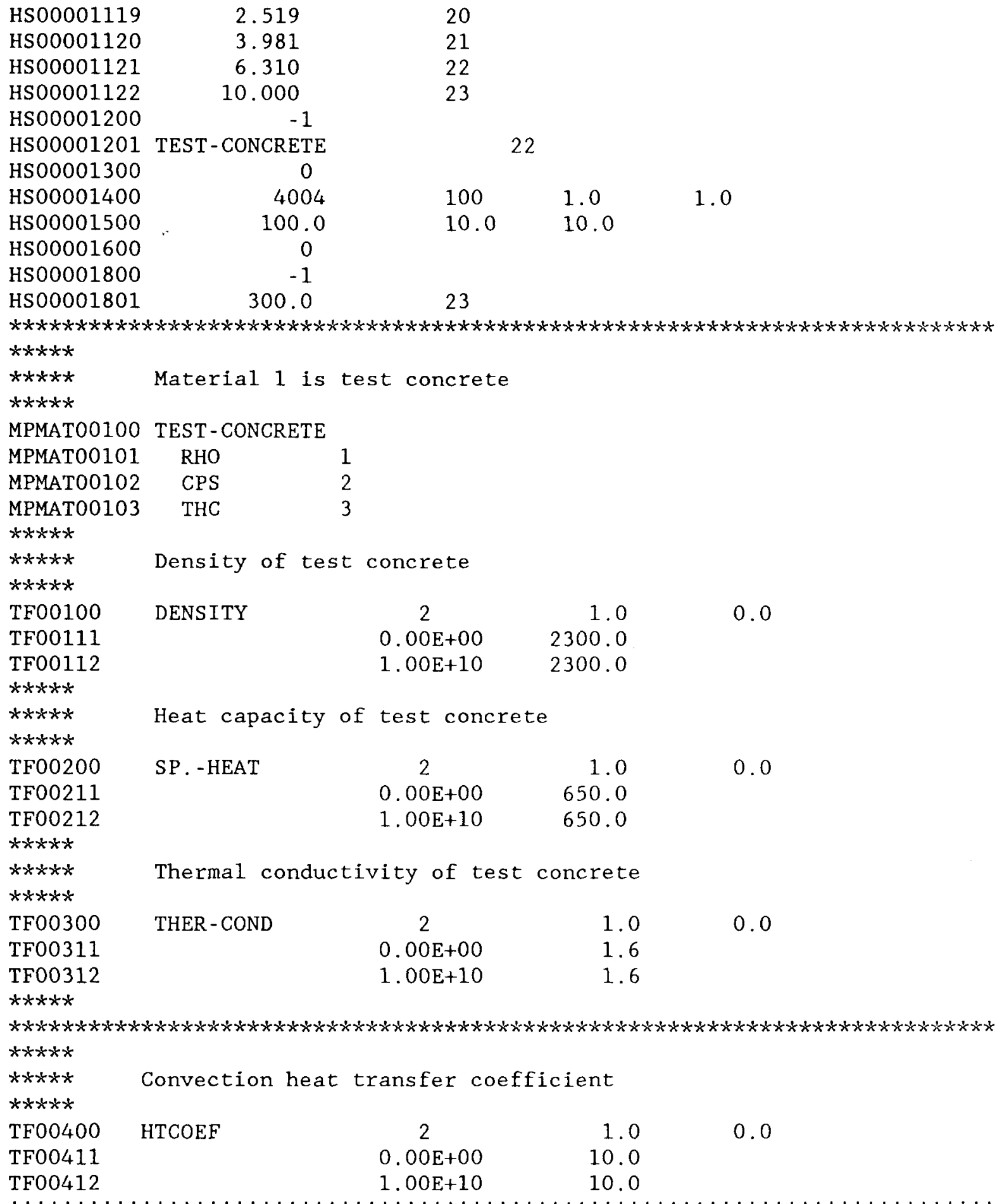


ST004: Semi-infinite Heat Structure Test

MELCOR Input

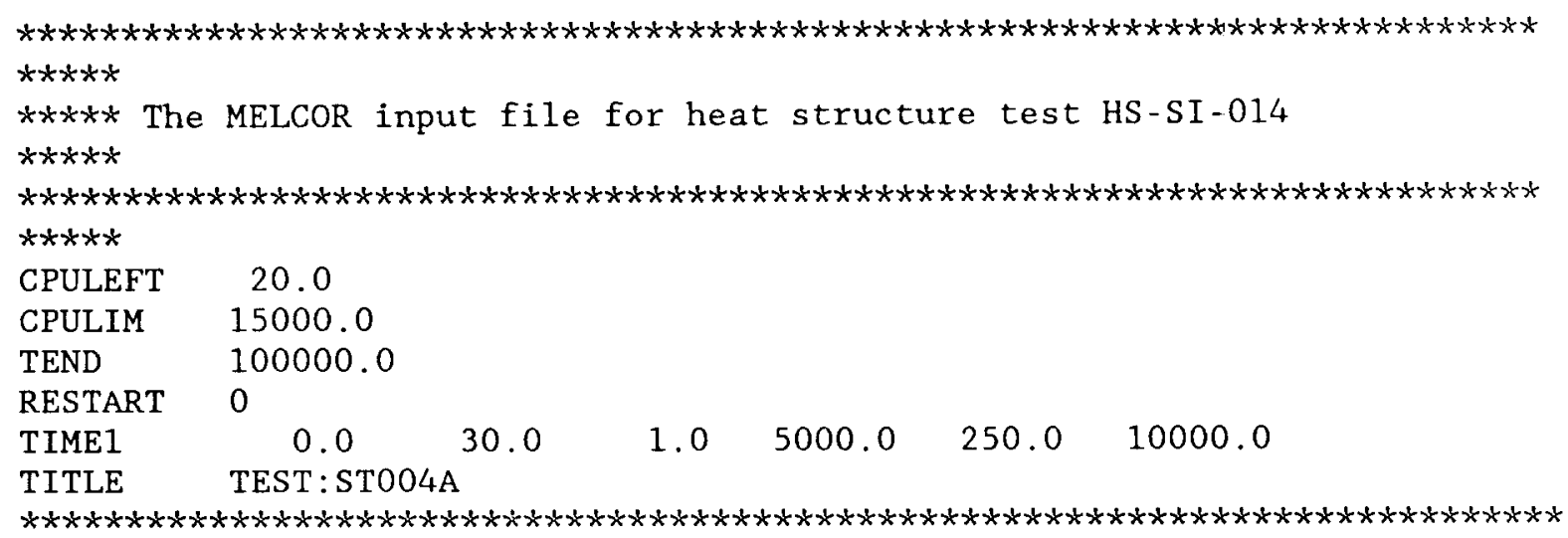

ST004: Semi-infinite Heat Structure Test

MELPLT Input

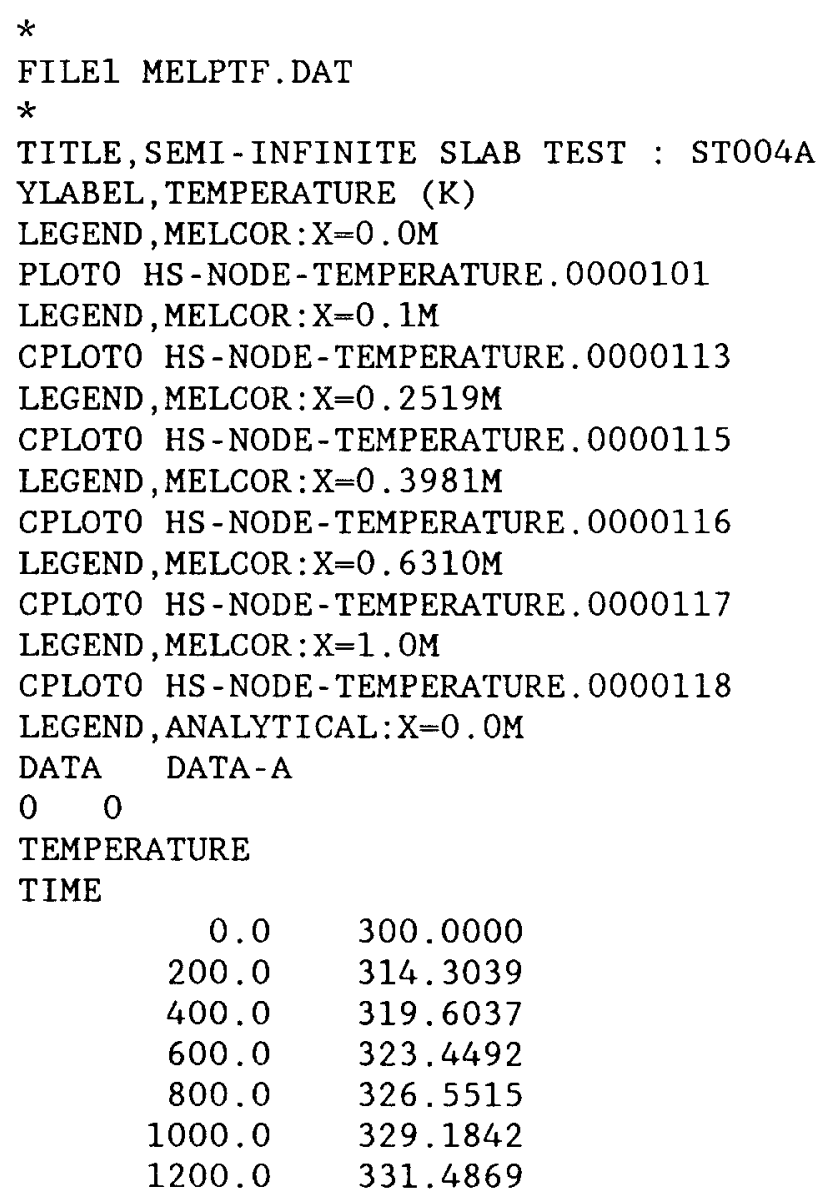




\begin{tabular}{rl}
1400.0 & 333.5422 \\
1600.0 & 335.4036 \\
1800.0 & 337.1081 \\
2000.0 & 338.6824 \\
2200.0 & 340.1466 \\
2400.0 & 341.5164 \\
2600.0 & 342.8039 \\
2800.0 & 344.0193 \\
3000.0 & 345.1705 \\
3200.0 & 346.2644 \\
3400.0 & 347.3067 \\
3600.0 & 348.3023 \\
3800.0 & 349.2553 \\
4000.0 & 350.1694 \\
4200.0 & 351.0476 \\
4400.0 & 351.8928 \\
4600.0 & 352.7074 \\
4800.0 & 353.4937 \\
5000.0 & 354.2534 \\
5200.0 & 354.9885 \\
5400.0 & 355.7003 \\
5600.0 & 356.3905 \\
5800.0 & 357.0602 \\
6000.0 & 357.7107 \\
6200.0 & 358.3429 \\
6400.0 & 358.9580 \\
6600.0 & 359.5567 \\
6800.0 & 360.1400 \\
7000.0 & 360.7085 \\
7200.0 & 361.2631 \\
7400.0 & 361.8043 \\
7600.0 & 362.3328 \\
7800.0 & 362.8491 \\
8000.0 & 363.3539 \\
8200.0 & 363.8475 \\
8400.0 & 364.3304 \\
8600.0 & 364.8031 \\
8800.0 & 365.2660 \\
9000.0 & 365.7195 \\
9200.0 & 366.1639 \\
9400.0 & 366.5996 \\
9600.0 & 367.0269 \\
9800.0 & 367.4461 \\
1116000.0 & 367.8574 \\
10200.0 & 368.2613 \\
10400.0 & 368.6578 \\
10600.0 & 369.0474 \\
10800.0 & 369.4301 \\
11000.0 & 369.8062 \\
& 370.1760 \\
1100.0 & 370.5396 \\
\hline
\end{tabular}


Note: The data for this curve has been truncated here. Data is available out to 100,000 seconds. For a more complete data set contact the editor of this report.

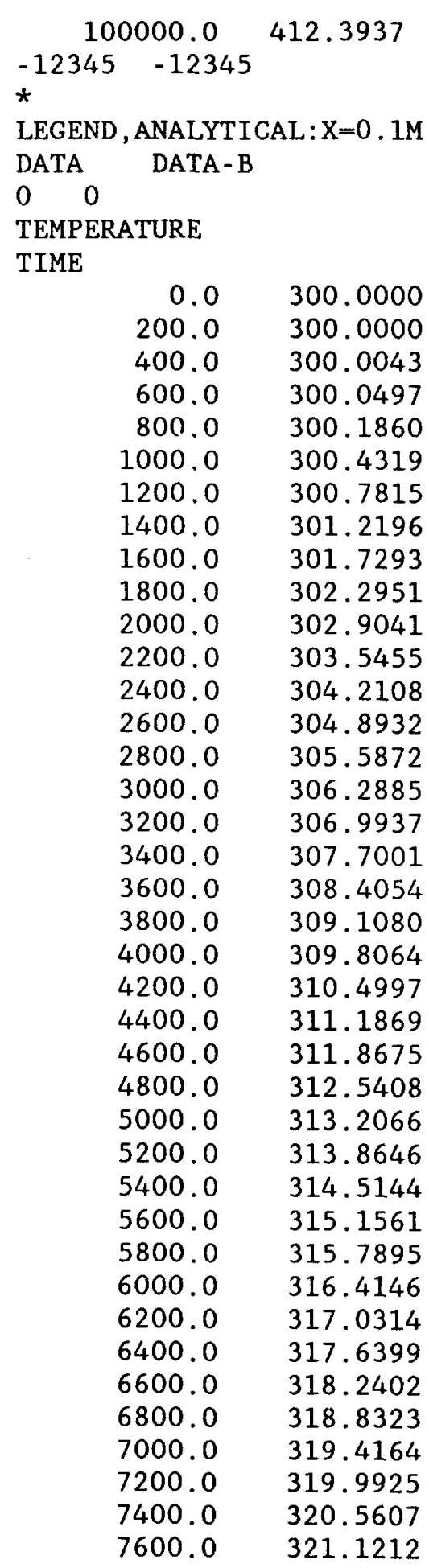


$7800.0 \quad 321.6741$

$8000.0 \quad 322.2195$

$8200.0 \quad 322.7575$

$8400.0 \quad 323.2883$

Note: The data for this curve has been truncated here. Data is available out to 100,000 seconds. For a more complete data set contact the editor of this report.

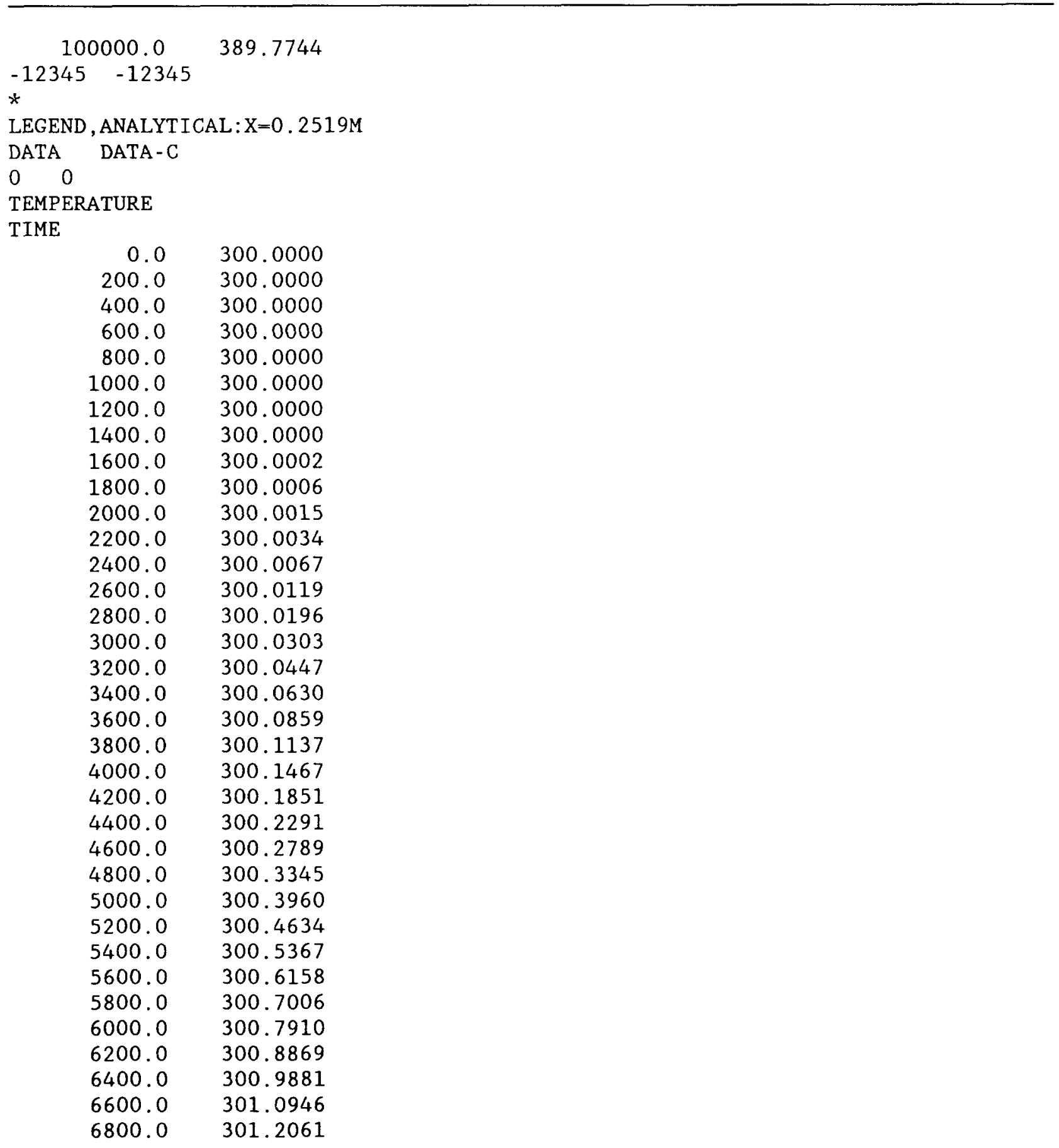




$\begin{array}{ll}7000.0 & 301.3225 \\ 7200.0 & 301.4436 \\ 7400.0 & 301.5693 \\ 7600.0 & 301.6994 \\ 7800.0 & 301.8337 \\ 8000.0 & 301.9721 \\ 8200.0 & 302.1143 \\ 8400.0 & 302.2603\end{array}$

Note: The data for this curve has been truncated here. Data is available out to 100,000 seconds. For a more complete data set contact the editor of this report.

\begin{tabular}{|c|c|c|}
\hline \multicolumn{2}{|c|}{100000.0} & \multirow[t]{2}{*}{359.9601} \\
\hline $\begin{array}{l}-12345 \\
*\end{array}$ & -12345 & \\
\hline \multicolumn{3}{|c|}{ LEGEND, ANALYTICAL $: \mathrm{X}=0.398$} \\
\hline DATA & DATA - D & \\
\hline 0 & & \\
\hline \multirow{2}{*}{\multicolumn{3}{|c|}{ TEMPERATURE }} \\
\hline TIME & & \\
\hline & 0.0 & 300.0000 \\
\hline & 200.0 & 300.0000 \\
\hline & 400.0 & 300.0000 \\
\hline & 600.0 & 300.0000 \\
\hline & 800.0 & 300.0000 \\
\hline & 1000.0 & 300.0000 \\
\hline & 1200.0 & 300.0000 \\
\hline & 1400.0 & 300.0000 \\
\hline & 1600.0 & 300.0000 \\
\hline & 1800.0 & 300.0000 \\
\hline & 2000.0 & 300.0000 \\
\hline & 2200.0 & 300.0000 \\
\hline & 2400.0 & 300.0000 \\
\hline & 2600.0 & 300.0000 \\
\hline & 2800.0 & 300.0000 \\
\hline & 3000.0 & 300.0000 \\
\hline & 3200.0 & 300.0000 \\
\hline & 3400.0 & 300.0000 \\
\hline & 3600.0 & 300.0001 \\
\hline & 3800.0 & 300.0002 \\
\hline & 4000.0 & 300.0003 \\
\hline & 4200.0 & 300.0005 \\
\hline & 4400.0 & 300.0007 \\
\hline & 4600.0 & 300.0011 \\
\hline & 4800.0 & 300.0016 \\
\hline & 5000.0 & 300.0023 \\
\hline & 5200.0 & 300.0033 \\
\hline & 5400.0 & 300.0045 \\
\hline & 5600.0 & 300.0060 \\
\hline & 5800.0 & 300.0078 \\
\hline & 6000.0 & 300.0101 \\
\hline
\end{tabular}




$\begin{array}{ll}6200.0 & 300.0128 \\ 6400.0 & 300.0160 \\ 6600.0 & 300.0198 \\ 6800.0 & 300.0242 \\ 7000.0 & 300.0293 \\ 7200.0 & 300.0351 \\ 7400.0 & 300.0416 \\ 7600.0 & 300.0490 \\ 7800.0 & 300.0572 \\ 8000.0 & 300.0663 \\ 8200.0 & 300.0763 \\ 8400.0 & 300.0874\end{array}$

Note: The data for this curve has been truncated here. Data is available out to 100,000 seconds. For a more complete data set please contact the editor of this report.

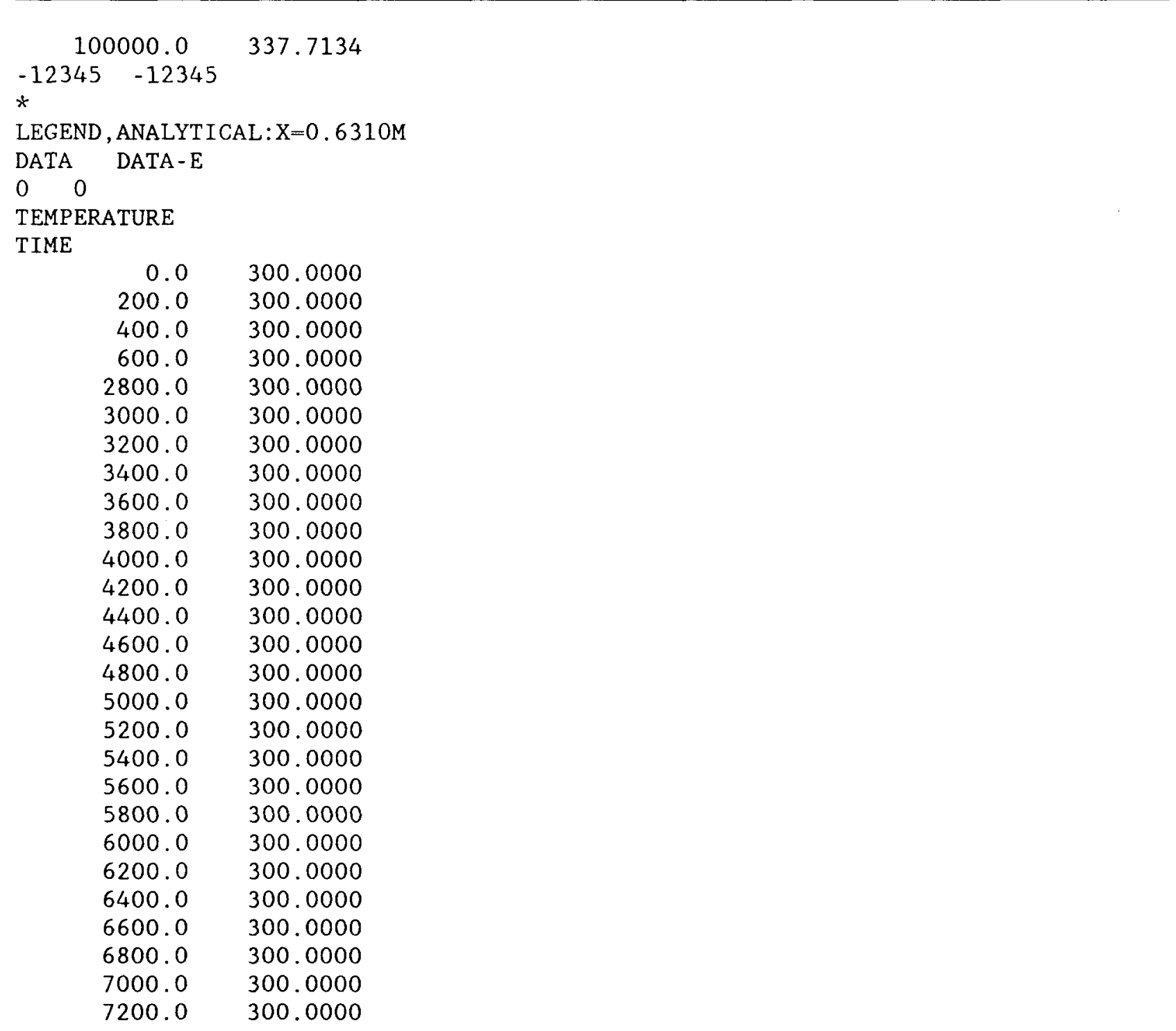




$\begin{array}{rr}7400.0 & 300.0000 \\ 7600.0 & 300.0000 \\ 7800.0 & 300.0000 \\ 8000.0 & 300.0000 \\ 8200.0 & 300.0000 \\ 8400.0 & 300.0001 \\ 8600.0 & 300.0001 \\ 8800.0 & 300.0001 \\ 9000.0 & 300.0001 \\ 9200.0 & 300.0002 \\ 9400.0 & 300.0002 \\ 9600.0 & 300.0003 \\ 9800.0 & 300.0003 \\ 10000.0 & 300.0004 \\ 10200.0 & 300.0005 \\ 10400.0 & 300.0006\end{array}$

Note: The data for this curve has been triuncated here. Data is available out to 100,000 seconds. For a more complete data set contact the editor of this report.

\begin{tabular}{|c|c|c|}
\hline \multicolumn{2}{|c|}{100000.0} & \multirow{2}{*}{315.3271} \\
\hline $\begin{array}{l}-12345 \\
*\end{array}$ & -12345 & \\
\hline \multicolumn{3}{|c|}{ LEGEND , ANALYTICAL: $\mathrm{X}=1.0 \mathrm{M}$} \\
\hline DATA & \multicolumn{2}{|l|}{ DATA - F } \\
\hline $0 \quad 0$ & \\
\hline \multirow{2}{*}{\multicolumn{3}{|c|}{ TEMPERATURE }} \\
\hline TIME & & \\
\hline & 0.0 & 300.0000 \\
\hline & 200.0 & 300.0000 \\
\hline & 400.0 & 300.0000 \\
\hline & 600.0 & 300.0000 \\
\hline & 800.0 & 300.0000 \\
\hline & 1000.0 & 300.0000 \\
\hline & 3200.0 & 300.0000 \\
\hline & 3400.0 & 300.0000 \\
\hline & 3600.0 & 300.0000 \\
\hline & 3800.0 & 300.0000 \\
\hline & 4000.0 & 300.0000 \\
\hline & +200.0 & 300.0000 \\
\hline & 400.0 & 300.0000 \\
\hline & +600.0 & 300.0000 \\
\hline & 4800.0 & 300.0000 \\
\hline & 5000.0 & 300.0000 \\
\hline & 200.0 & 300.0000 \\
\hline & 5400.0 & 300.0000 \\
\hline & 5600.0 & 300.0000 \\
\hline & 800.0 & 300.0000 \\
\hline & 5000.0 & 300.0000 \\
\hline & 200.0 & 300.0000 \\
\hline & 5400.0 & 300.0000 \\
\hline
\end{tabular}




$\begin{array}{ll}6600.0 & 300.0000 \\ 6800.0 & 300.0000 \\ 7000.0 & 300.0000 \\ 7200.0 & 300.0000 \\ 7400.0 & 300.0000 \\ 7600.0 & 300.0000 \\ 7800.0 & 300.0000 \\ 8000.0 & 300.0000 \\ 8200.0 & 300.0000 \\ 8400.0 & 300.0000 \\ 8600.0 & 300.0000 \\ 8800.0 & 300.0000 \\ 9000.0 & 300.0000 \\ 9200.0 & 300.0000 \\ 9400.0 & 300.0000 \\ 9600.0 & 300.0000\end{array}$

Note: The data for this curve has been truncated here. Data is available out to 100,000 seconds. For a more complete data set contact the editor of this report.

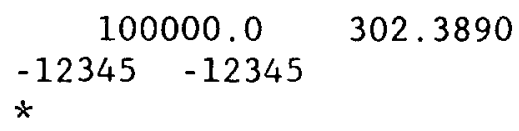

ST005: Saturated Liquid Depressurization Test

MELGEN Input

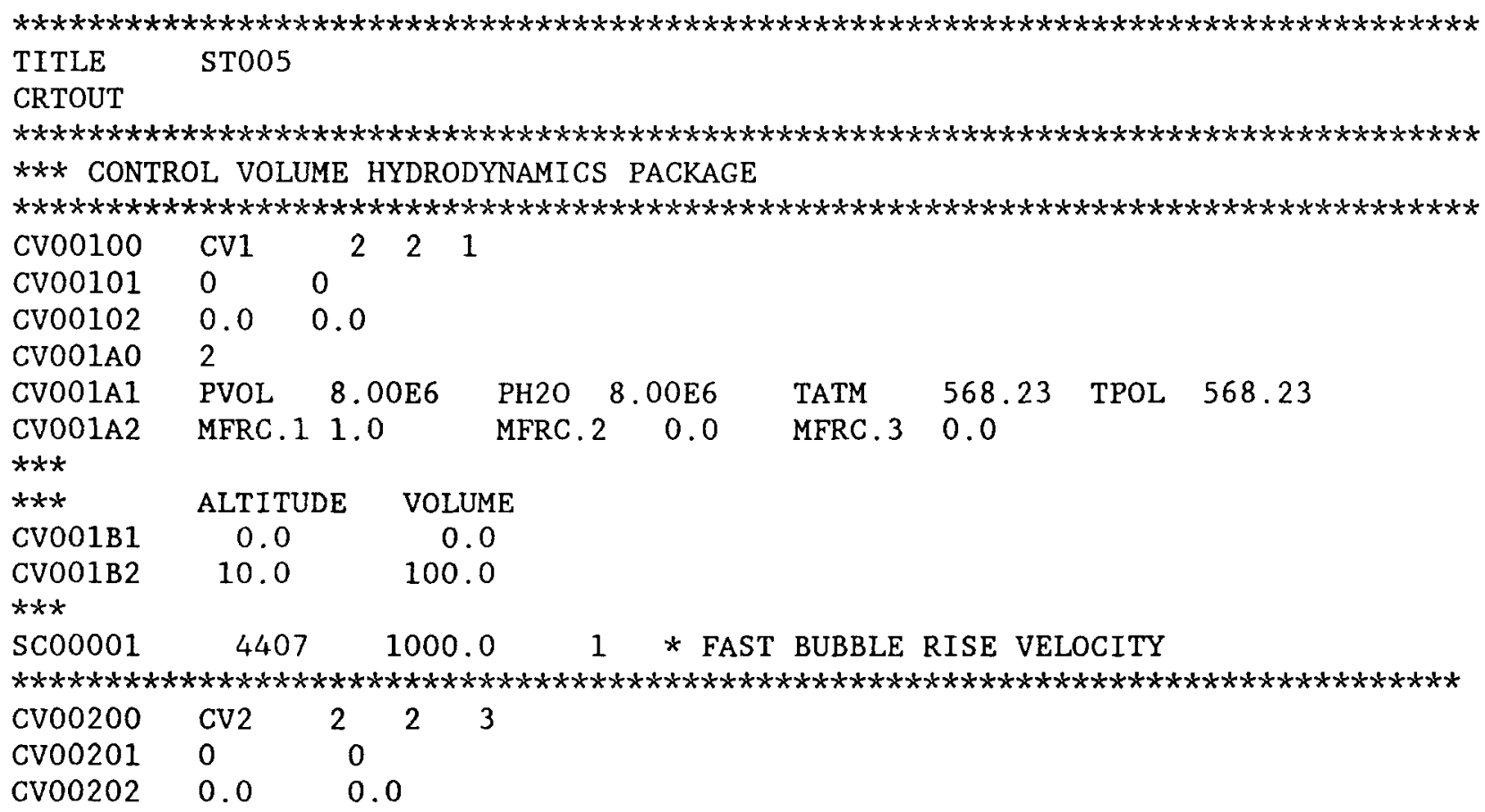




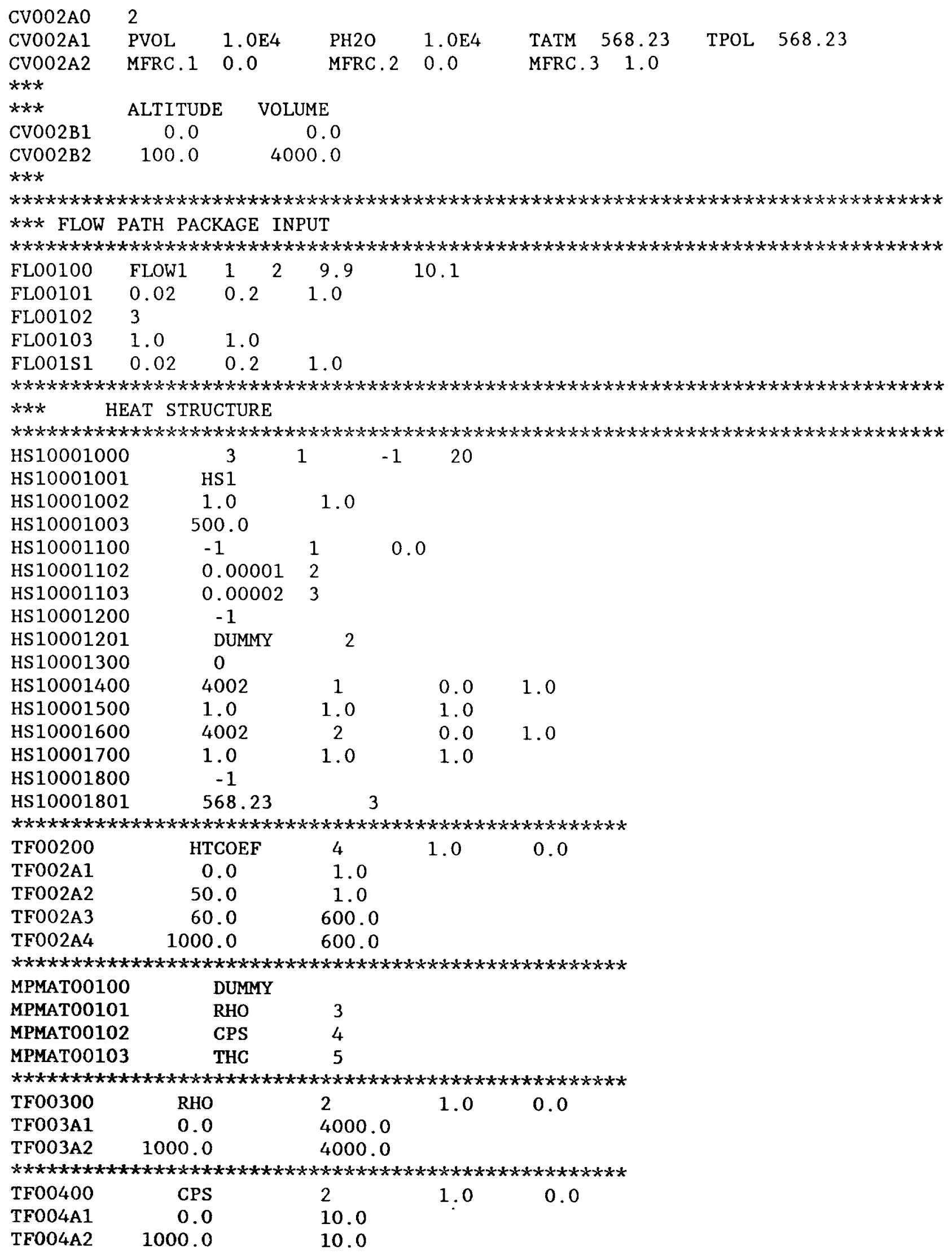




\begin{tabular}{|c|c|c|c|c|}
\hline TF00500 & THC & 2 & 1.0 & 0.0 \\
\hline TF005A1 & 0.0 & 50.0 & & \\
\hline TF005A2 & 1000.0 & 50.0 & & \\
\hline
\end{tabular}

ST005: Saturated Liquid Depressurization Test

MELCOR Input

\begin{tabular}{|c|c|c|c|c|c|c|}
\hline CPULEFT & 20.0 & & & & & \\
\hline CPULIM & 15000.0 & & & & & \\
\hline $\begin{array}{l}\text { CRTOUT } \\
\text { TEND }\end{array}$ & 3000.0 & & & & & \\
\hline RESTART & 0 & & & & & \\
\hline DTTIME & 0.01 & & & & & \\
\hline TIME1 & 0.0 & 0.01 & 0.005 & 1.0 & 0.01 & 1000.0 \\
\hline TIME2 & 1.0 & 0.1 & 0.05 & 5.0 & 0.1 & 1000.0 \\
\hline TIME3 & 10.0 & 1.0 & 0.1 & 500.0 & 2.0 & 1000.0 \\
\hline TIME4 & 1500.0 & 5.0 & 0.1 & 1000.0 & 5.0 & 1000.0 \\
\hline TITLE & ST005 & & & & & \\
\hline
\end{tabular}

ST005: Saturated Liquid Depressurization Test

MELPLT Input

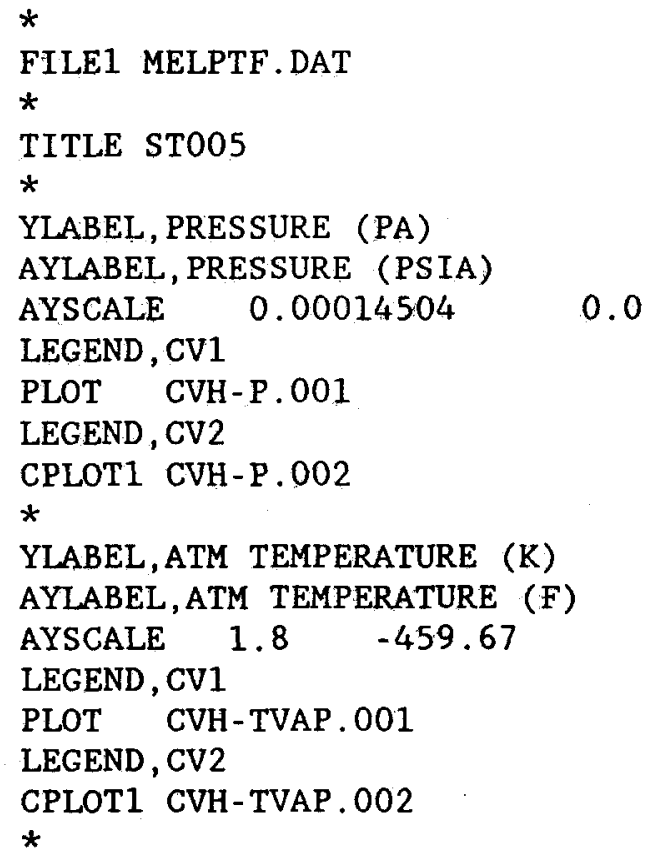




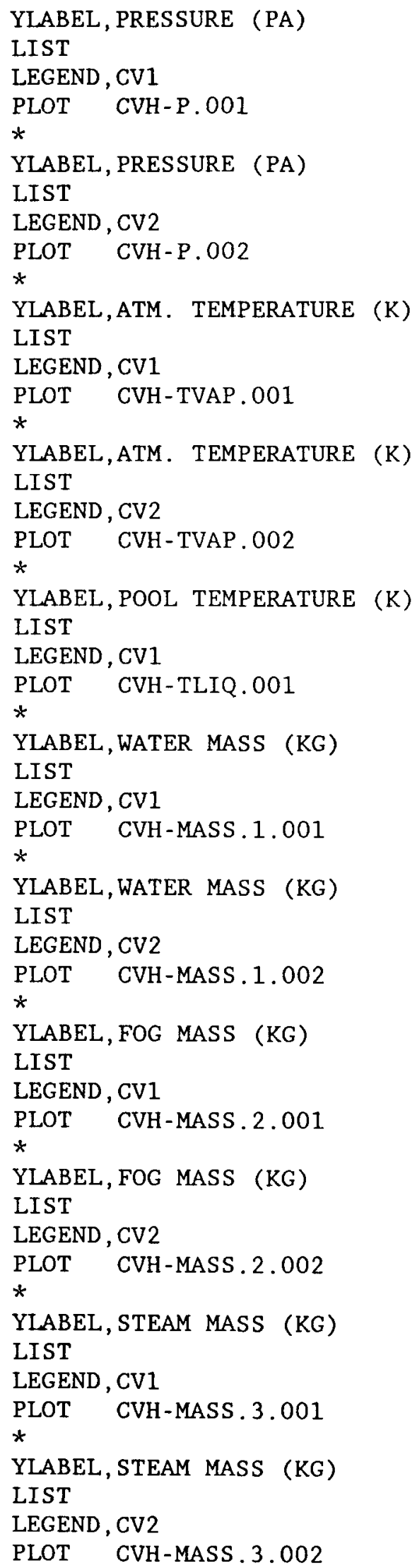




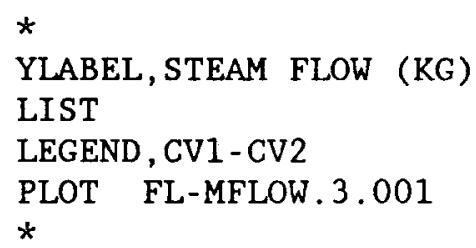

ST006: Browns Ferry Reactor Building Burns

MELGEN Input

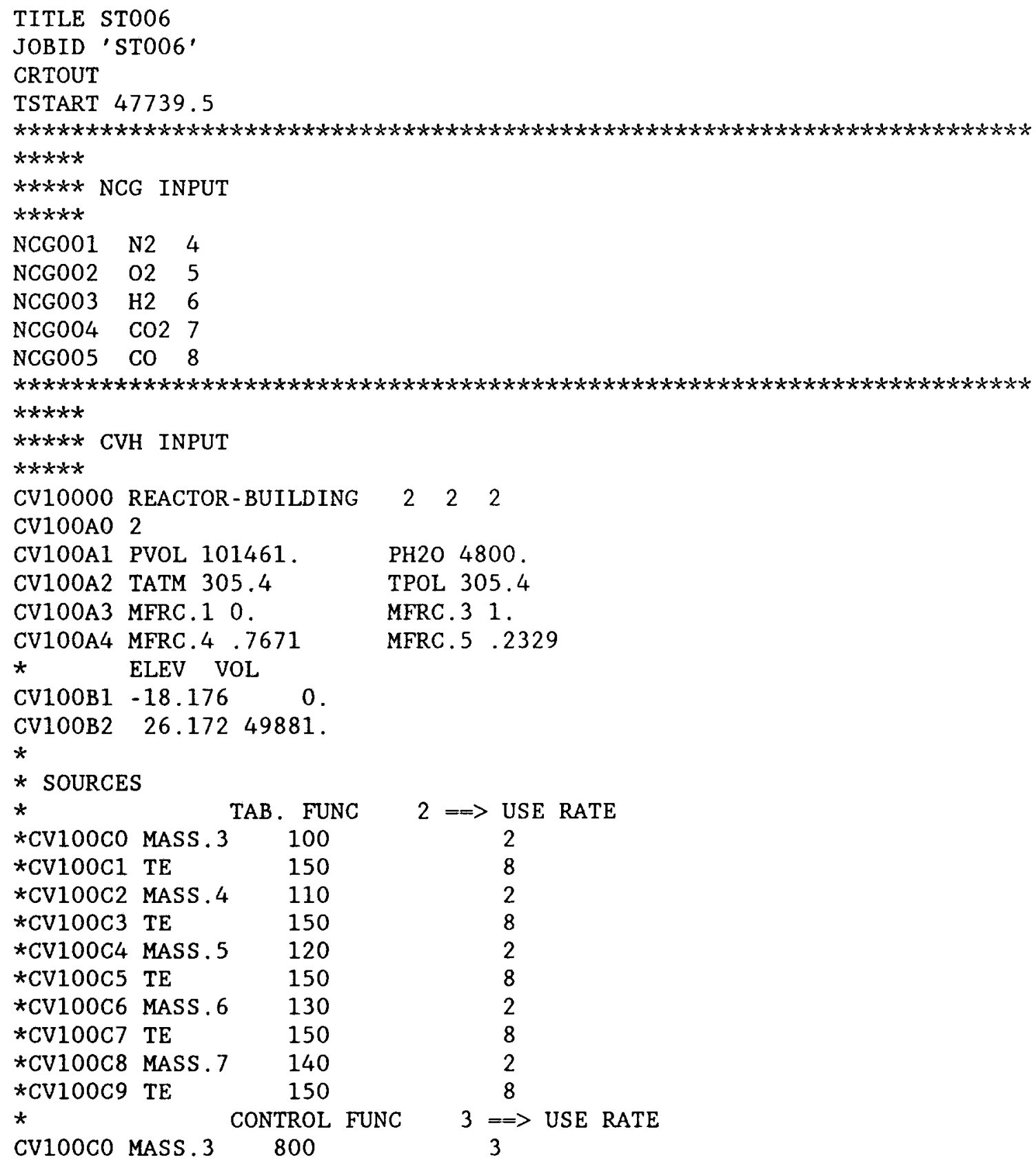




\begin{tabular}{|c|c|c|c|c|c|}
\hline CV100C1 & TE & 850 & & 9 & \\
\hline CV100C2 & MASS .4 & 810 & & 3 & \\
\hline CV100C3 & $\mathrm{TE}$ & 850 & & 9 & \\
\hline CV100C4 & MASS .5 & 820 & & 3 & \\
\hline CV100C5 & TE & 850 & & 9 & \\
\hline CV100C6 & MASS . 6 & 830 & & 3 & \\
\hline CV100C7 & TE & 850 & & 9 & \\
\hline CV100C8 & MASS .7 & 840 & & 3 & \\
\hline $\begin{array}{l}\text { CV100C9 } \\
\star\end{array}$ & $\mathrm{TE}$ & 850 & & 9 & \\
\hline CF 80000 & \multicolumn{2}{|c|}{ H2O-MASS - SRC } & TAB - FUN & 11. & 0. \\
\hline CF80003 & \multicolumn{2}{|c|}{100} & & & \\
\hline CF80010 & \multicolumn{2}{|c|}{ 1. 0. TIME } & & & \\
\hline * & \multicolumn{2}{|c|}{ NAME } & NUM PAIRS & MULT & ADD \\
\hline TF10000 & \multicolumn{2}{|c|}{ H2O-MASS-SRC } & 108 & 1. & 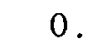 \\
\hline$*$ & \multicolumn{2}{|c|}{$\mathrm{X}$} & \multicolumn{2}{|c|}{$\mathrm{Y}$} & \\
\hline TF 10010 & \multicolumn{2}{|c|}{47402.00} & \multicolumn{2}{|c|}{$0.0000000 E+00$} & \\
\hline TF10011 & \multicolumn{2}{|c|}{47711.00} & \multicolumn{2}{|c|}{$0.0000000 \mathrm{E}+00$} & \\
\hline TF10012 & 477 & .00 & 54.75 & 000 & \\
\hline TF 10013 & 477 & .00 & 44.11 & 000 & \\
\hline TF 10014 & 478 & .00 & 43.34 & 000 & \\
\hline TF 10015 & 478 & .00 & 35.83 & 000 & \\
\hline TF10016 & 479 & .00 & $28.5 t$ & 000 & \\
\hline TF10017 & 479 & .00 & $23.2 \varepsilon$ & 000 & \\
\hline TF10018 & 480 & .00 & 19.23 & 000 & \\
\hline TF10019 & 481 & & 16.03 & 000 & \\
\hline TF10020 & 481 & .00 & 13.45 & 000 & \\
\hline TF10021 & 482 & .00 & $11.4 \varepsilon$ & 000 & \\
\hline TF10022 & 482 & & 9.920 & 000 & \\
\hline TF 10023 & 483 & .00 & 8.730 & 000 & \\
\hline TF10024 & 484 & .00 & 10.07 & 000 & \\
\hline TF10025 & 484 & & 12.75 & 000 & \\
\hline TF 10026 & 485 & .00 & 11.38 & 000 & \\
\hline TF 10027 & 485 & .00 & $11.8 \varepsilon$ & 000 & \\
\hline TF10028 & 486 & .00 & 13.55 & 000 & \\
\hline TF10029 & 487 & .00 & 11.79 & 000 & \\
\hline TF 10030 & 487 & & 13.98 & 000 & \\
\hline TF10031 & 488 & .00 & 16.22 & 000 & \\
\hline TF 10032 & 488 & .00 & 13.89 & 000 & \\
\hline TF 10033 & 489 & & 16.21 & 000 & \\
\hline TF10034 & 490 & & 15.25 & 000 & \\
\hline TF10035 & 490 & .00 & 15.49 & 000 & \\
\hline TF 10036 & 491 & .00 & 15.97 & 000 & \\
\hline TF10037 & 491 & .00 & 16.98 & 000 & \\
\hline TF10038 & 492 & .00 & 14.82 & 000 & \\
\hline TF10039 & 493 & .00 & 16.32 & 000 & \\
\hline $\mathrm{TF} 10040$ & 493 & .00 & 19.13 & 000 & \\
\hline TF10041 & 494 & .00 & 16.59 & 000 & \\
\hline TF10042 & 494 & .00 & 17.79 & 000 & \\
\hline TF10043 & 495 & .00 & 20.03 & 000 & \\
\hline TF10044 & 496 & .00 & 17.05 & 000 & \\
\hline TF10045 & 496 & .00 & 15.36 & 000 & \\
\hline TF10046 & 497 & .00 & 16.74 & 000 & \\
\hline TF10047 & 497 & .00 & 19.55 & 000 & \\
\hline
\end{tabular}




\begin{tabular}{|c|c|c|}
\hline TF10048 & 49852.00 & 16.94000 \\
\hline TF10049 & 49912.00 & 15.29000 \\
\hline TF10050 & 49972.00 & 17.53000 \\
\hline TF10051 & 50032.00 & 20.22000 \\
\hline TF10052 & 50092.00 & 17.49000 \\
\hline TF10053 & 50152.00 & 15.30000 \\
\hline TF10054 & 50212.00 & 16.67000 \\
\hline TF10055 & 50272.00 & 19.48000 \\
\hline TF10056 & 50332.00 & 16.87000 \\
\hline TF10057 & 50392.00 & 14.72000 \\
\hline TF10058 & 50452.00 & 16.19000 \\
\hline TF10059 & 50512.00 & 19.05000 \\
\hline TF10060 & 50572.00 & 16.52000 \\
\hline TF10061 & 50632.00 & 14.39000 \\
\hline TF10062 & 50692.00 & 15.91000 \\
\hline TF10063 & 50752.00 & 18.81000 \\
\hline TF10064 & 50812.00 & 16.31000 \\
\hline TF10065 & 50872.00 & 14.21000 \\
\hline TF10066 & 50932.00 & 15.64000 \\
\hline TF10067 & 50992.00 & 18.55000 \\
\hline TF10068 & 51052.00 & 16.02000 \\
\hline TF10069 & 51112.00 & 13.71000 \\
\hline TF10070 & 51172.00 & 15.53000 \\
\hline TF10071 & 51232.00 & 18.45000 \\
\hline TF10072 & 51292.00 & 16.01000 \\
\hline TF10073 & 51352.00 & 14.02000 \\
\hline TF10074 & 51412.00 & 15.44000 \\
\hline TF 10075 & 51472.00 & 18.54000 \\
\hline TF 10076 & 51532.00 & 16.06000 \\
\hline TF10077 & 51592.00 & 13.99000 \\
\hline TF10078 & 51652.00 & 15.41000 \\
\hline TF10079 & 51712.00 & 18.51000 \\
\hline TF10080 & 51772.00 & 16.03000 \\
\hline TF10081 & 51832.00 & 13.96000 \\
\hline TF10082 & 51892.00 & 15.29000 \\
\hline TF10083 & 51952.00 & 18.48000 \\
\hline TF10084 & 52012.00 & 16.02000 \\
\hline TF10085 & 52072.00 & 13.94000 \\
\hline TF10086 & 52132.00 & 15.32000 \\
\hline $\mathrm{TF} 10087$ & 52192.00 & 18.45000 \\
\hline TF10088 & 52252.00 & 16.03000 \\
\hline TF10089 & 52312.00 & 13.98000 \\
\hline TF10090 & 52372.00 & 15.57000 \\
\hline TF10091 & 52432.00 & 18.53000 \\
\hline TF10092 & 52492.00 & 10.65000 \\
\hline TF10093 & 52552.00 & 9.210000 \\
\hline TF10094 & 52612.00 & 8.390000 \\
\hline TF10095 & 52672.00 & 8.590000 \\
\hline TF10096 & 52732.00 & 10.22000 \\
\hline TF10097 & 52792.00 & 12.84000 \\
\hline TF10098 & 52852.00 & 10.23000 \\
\hline TF10099 & 52912.00 & 10.70000 \\
\hline TF100A0 & 52972.00 & 9.590000 \\
\hline TF100A1 & 53032.00 & 8.990000 \\
\hline
\end{tabular}




\begin{tabular}{|c|c|c|}
\hline TF100A2 & 53092.00 & 7.560000 \\
\hline TF100A3 & 53152.00 & 9.860000 \\
\hline TF100A4 & 53212.00 & 12.59000 \\
\hline TF100A5 & 53272.00 & 10.99000 \\
\hline TF100A6 & 53332.00 & 10.45000 \\
\hline TF100A7 & 53392.00 & 9.360000 \\
\hline TF100A8 & 53452.00 & 8.820000 \\
\hline TF100A9 & 53512.00 & 7.310000 \\
\hline TF100B0 & 53572.00 & 9.680000 \\
\hline TF100B1 & 53632.00 & 12.50000 \\
\hline TF100B2 & 53692.00 & 11.20000 \\
\hline TF100B3 & 53752.00 & 10.32000 \\
\hline TF100B 4 & 53812.00 & 9.120000 \\
\hline TF100B5 & 53872.00 & 8.690000 \\
\hline TF100B6 & 53932.00 & 8.020000 \\
\hline $\begin{array}{l}\text { TF100B } 7 \\
*\end{array}$ & 53992.00 & 9.610000 \\
\hline CF81000 & $\mathrm{N} 2$ - MASS - SRC & TAB-FUN 11 . \\
\hline CF81003 & & \\
\hline $\begin{array}{l}\text { CF81010 } \\
*\end{array}$ & 0. TIME & \\
\hline $\begin{array}{l}\text { TF11000 } \\
*\end{array}$ & $\begin{array}{c}\text { N2 - MASS - SRC } \\
\mathrm{X}\end{array}$ & 1. $\mathrm{Y}_{\mathrm{Y}}^{0}$. \\
\hline TF11010 & 47402.00 & $0.0000000 \mathrm{E}+00$ \\
\hline TF11011 & 47685.00 & $0.0000000 \mathrm{E}+00$ \\
\hline TF11012 & 47711.00 & 1.760000 \\
\hline TF11013 & 47749.00 & 11.88000 \\
\hline TF 11014 & 47752.00 & 11.23000 \\
\hline TF11015 & 47812.00 & 9.820000 \\
\hline TF11016 & 47872.00 & 9.800000 \\
\hline TF11017 & 47932.00 & 9.820000 \\
\hline TF11018 & 47992.00 & 9.500000 \\
\hline TF11019 & 48052.00 & 8.960000 \\
\hline TF11020 & 48112.00 & 8.340000 \\
\hline TF11021 & 48172.00 & 7.700000 \\
\hline TF11022 & 48232.00 & 7.050000 \\
\hline TF11023 & 48292.00 & 6.390000 \\
\hline TF11024 & 48352.00 & 5.740000 \\
\hline TF 11025 & 48412.00 & 5.900000 \\
\hline TF11026 & 48472.00 & 5.710000 \\
\hline TF11027 & 48532.00 & 4.580000 \\
\hline TF11028 & 48592.00 & 3.870000 \\
\hline TF11029 & 48652.00 & 3.370000 \\
\hline TF11030 & 48712.00 & 2.700000 \\
\hline TF11031 & 48772.00 & 2.290000 \\
\hline TF11032 & 48832.00 & 2.010000 \\
\hline TF11033 & 48892.00 & 1.590000 \\
\hline TF11034 & 48952.00 & 1.300000 \\
\hline TF11035 & 49012.00 & 1.110000 \\
\hline TF11036 & 49072.00 & 0.8800000 \\
\hline TF11037 & 49132.00 & 0.7100000 \\
\hline TF11038 & 49192.00 & 0.5900000 \\
\hline TF11039 & 49252.00 & 0.4600000 \\
\hline TF11040 & 49312.00 & 0.3700000 \\
\hline
\end{tabular}




\begin{tabular}{|c|c|c|}
\hline TF11041 & 49372.00 & 0.3200000 \\
\hline TF11042 & 49432.00 & 0.2500000 \\
\hline TF11043 & 49492.00 & 0.2000000 \\
\hline TF11044 & 49552.00 & 0.1700000 \\
\hline TF11045 & 49612.00 & 0.1300000 \\
\hline TF11046 & 49672.00 & 0.1000000 \\
\hline TF11047 & 49732.00 & $7.9999998 \mathrm{E}-02$ \\
\hline TF11048 & 49792.00 & $7.0000000 \mathrm{E}-02$ \\
\hline TF11049 & 49852.00 & $5.0000001 E-02$ \\
\hline TF11050 & 49912.00 & $3.9999999 E-02$ \\
\hline TF11051 & 49972.00 & $2.9999999 E-02$ \\
\hline TF11052 & 50032.00 & $2.9999999 E-02$ \\
\hline TF11053 & 50092.00 & $2.0000000 \mathrm{E}-02$ \\
\hline TF11054 & 50152.00 & $2.0000000 \mathrm{E}-02$ \\
\hline TF11055 & 50212.00 & $9.9999998 E-03$ \\
\hline TF11056 & 50272.00 & $9.9999998 \mathrm{E}-03$ \\
\hline TF11057 & 50332.00 & $9.9999998 \mathrm{E}-03$ \\
\hline TF11058 & 50392.00 & $9.9999998 \mathrm{E}-03$ \\
\hline TF11059 & 50452.00 & $9.9999998 E-03$ \\
\hline TF11060 & 50512.00 & $0.0000000 E+00$ \\
\hline TF11061 & 53992.00 & $0.0000000 \mathrm{E}+00$ \\
\hline CF82000 & O2 -MASS - SRC & TAB-FUN 11 . \\
\hline CF82003 & 120 & \\
\hline $\begin{array}{l}\text { CF82010 } \\
*\end{array}$ & $0 . \quad$ TIME & \\
\hline $\begin{array}{l}\text { TF12000 } \\
*\end{array}$ & $\begin{array}{c}\text { O2-MASS-SRC } \\
\mathrm{X}\end{array}$ & 1. ${ }_{\mathrm{Y}}^{0}$ \\
\hline TF12010 & 47402.00 & $0.0000000 \mathrm{E}+00$ \\
\hline $\mathrm{TF} 12011$ & 47685.00 & $0.0000000 \mathrm{E}+00$ \\
\hline $\mathrm{TF} 12012$ & 47711.00 & $7.0000000 E-02$ \\
\hline TF12013 & 47749.00 & 0.4900000 \\
\hline TF12014 & 47752.00 & 0.4700000 \\
\hline TF12015 & 47812.00 & 0.4100000 \\
\hline TF 12016 & 47872.00 & 0.4100000 \\
\hline TF12017 & 47932.00 & 0.4100000 \\
\hline TF12018 & 47992.00 & 0.3900000 \\
\hline TF12019 & 48052.00 & 0.3700000 \\
\hline TF12020 & 48112.00 & 0.3500000 \\
\hline TF12021 & 48172.00 & 0.3200000 \\
\hline TF 12022 & 48232.00 & 0.2900000 \\
\hline TF12023 & 48292.00 & 0.2600000 \\
\hline TF12024 & 48352.00 & 0.2400000 \\
\hline TF12025 & 48412.00 & 0.2400000 \\
\hline TF12026 & 48472.00 & 0.2400000 \\
\hline TF12027 & 48532.00 & 0.1900000 \\
\hline TF12028 & 48592.00 & 0.1600000 \\
\hline TF12029 & 48652.00 & 0.1400000 \\
\hline TF12030 & 48712.00 & 0.1100000 \\
\hline TF12031 & 48772.00 & $9.0000004 \mathrm{E}-02$ \\
\hline $\mathrm{TF} 12032$ & 48832.00 & $7.9999998 E-02$ \\
\hline TF12033 & 48892.00 & $7.0000000 E-02$ \\
\hline TF12034 & 48952.00 & $5.0000001 E-02$ \\
\hline TF12035 & 49012.00 & $5.0000001 \mathrm{E}-02$ \\
\hline
\end{tabular}




\begin{tabular}{|c|c|c|}
\hline TF12036 & 49072.00 & $3.9999999 \mathrm{E}-02$ \\
\hline TF12037 & 49132.00 & $2.9999999 \mathrm{E}-02$ \\
\hline TF12038 & 49192.00 & $2.0000000 \mathrm{E}-02$ \\
\hline TF12039 & 49252.00 & $2.0000000 \mathrm{E}-02$ \\
\hline TF12040 & 49312.00 & $2.0000000 \mathrm{E}-02$ \\
\hline $\mathrm{TF} 12041$ & 49372.00 & $9.9999998 \mathrm{E}-03$ \\
\hline TF12042 & 49612.00 & $9.9999998 \mathrm{E}-03$ \\
\hline TF12043 & 49672.00 & $0.0000000 \mathrm{E}+00$ \\
\hline $\begin{array}{l}\text { TF12044 } \\
*\end{array}$ & 53992.00 & $0.0000000 \mathrm{E}+00$ \\
\hline CF83000 & SS - SRC & TAB - FUN \\
\hline CF83003 & 130 & \\
\hline $\begin{array}{l}\text { CF83010 } \\
*\end{array}$ & 1. 0. TIME & \\
\hline $\begin{array}{l}\text { TF13000 } \\
*\end{array}$ & $\begin{array}{c}\mathrm{H} 2 \text { - MASS - SRC } \\
\mathrm{X}\end{array}$ & $\begin{array}{ll}\text { 1. } & 0 . \\
\mathrm{Y}\end{array}$ \\
\hline TF13010 & 47402.00 & $0.0000000 \mathrm{E}+00$ \\
\hline TF13011 & 47685.00 & $0.0000000 \mathrm{E}+00$ \\
\hline TF13012 & 47711.00 & 0.2000000 \\
\hline TF13013 & 47749.00 & 1.370000 \\
\hline TF13014 & 47752.00 & 1.300000 \\
\hline TF13015 & 47812.00 & 1.150000 \\
\hline TF13016 & 47872.00 & 1.160000 \\
\hline TF 13017 & 47932.00 & 1.180000 \\
\hline TF13018 & 47992.00 & 1.150000 \\
\hline TF13019 & 48052.00 & 1.090000 \\
\hline TF13020 & 48112.00 & 1.020000 \\
\hline TF13021 & 48172.00 & 0.9500000 \\
\hline TF 13022 & 48232.00 & 0.8700000 \\
\hline TF 13023 & 48292.00 & 0.8000000 \\
\hline TF 13024 & 48352.00 & 0.7200000 \\
\hline TF13025 & 48412.00 & 0.7400000 \\
\hline TF13026 & 48472.00 & 0.7200000 \\
\hline TF13027 & 48532.00 & 0.5800000 \\
\hline TF13028 & 48592.00 & 0.4900000 \\
\hline TF13029 & 48652.00 & 0.4300000 \\
\hline TF13030 & 48712.00 & 0.3500000 \\
\hline TF13031 & 48772.00 & 0.3000000 \\
\hline TF13032 & 48832.00 & 0.2600000 \\
\hline TF13033 & 48892.00 & 0.2100000 \\
\hline TF13034 & 48952.00 & 0.1800000 \\
\hline TF13035 & 49012.00 & 0.1600000 \\
\hline TF13036 & 49072.00 & 0.1300000 \\
\hline TF13037 & 49132.00 & 0.1100000 \\
\hline TF13038 & 49192.00 & $9.0000004 \mathrm{E}-02$ \\
\hline TF13039 & 49252.00 & $7.9999998 \mathrm{E}-02$ \\
\hline TF13040 & 49312.00 & $7.0000000 \mathrm{E}-02$ \\
\hline TF13041 & 49372.00 & $5.9999999 E-02$ \\
\hline TF13042 & 49432.00 & $5.0000001 E-02$ \\
\hline TF13043 & 49492.00 & $3.9999999 \mathrm{E}-02$ \\
\hline TF13044 & 49612.00 & $3.9999999 \mathrm{E}-02$ \\
\hline TF13045 & 49672.00 & $2.9999999 E-02$ \\
\hline TF13046 & 49912.00 & $2.9999999 \mathrm{E}-02$ \\
\hline TF13047 & 49972.00 & $2.0000000 E-02$ \\
\hline
\end{tabular}




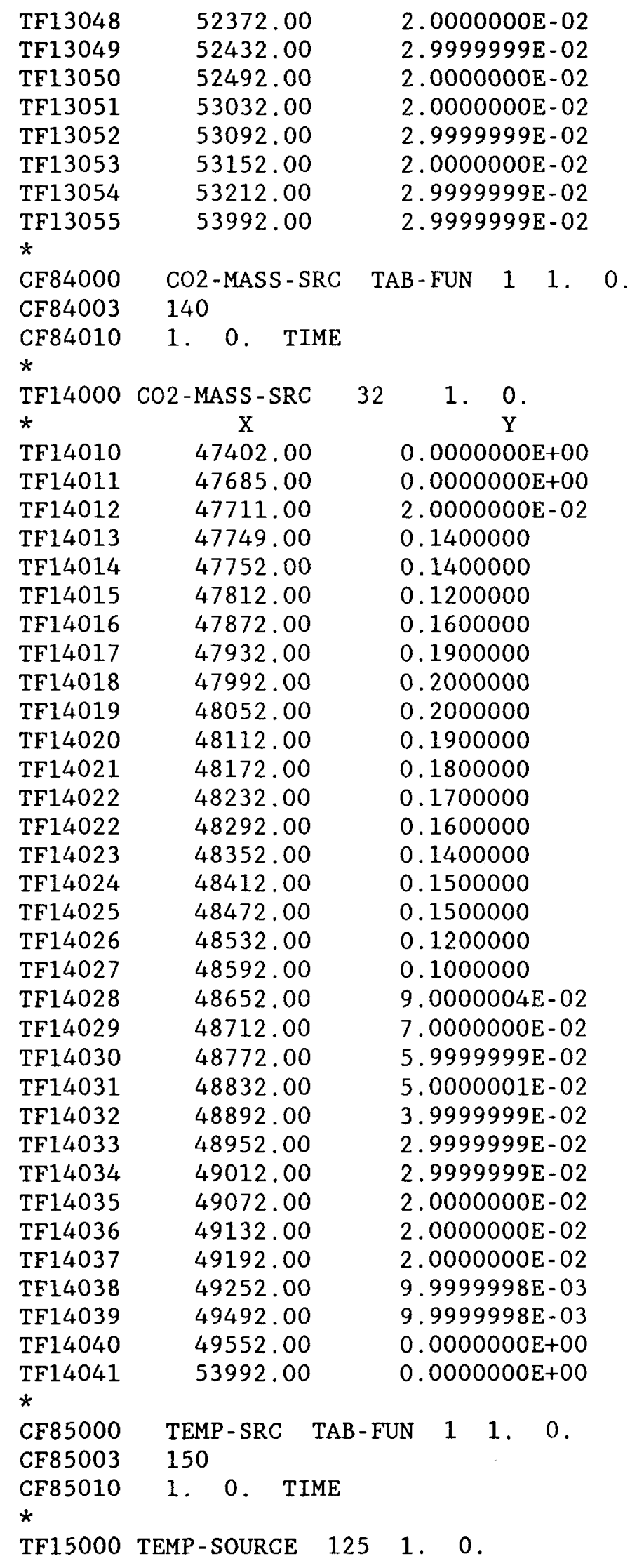




\begin{tabular}{|c|c|c|}
\hline * & $\mathrm{X}$ & $\mathrm{Y}$ \\
\hline TF15010 & 47402.00 & 428.9000 \\
\hline TF15011 & 47479.00 & 428.9000 \\
\hline TF15012 & 47485.00 & 428.8000 \\
\hline TF15013 & 47563.00 & 428.8000 \\
\hline TF15014 & 47569.00 & 428.7000 \\
\hline TF15015 & 47599.00 & 428.7000 \\
\hline TF15016 & 47605.00 & 429.1000 \\
\hline TF15017 & 47611.00 & 429.1000 \\
\hline TF15018 & 47617.00 & 428.8000 \\
\hline TF15019 & 47623.00 & 428.7000 \\
\hline $\mathrm{TF} 15020$ & 47653.00 & 428.7000 \\
\hline TF 15021 & 47659.00 & 437.3000 \\
\hline TF15022 & 47660.00 & 437.5000 \\
\hline TF15023 & 47661.00 & 439.0000 \\
\hline TF15024 & 47663.00 & 439.7000 \\
\hline TF15025 & 47667.00 & 441.3000 \\
\hline TF15026 & 47673.00 & 442.2000 \\
\hline TF15027 & 47685.00 & 443.8000 \\
\hline TF15028 & 47711.00 & 444.6000 \\
\hline TF15029 & 47749.00 & 530.4000 \\
\hline TF 15030 & 47752.00 & 533.1000 \\
\hline TF15031 & 47812.00 & 705.3000 \\
\hline TF15032 & 47872.00 & 833.0000 \\
\hline TF15033 & 47932.00 & 723.5000 \\
\hline TF15034 & 47992.00 & 698.2000 \\
\hline TF15035 & 48052.00 & 696.0000 \\
\hline TF15036 & 48112.00 & 697.0000 \\
\hline TF15037 & 48172.00 & 694.5000 \\
\hline TF15038 & 48232.00 & 672.7000 \\
\hline TF15039 & 48292.00 & 652.5000 \\
\hline TF 15040 & 48352.00 & 649.8000 \\
\hline TF15041 & 48412.00 & 648.7000 \\
\hline TF15042 & 48472.00 & 622.5000 \\
\hline TF15043 & 48532.00 & 639.4000 \\
\hline TF15044 & 48592.00 & 636.9000 \\
\hline TF15045 & 48652.00 & 620.6000 \\
\hline TF15046 & 48712.00 & 628.5000 \\
\hline TF15047 & 48772.00 & 631.5000 \\
\hline TF15048 & 48832.00 & 609.7000 \\
\hline TF15049 & 48892.00 & 619.9000 \\
\hline TF15050 & 48952.00 & 625.7000 \\
\hline TF15051 & 49012.00 & 603.2000 \\
\hline TF15052 & 49072.00 & 614.1000 \\
\hline TF15053 & 49132.00 & 619.8000 \\
\hline TF15054 & 49192.00 & 603.7000 \\
\hline TF15055 & 49252.00 & 619.9000 \\
\hline TF15056 & 49312.00 & 622.4000 \\
\hline TF15057 & 49372.00 & 593.7000 \\
\hline TF15058 & 49432.00 & 614.0000 \\
\hline TF15059 & 49492.00 & 616.5000 \\
\hline TF15060 & 49552.00 & 595.5000 \\
\hline $\mathrm{TF} 15061$ & 49612.00 & 605.1000 \\
\hline TF15062 & 49672.00 & 611.3000 \\
\hline
\end{tabular}




\begin{tabular}{|c|c|c|}
\hline TF15063 & 49732.00 & 619.1000 \\
\hline TF15064 & 49792.00 & 590.3000 \\
\hline TF15065 & 49852.00 & 609.6000 \\
\hline TF15066 & 49912.00 & 612.9000 \\
\hline TF15067 & 49972.00 & 610.3000 \\
\hline TF15068 & 50032.00 & 591.2000 \\
\hline TF15069 & 50092.00 & 606.7000 \\
\hline TF15070 & 50152.00 & 610.2000 \\
\hline TF15071 & 50212.00 & 614.9000 \\
\hline TF15072 & 50272.00 & 588.1000 \\
\hline TF15073 & 50332.00 & 607.6000 \\
\hline TF 15074 & 50392.00 & 611.2000 \\
\hline TF15075 & 50452.00 & 615.5000 \\
\hline TF15076 & 50512.00 & 586.8000 \\
\hline TF15077 & 50572.00 & 608.2000 \\
\hline TF15078 & 50632.00 & 611.8000 \\
\hline TF15079 & 50692.00 & 615.9000 \\
\hline TF15080 & 50752.00 & 586.1000 \\
\hline TF15081 & 50812.00 & 608.6000 \\
\hline TF15082 & 50872.00 & 612.2000 \\
\hline TF15083 & 50932.00 & 616.2000 \\
\hline TF15084 & 50992.00 & 594.9000 \\
\hline TF15085 & 51052.00 & 605.0000 \\
\hline TF15086 & 51112.00 & 610.2000 \\
\hline TF15087 & 51172.00 & 615.6000 \\
\hline TF15088 & 51232.00 & 595.4000 \\
\hline TF15089 & 51292.00 & 605.4000 \\
\hline TF15090 & 51352.00 & 610.3000 \\
\hline TF15091 & 51412.00 & 615.7000 \\
\hline TF15092 & 51472.00 & 595.7000 \\
\hline TF15093 & 51532.00 & 610.6000 \\
\hline TF15094 & 51592.00 & 611.8000 \\
\hline TF15095 & 51652.00 & 617.0000 \\
\hline TF15096 & 51712.00 & 595.7000 \\
\hline TF15097 & 51772.00 & 611.0000 \\
\hline TF15098 & 51832.00 & 612.4000 \\
\hline TF15099 & 51892.00 & 617.4000 \\
\hline TF150A0 & 51952.00 & 596.6000 \\
\hline TF150A1 & 52012.00 & 611.6000 \\
\hline TF150A2 & 52072.00 & 612.9000 \\
\hline TF150A3 & 52132.00 & 608.5000 \\
\hline TF150A4 & 52192.00 & 594.3000 \\
\hline TF150A5 & 52252.00 & 620.5000 \\
\hline TF150A6 & 52312.00 & 628.1000 \\
\hline TF150A7 & 52372.00 & 639.2000 \\
\hline TF150A8 & 52432.00 & 611.1000 \\
\hline TF150A9 & 52492.00 & 648.5000 \\
\hline TF150B0 & 52552.00 & 665.3000 \\
\hline TF150B1 & 52612.00 & 669.5000 \\
\hline TF150B2 & 52672.00 & 676.5000 \\
\hline TF150B3 & 52732.00 & 682.7000 \\
\hline TF150B4 & 52792.00 & 643.9000 \\
\hline TF150B5 & 52852.00 & 682.9000 \\
\hline TF150B6 & 52912.00 & 684.0000 \\
\hline
\end{tabular}




\begin{tabular}{|c|c|c|}
\hline TF150B 7 & 52972.00 & 685.3000 \\
\hline TF150B8 & 53032.00 & 685.6000 \\
\hline TF150B9 & 53092.00 & 692.6000 \\
\hline TF150C0 & 53152.00 & 699.7000 \\
\hline TF150C1 & 53212.00 & 671.1000 \\
\hline TF $150 \mathrm{C} 2$ & 53272.00 & 696.1000 \\
\hline TF150C3 & 53332.00 & 694.6000 \\
\hline TF150C4 & 53392.00 & 697.5000 \\
\hline TF150C5 & 53452.00 & 701.4000 \\
\hline TF150C6 & 53512.00 & 705.8000 \\
\hline TF150C7 & 53572.00 & 712.3000 \\
\hline TF150C8 & 53632.00 & 684.9000 \\
\hline TF150C 9 & 53692.00 & 708.1000 \\
\hline TF150D0 & 53752.00 & 704.3000 \\
\hline TF150D1 & 53812.00 & 708.3000 \\
\hline TF150D2 & 53872.00 & 712.6000 \\
\hline TF150D3 & 53932.00 & 718.9000 \\
\hline $\begin{array}{l}\text { TF150D4 } \\
*\end{array}$ & 53992.00 & 726.0000 \\
\hline \multicolumn{3}{|l|}{ * } \\
\hline CV20000 & REFUELING - BAY & 22 \\
\hline CV200A0 & 2 & \\
\hline CV200A1 & PVOL 100967 & PH2O 3480 . \\
\hline CV200A2 & TATM 299.8 & TPOL 299.8 \\
\hline CV200A3 & MFRC. 10. & MFRC. 31 \\
\hline CV200A4 & MFRC.4 .7671 & MFRC. $5 \quad .2329$ \\
\hline * & ELEV VOL & \\
\hline CV200B1 & 26.401 & \\
\hline $\begin{array}{l}\text { CV200B2 } \\
*\end{array}$ & 41.86974175 & \\
\hline CV 30000 & TURBINE-BUILDING & $\begin{array}{lll}2 & 2 & 2\end{array}$ \\
\hline CV300A0 & 2 & \\
\hline CV300A1 & PVOL 101130. & PH2O 3480 . \\
\hline CV300A2 & TATM 299.8 & TPOL 299.8 \\
\hline CV300A3 & MFRC. 10. & MFRC. 31. \\
\hline CV300A4 & MFRC.4 .7671 & MFRC.5 .2329 \\
\hline * & ELEV VOL & \\
\hline CV300B1 & 11.6943 & \\
\hline $\begin{array}{l}\text { CV300B2 } \\
*\end{array}$ & $31.354 \quad 158303$. & \\
\hline CV40000 & ENVIRONMENT & 22 \\
\hline CV400A0 & & \\
\hline CV400A1 & PVOL 101484. & PH2O 3480 . \\
\hline CV400A2 & TATM 299.8 & TPOL 299.8 \\
\hline CV400A3 & MFRC. 10. & MFRC. 31 . \\
\hline CV400A4 & MFRC.4 .7671 & MFRC. $5 \quad .2329$ \\
\hline * & ELEV VOL & \\
\hline CV400B1 & -20 & \\
\hline CV400B2 & 1. E10 & \\
\hline
\end{tabular}




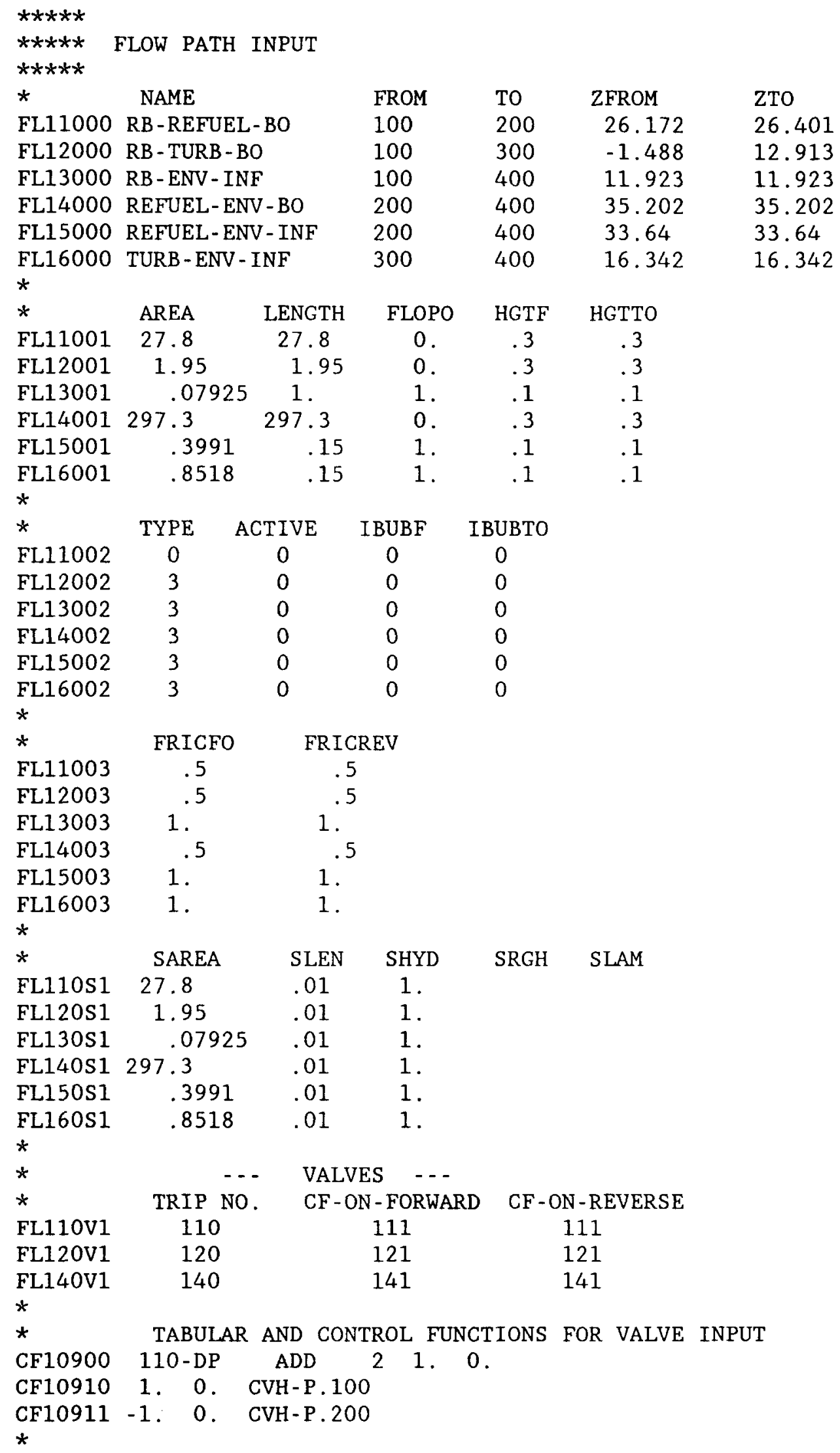

FL12003

FL1 3003

FL14003

FL15003

FL16003

*

$*$

FL110S1

FRICFO

FR ICREV

.5

.5

1.

.5

1.

1 .

.5

.5

1.

.5

1.

1.

SAREA SLEN SHYD SRGH SLAM

$27.8 \quad .01 \quad 1$.

FL120S1 $1.95 \quad .01 \quad 1$.

FL130S1 $\quad .07925 \quad .01 \quad 1$.

FL140S1 297.3 .01 1.

$\begin{array}{llll}\text { FL150S1 } & .3991 & .01 & 1 .\end{array}$

$\begin{array}{llll}\text { FL160S1 } & .8518 \quad .01 & 1 .\end{array}$

*

$*$

FL110V1

TRIP NO.

VALVES - - -

110

120

CF - ON - FORWARD

CF - ON-REVERSE

$\begin{array}{ll}111 & 111 \\ 121 & 121 \\ 141 & 141\end{array}$

$\begin{array}{llll}\text { FL140V1 } & 140 & 141 & 141\end{array}$

*

TABULAR AND CONTROL FUNCTIONS FOR VALVE INPUT

CF10900 110-DP ADD 21.0.

CF10910 1. 0. CVH-P.100

CF10911 -1. 0. CVH-P. 200

$*$ 


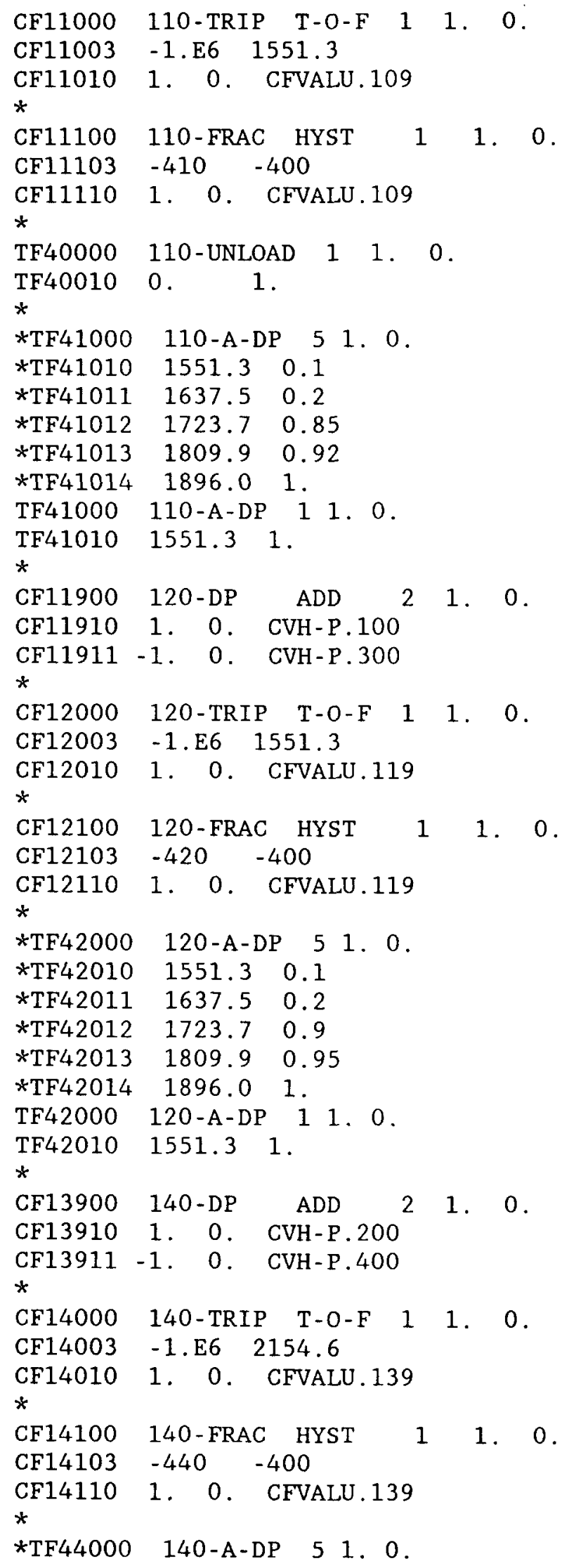




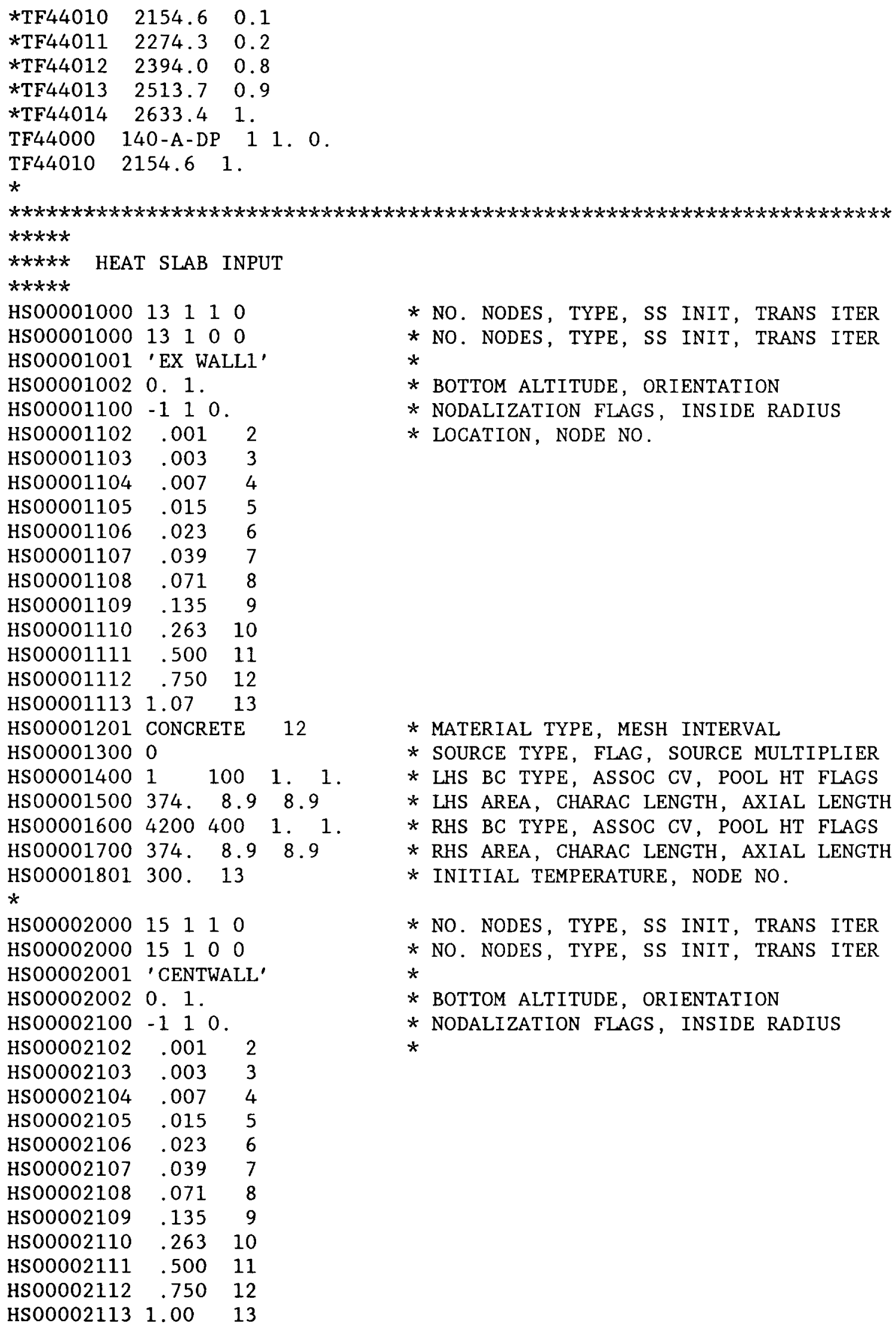

* NO. NODES, TYPE, SS INIT, TRANS ITER

* NO. NODES, TYPE, SS INIT, TRANS ITER

* BOTTOM ALTITUDE, ORIENTATION

* NODALIZATION FLAGS, INSIDE RADIUS

* LOCATION, NODE NO.

* NO. NODES, TYPE, SS INIT, TRANS ITER

* NO. NODES, TYPE, SS INIT, TRANS ITER

$*$

* BOTTOM ALTITUDE, ORIENTATION

* NODALIZATION FLAGS, INSIDE RADIUS 


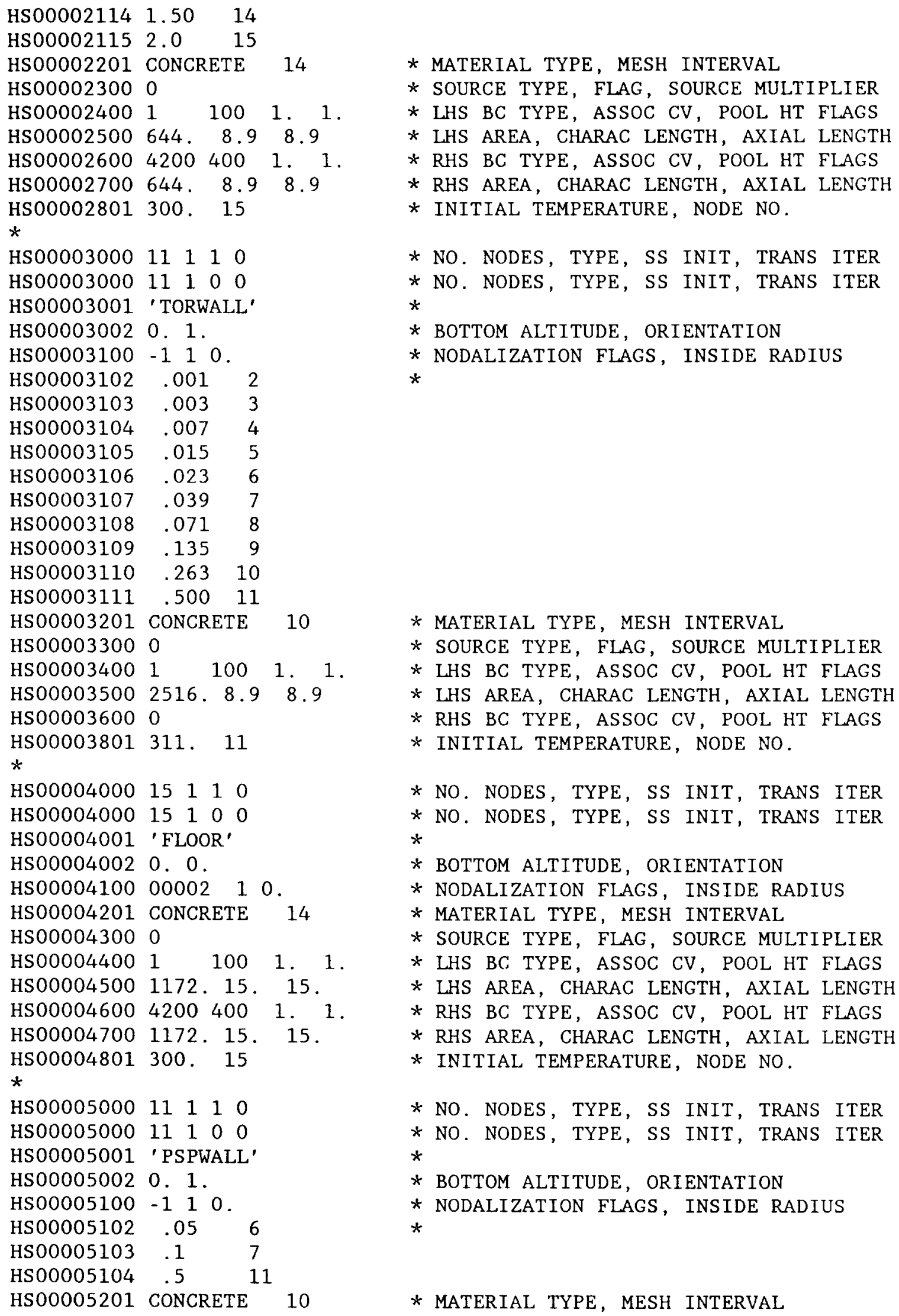




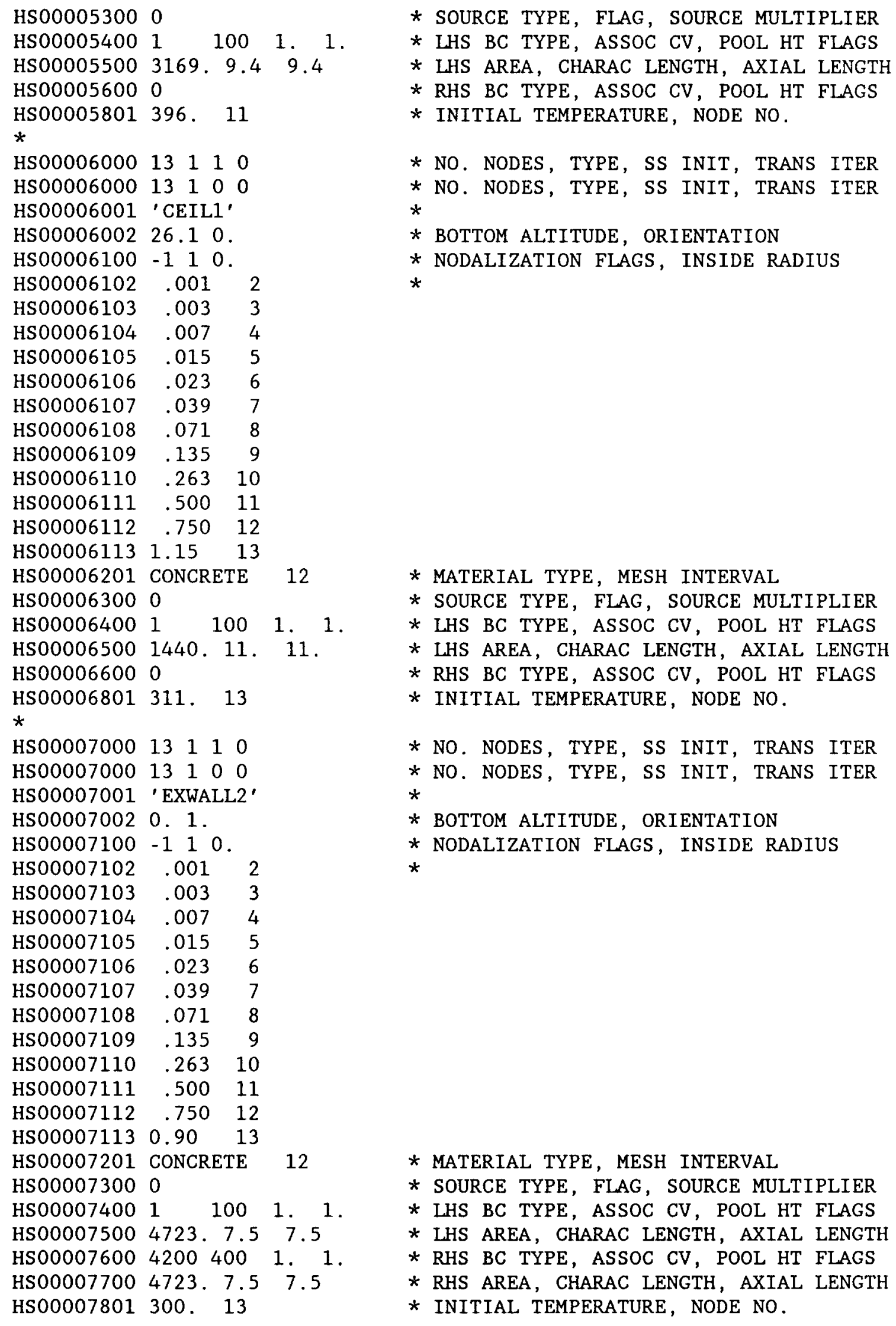




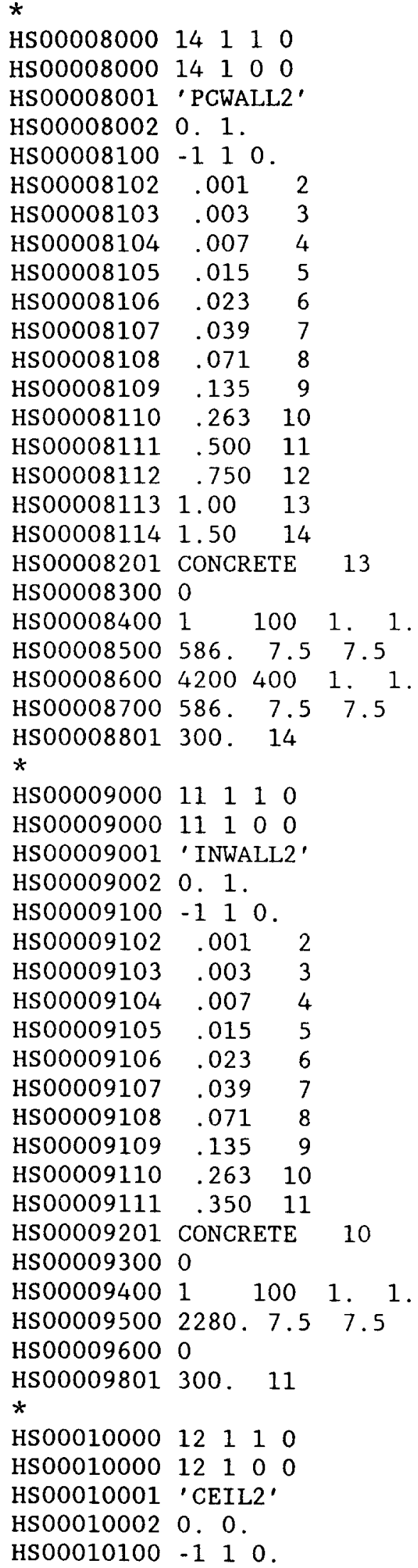

* NO. NODES, TYPE, SS INIT, TRANS ITER

* NO. NODES, TYPE, SS INIT, TRANS ITER

* BOTTOM ALTITUDE, ORIENTATION

* NODAlization Flags, INSIDE RADIUS

*

* MATERIAl tYPe, MESH INTERVAL

* SOURCE TYPE, FLAG, SOURCE MULTIPLIER

* LHS BC TYPE, ASSOC CV, POOL hT FLAGS

* LHS AREA, CHARAC LENGTH, AXIAL LENGTH

* RHS BC TYPE, ASSOC CV POOL HT FLAGS

* RHS aRea, charac length, axial length

* initial temperature, nOde no.

* NO. NODES, TYPE, SS INIT, TRANS ITER

* NO. NODES, TYPE, SS INIT, TRANS ITER

*

* BOTTOM ALTITUde, ORIENTATION

* Nodalization flags, inside Radius

$*$

\footnotetext{
* material type, mesh interval

* SOURCE TYPE, FLAG, SOURCE MULTIPLIER

* LHS bC TYPe, assoc CV, pOOL ht flags

* Lhs area, charac length, axial length

* RHS BC TYPE, ASSOC CV, POOL hT FLAGS

* initial temperature, Node No.

* NO. NODES, TYPE, SS INIT, TRANS ITER

* NO. NODES, TYPE, SS INIT, TRANS ITER

*

* BotTOM altitude, ORIENTATION

* NODALIZATION FLAGS, INSIDE RADIUS
} 


\begin{tabular}{|c|c|c|c|c|}
\hline HS00010102 & .001 & & * & \\
\hline HS00010103 & .003 & & & \\
\hline HS00010104 & .007 & & & \\
\hline HS00010105 & .015 & & & \\
\hline HS00010106 & .023 & & & \\
\hline HS00010107 & .039 & & & \\
\hline HS00010108 & .071 & & & \\
\hline HS00010109 & .135 & & & \\
\hline HS00010110 & .263 & & & \\
\hline HS00010111 & .500 & & & \\
\hline HS00010112 & $.600 \quad 12$ & & & \\
\hline HS00010201 & CONCRETE & 11 & * & MATERIAL TYPE, MESH INTERVAL \\
\hline HS00010300 & 0 & & & SOURCE TYPE, FLAG, SOURCE MULTIPLIER \\
\hline HS00010400 & 100 & 1. & * & LHS BC TYPE, ASSOC CV, POOL HT FLAGS \\
\hline HSO0010500 & 4110. 11. & 11. & * & LHS AREA, CHARAC LENGTH, AXIAL LENGTH \\
\hline HS00010600 & & & * & RHS BC TYPE, ASSOC CV, POOL HT FLAGS \\
\hline $\begin{array}{l}\text { HS00010801 } \\
*\end{array}$ & 300. 12 & & * & INITIAL TEMPERATURE, NODE NO. \\
\hline HS00011000 & 21110 & & * & NO. NODES, TYPE, SS INIT, TRANS ITER \\
\hline HS00011000 & 41000 & & * & NO. NODES, TYPE, SS INIT, TRANS ITER \\
\hline HS00011001 & 'STEEL2' & & * & \\
\hline HS00011002 & 0.1 . 1. & & * & BOTTOM ALTITUDE, ORIENTATION \\
\hline HS00011100 & $\begin{array}{lll}-1 & 1 & 0\end{array}$ & & * & NODALIZATION FLAGS, INSIDE RADIUS \\
\hline HS00011102 & .006354 & & * & \\
\hline HS00011201 & 'STAINLESS & S STEEL' 3 & * & MATERIAL TYPE, MESH INTERVAL \\
\hline HS00011300 & 0 & & * & SOURCE TYPE, FLAG, SOURCE MULTIPLIER \\
\hline HS00011400 & 100 & & * & LHS BC TYPE, ASSOC CV, POOL HT FLAGS \\
\hline HS00011500 & 775.63. & 3. & * & LHS AREA, CHARAC LENGTH, AXIAL LENGTH \\
\hline HS00011600 & 0 & & * & RHS BC TYPE, ASSOC CV, POOL HT FLAGS \\
\hline $\begin{array}{l}\text { HSO0011801 } \\
*\end{array}$ & 305.44 & & * & INITIAL TEMPERATURE, NODE NO. \\
\hline HS00012000 & 151110 & & * & NO. NODES, TYPE, SS INIT, TRANS ITER \\
\hline HS00012000 & 15100 & & * & NO. NODES, TYPE, SS INIT, TRANS ITER \\
\hline HS00012001 & 'PCWALL3' & & * & \\
\hline HS00012002 & 0.1 . & & * & BOTTOM ALTITUDE, ORIENTATION \\
\hline HS00012100 & $\begin{array}{lll}-1 & 1 & 0\end{array}$ & & * & NODALIZATION FLAGS, INSIDE RADIUS \\
\hline HS00012102 & .001 & & * & \\
\hline HS00012103 & .003 & & & \\
\hline HS00012104 & .007 & & & \\
\hline HS00012105 & .015 & & & \\
\hline HS00012106 & .023 & & & \\
\hline HS00012107 & .039 & & & \\
\hline HS00012108 & .071 & & & \\
\hline HS00012109 & .135 & & & \\
\hline HS00012110 & .263 & & & \\
\hline HS00012111 & .500 & & & \\
\hline HS00012112 & .750 & & & \\
\hline HSO0012113 & 1.0 & & & \\
\hline HS00012114 & 1.5 & & & \\
\hline HS00012115 & 1.7 & & & \\
\hline HS00012201 & CONCRETE & 14 & * & MATERIAL TYPE, MESH INTERVAL \\
\hline HSO0012300 & 0 & & * & SOURCE TYPE, FLAG, SOURCE MULTIPLIER \\
\hline HS00012400 & 100 & 1 . & * & LHS BC TYPE, ASSOC CV, POOL HT FLAGS \\
\hline HSO0012500 & 8.3 & 8 & & LHS AREA, CHARAC LENGTH, AXIAL LENGTH \\
\hline
\end{tabular}




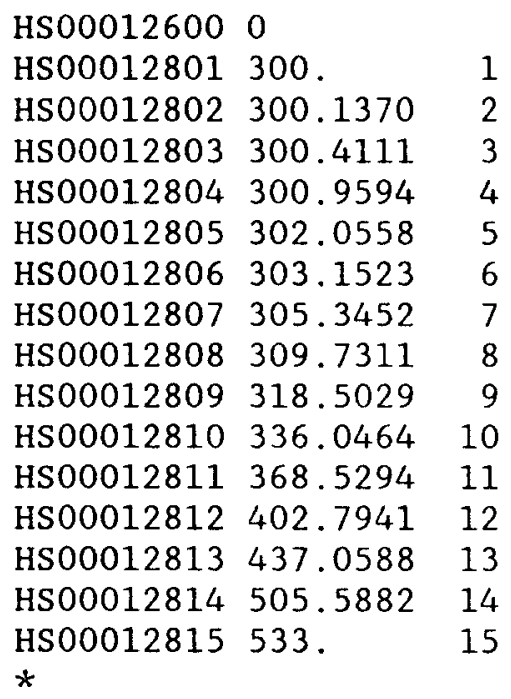

* RHS BC TYPE, ASSOC CV, POOL HT FLAGS

* initial temperature, nOde No.

* NO. NODES, TYPE, SS INIT, TRANS ITER

* NO. NODES, TYPE, SS INIT, TRANS ITER

*

* BOtTOM altitude, ORIENTATION

* NODALIZATION FLAGS, INSIDE RADIUS *

* material type, MESh interval

* SOURCE TYPE, FLAG, SOURCE MULTIPLIER

* LHS BC TYPE, ASSOC CV, POOL HT FLAGS

* LHS AREA, CHARAC LENGTH, AXIAL LENGTH

* RHS BC TYPE, ASSOC CV, POOL HT FLAGS

* initial temperature, nODE no.

* NO. NODES, TYPE, SS INIT, TRANS ITER

* NO. NODES, TYPE, SS INIT, TRANS ITER

*

* BotTom altitude, oRIEntation

* NODAlization Flags, INSide Radius 


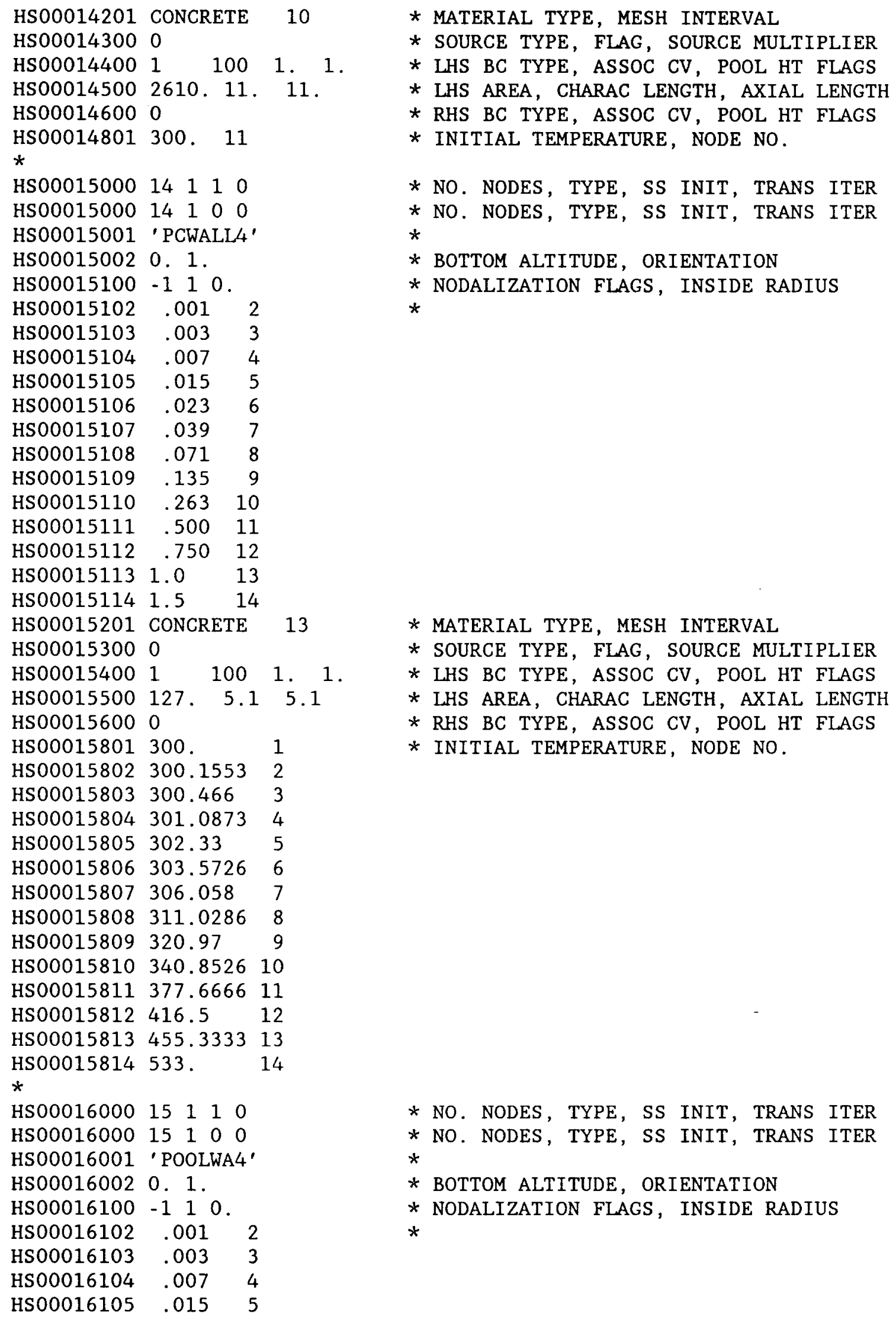




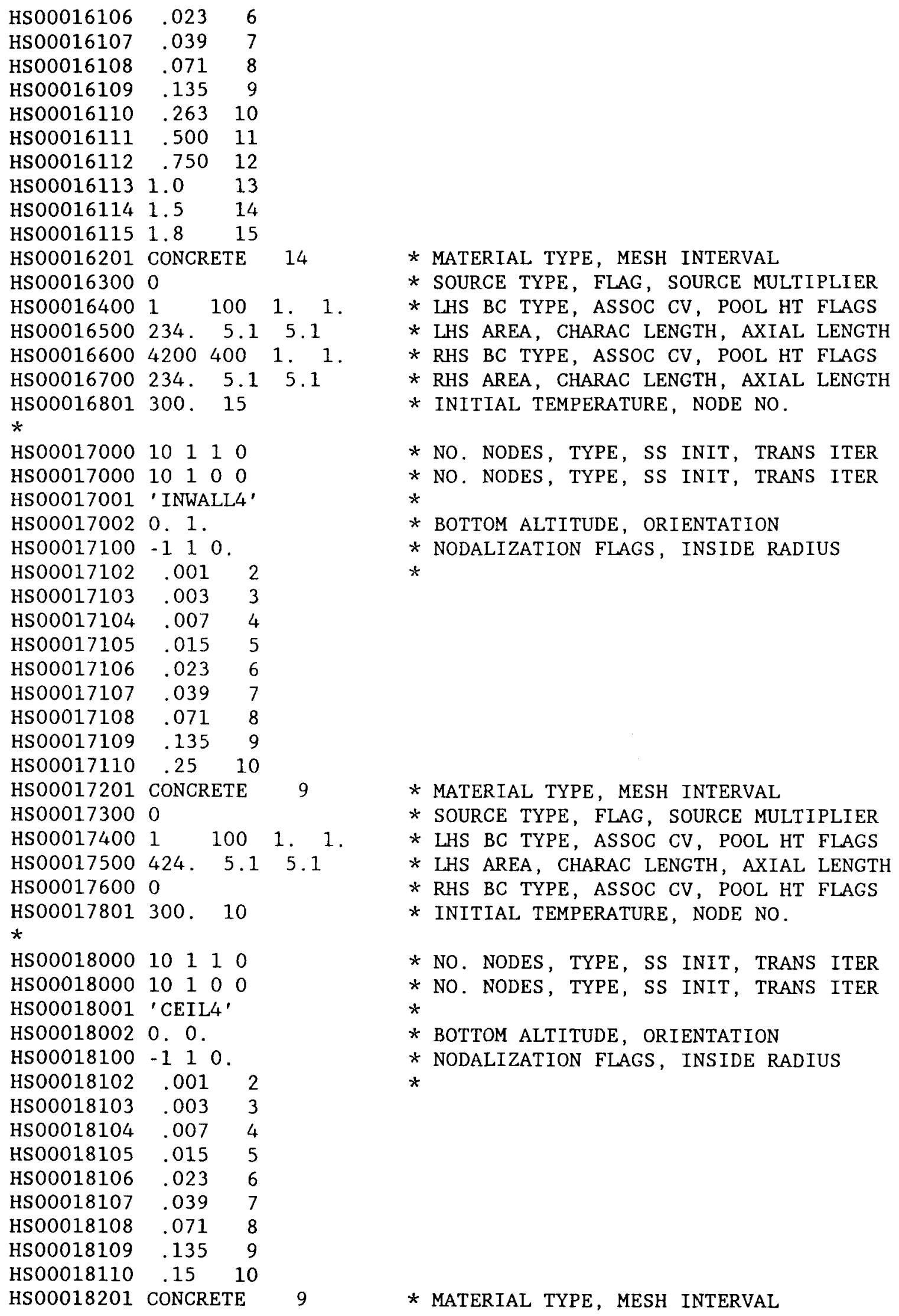




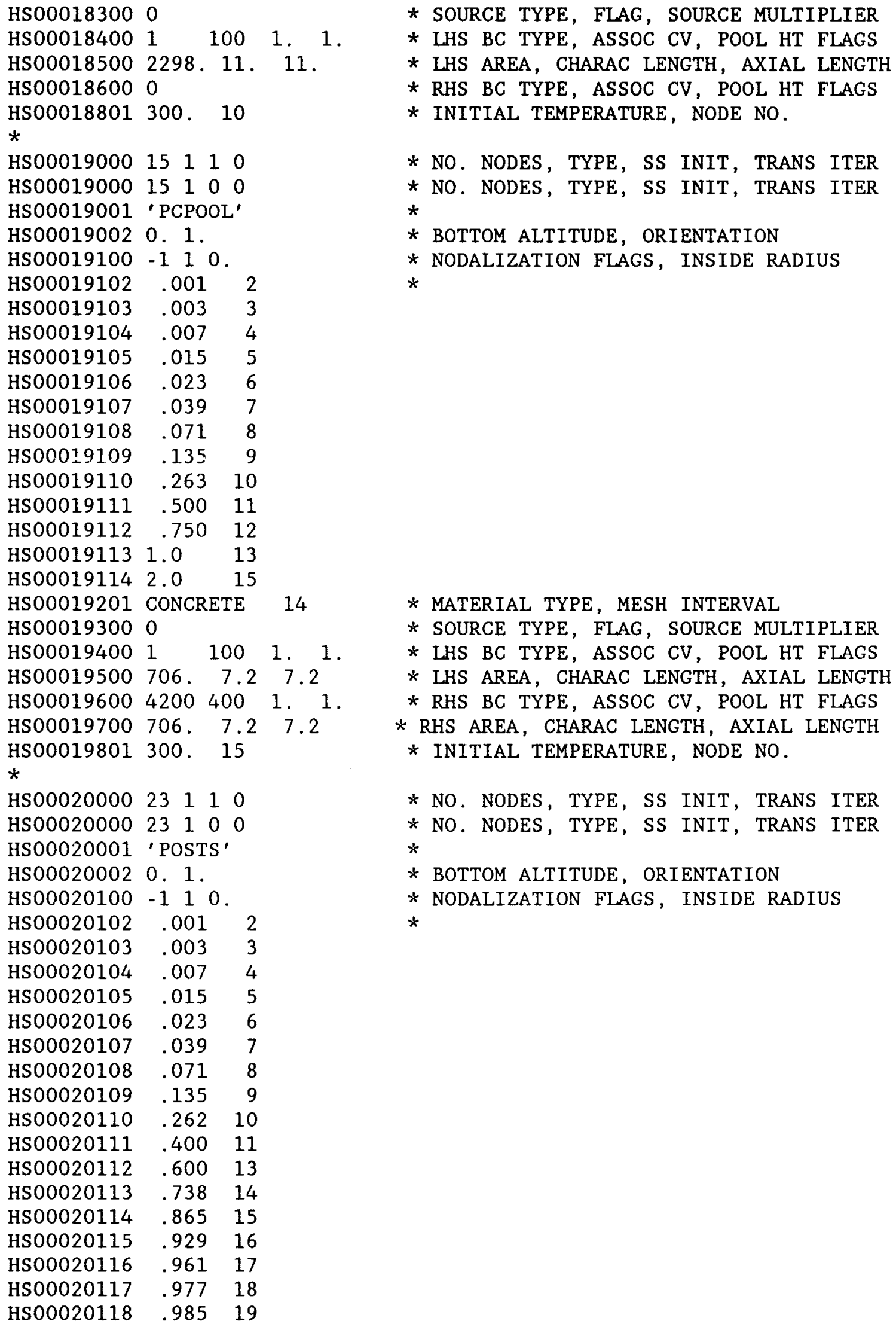




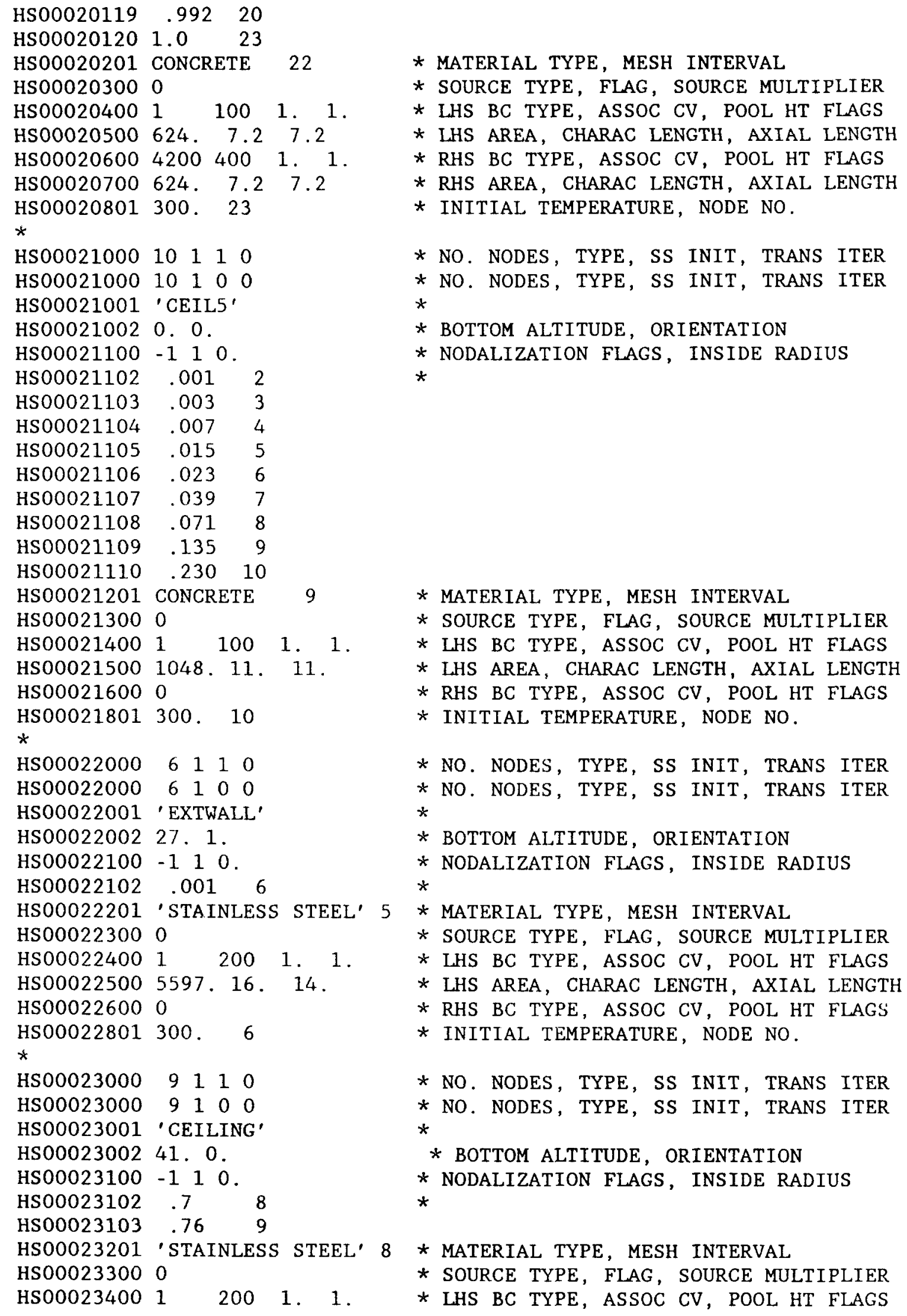$$
\text { HS00022000 } 611110
$$ 
HS 000235004756.16 .16$.

HSO0023600 0

HS00023801 300. 9

*

HS00024000 101110

HSOOO24000 $10 \quad 1 \quad 0 \quad 0$

HSO0024001 'FLOOR'

HSO0024002 33. 0 .

HSO0024100 - 110 .

HSO0024102 .001 2

HSO0024103 .003 3

HSO0024104 .007 4

HS00024105 .015 5

$\begin{array}{lll}\mathrm{HS} 00024106 & .023 \quad 6\end{array}$

$\begin{array}{lll}\text { HSO0024107 } & .039 \quad 7\end{array}$

$\begin{array}{lll}\text { HSO0024108 } & .071 \quad 8\end{array}$

HSOOO24109 .135 9

HS00024110 .230 10

HSO0024201 CONCRETE 9

HSO0024300 0

HS00024400 1 200 1. 1 .

HS00024500 4184. 16. 16.

HS00024600 0

HS00024801 300. 10

*

HS00025000 41100

HS00025001 'STEEL'

HSO0025002 33. 1 .

HSO0025100 -1110 .

HS00025102 .00635 4

HS00025201 'STAINLESS STEEL' 3

HSO0025300 0

HS00025400 1 200 1. 1.

HSO0025500 712. 3. 3.

HS00025600 0

HSO0025801 $299.8 \quad 4$

*

HS00026000 $6 \begin{array}{llll}1 & 1 & 0\end{array}$

HS00026000 61100

HS00026001 'EXTWALL'

HS00026002 12. 1.

HSO0026100 $-1 \quad 10$.

HS00026102 .001 6

HS00026201 'STAINLESS STEEL' 5

HS00026300 0

HS00026400 $1 \quad 300 \quad 1.1$.

HS00026500 76248. 65.16 .

HS00026600 0

HS00026801 300. 6

*

HSOOO27000 91100

HS00027001 'CEILING'

HS00027002 12. 0 .

HS00027100 - 1110 .
* liss area, charac length, axial length

* RHS BC TYPE, asSOC CV, POOL ht Flags

* initial temperature, NODE No.

* NO. NODES, TYPE, SS INIT, TRANS ITER

* NO. NODES, TYPE, SS INIT, TRANS ITER

* BotTom altitude, ORIENTATION

* NODALIZATION FLAGS, INSIDE RADIUS

*

* MATERIAL tYPe, MESH INTERVAL

* SOURCE TYPE, FLAG, SOURCE MULTIPLIER

* LHS BC TYPE, ASSOC CV, POOL hT FLags

* LHS AREa, CHARAC LENGTH, AXIAL LENGTH

* RHS BC TYPE, ASSOC CV, POOL hT FLAGS

* inItial temPERATURE, NODE NO.

* NO. NODES, TYPE, SS INIT, TRANS ITER

*

* BOTTOM ALTITUDE, ORIENTATION

* NODALIZATION FLAGS, INSIDE RADIUS

*

* material type, mesh interval

* SOURCE TYPE, FLAG, SOURCE MULTIPLIER

* LHS bC TYPE, asSOC CV, pOOL ht fLags

* lHS aREa, charac length, axial length

* RHS BC TYPE, ASSOC CV, POOL hT FLAGS

* inttial temperature, NODE No.

* NO. NODES, TYPE, SS INIT, TRANS ITER

* NO. NODES, TYPE, SS INIT, TRANS ITER

*

* BOTTOM ALTITUDE, ORIENTATION

* NODALIZATION FLAGS, INSIDE RADIUS

x

* material type, mesh interval

* SOURCE TYPE, FLAG, SOURCE MULTIPLIER

* LHS BC TYPE, ASSOC CV, POOL HT FLAGS

* LHS AREA, CHARAC LENGTH, AXIAL LENGTH

* RHS BC TYPE, ASSOC CV, POOL HT FLAGS

* initial temperature, NODE No.

* NO. NODES, TYPE, SS INIT, TRANS ITER

*

* BOTTOM ALTITUDE, ORIENTATION

* NODALIZATION FLAGS, INSIDE RADIUS 


\begin{tabular}{|c|c|c|c|c|c|}
\hline HSO0027102 & .7 & & & * & \\
\hline HSO0027103 & .76 & & & & \\
\hline HS00027201 & ' STAINLESS & STEEL' & 8 & * & MATERIAL TYPE, MESH INTERVAL \\
\hline HSO0027300 & 0 & & & * & SOURCE TYPE, FLAG, SOURCE MULTIPLIER \\
\hline 0027400 & 300 & 1 . & & * & LHS BC TYPE, ASSOC CV, POOL HT FLAGS \\
\hline 0027500 & 8279.16 . & 16 & & * & LHS AREA, CHARAC LENGTH, AXIAL LENGTH \\
\hline S00027600 & & & & $\star$ & RHS BC TYPE, ASSOC CV, POOL HT FLAGS \\
\hline 7801 & 300. & & & * & INITIAL TEMPERATURE, NODE NO. \\
\hline 28000 & $\begin{array}{llll}6 & 1 & 1 & 0\end{array}$ & & & $*$ & NO. NODES, TYPE, SS INIT, TRANS ITER \\
\hline 28000 & $\begin{array}{llll}6 & 1 & 0 & 0\end{array}$ & & & * & NO. NODES, TYPE, SS INIT, TRANS ITER \\
\hline 028001 & 'FLOOR' & & & * & \\
\hline 028002 & 12. 0 . & & & $*$ & BOTTOM ALTITUDE, ORIENTATION \\
\hline 28100 & -110 & & & * & NODALIZATION FLAGS, INSIDE RADIUS \\
\hline 028102 & .2 & & & * & \\
\hline 03 & .23 & & & & \\
\hline 01 & CONCRETE & 5 & & $*$ & MATERIAL TYPE, MESH INTERVAL \\
\hline 028300 & 0 & & & * & SOURCE TYPE, FLAG, SOURCE MULTIPLIER \\
\hline 00 & 300 & 1 . & & * & LHS BC TYPE, ASSOC CV, POOL HT FLAGS \\
\hline 028500 & 8279.16. & 16. & & $*$ & LHS AREA, CHARAC LENGTH, AXIAL LENGTH \\
\hline 028600 & & & & $*$ & RHS BC TYPE, ASSOC CV, POOL HT FLAGS \\
\hline 28801 & 300. & & & * & INITIAL TEMPERATURE, NODE NO. \\
\hline 00 & $\begin{array}{llll}4 & 1 & 1 & 0\end{array}$ & & & * & NO. NODES, TYPE, SS INIT, TRANS ITER \\
\hline 1029000 & 4100 & & & $*$ & NO. NODES, TYPE, SS INIT, TRANS ITER \\
\hline 0029001 & 'STEEL' & & & * & \\
\hline 0029002 & 12. 1. & & & $*$ & BOTTOM ALTITUDE, ORIENTATION \\
\hline 00029100 & -110 & & & * & NODALIZATION FLAGS, INSIDE RADIUS \\
\hline 1029102 & .00635 & & & * & \\
\hline HS00029201 & 'STAINLESS & STEEL' & 3 & * & MATERIAL TYPE, MESH INTERVAL \\
\hline 0029300 & 0 & & & $*$ & SOURCE TYPE, FLAG, SOURCE MULTIPLIER \\
\hline HSO0029400 & 300 & 1. & & * & LHS BC TYPE, ASSOC CV, POOL HT FLAGS \\
\hline 00029500 & 712. & 3. & & * & LHS AREA, CHARAC LENGTH, AXIAL LENGTH \\
\hline 029600 & & & & * & RHS BC TYPE, ASSOC CV, POOL HT FLAGS \\
\hline 00029801 & 299.8 & & & 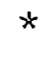 & INITIAL TEMPERATURE, NODE NO. \\
\hline
\end{tabular}

$\begin{array}{lll}* * * * * & & \\ * * * * * & \text { MATERIAL PROPERTY } & \text { INPUT } \\ * * * * * & & \\ \text { MPMAT00100 } & \text { CONCRETE } & \\ \text { MPMAT00101 } & \text { THC } & 310 \\ \text { MPMAT00102 } & \text { RHO } & 320 \\ \text { MPMAT00103 } & \text { CPS } & 330\end{array}$

$* * * * *$

$* * * * *$ TABULAR FUNCTION INPUT FOR HEAT SLABA

$* * * * * x$

TF20000 'RHS HT COEF' 1 1. $0 . *$ NAME, NO. PAIRS, MUL CONST, ADD CONST

TF20010 0.6.08 * TIME, HEAT TRANSFER COEFFICIENT

*

TF31000 'THC CONC' $21.0 . *$ NAME, NO. PAIRS, MUL CONST, ADD CONST

TF31010 200. 1.454

TF31011 5000. 1.454

* TEMPERATURE, CONDUCTIVITY

* 


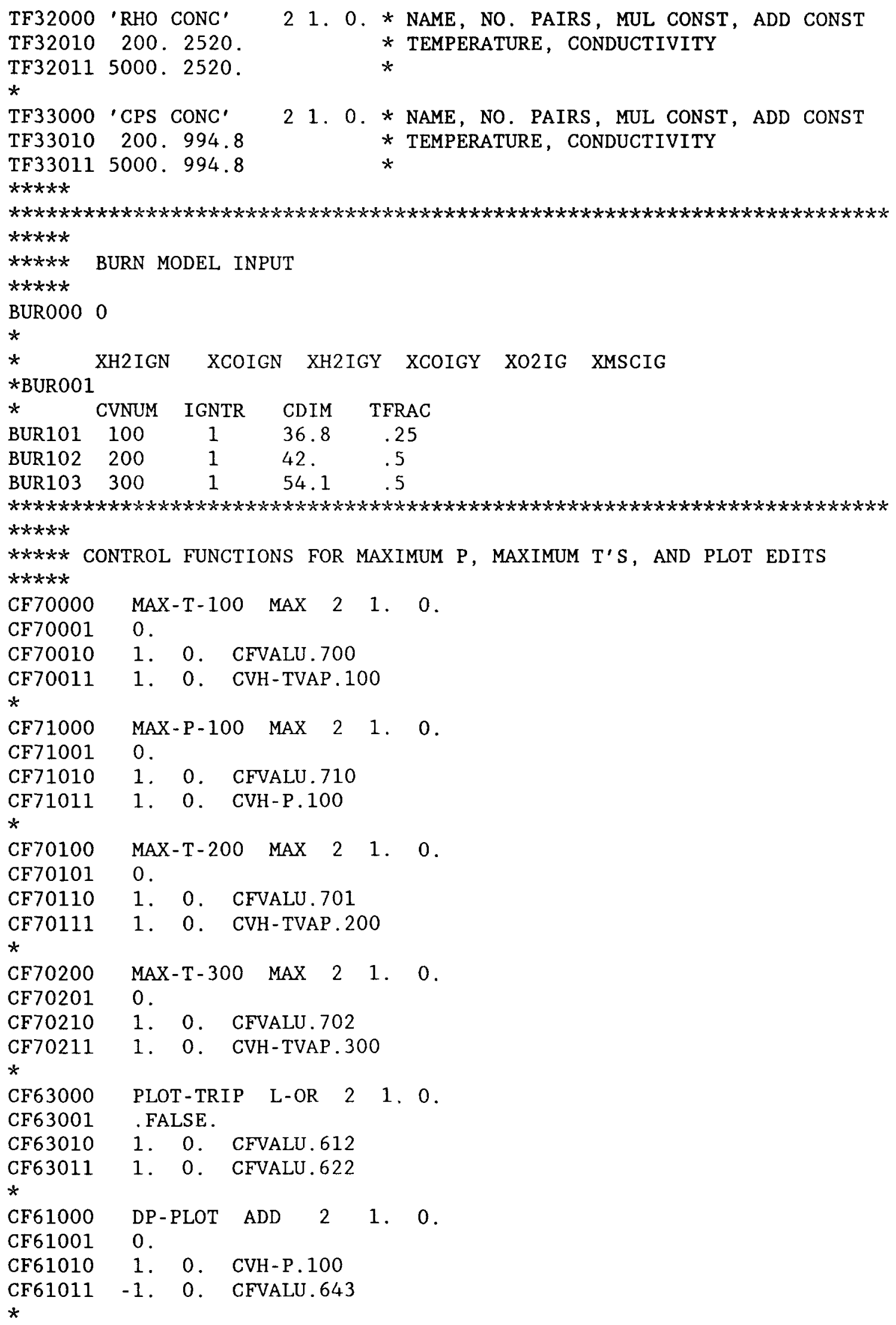




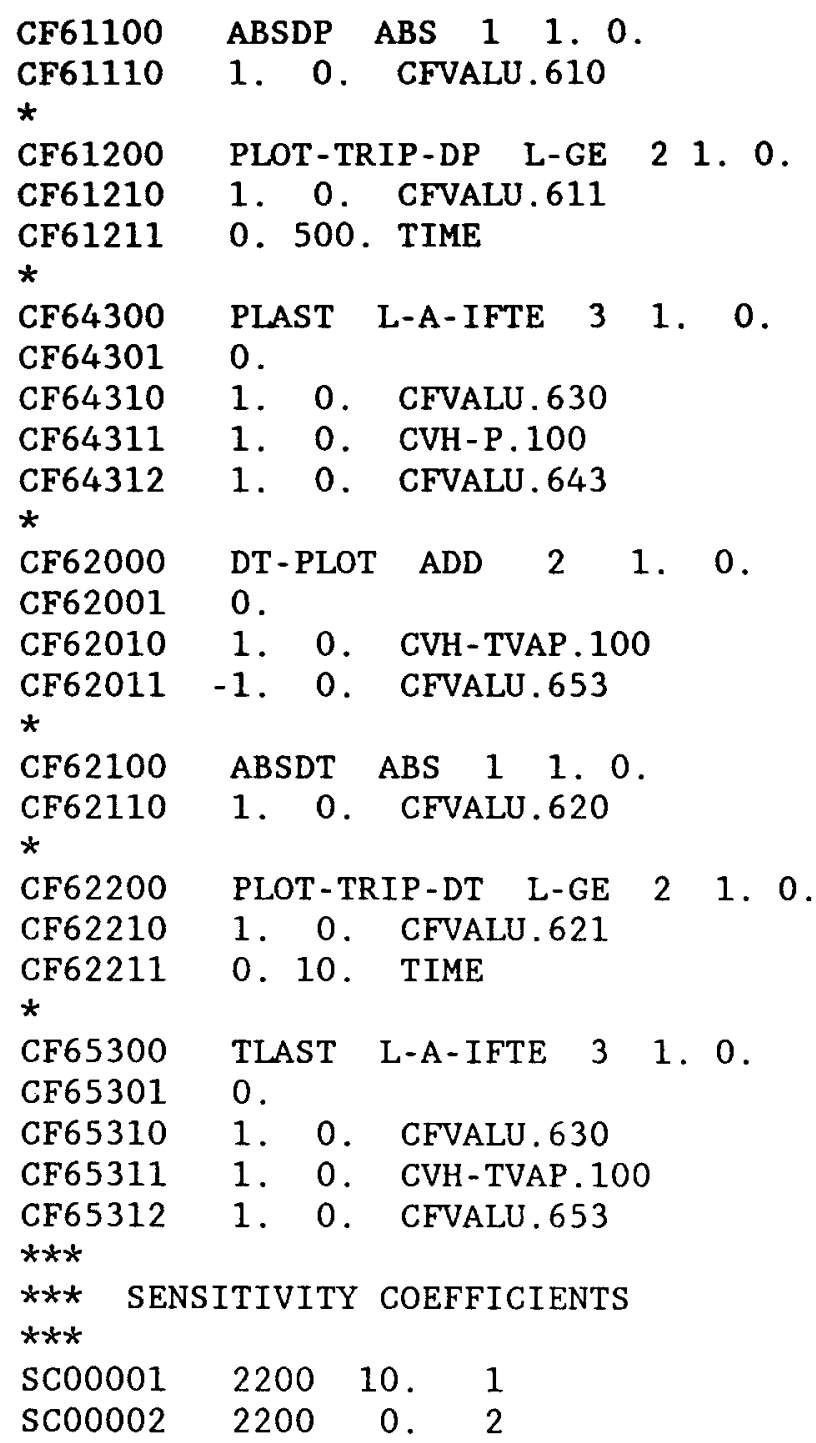




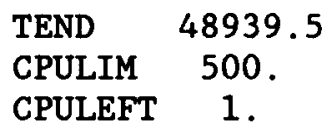




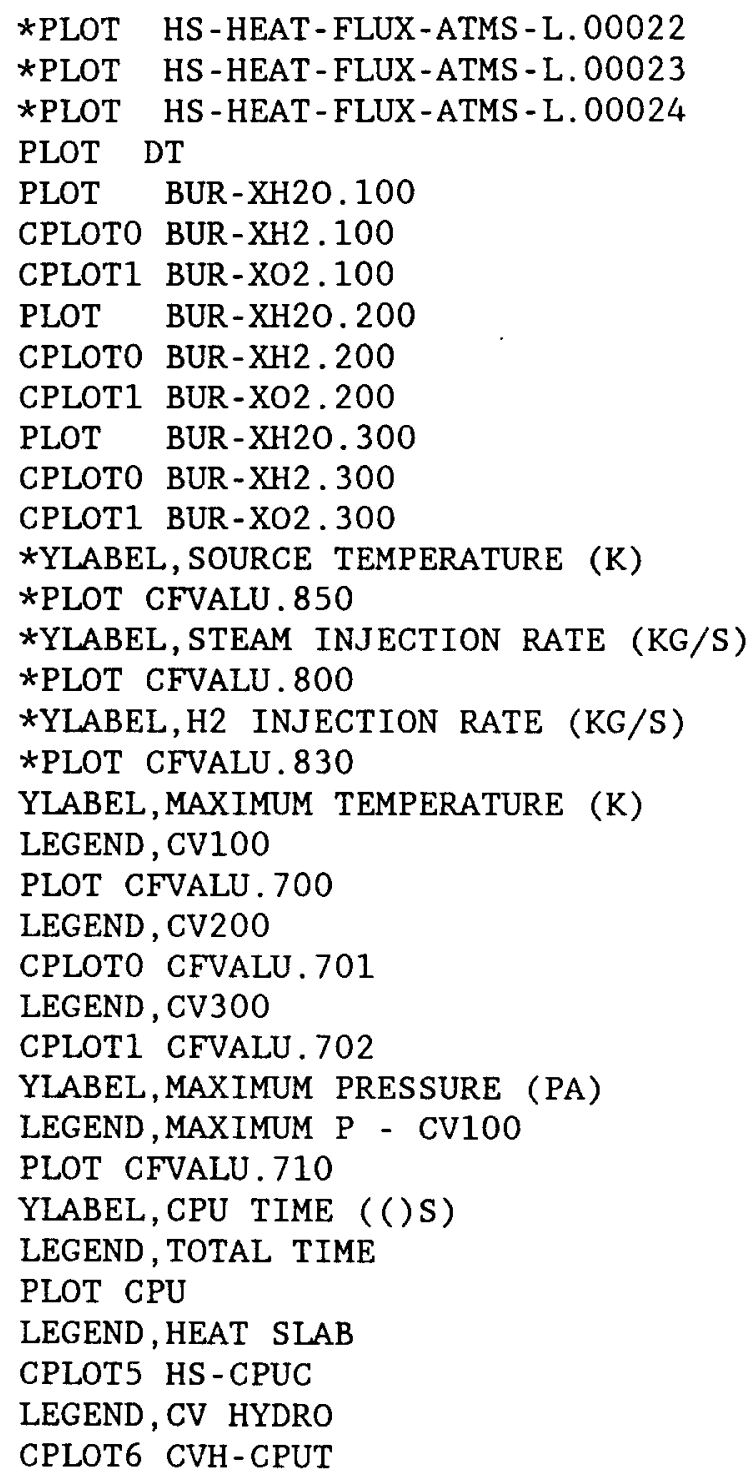

ST007: HDR Steam Blowdown Test

MELGEN Input

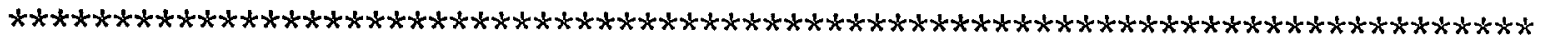
$* * * * * *$

$* * * * *$ This is a MELCOR test calculation for the HDR containment $* * * * *$ experiment $\mathrm{V} 44$.

$* * * * * x$

TITLE STO07

CRTOUT

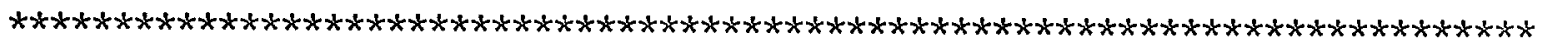
$* * * * *$ NONCONDENSIBLE GASES DATA

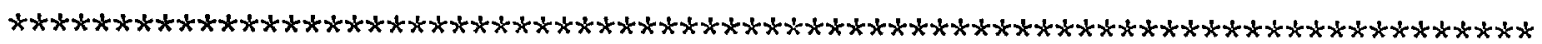
$* * * * * *$
} 


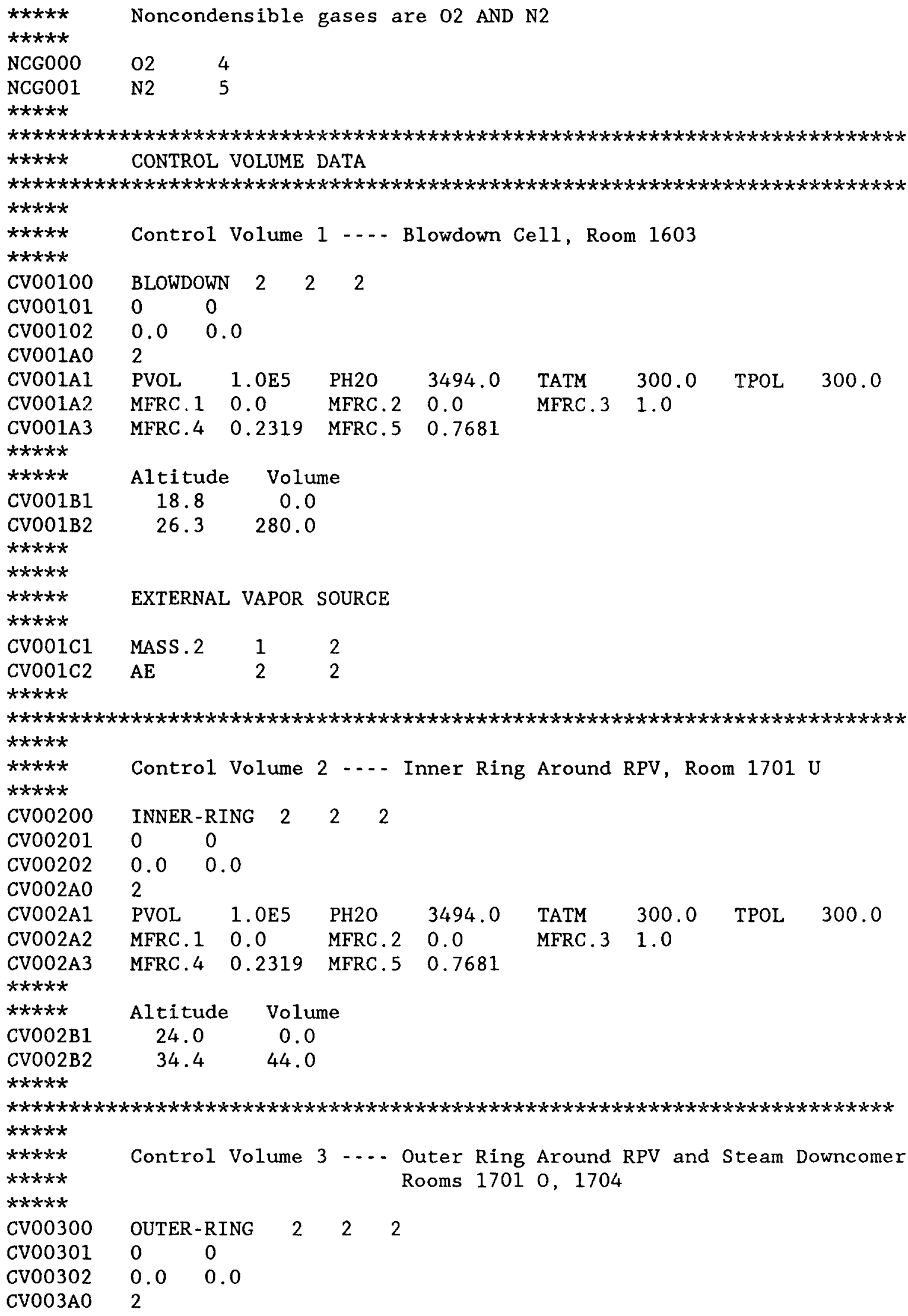




\begin{tabular}{|c|c|c|c|c|c|c|c|c|}
\hline CVOO3A1 & PVOL & $1.0 \mathrm{E} 5$ & $\mathrm{PH} 2 \mathrm{O}$ & 3494.0 & TATM & 300.0 & TPOL & 300.0 \\
\hline CV003A2 & MFRC . 1 & 0.0 & MFRC. 2 & 0.0 & MFRC . 3 & 1.0 & & \\
\hline $\begin{array}{l}\text { CV003A3 } \\
* * * * * x\end{array}$ & MFRC . 4 & 0.2319 & MFRC. 5 & 0.7681 & & & & \\
\hline$x+x * x$ & Altitude & Volum & & & & & & \\
\hline CV003B1 & 27.6 & 0.0 & & & & & & \\
\hline $\begin{array}{l}\text { CVOO3B2 } \\
* * * * * 4\end{array}$ & 35.9 & 912.0 & & & & & & \\
\hline$* x * x * x * x=$ & $* * * * * * * * * x$ & $* * * * * * * * * * *$ & $* * * * * * * * * x$ & $* * * * * * * x * 3$ & $* * * * * * * * * * x$ & $* * * * * * * * * *$ & $* x * x * * x$ & $x * x+x+x+x$ \\
\hline$x * x+x$ & & & & & & & & \\
\hline$x * x+x$ & Control & Volume 4 & $4 \ldots-\mathrm{L}$ & ower Roo & 1s , 1201 & through & 1514 & \\
\hline$* * * * *$ & & & & & & & & \\
\hline CV00400 & LOWER - RO & OOMS & 2 & & & & & \\
\hline CV00401 & 0 & & & & & & & \\
\hline CV00402 & $0.0 \quad 0$. & 0 & & & & & & \\
\hline CV004AO & 2 & & & & & & & \\
\hline CV004A1 & PVOL & 1. $0 \mathrm{E} 5$ & $\mathrm{PH} 2 \mathrm{O}$ & 3494.0 & TATM & 300.0 & TPOL & 300.0 \\
\hline CV004A2 & MFRC . 1 & 0.0 & MFRC. 2 & 0.0 & MFRC. 3 & 1.0 & & \\
\hline $\begin{array}{l}\text { CV004A3 } \\
x^{2}+x+x+2\end{array}$ & MFRC. 4 & 0.2319 & MFRC .5 & 0.7681 & & & & \\
\hline$x+x * x+x$ & Altitude & Volu & ume & & & & & \\
\hline CV004BI & $\therefore .0$ & 0.0 & & & & & & \\
\hline $\begin{array}{l}\text { CV004B2 } \\
* * * * * *\end{array}$ & 18.0 & 3003.0 & & & & & & \\
\hline $\begin{array}{l}* * * * * * * * \\
* * x * *\end{array}$ & $* * * * * * * * * * x$ & $* x * x * * * * * x$ & $* * * * * * * * * x$ & $2 x+x * x * x * x$ & $x * x * x * x * 3$ & $* * * * * * * * * x * x$ & $k * * x * x *$ & $x * x * x * x$ \\
\hline$* x * x * x$ & Control & Volume 5 & $5 \ldots u$ & pper Roo & as, 1602 & through & 11004 & \\
\hline$x+x * x$ & & & & & & & & \\
\hline CV00500 & UPPER - RC & OOMS & 2 & & & & & \\
\hline CV00501 & 0 & 0 & & & & & & \\
\hline CV00502 & 0.0 & 0.0 & & & & & & \\
\hline CV005AO & 2 & & & & & & & \\
\hline CV005A1 & PVOL & $1.0 \mathrm{E} 5$ & $\mathrm{PH} 2 \mathrm{O}$ & 3494.0 & TATM & 300.0 & TPOL & 300.0 \\
\hline CV005A2 & MFRC . 1 & 0.0 & MFRC. 2 & 0.0 & MFRC. 3 & 1.0 & & \\
\hline $\begin{array}{l}\text { CV005A3 } \\
* * x * * x\end{array}$ & MFRC . 4 & 0.2319 & MFRC. 5 & 0.7681 & & & & \\
\hline$* * * * * *$ & Altitude & Volu & ume & & & & & \\
\hline CV005B 1 & 35.4 & 0.0 & & & & & & \\
\hline CV005B2 & 63.5 & 7102.0 & & & & & & \\
\hline$x * x * *$ & & & & & & & & \\
\hline$x * x * x+x+$ & $x * x * x+x * x+3$ & $x+x * x+x * x$ & $* x * x * x * x$ & $x * x * x * x * x$ & $x * x+x * x+2 x$ & $* * * * x * * * 2$ & $k * * * x+2$ & $x+2 x+x+4$ \\
\hline$* * * * * x$ & FLOW PA & ATH DATA & & & & & & \\
\hline$x * x * x * x$ & $x * x * x * x * x$ & $x+x+x+x * x+x$ & $x+3 x+x * x+x$ & $x+x+x * 2$ & $4 * x+x * x * x)$ & $* * * * x * x *$ & $k x+x+x * 2$ & $* * * * * * *$ \\
\hline$* x * x *$ & Volume & 1 to Vol & lume 2 & & & & & \\
\hline$* x * * *$ & & & & & & & & \\
\hline FL00100 & $\mathrm{V} 1-\mathrm{V} 2$ & 1 & 2 & 24.0 & 25.0 & & & \\
\hline FL00101 & 3.196 & 2.0 & 1.0 & 2.017 & 2.017 & & & \\
\hline FL00102 & 3 & 0 & 0 & 0 & & & & \\
\hline FL00103 & 1.028 & 1.028 & 1.028 & 1.028 & & & & \\
\hline FL00104 & 0.0 & 0.0 & & & & & & \\
\hline FL001S I & 3.196 & 1.0 & 2.017 & 1. $0 \mathrm{E}-6$ & 16.0 & & & \\
\hline
\end{tabular}




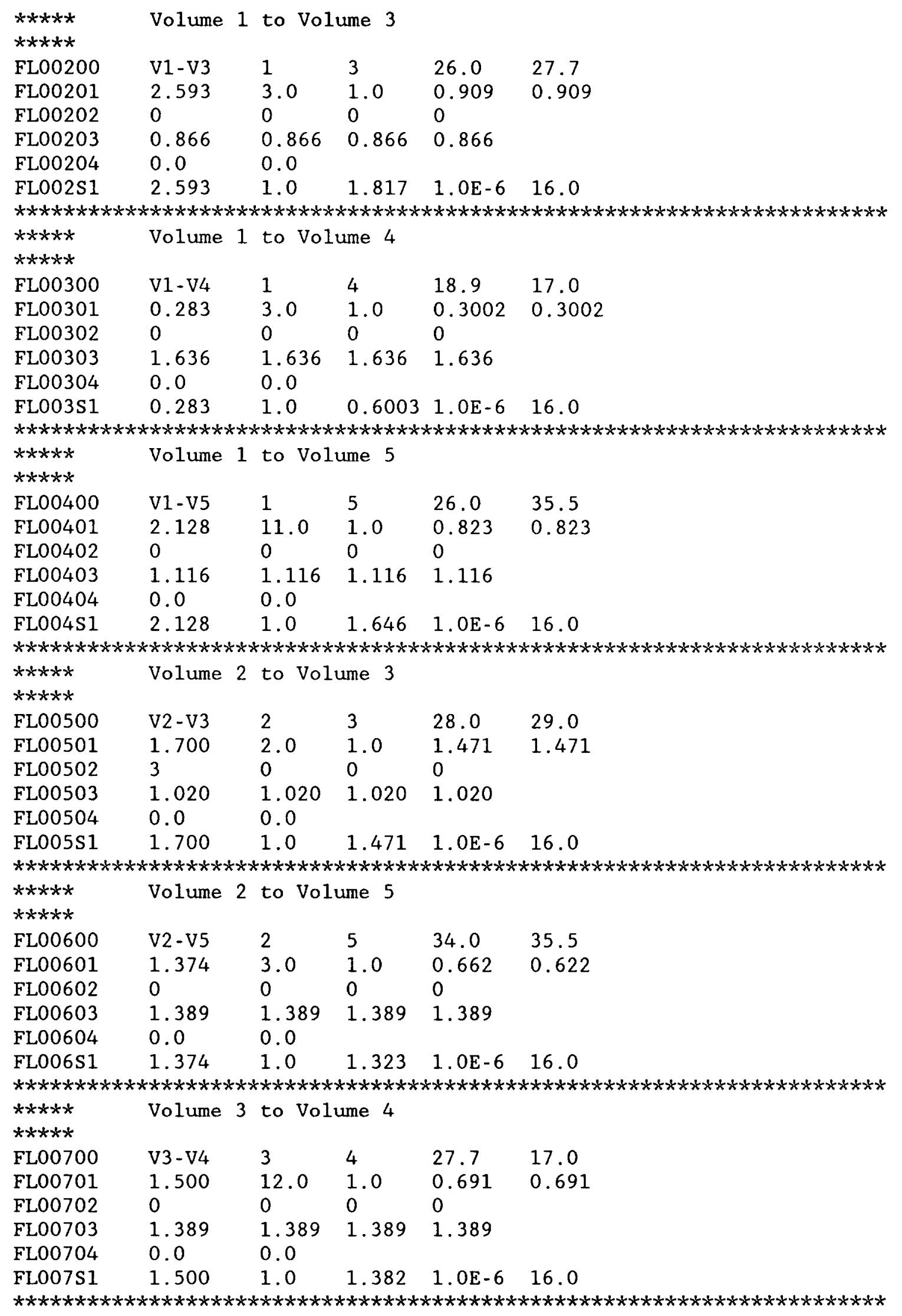




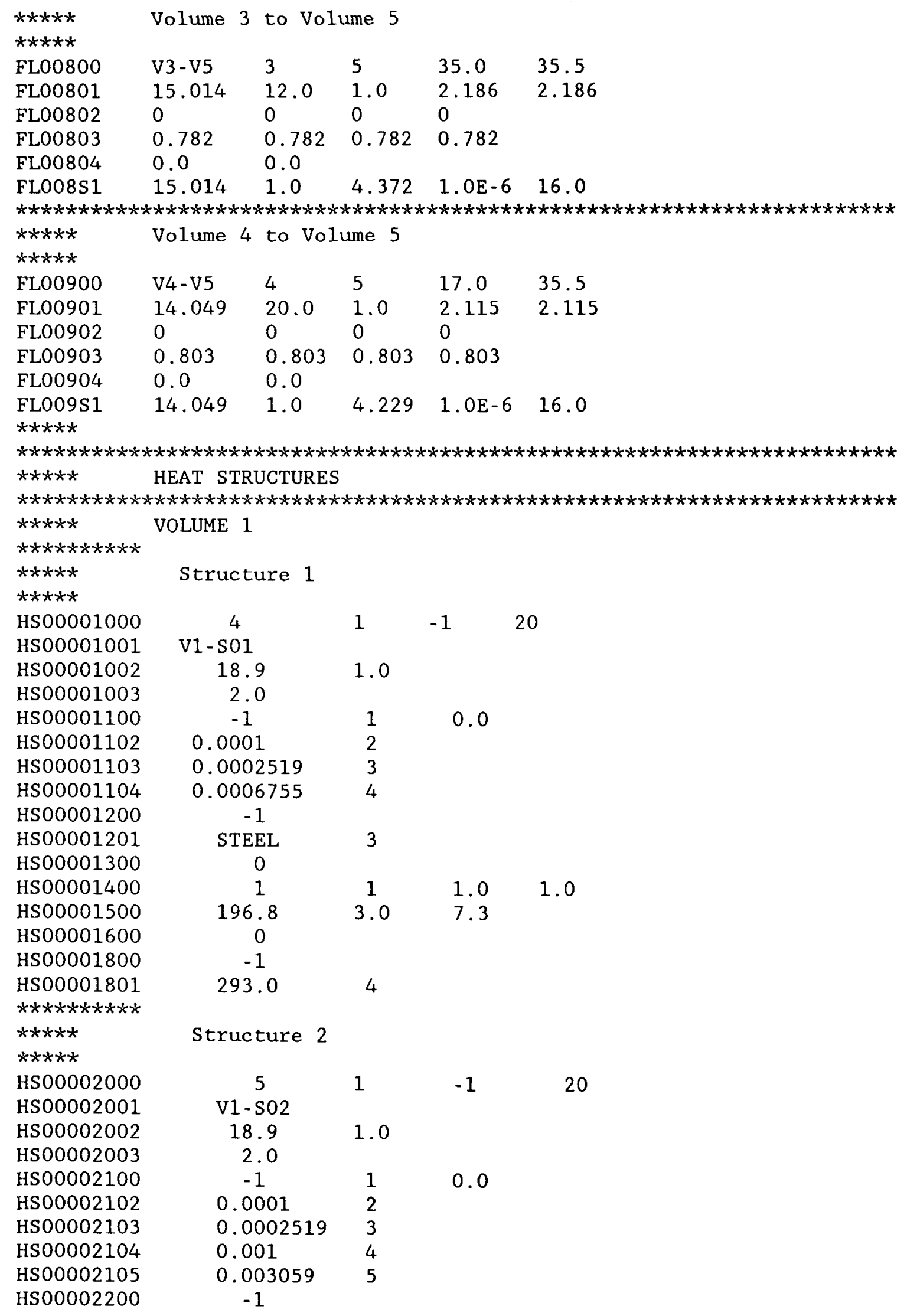




\begin{tabular}{|c|c|c|c|c|}
\hline HS00002201 & STEEL & 4 & & \\
\hline HSO0002300 & 0 & & & \\
\hline HS00002400 & 1 & 1 & 1.0 & 1.0 \\
\hline HSO0002500 & 287.0 & 3.0 & 7.3 & \\
\hline HS00002600 & 0 & & & \\
\hline $\mathrm{HS} 00002800$ & -1 & & & \\
\hline HS00002801 & 293.0 & 5 & & \\
\hline \multicolumn{5}{|l|}{$* * * * * * * * * * * *$} \\
\hline$* * * * * *$ & Structure 3 & 3 & & \\
\hline \multicolumn{5}{|l|}{$x * x * x+x$} \\
\hline HS00003000 & 6 & 1 & -1 & 20 \\
\hline HS00003001 & $\mathrm{V} 1-\mathrm{S} 003$ & & & \\
\hline HSO0003002 & 18.9 & 1.0 & & \\
\hline HSO0003003 & 2.0 & & & \\
\hline HS00003100 & -1 & 1 & 0.0 & \\
\hline HS00003102 & 0.0001 & 2 & & \\
\hline HS00003103 & 0.0002519 & 3 & & \\
\hline HS00003104 & 0.001 & 4 & & \\
\hline HS00003105 & 0.002519 & 5 & & \\
\hline HS00003106 & 0.01109 & 6 & & \\
\hline HS00003200 & -1 & & & \\
\hline HS00003201 & STEEL & 5 & & \\
\hline HSO0003300 & 0 & & & \\
\hline HSO0003400 & 1 & 1 & 1.0 & 1.0 \\
\hline HS00003500 & 144.2 & 3.0 & 7.3 & \\
\hline HS00003600 & 0 & & & \\
\hline HS00003800 & -1 & & & \\
\hline HS00003801 & 293.0 & 6 & & \\
\hline \multicolumn{5}{|l|}{$* * * * * * * * * * * *$} \\
\hline$* * x * * *$ & Structure & e 4 & & \\
\hline \multicolumn{5}{|l|}{$x+x * x+$} \\
\hline HSO0004000 & 6 & 1 & -1 & 20 \\
\hline HS00004001 & V1-S04 & & & \\
\hline HS00004002 & 18.9 & 1.0 & & \\
\hline HS00004003 & 2.0 & & & \\
\hline HSO0004100 & -1 & 1 & 0.0 & \\
\hline HS00004102 & 0.0001 & 2 & & \\
\hline HSO0004103 & 0.0002519 & 3 & & \\
\hline HSO0004104 & 0.001 & 4 & & \\
\hline HS00004105 & 0.002519 & 5 & & \\
\hline HSO0004106 & 0.010145 & 6 & & \\
\hline HSO0004200 & -1 & & & \\
\hline HS00004201 & STEEL & 5 & & \\
\hline HSO0004300 & 0 & & & \\
\hline HS00004400 & 1 & 1 & 1.0 & 1.0 \\
\hline HS00004500 & 1.5 & 3.0 & 1.0 & \\
\hline HSO0004600 & 0 & & & \\
\hline HS00004800 & -1 & & & \\
\hline HS00004801 & 293.0 & 6 & & \\
\hline \multicolumn{5}{|l|}{$* * x * * * * * * * * *$} \\
\hline$* * * * *$ & Structure 5 & & & \\
\hline \multicolumn{5}{|l|}{$x * x * * x$} \\
\hline HSO0005000 & 16 & 1 & -1 & 20 \\
\hline HS00005001 & V1-S05 & & & \\
\hline
\end{tabular}




\begin{tabular}{|c|c|c|c|c|}
\hline HSO0005002 & 18.9 & 1.0 & & \\
\hline HSO0005100 & -1 & 1 & 0.0 & \\
\hline HSO0005102 & 0.0005 & 2 & & \\
\hline HSO0005103 & 0.001 & 3 & & \\
\hline HS00005104 & 0.001585 & 4 & & \\
\hline HS00005105 & 0.002519 & 5 & & \\
\hline HS00005106 & 0.003981 & 6 & & \\
\hline HS00005107 & 0.006310 & 7 & & \\
\hline HSO0005108 & 0.01 & 8 & & \\
\hline HSO0005109 & 0.01585 & 9 & & \\
\hline HSO0005110 & 0.02519 & 10 & & \\
\hline HSO0005111 & 0.03981 & 11 & & \\
\hline HSO0005112 & 0.06310 & 12 & & \\
\hline HSO0005113 & 0.1 & 13 & & \\
\hline HSO0005114 & 0.1585 & 14 & & \\
\hline HSO0005115 & 0.2519 & 15 & & \\
\hline HS00005116 & 0.3048 & 16 & & \\
\hline HSO0005200 & -1 & & & \\
\hline HSO0005201 & CONCRETE & 15 & & \\
\hline HSO0005300 & 0 & & & \\
\hline HSO0005400 & 1 & 1 & 1.0 & 1.0 \\
\hline HSO0005500 & 240.0 & 3.0 & 7.3 & \\
\hline HS00005600 & 0 & & & \\
\hline HSO0005800 & -1 & & & \\
\hline HS00005801 & 293.0 & 16 & & \\
\hline$* * * * * * * * * * * * *$ & & & & \\
\hline$* x * x * x$ & Structure 6 & & & \\
\hline$* * * x *$ & & & & \\
\hline HSO00006000 & 16 & 1 & -1 & 20 \\
\hline HS00006001 & V1-S06 & & & \\
\hline HSO0006002 & 26.3 & 0.0 & & \\
\hline HSO0006100 & -1 & 1 & 0.0 & \\
\hline HS00006102 & 0.0005 & 2 & & \\
\hline HSO0006103 & 0.001 & 3 & & \\
\hline HSO0006104 & 0.001585 & 4 & & \\
\hline HS00006105 & 0.002519 & 5 & & \\
\hline HS00006106 & 0.003981 & 6 & & \\
\hline HS00006107 & 0.006310 & 7 & & \\
\hline HS00006108 & 0.01 & 8 & & \\
\hline HS00006109 & 0.01585 & 9 & & \\
\hline HS00006110 & 0.02519 & 10 & & \\
\hline HS00006111 & 0.03981 & 11 & & \\
\hline HS00006112 & 0.06310 & 12 & & \\
\hline HS00006113 & 0.1 & 13 & & \\
\hline HSO0006114 & 0.1585 & 14 & & \\
\hline HS00006115 & 0.2519 & 15 & & \\
\hline HS00006116 & 0.3048 & 16 & & \\
\hline HS00006200 & -1 & & & \\
\hline HS00006201 & CONCRETE & 15 & & \\
\hline HS00006300 & 0 & & & \\
\hline HSO0006400 & 1 & 1 & 1.0 & 1.0 \\
\hline HSO0006500 & 45.2 & 3.0 & 6.7 & \\
\hline HSO0006600 & 0 & & & \\
\hline HSO0006800 & -1 & & & \\
\hline
\end{tabular}




\begin{tabular}{|c|c|c|c|c|}
\hline $\begin{array}{l}\text { HS00006801 } \\
* * * * * * * * * *\end{array}$ & 293.0 & 16 & & \\
\hline $\begin{array}{l}* * * * * \\
* * * * * *\end{array}$ & Structure 7 & 7 & & \\
\hline HS00007000 & 16 & 1 & -1 & 20 \\
\hline HS00007001 & V1-S07 & & & \\
\hline HS00007002 & 18.8 & 0.0 & & \\
\hline HSO0007100 & -1 & 1 & 0.0 & \\
\hline HS00007102 & 0.0005 & 2 & & \\
\hline HS00007103 & 0.001 & 3 & & \\
\hline HS00007104 & 0.001585 & 4 & & \\
\hline HS00007105 & 0.002519 & 5 & & \\
\hline HS00007106 & 0.003981 & 6 & & \\
\hline HS00007107 & 0.006310 & 7 & & \\
\hline HS00007108 & 0.01 & 8 & & \\
\hline HSO0007109 & 0.01585 & 9 & & \\
\hline HS00007110 & 0.02519 & 10 & & \\
\hline HS00007111 & 0.03981 & 11 & & \\
\hline HSO0007112 & 0.06310 & 12 & & \\
\hline HSO0007113 & 0.1 & 13 & & \\
\hline HS00007114 & 0.1585 & 14 & & \\
\hline HS00007115 & 0.2519 & 15 & & \\
\hline HS00007116 & 0.3048 & 16 & & \\
\hline HSO0007200 & -1 & & & \\
\hline HS00007201 & CONCRETE & 15 & & \\
\hline HS00007300 & 0 & & & \\
\hline HSO0007400 & 1 & 1 & 0.0 & 0.0 \\
\hline HSO0007500 & 45.2 & 3.0 & 6.7 & \\
\hline HSO0007600 & 0 & & & \\
\hline HS00007800 & -1 & & & \\
\hline HSO0007801 & 293.0 & 16 & & \\
\hline$x * * x * x+x+* x$ & & & & \\
\hline$* * * * * *$ & Structure 8 & 8 & & \\
\hline$* * * * *$ & & & & \\
\hline HSO0008000 & 4 & 1 & -1 & 20 \\
\hline HS 00008001 & V2-S08 & & & \\
\hline HS00008002 & 24.1 & 1.0 & & \\
\hline HSO0008003 & 2.0 & & & \\
\hline HS00008100 & -1 & 1 & 0.0 & \\
\hline HS00008102 & 0.0001 & 2 & & \\
\hline HSO0008103 & 0.0002519 & 3 & & \\
\hline HS00008104 & 0.0007305 & 4 & & \\
\hline HSO0008200 & -1 & & & \\
\hline HSOOO08201 & STEEL & 3 & & \\
\hline HS00008300 & 0 & & & \\
\hline HSO0008400 & 1 & 2 & 1.0 & 1.0 \\
\hline HS00008500 & 92.95 & 5.0 & 10.2 & \\
\hline HSO0008600 & 0 & & & \\
\hline HSO0008800 & -1 & & & \\
\hline HS00008801 & 330.0 & 4 & & \\
\hline $\begin{array}{l}* * x * x * * x * x * \\
* * * * *\end{array}$ & Structure & 9 & & \\
\hline$* * * * *$ & & & & \\
\hline HSO0009000 & 5 & 1 & -1 & 20 \\
\hline
\end{tabular}




\begin{tabular}{|c|c|c|c|c|}
\hline HS00009001 & V2-S09 & & & \\
\hline HS00009002 & 24.1 & 1.0 & & \\
\hline HS00009003 & 2.0 & & & \\
\hline HS00009100 & -1 & 1 & 0.0 & \\
\hline HSO0009102 & 0.0001 & 2 & & \\
\hline HS00009103 & 0.0002519 & 3 & & \\
\hline HS00009104 & 0.001 & 4 & & \\
\hline HS00009105 & 0.003373 & 5 & & \\
\hline HSO0009200 & -1 & & & \\
\hline HS00009201 & STEEL & 4 & & \\
\hline HS00009300 & 0 & & & \\
\hline HS00009400 & 1 & 2 & 1.0 & 1.0 \\
\hline HS00009500 & 63.8 & 5.0 & 10.2 & \\
\hline HS00009600 & 0 & & & \\
\hline HSO0009800 & -1 & & & \\
\hline $\begin{array}{l}\text { HS00009801 } \\
* * * * * * * * * * *\end{array}$ & 330.0 & 5 & & \\
\hline $\begin{array}{l}* * * * * * \\
* * * * * *\end{array}$ & \multicolumn{2}{|c|}{ Structure 10} & & \\
\hline HSO0010000 & 6 & 1 & -1 & 20 \\
\hline HS00010001 & $\mathrm{V} 2-\mathrm{S} 10$ & & & \\
\hline HS00010002 & 24.1 & 1.0 & & \\
\hline HS00010003 & 2.0 & & & \\
\hline HS00010100 & -1 & 1 & 0.0 & \\
\hline HS00010102 & 0.0001 & 2 & & \\
\hline HS00010103 & 0.0002519 & 3 & & \\
\hline HSO0010104 & 0.001 & 4 & & \\
\hline HS00010105 & 0.002519 & 5 & & \\
\hline HS00010106 & 0.01039 & 6 & & \\
\hline HS00010200 & -1 & & & \\
\hline HS00010201 & STEEL & 5 & & \\
\hline HSO0010300 & 0 & & & \\
\hline HS00010400 & 1 & 2 & 1.0 & 1.0 \\
\hline HS00010500 & 20.9 & 5.0 & 10.2 & \\
\hline HS00010600 & 0 & & & \\
\hline HS00010800 & -1 & & & \\
\hline $\begin{array}{l}\text { HS00010801 } \\
* * * * * * * * * * * *\end{array}$ & 330.0 & 6 & & \\
\hline$* * * * * *$ & Structure & 11 & & \\
\hline$* x * * * x$ & & & & \\
\hline HS00011000 & 8 & 1 & -1 & 20 \\
\hline HS00011001 & $\mathrm{V} 2-\mathrm{S} 11$ & & & \\
\hline HS00011002 & 24.1 & 1.0 & & \\
\hline HS00011003 & 2.0 & & & \\
\hline HSO0011100 & -1 & 1 & 0.0 & \\
\hline HS00011102 & 0.0001 & 2 & & \\
\hline HS00011103 & 0.0002519 & 3 & & \\
\hline HS00011104 & 0.001 & 4 & & \\
\hline HS00011105 & 0.002519 & 5 & & \\
\hline HS00011106 & 0.01 & 6 & & \\
\hline HS00011107 & 0.02519 & 7 & & \\
\hline HS00011108 & 0.0598 & 8 & & \\
\hline HSO0011200 & -1 & & & \\
\hline HS00011201 & STEEL & 7 & & \\
\hline
\end{tabular}




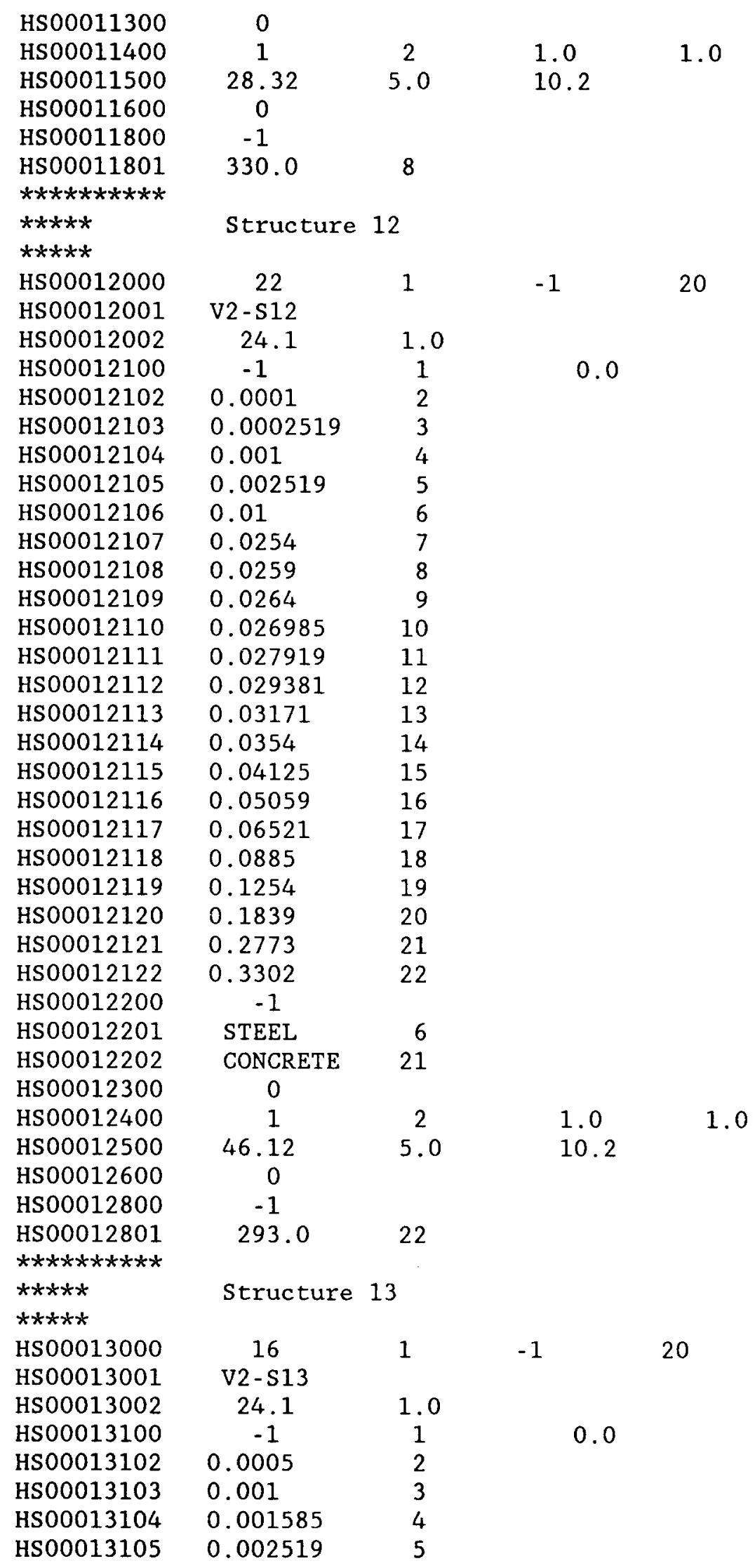




\begin{tabular}{|c|c|c|c|c|c|}
\hline HS00013106 & 0.003981 & 6 & & & \\
\hline HS00013107 & 0.006310 & 7 & & & \\
\hline HS00013108 & 0.01 & 8 & & & \\
\hline HS00013109 & 0.01585 & 9 & & & \\
\hline HS00013110 & 0.02519 & 10 & & & \\
\hline HS00013111 & 0.03981 & 11 & & & \\
\hline HS00013112 & 0.06310 & 12 & & & \\
\hline HS00013113 & 0.1 & 13 & & & \\
\hline HS00013114 & 0.1585 & 14 & & & \\
\hline HS00013115 & 0.2519 & 15 & & & \\
\hline HS00013116 & 0.3048 & 16 & & & \\
\hline HS00013200 & -1 & & & & \\
\hline HS00013201 & CONCRETE & 15 & & & \\
\hline HSO0013300 & 0 & & & & \\
\hline HSO0013400 & 1 & 2 & & & 1.0 \\
\hline HSO0013500 & 28.7 & 5.0 & 10 & & \\
\hline HS00013600 & 0 & & & & \\
\hline HSO0013800 & -1 & & & & \\
\hline HSO0013801 & 293.0 & 16 & & & \\
\hline $\begin{array}{l}* * * * * * * * * * * \\
* * * * * x\end{array}$ & \multirow{2}{*}{\multicolumn{2}{|c|}{ Structure 14}} & & & \\
\hline$x+x+3 x+x$ & & & & & \\
\hline HSO0014000 & 16 & 1 & -1 & 20 & \\
\hline HSO0014001 & $\mathrm{V} 2-\mathrm{S} 14$ & & & & \\
\hline HSO0014002 & 34.4 & 0.0 & & & \\
\hline HS00014100 & -1 & 1 & & 0.0 & \\
\hline HSO0014102 & 0.0005 & 2 & & & \\
\hline HSO0014103 & 0.001 & 3 & & & \\
\hline HSO0014104 & 0.001585 & 4 & & & \\
\hline HS00014105 & 0.002519 & 5 & & & \\
\hline HS00014106 & 0.003981 & 6 & & & \\
\hline HS00014107 & 0.006310 & 7 & & & \\
\hline HS00014108 & 0.01 & 8 & & & \\
\hline HS00014109 & 0.01585 & 9 & & & \\
\hline HS00014110 & 0.02519 & 10 & & & \\
\hline HS00014111 & 0.03981 & 11 & & & \\
\hline HS00014112 & 0.06310 & 12 & & & \\
\hline HS00014113 & 0.1 & 13 & & & \\
\hline HSO0014114 & 0.1585 & 14 & & & \\
\hline HS00014115 & 0.2519 & 15 & & & \\
\hline HS00014116 & 0.3048 & 16 & & & \\
\hline HSO0014200 & -1 & & & & \\
\hline HS00014201 & CONCRETE & 15 & & & \\
\hline HSO0014300 & 0 & & & & \\
\hline HSO0014400 & 1 & 2 & & 1.0 & 1.0 \\
\hline HS00014500 & 35.94 & 5.0 & & 6.0 & \\
\hline HS00014600 & 0 & & & & \\
\hline HS00014800 & -1 & & & & \\
\hline 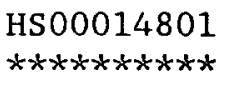 & 293.0 & 16 & & & \\
\hline $\begin{array}{l}* x * x * \\
x * x * x\end{array}$ & Structure & 15 & & & \\
\hline HS00015000 & 16 & 1 & -1 & 20 & \\
\hline HS00015001 & V2-S15 & & & & \\
\hline
\end{tabular}




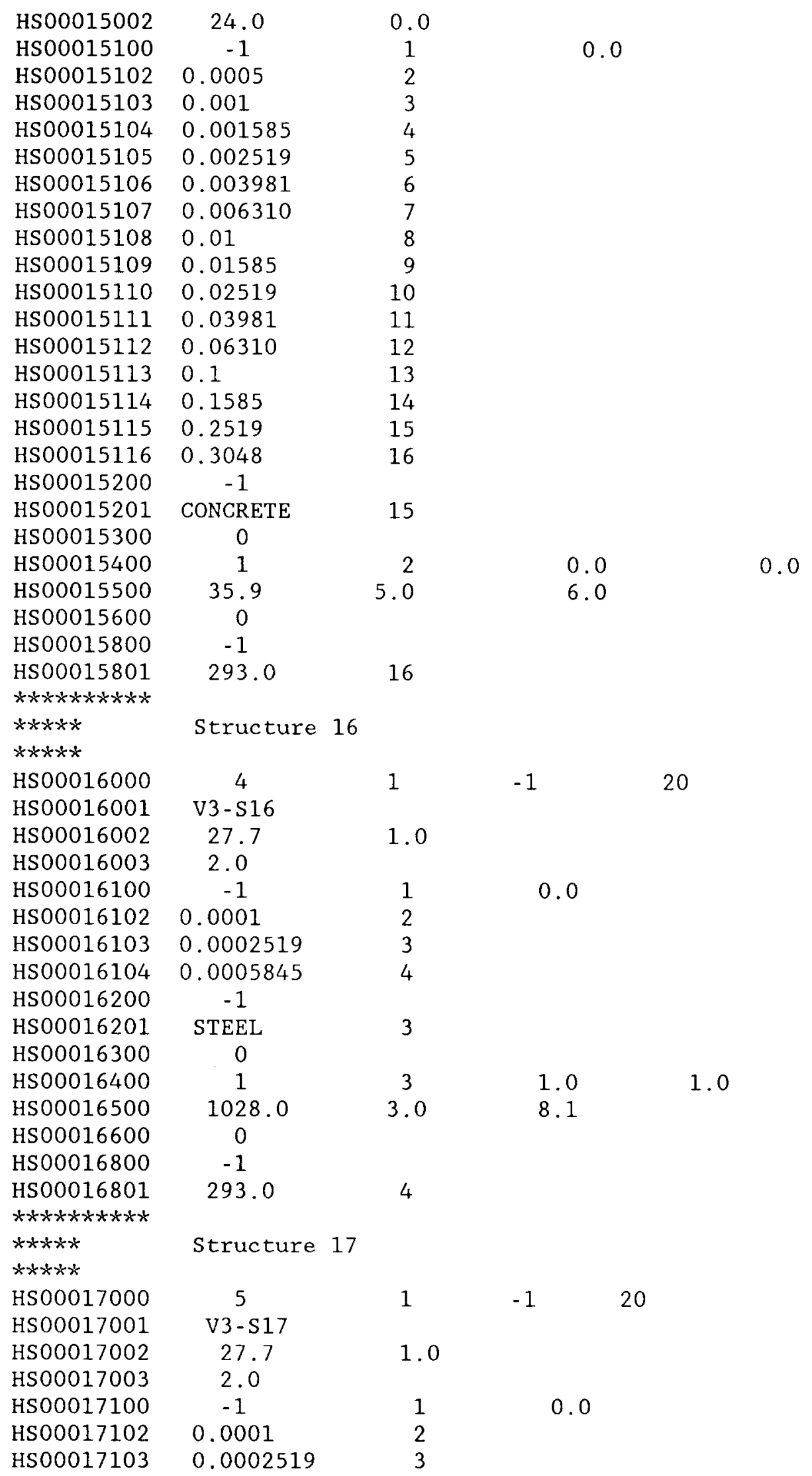




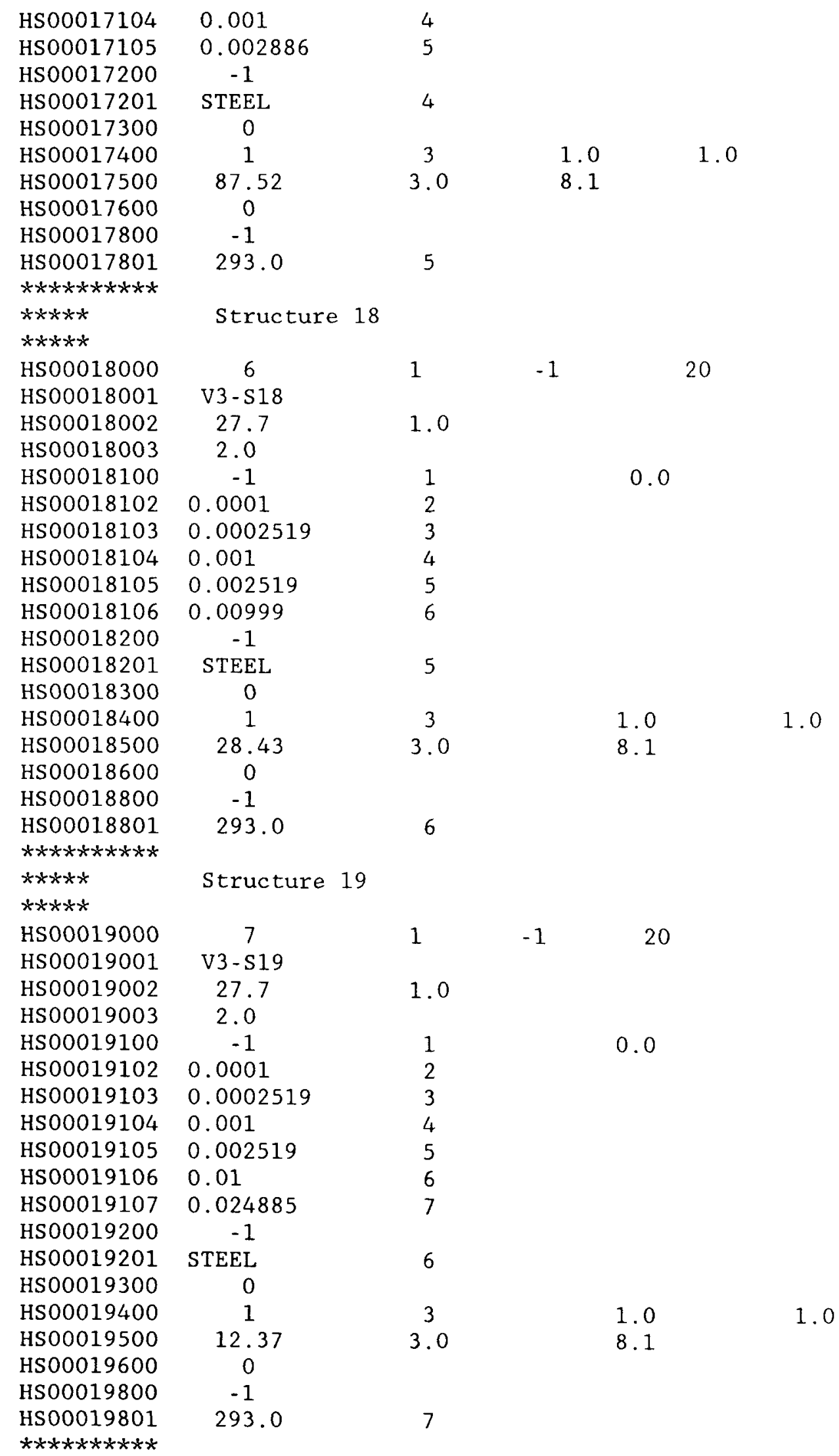




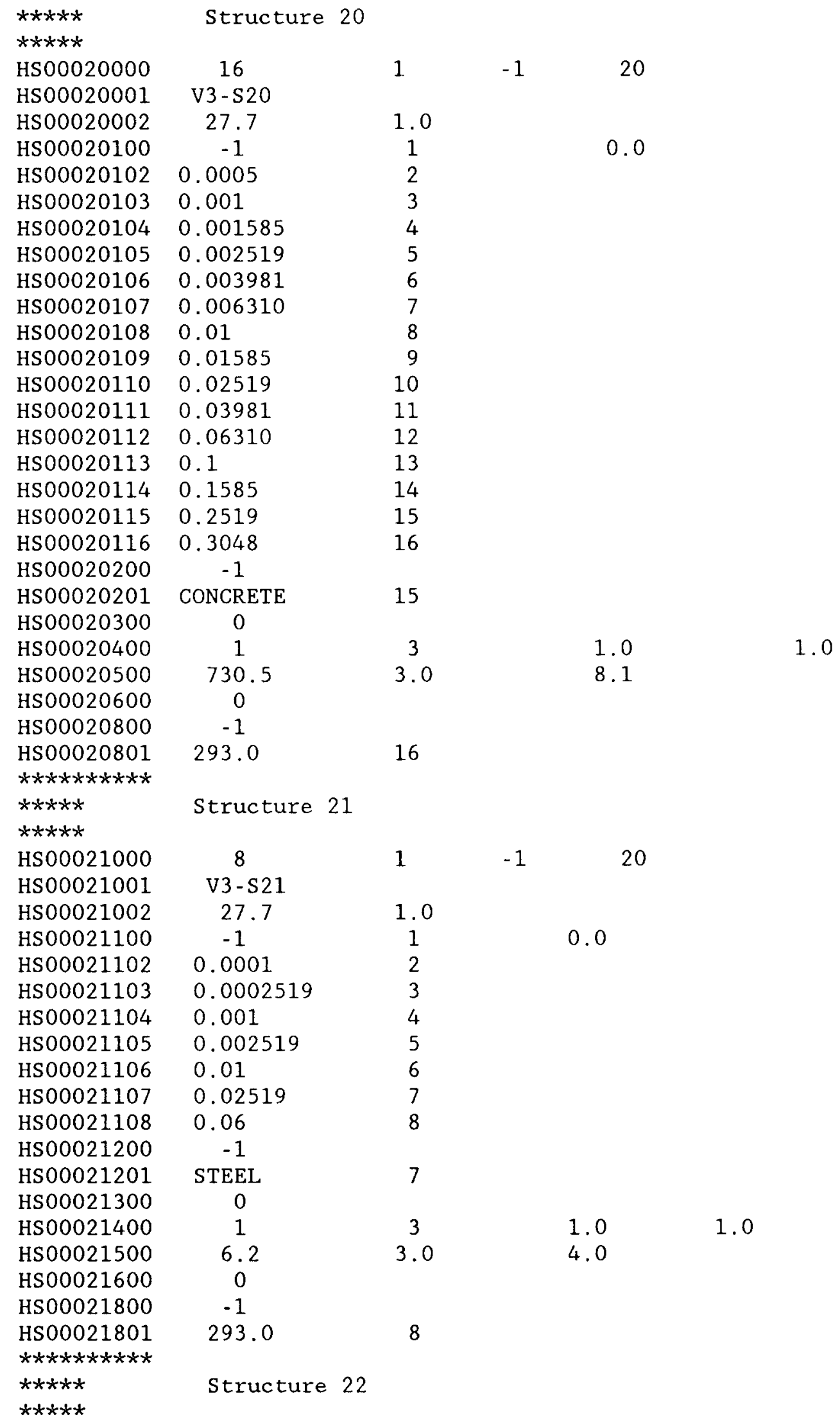




\begin{tabular}{|c|c|c|c|c|c|c|}
\hline HSO0022000 & 22 & 1 & -1 & & \multirow{2}{*}{\multicolumn{2}{|c|}{20}} \\
\hline HS00022001 & $v 3-s 22$ & & & & & \\
\hline HSO0022002 & 27.7 & 1.0 & & & & \\
\hline HS00022100 & -1 & 1 & & 0.0 & & \\
\hline HS00022102 & 0.0001 & 2 & & & & \\
\hline HS00022103 & 0.0002519 & 3 & & & & \\
\hline HSO0022104 & 0.001 & 4 & & & & \\
\hline HSO0022105 & 0.002519 & 5 & & & & \\
\hline HS00022106 & 0.01 & 6 & & & & \\
\hline HS00022107 & 0.0254 & 7 & & & & \\
\hline HSO0022108 & 0.0259 & 8 & & & & \\
\hline HS00022109 & 0.0264 & 9 & & & & \\
\hline HS00022110 & 0.026985 & 10 & & & & \\
\hline HS00022111 & 0.027919 & 11 & & & & \\
\hline HS00022112 & 0.029381 & 12 & & & & \\
\hline HSO0022113 & 0.03171 & 13 & & & & \\
\hline HS00022114 & 0.0354 & 14 & & & & \\
\hline HS00022115 & 0.04125 & 15 & & & & \\
\hline HS00022116 & 0.05059 & 16 & & & & \\
\hline HS00022117 & 0.06521 & 17 & & & & \\
\hline HSO0022118 & 0.0885 & 18 & & & & \\
\hline HSO0022119 & 0.1254 & 19 & & & & \\
\hline HS00022120 & 0.1839 & 20 & & & & \\
\hline HS00022121 & 0.2773 & 21 & & & & \\
\hline HSO0022122 & 0.3302 & 22 & & & & \\
\hline HSOOO22200 & -1 & & & & & \\
\hline HSO0022201 & STEEL & 6 & & & & \\
\hline HSO0022202 & CONCRETE & 21 & & & & \\
\hline HSO0022300 & 0 & & & & & \\
\hline HS00022400 & 1 & 3 & & 1.0 & & 1.0 \\
\hline HSO0022500 & 30.17 & 3.0 & & 8.1 & & \\
\hline HS00022600 & 0 & & & & & \\
\hline HS00022800 & -1 & & & & & \\
\hline $\begin{array}{l}\text { HSOOO22801 } \\
* * * * * * * * * * * x\end{array}$ & 293.0 & 22 & & & & \\
\hline$* * * * x * x$ & Structure 23 & & & & & \\
\hline$x+x * x x$ & & & & & & \\
\hline HSOO023000 & 16 & 1 & -1 & & 20 & \\
\hline HSO0023001 & V3-S23 & & & & & \\
\hline HSOOO23002 & 35.9 & 0.0 & & & & \\
\hline HSO0023100 & -1 & 1 & & 0.0 & & \\
\hline HS00023102 & 0.0005 & 2 & & & & \\
\hline HSO0023103 & 0.001 & 3 & & & & \\
\hline HSO0023104 & 0.001585 & 4 & & & & \\
\hline HS00023105 & 0.002519 & 5 & & & & \\
\hline HS00023106 & 0.003981 & 6 & & & & \\
\hline HS00023107 & 0.006310 & 7 & & & & \\
\hline HS00023108 & 0.01 & 8 & & & & \\
\hline HS00023109 & 0.01585 & 9 & & & & \\
\hline HS00023110 & 0.02519 & 10 & & & & \\
\hline HSO0023111 & 0.03981 & 11 & & & & \\
\hline HSO0023112 & 0.06310 & 12 & & & & \\
\hline HSO0023113 & 0.1 & 13 & & & & \\
\hline HS00023114 & 0.1585 & 14 & & & & \\
\hline
\end{tabular}




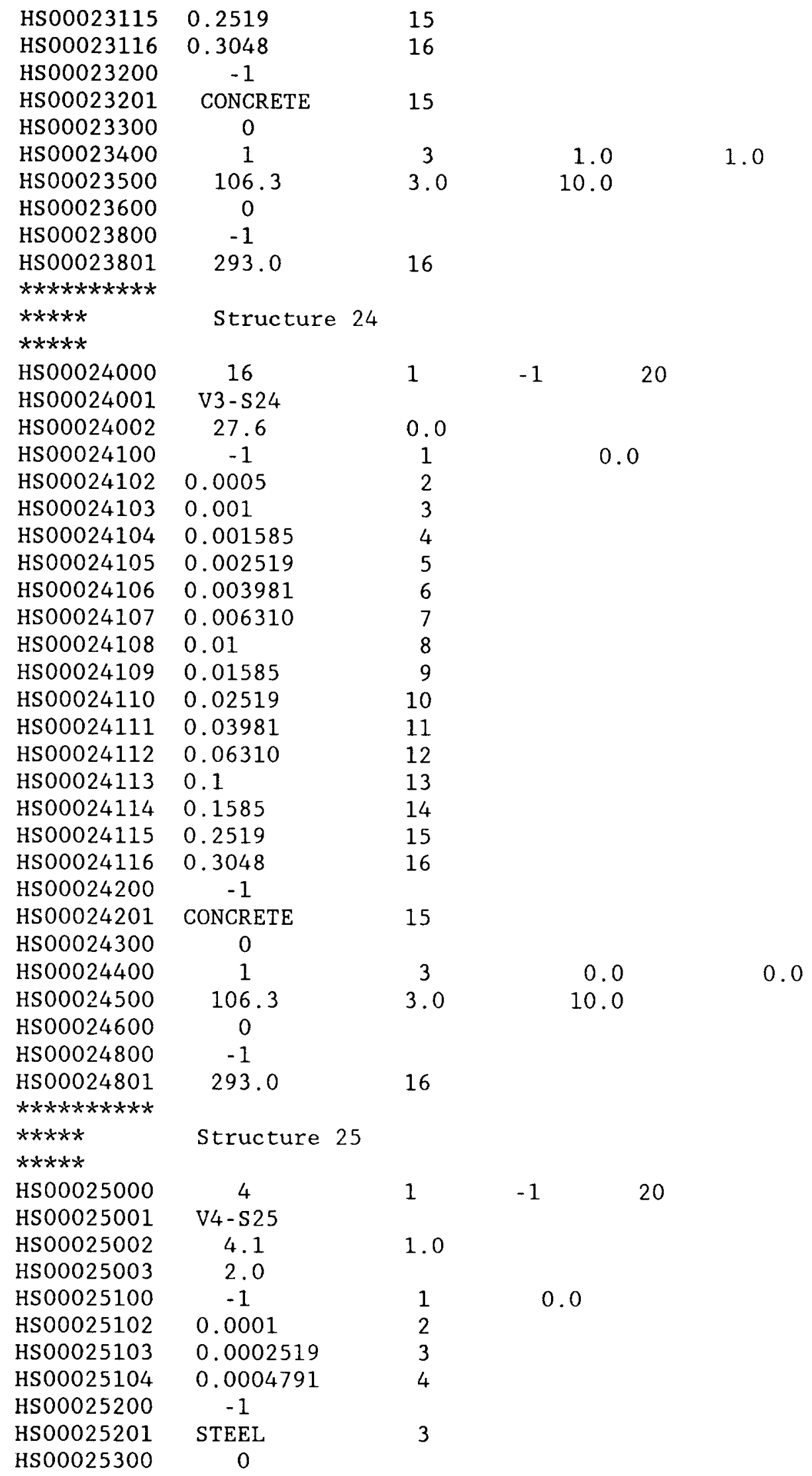




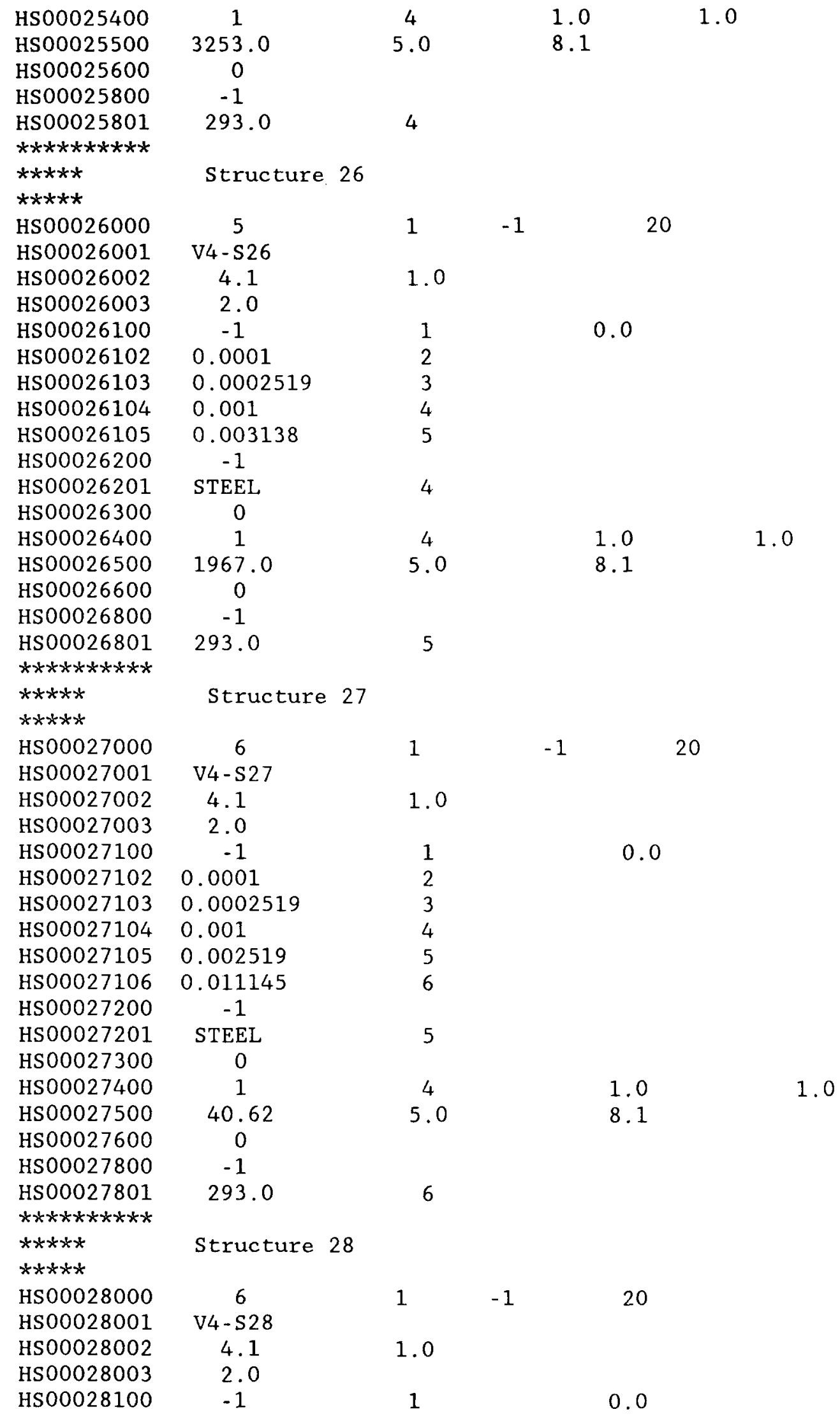




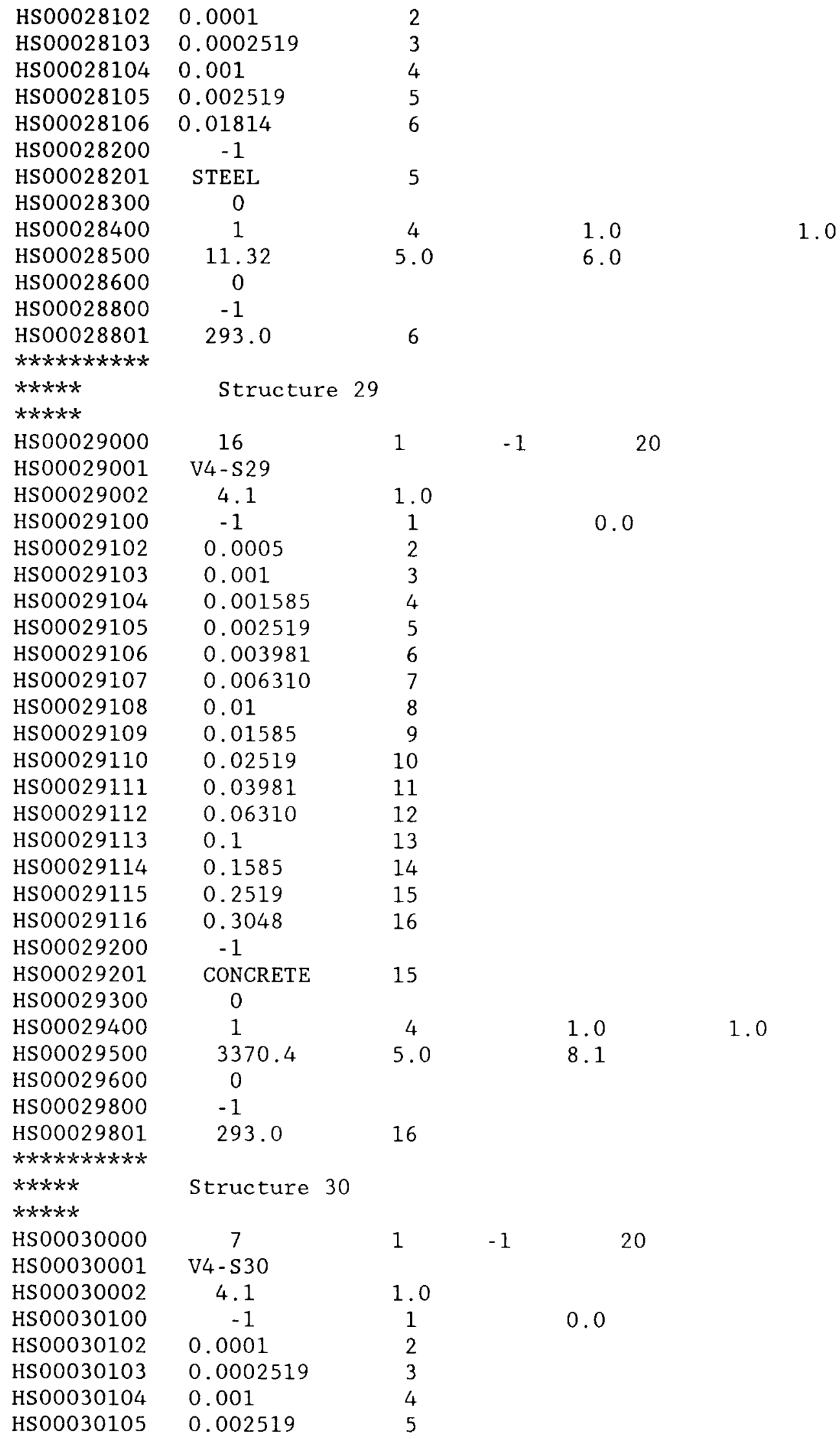




\begin{tabular}{|c|c|c|c|c|c|c|}
\hline HS00030106 & 0.01 & 6 & & & & \\
\hline HS00030107 & 0.030 & 7 & & & & \\
\hline HS00030200 & -1 & & & & & \\
\hline HS00030201 & STEEL & 6 & & & & \\
\hline HSO0030300 & 0 & & & & & \\
\hline HSO0030400 & 1 & 4 & & 1.0 & & 1.0 \\
\hline HS00030500 & 199.6 & 5.0 & & 8.1 & & \\
\hline HS00030600 & 0 & & & & & \\
\hline HS00030800 & -1 & & & & & \\
\hline HS00030801 & 293.0 & 7 & & & & \\
\hline$* * * * * * x * * * * x$ & & & & & & \\
\hline$* * * * *$ & Structure 31 & & & & & \\
\hline$* * * * *$ & & & & & & \\
\hline HS00031000 & 16 & 1 & -1 & & 20 & \\
\hline HS00031001 & V4-S 31 & & & & & \\
\hline HS00031002 & 18.0 & 0.0 & & & & \\
\hline HS00031100 & -1 & 1 & & & 0.0 & \\
\hline HS00031102 & 0.0005 & 2 & & & & \\
\hline HS00031103 & 0.001 & 3 & & & & \\
\hline HS00031104 & 0.001585 & 4 & & & & \\
\hline HS00031105 & 0.002519 & 5 & & & & \\
\hline HS00031106 & 0.003981 & 6 & & & & \\
\hline HS00031107 & 0.006310 & 7 & & & & \\
\hline HS00031108 & 0.01 & 8 & & & & \\
\hline HS00031109 & 0.01585 & 9 & & & & \\
\hline HS00031110 & 0.02519 & 10 & & & & \\
\hline HS00031111 & 0.03981 & 11 & & & & \\
\hline HS00031112 & 0.06310 & 12 & & & & \\
\hline HSO0031113 & 0.1 & 13 & & & & \\
\hline HS00031114 & 0.1585 & 14 & & & & \\
\hline HSO0031115 & 0.2519 & 15 & & & & \\
\hline HS00031116 & 0.3048 & 16 & & & & \\
\hline HSO0031200 & -1 & & & & & \\
\hline HS00031201 & CONCRETE & 15 & & & & \\
\hline HSO0031300 & 0 & & & & & \\
\hline HS00031400 & 1 & 4 & & 1.0 & & 1.0 \\
\hline HS00031500 & 624.8 & 5.0 & & 25.0 & & \\
\hline HSO0031600 & 0 & & & & & \\
\hline HSO0031800 & -1 & & & & & \\
\hline $\begin{array}{l}\text { HS00031801 } \\
* * * * * * * * * *\end{array}$ & 293.0 & 16 & & & & \\
\hline$* * * * *$ & Structure 32 & & & & & \\
\hline$* * * * * x$ & & & & & & \\
\hline HSO0032000 & 16 & 1 & -1 & & 20 & \\
\hline HS00032001 & $V 4-S 32$ & & & & & \\
\hline HSO0032002 & 4.0 & 0.0 & & & & \\
\hline HSO0032100 & -1 & 1 & & 0.0 & & \\
\hline HS00032102 & 0.0005 & 2 & & & & \\
\hline HS00032103 & 0.001 & 3 & & & & \\
\hline HSO0032104 & 0.001585 & 4 & & & & \\
\hline HS00032105 & 0.002519 & 5 & & & & \\
\hline HS00032106 & 0.003981 & 6 & & & & \\
\hline HS00032107 & 0.006310 & 7 & & & & \\
\hline HS00032108 & 0.01 & 8 & & & & \\
\hline
\end{tabular}




\begin{tabular}{|c|c|c|c|c|c|}
\hline HSO0032109 & 0.01585 & 9 & & & \\
\hline HS00032110 & 0.02519 & 10 & & & \\
\hline HS00032111 & 0.03981 & 11 & & & \\
\hline HSO0032112 & 0.06310 & 12 & & & \\
\hline HS00032113 & 0.1 & 13 & & & \\
\hline HSO0032114 & 0.1585 & 14 & & & \\
\hline HS00032115 & 0.2519 & 15 & & & \\
\hline HS00032116 & 0.3048 & 16 & & & \\
\hline HSO0032200 & -1 & & & & \\
\hline HS00032201 & CONCRETE & 15 & & & \\
\hline HSO0032300 & 0 & & & & \\
\hline HSO0032400 & 1 & 4 & & 0.0 & 0.0 \\
\hline HSO0032500 & 624.8 & 5.0 & & 25.0 & \\
\hline HSO0032600 & 0 & & & & \\
\hline HS00032800 & -1 & & & & \\
\hline HSO0032801 & 293.0 & 16 & & & \\
\hline$* * * * * * * * * * *$ & & & & & \\
\hline$* * * * *$ & Structure 33 & & & & \\
\hline$x * x * x$ & & & & & \\
\hline HSO0033000 & 4 & 1 & -1 & 20 & \\
\hline HS00033001 & V5-S33 & & & & \\
\hline HSO0033002 & 35.5 & 1.0 & & & \\
\hline HS00033003 & 2.0 & & & & \\
\hline HSO0033100 & -1 & 1 & & 0.0 & \\
\hline HSO0033102 & 0.0001 & 2 & & & \\
\hline HSO0033103 & 0.0002519 & 3 & & & \\
\hline HS00033104 & 0.0004954 & 4 & & & \\
\hline $\mathrm{HSO} 0033200$ & -1 & & & & \\
\hline HSO0033201 & STEEL & 3 & & & \\
\hline HS00033300 & 0 & & & & \\
\hline HS00033400 & 1 & 5 & & 1.0 & 1.0 \\
\hline HS00033500 & 3197.0 & 10.0 & & 28.0 & \\
\hline HSO0033600 & 0 & & & & \\
\hline HS00033800 & -1 & & & & \\
\hline HS00033801 & 293.0 & 4 & & & \\
\hline$* * * * * * * * * * *$ & & & & & \\
\hline$* * * * *$ & Structure 34 & & & & \\
\hline$* x * * *$ & & & & & \\
\hline HSO0034000 & 5 & 1 & -1 & 20 & \\
\hline HSO0034001 & V5-S34 & & & & \\
\hline HSO0034002 & 35.5 & 1.0 & & & \\
\hline HSO0034003 & 2.0 & & & & \\
\hline HSO0034100 & -1 & 1 & & 0.0 & \\
\hline HS00034102 & 0.0001 & 2 & & & \\
\hline HS00034103 & 0.0002519 & 3 & & & \\
\hline HSO0034104 & 0.001 & 4 & & & \\
\hline HS00034105 & 0.0029615 & 5 & & & \\
\hline HSO0034200 & -1 & & & & \\
\hline HS00034201 & STEEL & 4 & & & \\
\hline HS00034300 & 0 & & & & \\
\hline HSO0034400 & 1 & 5 & & 1.0 & 1.0 \\
\hline HSO0034500 & 3667.0 & 10.0 & & 28.0 & \\
\hline HSO0034600 & 0 & & & & \\
\hline HSO0034800 & -1 & & & & \\
\hline
\end{tabular}




\begin{tabular}{|c|c|c|c|c|c|c|}
\hline $\begin{array}{l}\mathrm{HS} 00034801 \\
* * * * * * * * * * *\end{array}$ & 293.0 & 5 & & & & \\
\hline$* * * * *$ & Structure 35 & & & & & \\
\hline \multicolumn{7}{|l|}{$* * * * *$} \\
\hline HS00035000 & 6 & 1 & -1 & 20 & & \\
\hline HS00035001 & V5-S35 & & & & & \\
\hline HS00035002 & 35.5 & 1.0 & & & & \\
\hline HSO0035003 & 2.0 & & & & & \\
\hline HS00035100 & -1 & 1 & & 0.0 & & \\
\hline HS00035102 & 0.0001 & 2 & & & & \\
\hline HS00035103 & 0.0002519 & 3 & & & & \\
\hline HSO0035104 & 0.001 & 4 & & & & \\
\hline HSO0035105 & 0.002519 & 5 & & & & \\
\hline HS00035106 & 0.00701 & 6 & & & & \\
\hline HSO0035200 & -1 & & & & & \\
\hline HS00035201 & STEEL & 5 & & & & \\
\hline HS00035300 & 0 & & & & & \\
\hline HS00035400 & 1 & 5 & & 1.0 & & 1.0 \\
\hline HSO0035500 & 404.6 & 10.0 & & 28.0 & & \\
\hline HS00035600 & 0 & & & & & \\
\hline HSO0035800 & -1 & & & & & \\
\hline $\begin{array}{l}\text { HS00035801 } \\
* * * * * * * * * * *\end{array}$ & 293.0 & 6 & & & & \\
\hline$* * * * * *$ & Structure 36 & & & & & \\
\hline \multicolumn{7}{|l|}{$* * * * * *$} \\
\hline HSO0036000 & 7 & 1 & -1 & 20 & & \\
\hline HSO0036001 & V5-S36 & & & & & \\
\hline HSO0036002 & 35.5 & 1.0 & & & & \\
\hline HSO0036003 & 2.0 & & & & & \\
\hline HS00036100 & -1 & 1 & & 0.0 & & \\
\hline HS00036102 & 0.0001 & 2 & & & & \\
\hline HS00036103 & 0.0002519 & 3 & & & & \\
\hline HS00036104 & 0.001 & 4 & & & & \\
\hline HS00036105 & 0.002519 & 5 & & & & \\
\hline HS00036106 & 0.01 & 6 & & & & \\
\hline HS00036107 & 0.02598 & 7 & & & & \\
\hline HSO0036200 & -1 & & & & & \\
\hline HS00036201 & STEEL & 6 & & & & \\
\hline HS00036300 & 0 & & & & & \\
\hline HS00036400 & 1 & 5 & & 1.0 & 1.0 & \\
\hline HSO0036500 & 190.3 & 10.0 & & 28.0 & & \\
\hline HS00036600 & 0 & & & & & \\
\hline HS00036800 & -1 & & & & & \\
\hline HSO0036801 & 293.0 & 7 & & & & \\
\hline$* * * * * * * * * * * *$ & & & & & & \\
\hline$* * * * * *$ & Structure 37 & & & & & \\
\hline \multicolumn{7}{|l|}{$* * * * * x$} \\
\hline HSO0037000 & 16 & 1 & -1 & 20 & & \\
\hline HS00037001 & V5-S37 & & & & & \\
\hline HS00037002 & 35.5 & 1.0 & & & & \\
\hline HS00037100 & -1 & 1 & & 0.0 & & \\
\hline HS00037102 & 0.0005 & 2 & & & & \\
\hline HSO0037103 & 0.001 & 3 & & & & \\
\hline HS00037104 & 0.001585 & 4 & & & & \\
\hline
\end{tabular}




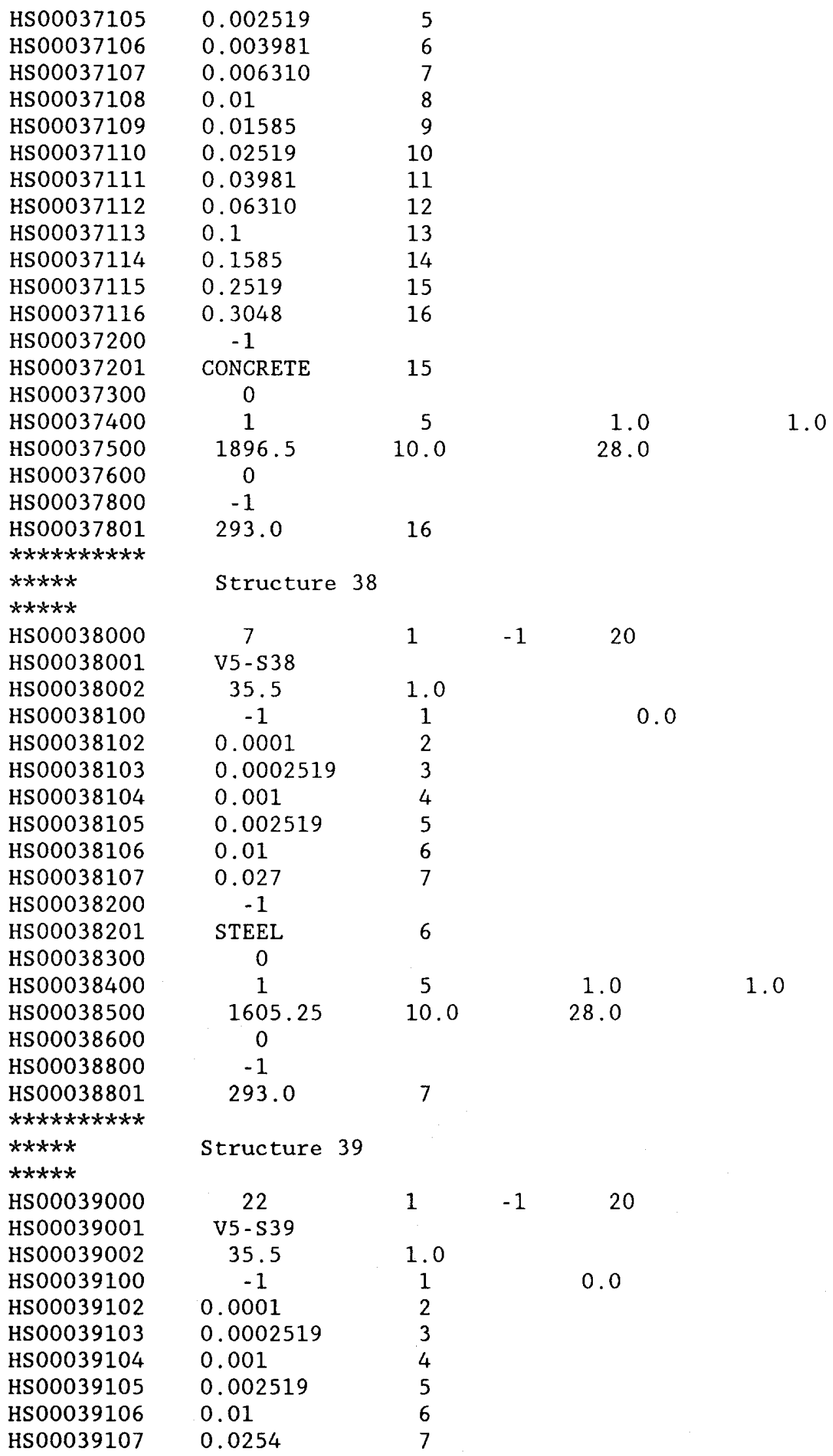




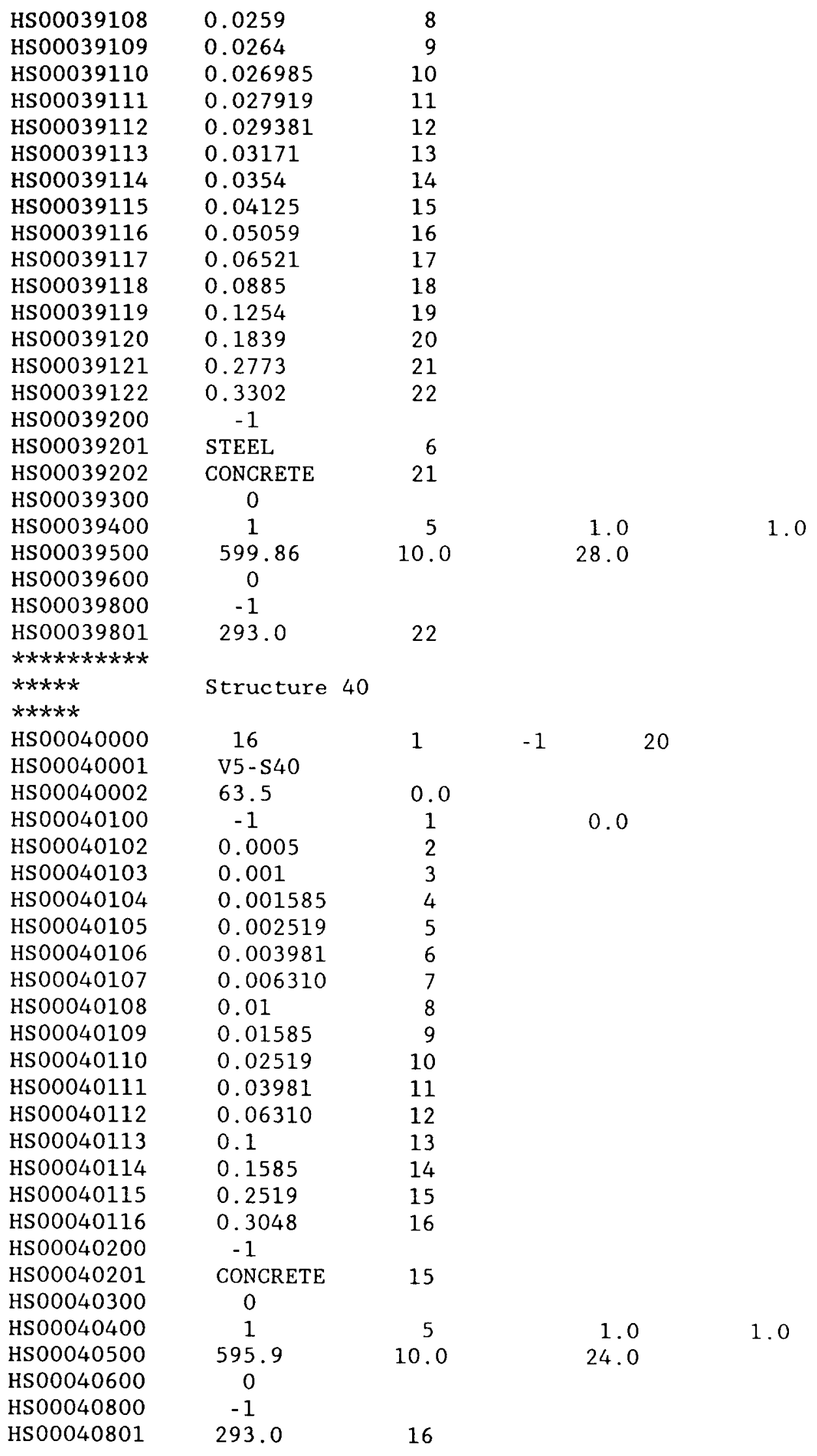




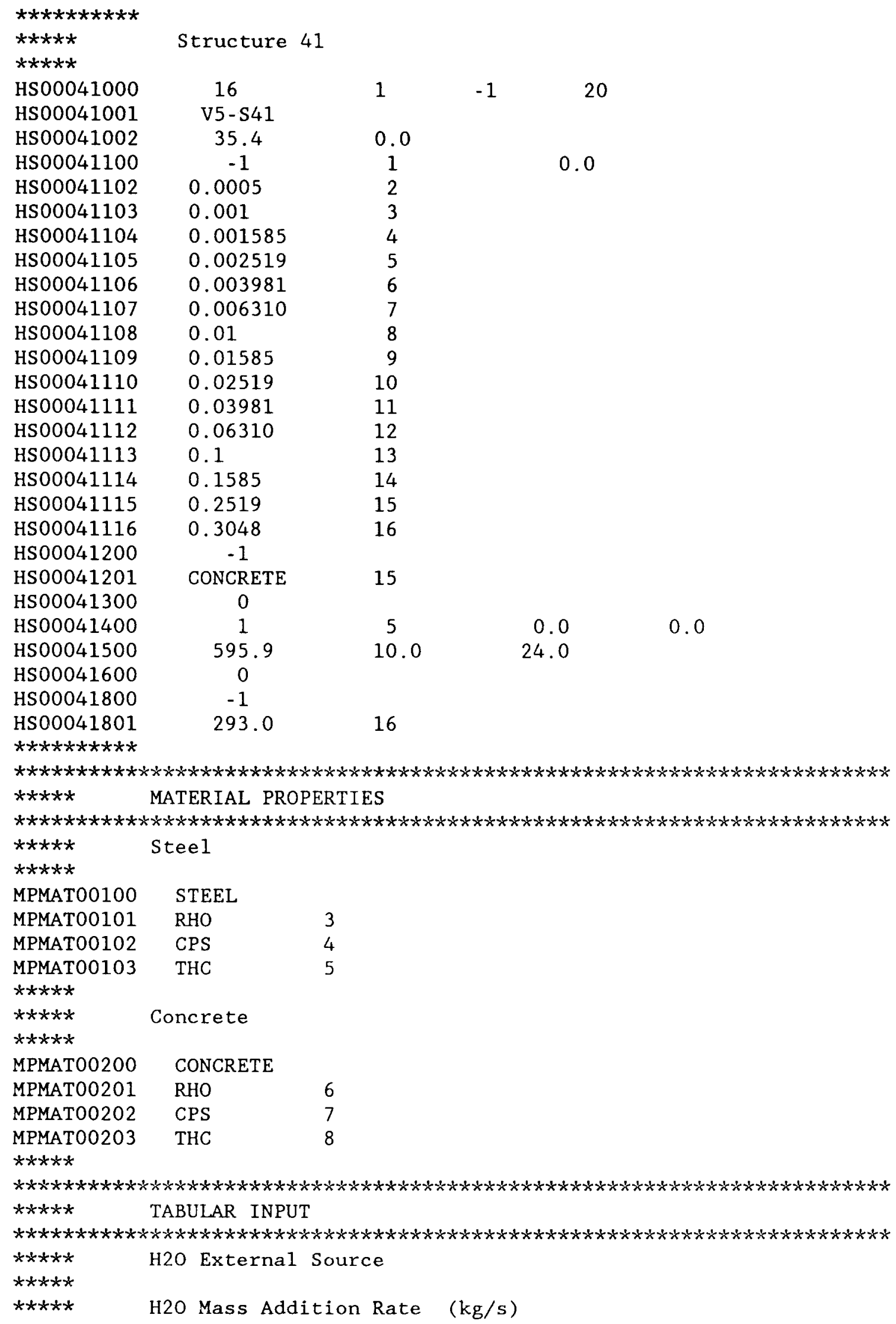




\begin{tabular}{|c|c|c|c|c|}
\hline$\star * \star * * *$ & & & & \\
\hline TF00100 & MASS & 90 & 1.0 & 0.0 \\
\hline TF001A0 & 0.0 & 0.0 & & \\
\hline TF001A1 & 0.02 & 1391.0 & & \\
\hline TF001A2 & 0.04 & 1245.0 & & \\
\hline TF001A3 & 0.06 & 1307.0 & & \\
\hline TF001A4 & 0.08 & 1422.0 & & \\
\hline TF001A5 & 0.10 & 1405.0 & & \\
\hline TF001A6 & 0.12 & 1362.0 & & \\
\hline TF001A7 & 0.14 & 1283.0 & & \\
\hline TF001A8 & 0.16 & 1277.0 & & \\
\hline TF001A9 & 0.18 & 1315.0 & & \\
\hline TF001B0 & 0.20 & 1335.0 & & \\
\hline TF001B1 & 0.22 & 1248.0 & & \\
\hline TF001B2 & 0.24 & 1230.0 & & \\
\hline TF001B 3 & 0.26 & 1230.0 & & \\
\hline TF001B4 & 0.28 & 1268.0 & & \\
\hline TF001B5 & 0.30 & 1306.0 & & \\
\hline TF001B6 & 0.40 & 1497.0 & & \\
\hline TF001B 7 & 0.50 & 1688.0 & & \\
\hline TF001B8 & 0.60 & 1879.0 & & \\
\hline TF001B9 & 0.70 & 2038.0 & & \\
\hline TF001C0 & 0.80 & 2152.0 & & \\
\hline TF001C1 & 0.90 & 2227.0 & & \\
\hline TF001C2 & 1.0 & 2282.1 & & \\
\hline TF001C3 & 1.1 & 2324.0 & & \\
\hline TF001C4 & 1.2 & 2352.0 & & \\
\hline TF001C5 & 1.3 & 2375.0 & & \\
\hline TF001C6 & 1.4 & 2388.0 & & \\
\hline TF001C7 & 1.5 & 2401.2 & & \\
\hline TF001C8 & 1.6 & 2406.0 & & \\
\hline TF001C9 & 1.7 & 2469.0 & & \\
\hline TF001D0 & 1.8 & 2404.0 & & \\
\hline TF001D1 & 1.9 & 2400.0 & & \\
\hline TF001D2 & 2.0 & 2395.2 & & \\
\hline TF001D3 & 2.5 & 2344.4 & & \\
\hline TF001D4 & 3.0 & 2283.1 & & \\
\hline TF001D5 & 3.5 & 2216.1 & & \\
\hline TF001D6 & 4.0 & 2148.6 & & \\
\hline TF001D7 & 4.5 & 2081.8 & & \\
\hline TF001D8 & 5.0 & 2016.5 & & \\
\hline TF001D9 & 5.5 & 1950.7 & & \\
\hline TF001E0 & 6.0 & 1883.3 & & \\
\hline TF001E1 & 6.5 & 1817.3 & & \\
\hline TF001E2 & 7.0 & 1750.8 & & \\
\hline TF001E3 & 7.5 & 1684.2 & & \\
\hline TF001E4 & 8.0 & 1622.7 & & \\
\hline TF001E5 & 8.5 & 1511.9 & & \\
\hline TF001E6 & 9.0 & 1460.0 & & \\
\hline TF001E7 & 9.5 & 1413.4 & & \\
\hline TF001E8 & 10.0 & 1365.0 & & \\
\hline TF001E9 & 11.0 & 1262.9 & & \\
\hline TF001F0 & 12.0 & 1159.0 & & \\
\hline TF001F1 & 13.0 & 1055.7 & & \\
\hline
\end{tabular}




\begin{tabular}{|c|c|c|}
\hline TF001F2 & 14.0 & 957.62 \\
\hline TF001F3 & 15.0 & 864.28 \\
\hline TF001F4 & 16.0 & 774.33 \\
\hline TF001F5 & 17.0 & 691.92 \\
\hline TF001F6 & 18.0 & 617.09 \\
\hline TF001F7 & 19.0 & 547.40 \\
\hline TF001F8 & 20.0 & 479.19 \\
\hline TF001F9 & 21.0 & 416.62 \\
\hline TF001G0 & 22.0 & 363.80 \\
\hline TF001G1 & 23.0 & 319.37 \\
\hline TF001G2 & 24.0 & 287.92 \\
\hline TF001G3 & 25.0 & 259.30 \\
\hline TF001G4 & 26.0 & 236.02 \\
\hline TF001G5 & 27.0 & 215.81 \\
\hline TF001G6 & 28.0 & 196.81 \\
\hline TF001G7 & 29.0 & 179.10 \\
\hline TF001G8 & 30.0 & 166.96 \\
\hline TF001G9 & 31.0 & 157.05 \\
\hline TF001HO & 32.0 & 147.75 \\
\hline TF001H1 & 33.0 & 138.84 \\
\hline TF001H2 & 34.0 & 130.49 \\
\hline TF001H3 & 35.0 & 118.43 \\
\hline TF001H4 & 36.0 & 103.46 \\
\hline TF001H5 & 37.0 & 91.452 \\
\hline TF001H6 & 38.0 & 82.058 \\
\hline TF001H7 & 39.0 & 74.413 \\
\hline TF001H8 & 40.0 & 67.821 \\
\hline TF001H9 & 41.0 & 62.054 \\
\hline TF001I0 & 42.0 & 57.036 \\
\hline TF001I1 & 43.0 & 52.618 \\
\hline TF001I 2 & 44.0 & 48.630 \\
\hline TF001I3 & 45.0 & 45.052 \\
\hline TF001I4 & 46.0 & 41.756 \\
\hline TF001I5 & 47.0 & 38.707 \\
\hline TF001I6 & 48.0 & 35.865 \\
\hline TF001I7 & 50.0 & 30.733 \\
\hline TF001I8 & 70.0 & 0.0 \\
\hline TF001I9 & 10000.0 & 0.0 \\
\hline
\end{tabular}

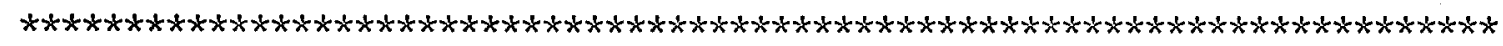
$x * x * x$

$\star * x * x$

$\star * * * * * x$

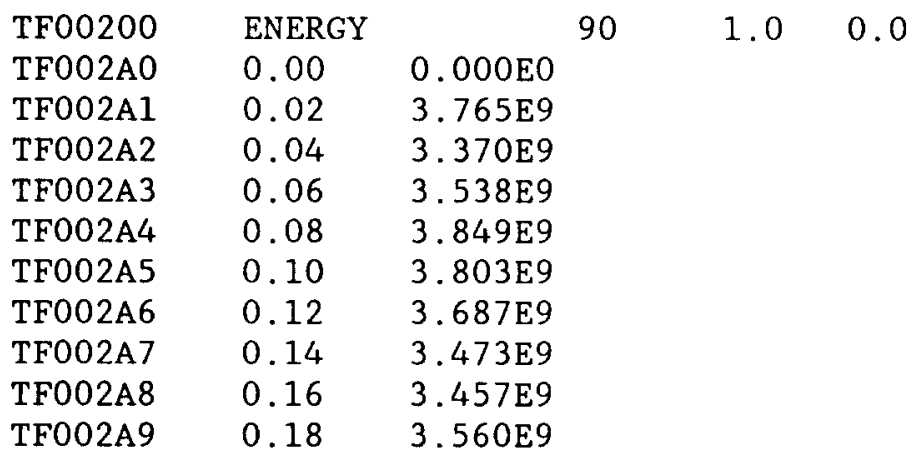




$\begin{array}{lrr}\text { TF002B0 } & 0.20 & 3.614 \mathrm{E} 9 \\ \text { TF002B1 } & 0.22 & 3.378 \mathrm{E} 9 \\ \text { TF002B2 } & 0.24 & 3.330 \mathrm{E} 9 \\ \text { TF002B3 } & 0.26 & 3.330 \mathrm{E} 9 \\ \text { TF002B4 } & 0.28 & 3.346 \mathrm{E} 9 \\ \text { TF002B5 } & 0.30 & 3.358 \mathrm{E} 9 \\ \text { TF002B6 } & 0.4 & 3.341 \mathrm{E} 9 \\ \text { TF002B7 } & 0.5 & 3.197 \mathrm{E} 9 \\ \text { TF002B8 } & 0.6 & 2.922 \mathrm{E} 9 \\ \text { TF002B9 } & 0.7 & 3.094 \mathrm{E} 9 \\ \text { TF002C0 } & 0.8 & 3.219 \mathrm{E} 9 \\ \text { TF002C1 } & 0.9 & 3.300 \mathrm{E} 9 \\ \text { TF002C2 } & 1.0 & 3.360 \mathrm{E} 9 \\ \text { TF002C3 } & 1.1 & 3.405 \mathrm{E} 9 \\ \text { TF002C4 } & 1.2 & 3.436 \mathrm{E} 9 \\ \text { TF002C5 } & 1.3 & 3.460 \mathrm{E} 9 \\ \text { TF002C6 } & 1.4 & 3.472 \mathrm{E} 9 \\ \text { TF002C7 } & 1.5 & 3.486 \mathrm{E} 9 \\ \text { TF002C8 } & 1.6 & 3.489 \mathrm{E} 9 \\ \text { TF002C9 } & 1.7 & 3.578 \mathrm{E} 9 \\ \text { TF002D0 } & 1.8 & 3.481 \mathrm{E} 9 \\ \text { TF002D1 } & 1.9 & 3.473 \mathrm{E} 9 \\ \text { TF002D2 } & 2.0 & 3.465 \mathrm{E} 9 \\ \text { TF002D3 } & 2.5 & 3.392 \mathrm{E} 9 \\ \text { TF002D4 } & 3.0 & 3.308 \mathrm{E} 9 \\ \text { TF002D5 } & 3.5 & 3.218 \mathrm{E} 9 \\ \text { TF002D6 } & 4.0 & 3.128 \mathrm{E} 9 \\ \text { TF002D7 } & 4.5 & 3.041 \mathrm{E} 9 \\ \text { TF002D8 } & 5.0 & 2.958 \mathrm{E} 9 \\ \text { TF002D9 } & 5.5 & 2.874 \mathrm{E} 9 \\ \text { TF002E0 } & 6.0 & 2.787 \mathrm{E} 9 \\ \text { TF002E1 } & 6.5 & 2.705 \mathrm{E} 9 \\ \text { TF002E2 } & 7.0 & 2.622 \mathrm{E} 9 \\ \text { TF002E3 } & 7.5 & 2.537 \mathrm{E} 9 \\ \text { TF002E4 } & 8.0 & 2.462 \mathrm{E} 9 \\ \text { TF002E5 } & 8.5 & 2.345 \mathrm{E} 9 \\ \text { TF002E6 } & 9.0 & 2.270 \mathrm{E} 9 \\ \text { TF002E7 } & 9.5 & 2.204 \mathrm{E} 9 \\ \text { TF0002G1 } & 23.0 & 7.024 \mathrm{E} 8 \\ \text { TF02G2 } & 24.0 & 6.526 \mathrm{E} 8 \\ \text { TF002E9 } & 10.0 & 2.136 \mathrm{E} 9 \\ \text { TF002G3 } & 25.0 & 6.067 \mathrm{E} 8 \\ \text { TF002F0 } & 11.0 & 2.001 \mathrm{E} 9 \\ \text { TF002F1 } & 13.0 & 1.864 \mathrm{E} 9 \\ \text { TF002F2 } & 14.0 & 1.728 \mathrm{E} 9 \\ \text { TF002F3 } & 15.0 & 1.598 \mathrm{E} 9 \\ \text { TF002F4 } & 16.0 & 1.372 \mathrm{E} 9 \\ \text { TF002F5 } & 17.0 & 1.235 \mathrm{E} 9 \\ \text { TF002F6 } & 18.0 & 1.130 \mathrm{E} 9 \\ \text { TF002F7 } & 19.0 & 1.031 \mathrm{E} 9 \\ \text { TF002F8 } & 20.0 & 9.344 \mathrm{E} 8 \\ \text { TF002F9 } & 21.0 & 8.450 \mathrm{E} 8 \\ \text { TF002G0 } & 22.0 & 7.677 \mathrm{E} 8 \\ \text { TF } & & \end{array}$




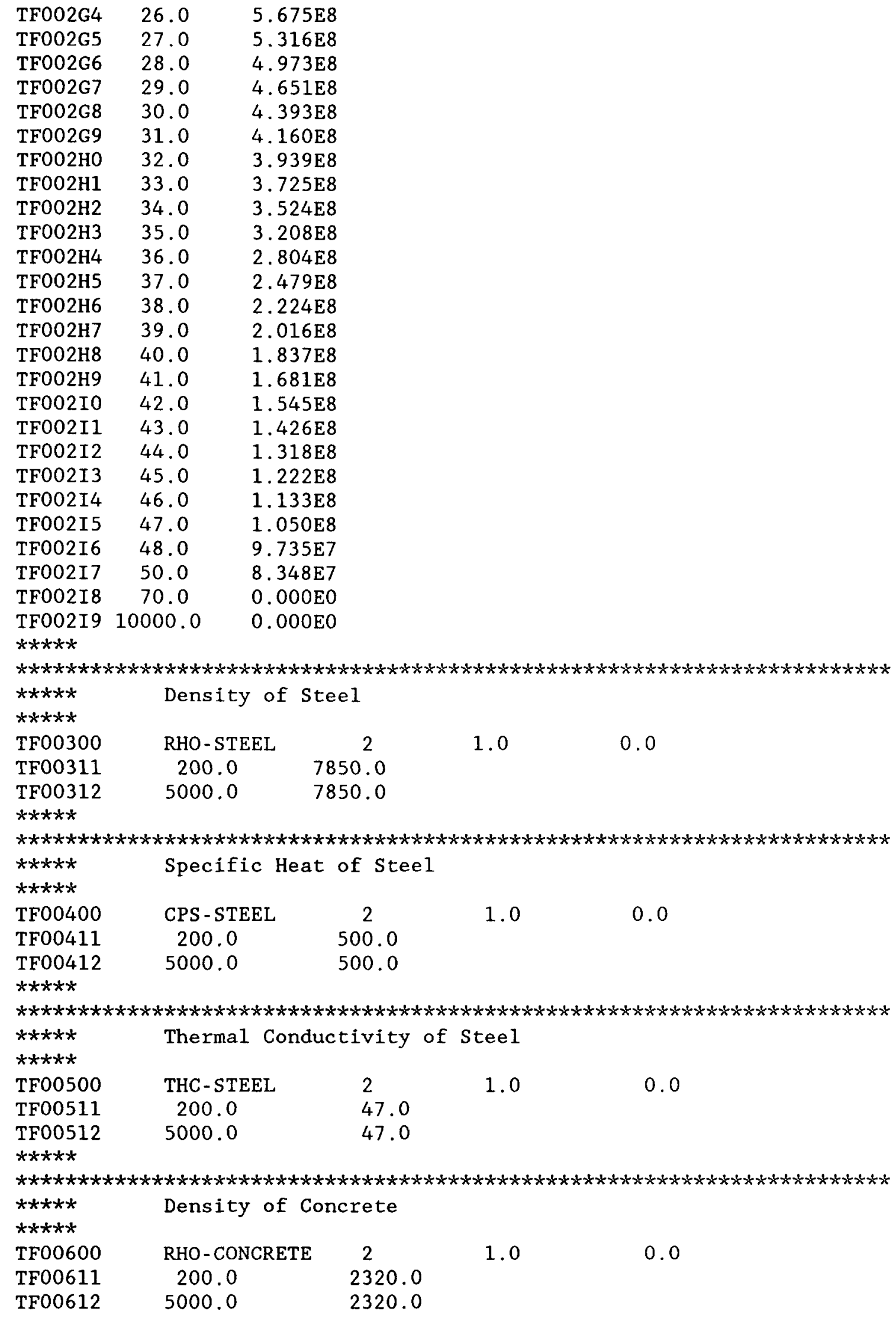




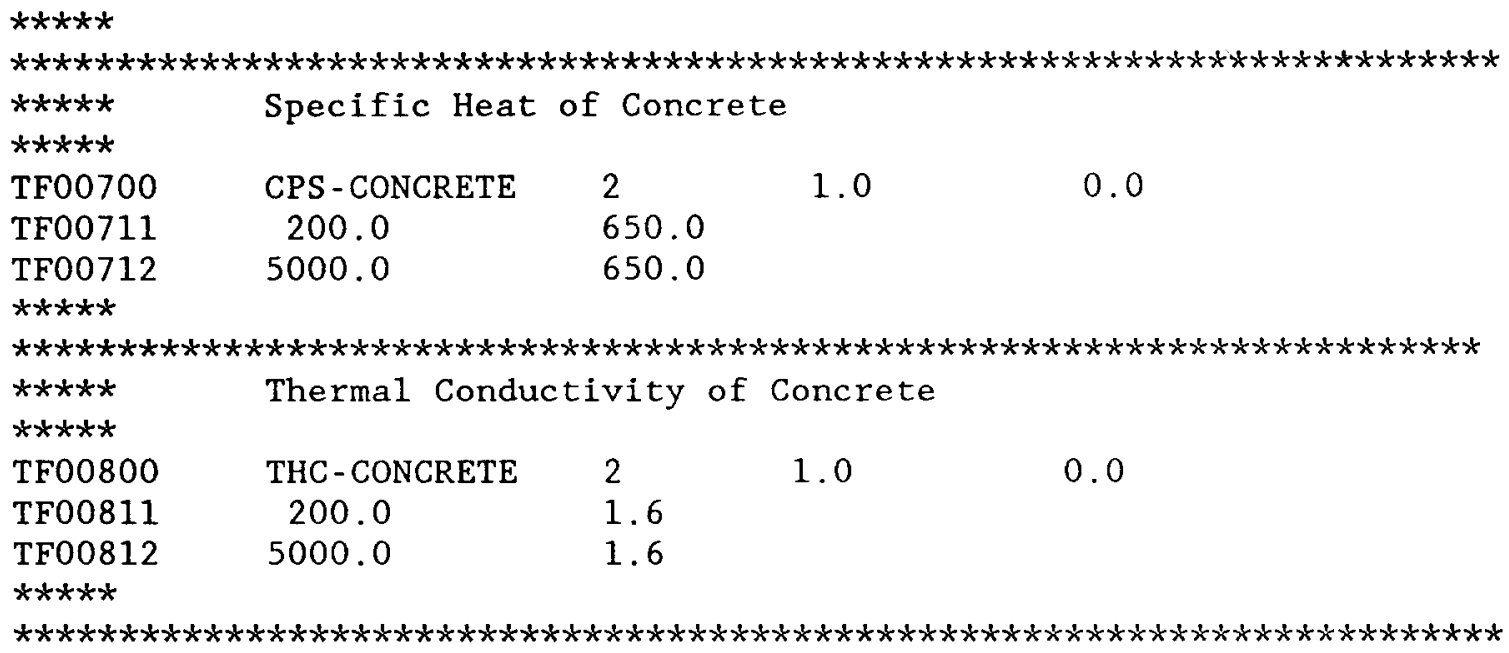

ST007: HDR Steam Blowdown Test

MELCOR Input

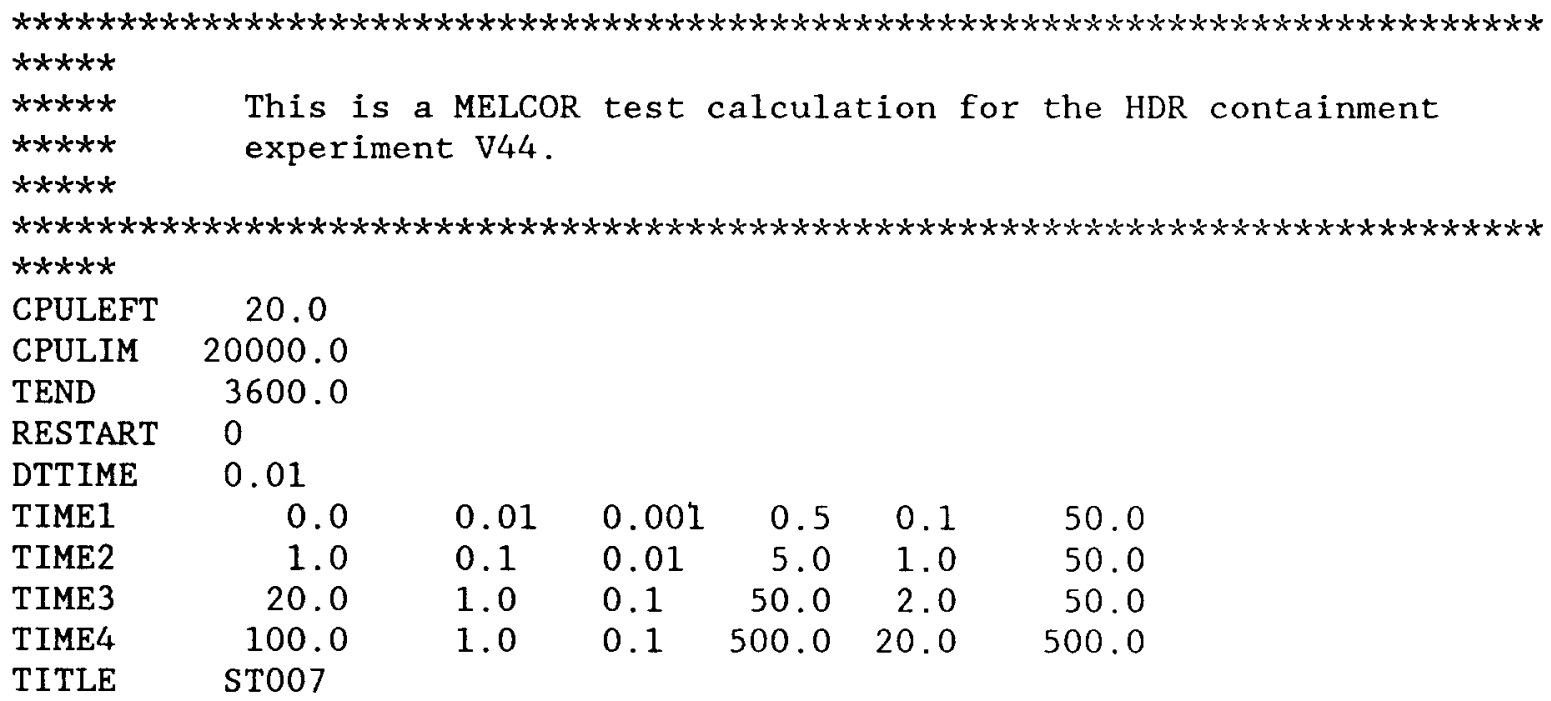




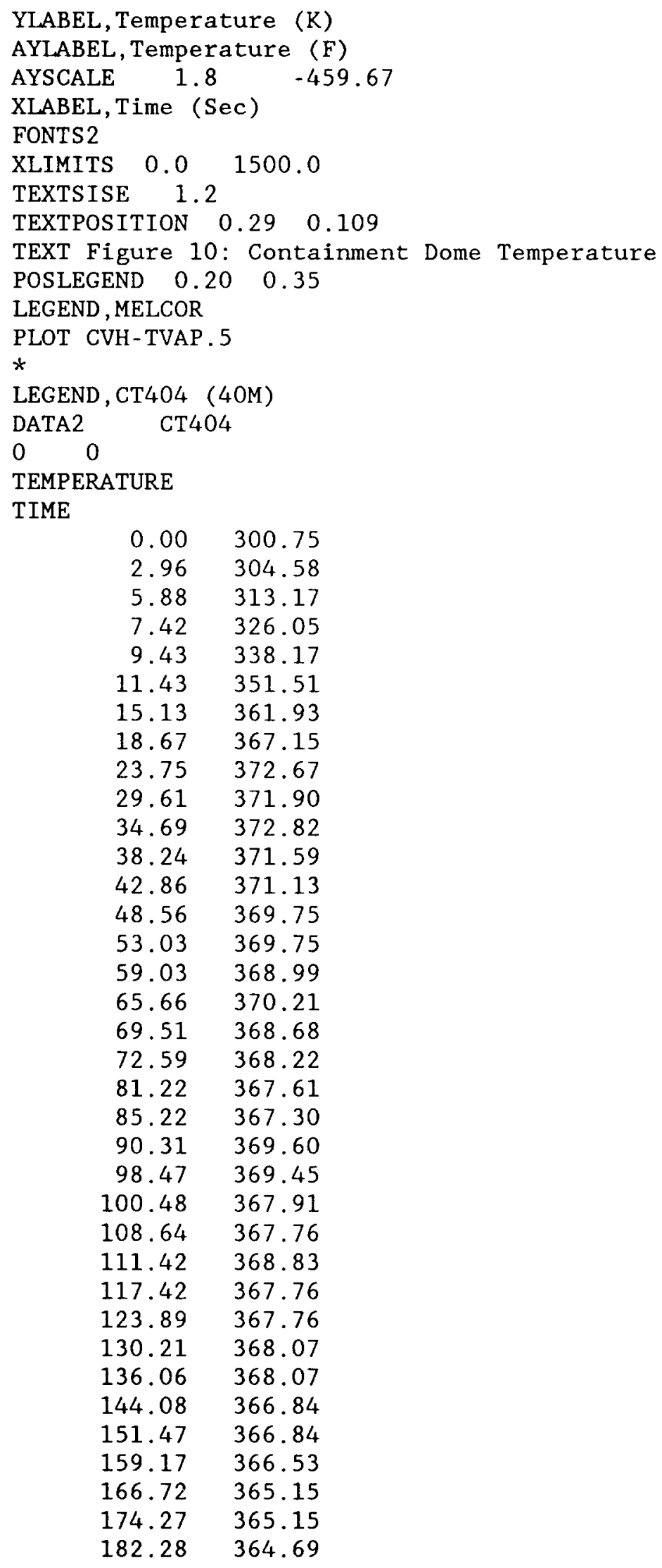




\begin{tabular}{|c|c|c|}
\hline & & \\
\hline & 190.45 & 364.54 \\
\hline & 279.83 & 358.90 \\
\hline & 376.89 & 355.83 \\
\hline & 460.08 & 353.83 \\
\hline & 612.61 & 350.60 \\
\hline & 765.13 & 347.22 \\
\hline & 959.24 & 345.53 \\
\hline & 1264.28 & 342.30 \\
\hline & 1541.60 & 339.85 \\
\hline & 1860.50 & 337.85 \\
\hline & 2234.87 & 334.62 \\
\hline & 2678.57 & 332.32 \\
\hline & 2969.75 & 330.32 \\
\hline & 3288.65 & 329.55 \\
\hline & 3468.91 & 329.09 \\
\hline $\begin{array}{l}-12345 \\
\star\end{array}$ & $5 \quad-12345$ & \\
\hline LEGEND & $\mathrm{D}, \mathrm{CT} 410$ & 34M) \\
\hline DATA0 & CT410 & \\
\hline & 0 & \\
\hline TEMPER & RATURE & \\
\hline TIME & & \\
\hline & 0.00 & 299.47 \\
\hline & 3.86 & 302.99 \\
\hline & 5.86 & 309.26 \\
\hline & 8.33 & 320.12 \\
\hline & 12.64 & 338.94 \\
\hline & 14.18 & 348.73 \\
\hline & 16.80 & 354.70 \\
\hline & 19.57 & 356.69 \\
\hline & 23.72 & 358.53 \\
\hline & 28.03 & 361.59 \\
\hline & 32.65 & 361.59 \\
\hline & 38.81 & 362.35 \\
\hline & 44.97 & 361.74 \\
\hline & 51.74 & 361.89 \\
\hline & 58.52 & 362.66 \\
\hline & 66.37 & 362.51 \\
\hline & 77.30 & 360.98 \\
\hline & 87.00 & 360.82 \\
\hline & 95.47 & 359.60 \\
\hline & 109.48 & 359.14 \\
\hline & 118.40 & 360.52 \\
\hline & 128.57 & 359.45 \\
\hline & 139.50 & 359.75 \\
\hline & 148.43 & 360.36 \\
\hline & 157.82 & 360.21 \\
\hline & 168.75 & 359.75 \\
\hline & 176.29 & 359.75 \\
\hline & 186.76 & 359.14 \\
\hline & 193.38 & 358.83 \\
\hline & 239.66 & 353.96 \\
\hline & 309.04 & 352.58 \\
\hline & 364.54 & 349.97 \\
\hline
\end{tabular}




\begin{tabular}{|c|c|c|}
\hline & & \\
\hline & 489.42 & 348.13 \\
\hline & 558.80 & 346.14 \\
\hline & 669.80 & 344.61 \\
\hline & 766.93 & 343.07 \\
\hline & 877.93 & 341.08 \\
\hline & 1058.30 & 339.09 \\
\hline & $L 224.81$ & 337.55 \\
\hline & 1377.44 & 336.17 \\
\hline & 516.19 & 334.79 \\
\hline & 1654.94 & 333.72 \\
\hline & 1835.32 & 332.95 \\
\hline & 974.07 & 331.73 \\
\hline & 2140.57 & 330.96 \\
\hline & 2320.95 & 329.73 \\
\hline & 598.46 & 328.81 \\
\hline & 875.96 & 328.05 \\
\hline & 3056.34 & 327.28 \\
\hline & 3208.97 & 326.51 \\
\hline & 3375.47 & 326.05 \\
\hline & 3486.47 & 325.90 \\
\hline $\begin{array}{l}-12345 \\
*\end{array}$ & -12345 & \\
\hline LEGEND & , CONTAIN & \\
\hline DATA1 & CONTAI & \\
\hline & & \\
\hline TEMPER & RATURE & \\
\hline TIME & & \\
\hline & 2.26 & 358.29 \\
\hline & 6.77 & 372.53 \\
\hline & 9.03 & 380.23 \\
\hline & 15.80 & 386.77 \\
\hline & 15.80 & 390.27 \\
\hline & 20.31 & 392.14 \\
\hline & 38.36 & 390.97 \\
\hline & 49.65 & 388.40 \\
\hline & 58.67 & 384.90 \\
\hline & 72.21 & 381.40 \\
\hline & 97.04 & 379.06 \\
\hline & 126.38 & 375.80 \\
\hline & 155.71 & 372.53 \\
\hline & 178.28 & 370.43 \\
\hline & 194.08 & 367.39 \\
\hline & 234.70 & 364.82 \\
\hline & 273.06 & 362.02 \\
\hline & 313.68 & 359.92 \\
\hline & 365.59 & 357.35 \\
\hline & 419.75 & 355.25 \\
\hline & 491.96 & 353.38 \\
\hline & 564.18 & 351.05 \\
\hline & 645.42 & 348.95 \\
\hline & 719.89 & 347.31 \\
\hline & 801.13 & 345.45 \\
\hline & 873.34 & 344.04 \\
\hline & 925.25 & 342.88 \\
\hline
\end{tabular}




\begin{tabular}{|c|c|}
\hline 1001.97 & 341.01 \\
\hline 1083.22 & 340.08 \\
\hline 1168.97 & 339.61 \\
\hline 1243.44 & 338.44 \\
\hline 1329.20 & 337.97 \\
\hline 1414.95 & 337.51 \\
\hline 1457.83 & 336.81 \\
\hline 1500.71 & 336.34 \\
\hline-12345 & -12345 \\
\hline
\end{tabular}

FILE1 MELPTF.DAT

*

TITLE, .

YLABEL, Temperature (K)

AYLABEL, Temperature (F)

$\begin{array}{lll}\text { AYSCALE } & 1.8 & -459.67\end{array}$

XLABEL, Time ( $\mathrm{Sec}$ )

FONTS2

XLIMITS $0.0 \quad 1500.0$

TEXTSISE 1.2

$\begin{array}{lll}\text { TEXTPOSITION } & 0.29 & 0.109\end{array}$

TEXT Figure 10: Containment Dome Temperature $\begin{array}{lll}\text { POSLEGEND } & 0.20 & 0.35\end{array}$

LEGEND , MELCOR

PLOT CVH-TVAP. 5

*

LEGEND, CT404 (40M)

DATA2 CT404

$0 \quad 0$

TEMPERATURE

TIME

$\begin{array}{rr}0.00 & 300.75 \\ 2.96 & 304.58 \\ 5.88 & 313.17 \\ 7.42 & 326.05 \\ 9.43 & 338.17 \\ 11.43 & 351.51 \\ 15.13 & 361.93 \\ 18.67 & 367.15 \\ 23.75 & 372.67 \\ 29.61 & 371.90 \\ 34.69 & 372.82 \\ 38.24 & 371.59 \\ 42.86 & 371.13 \\ 48.56 & 369.75 \\ 53.03 & 369.75 \\ 59.03 & 368.99 \\ 65.66 & 370.21 \\ 69.51 & 368.68 \\ 72.59 & 368.22 \\ 81.22 & 367.61 \\ 85.22 & 367.30 \\ 90.31 & 369.60\end{array}$




\begin{tabular}{|c|c|c|}
\hline & & \\
\hline & 98.47 & $\begin{array}{l}369.45 \\
367\end{array}$ \\
\hline & 100.48 & $\begin{array}{l}367.91 \\
367.76\end{array}$ \\
\hline & 108.64 & 367.76 \\
\hline & 111.42 & 368.83 \\
\hline & 117.42 & 367.76 \\
\hline & 123.89 & 367.76 \\
\hline & 130.21 & 368.07 \\
\hline & 136.06 & 368.07 \\
\hline & 144.08 & 366.84 \\
\hline & 151.47 & 366.84 \\
\hline & 159.17 & 366.53 \\
\hline & 166.72 & 365.15 \\
\hline & 174.27 & 365.15 \\
\hline & 182.28 & 364.69 \\
\hline & 190.45 & 364.54 \\
\hline & 279.83 & 358.90 \\
\hline & 376.89 & 355.83 \\
\hline & 460.08 & 353.83 \\
\hline & 612.61 & 350.60 \\
\hline & 765.13 & 347.22 \\
\hline & 959.24 & 345.53 \\
\hline & 264.28 & 342.30 \\
\hline & 541.60 & 339.85 \\
\hline & 860.50 & 337.85 \\
\hline & 234.87 & 334.62 \\
\hline & 678.57 & 332.32 \\
\hline & 969.75 & 330.32 \\
\hline & 288.65 & 329.55 \\
\hline & 468.91 & 329.09 \\
\hline $\begin{array}{l}-1234 \\
*\end{array}$ & -12349 & \\
\hline LEGEN & , CT410 & $34 M)$ \\
\hline DATAC & CT410 & \\
\hline & & \\
\hline TEMPE & ATURE & \\
\hline TIME & & \\
\hline & 0.00 & 299.47 \\
\hline & 3.86 & 302.99 \\
\hline & 5.86 & 309.26 \\
\hline & 8.33 & 320.12 \\
\hline & 12.64 & 338.94 \\
\hline & 14.18 & 348.73 \\
\hline & 16.80 & 354.70 \\
\hline & 19.57 & 356.69 \\
\hline & 23.72 & 358.53 \\
\hline & 28.03 & 361.59 \\
\hline & 32.65 & 361.59 \\
\hline & 38.81 & 362.35 \\
\hline & 44.97 & 361.74 \\
\hline & 51.74 & 361.89 \\
\hline & 58.52 & 362.66 \\
\hline & 66.37 & 362.51 \\
\hline & 77.30 & 360.98 \\
\hline & 87.00 & 360.82 \\
\hline
\end{tabular}




\begin{tabular}{|c|c|c|}
\hline & & \\
\hline & 95.47 & 359.60 \\
\hline & 109.48 & 359.14 \\
\hline & 118.40 & 360.52 \\
\hline & 128.57 & 359.45 \\
\hline & 139.50 & 359.75 \\
\hline & 148.43 & 360.36 \\
\hline & 157.82 & 360.21 \\
\hline & 168.75 & 359.75 \\
\hline & 176.29 & 359.75 \\
\hline & 186.76 & 359.14 \\
\hline & 193.38 & 358.83 \\
\hline & 239.66 & 353.96 \\
\hline & 309.04 & 352.58 \\
\hline & 364.54 & 349.97 \\
\hline & 489.42 & 348.13 \\
\hline & 558.80 & 346.14 \\
\hline & 669.80 & 344.61 \\
\hline & 766.93 & 343.07 \\
\hline & 877.93 & 341.08 \\
\hline & 058.30 & 339.09 \\
\hline & 224.81 & 337.55 \\
\hline & 377.44 & 336.17 \\
\hline & 516.19 & 334.79 \\
\hline & 654.94 & 333.72 \\
\hline & 835.32 & 332.95 \\
\hline & 974.07 & 331.73 \\
\hline & 140.57 & 330.96 \\
\hline & 320.95 & 329.73 \\
\hline & 598.46 & 328.81 \\
\hline & 875.96 & 328.05 \\
\hline & 056.34 & 327.28 \\
\hline & 208.97 & 326.51 \\
\hline & 375.47 & 326.05 \\
\hline & 486.47 & 325.90 \\
\hline $\begin{array}{l}-12345 \\
*\end{array}$ & -12345 & \\
\hline LEGEND & , CONTAIN & \\
\hline DATA1 & CONTAIN & \\
\hline & & \\
\hline TEMPER & ATURE & \\
\hline TTMF & & \\
\hline & 2.26 & 358.29 \\
\hline & 6.77 & 372.53 \\
\hline & 9.03 & 380.23 \\
\hline & 15.80 & 386.77 \\
\hline & 15.80 & 390.27 \\
\hline & 20.31 & 392.14 \\
\hline & 38.36 & 390.97 \\
\hline & 49.65 & 388.40 \\
\hline & 58.67 & 384.90 \\
\hline & 72.21 & 381.40 \\
\hline & 97.04 & 379.06 \\
\hline & 126.38 & 375.80 \\
\hline & 155.71 & 372.53 \\
\hline & 178.28 & 370.43 \\
\hline
\end{tabular}




$\begin{array}{rr}194.08 & 367.39 \\ 234.70 & 364.82 \\ 273.06 & 362.02 \\ 313.68 & 359.92 \\ 365.59 & 357.35 \\ 419.75 & 355.25 \\ 491.96 & 353.38 \\ 564.18 & 351.05 \\ 645.42 & 348.95 \\ 719.89 & 347.31 \\ 801.13 & 345.45 \\ 873.34 & 344.04 \\ 925.25 & 342.88 \\ 1001.97 & 341.01 \\ 1083.22 & 340.08 \\ 1168.97 & 339.61 \\ 1243.44 & 338.44 \\ 1329.20 & 337.97 \\ 1414.95 & 337.51 \\ 1457.83 & 336.81 \\ 1500.71 & 336.34 \\ -12345 & -12345 \\ * & \end{array}$

ST008: ABCOVE Aerosol Experiments Test AB6

MELGEN Input

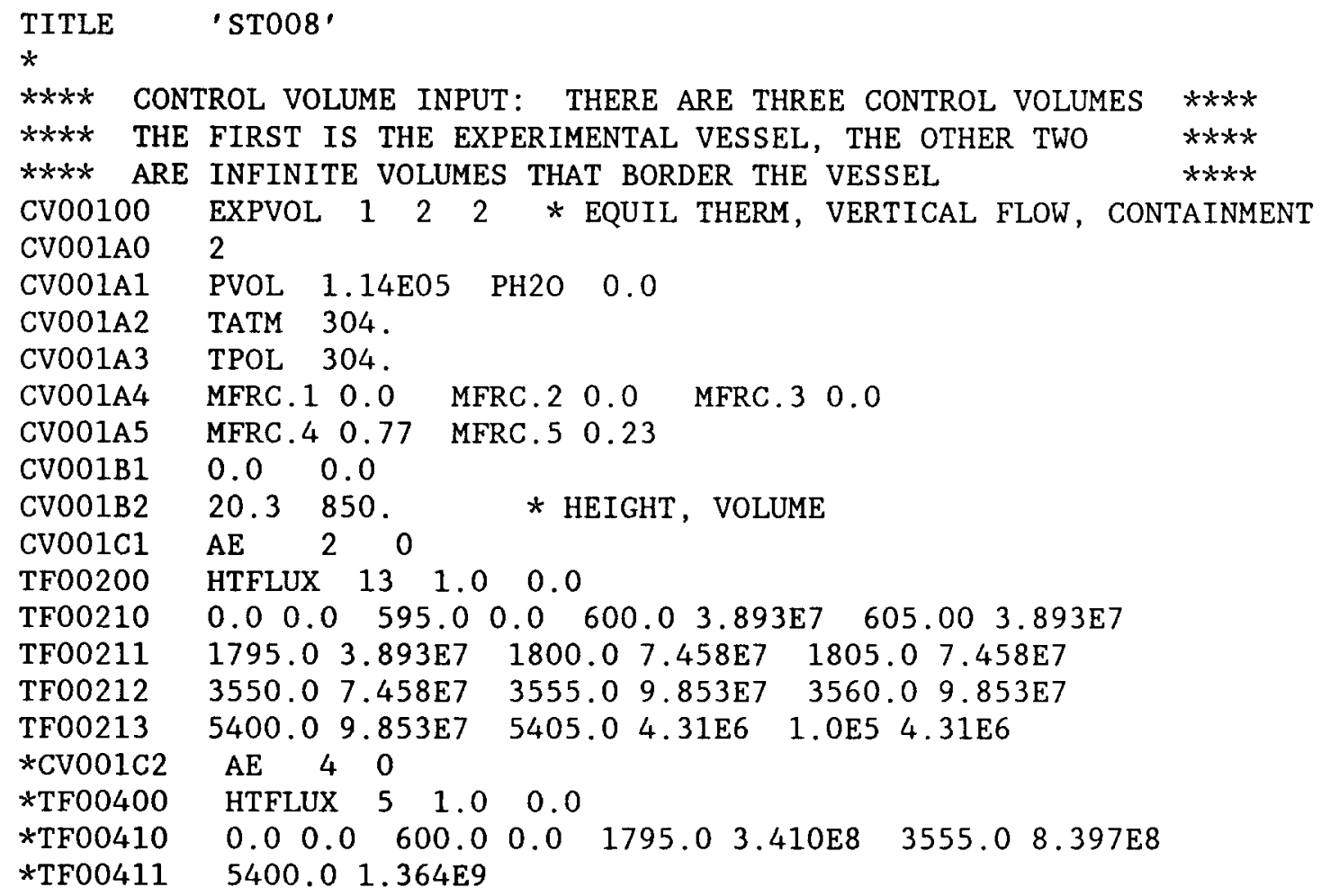




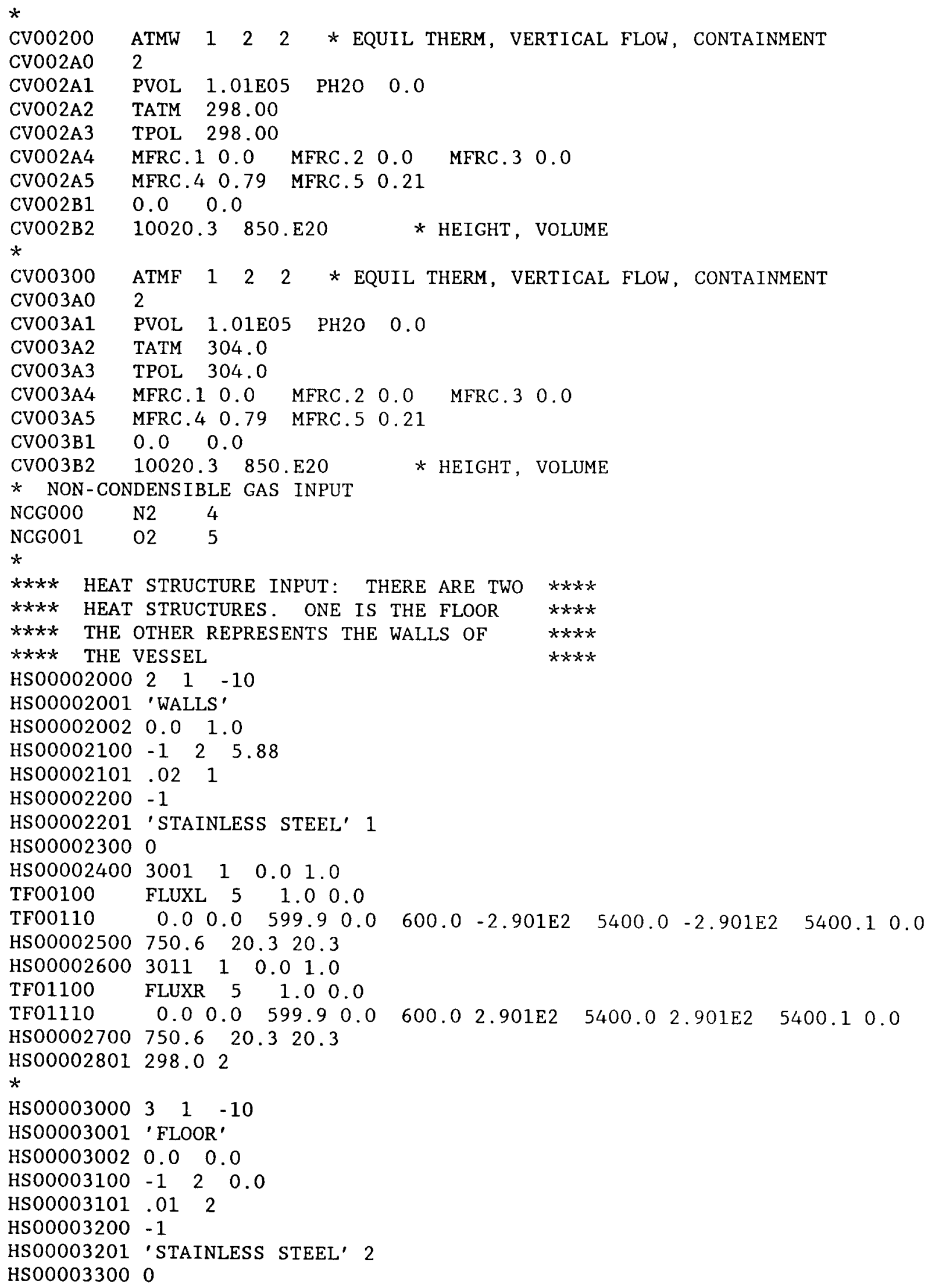




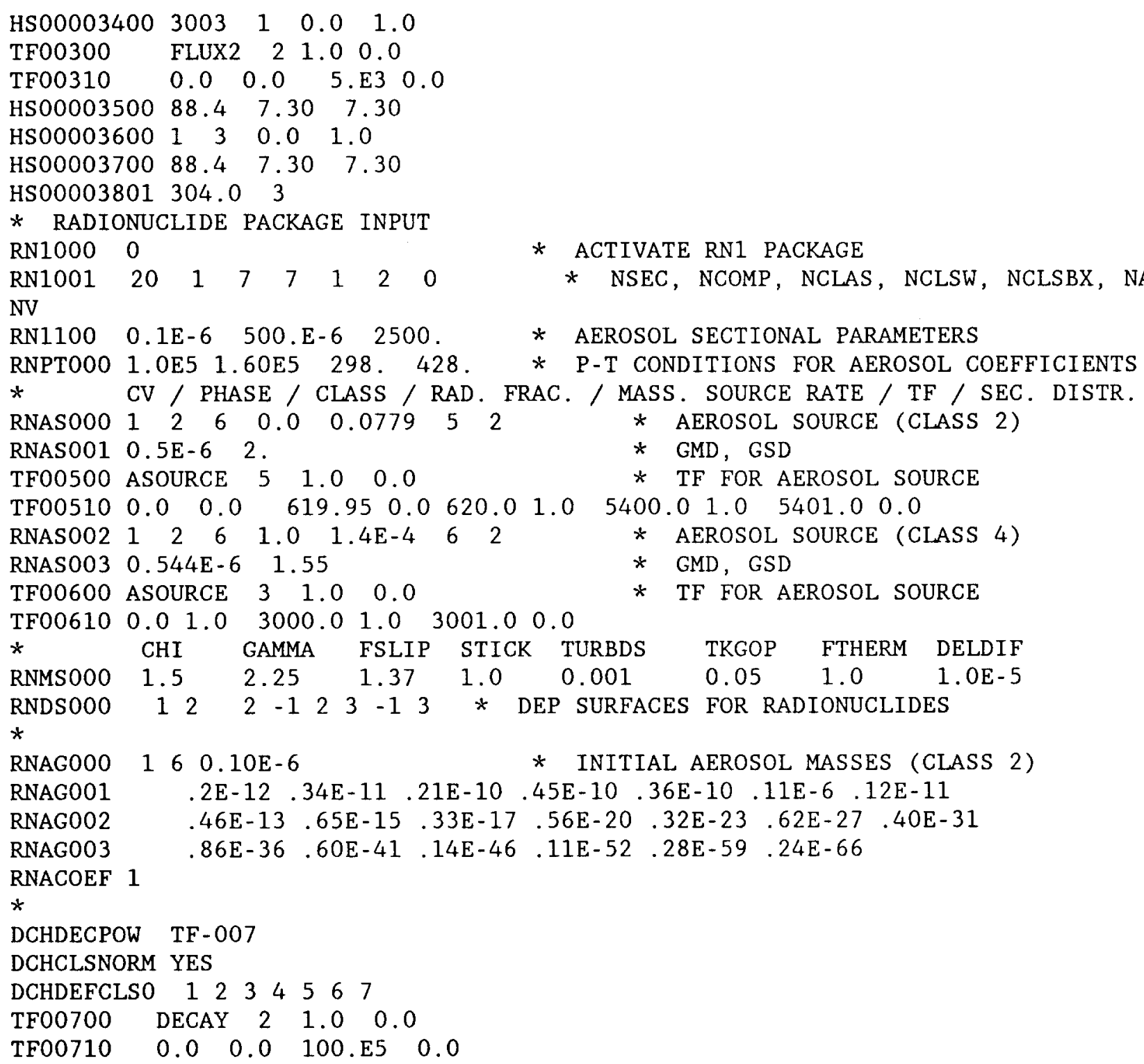


XLABEL (SEC)

LISTS

PLOT RN1-MDTT - 3-1

DATA1 FLOORM CONTAB6.DAT

ST008: ABCOVE Aerosol Experiments Test AB6

$\mathrm{NaOH}$ Data

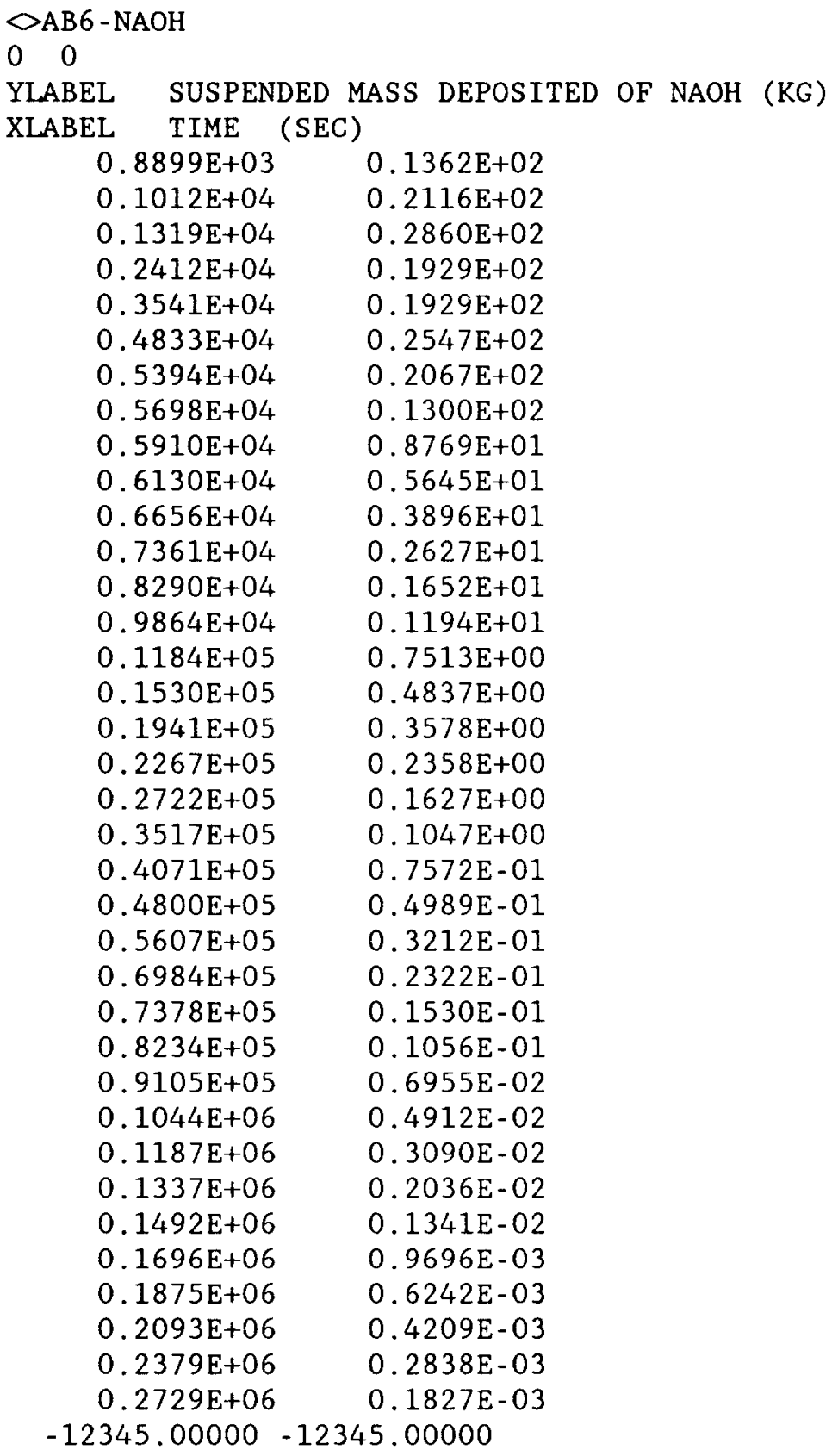




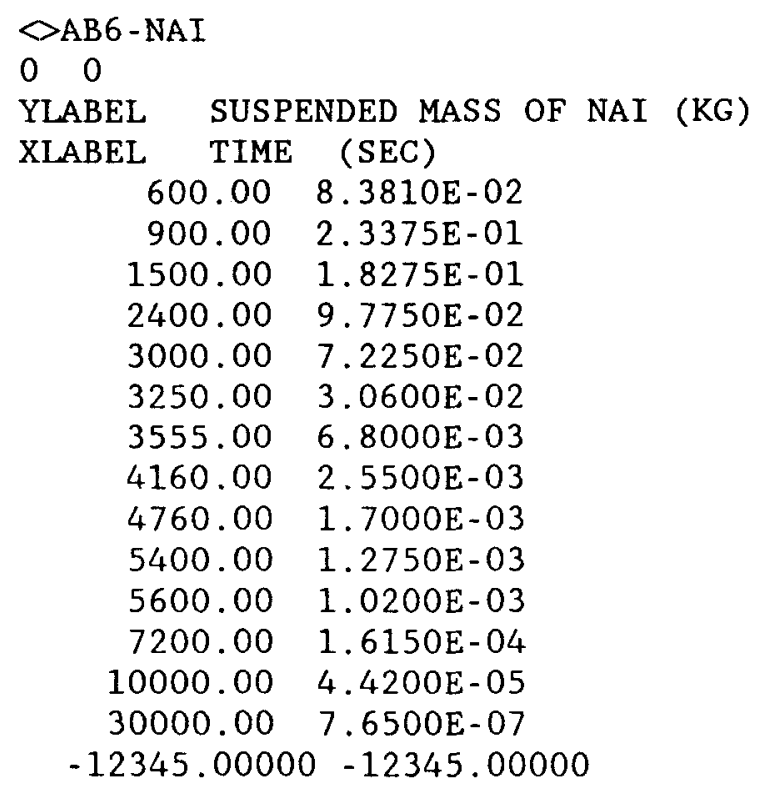

ST009A: Batte1le-Frankfurt Gas Mixing Experiments

Note: The input data for ST009B is not included here. Input data for ST009B can be obtained from the editor of this report.

MELGEN Input

TITLE 'BATELLE-FRANKFURT TEST 2 (TOTAL VOLUME 70.62 stere)'

*

DTTIME 0.5

RESTARTF 'MELRST2'

*

NCG001 N2 4

NCG002 $02 \quad 5$

NCG003 H2 6

*

* SOURCE IN VOLUME 15

*

CV015CO MASS.4 $1 \quad 2$

CV015C1 TE 28

CV015C2 MASS. $6 \quad 3 \quad 2$

CV015C3 TE 28

*

TF00100 'N2SOURCE' $3 \quad 1.1775$ 0. * RHO AT TOTAL P, 290.15 K

TF00101 00

TF00110 0.,1.1E-04 1.361E4,1.1E-04 1.362E4,0. * TABLE VALUES ARE VOL/S 


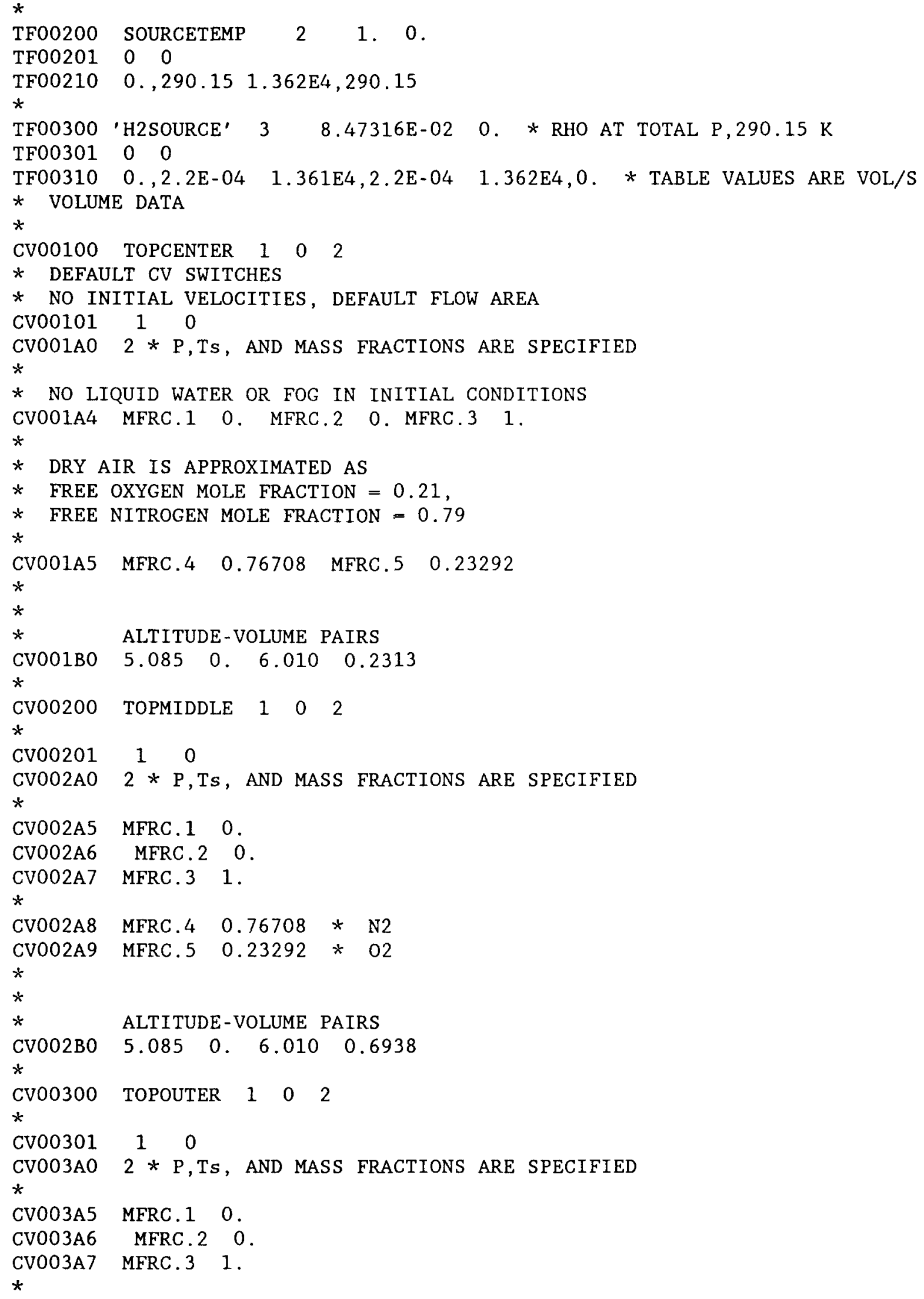$$
\star
$$ 


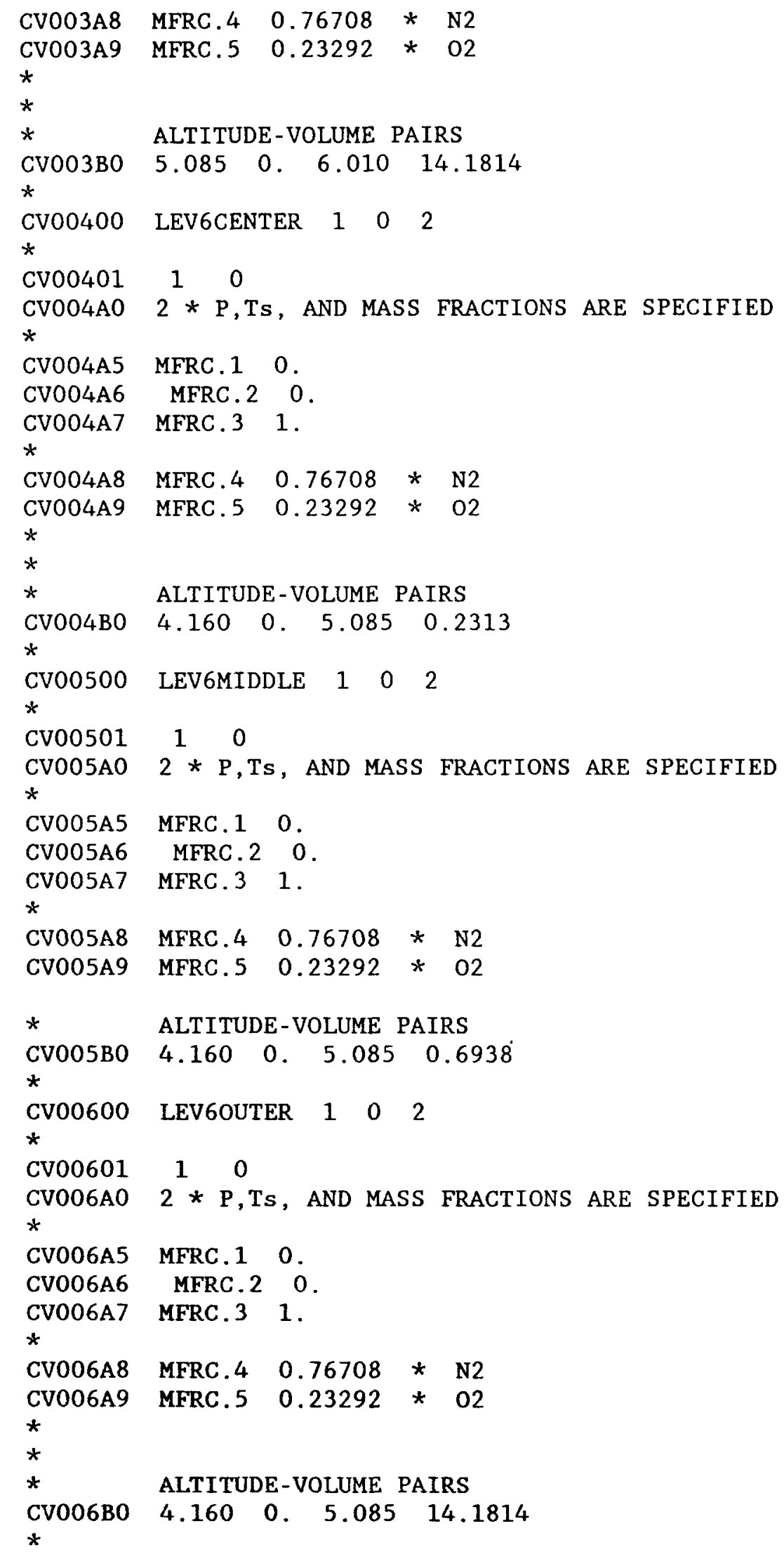




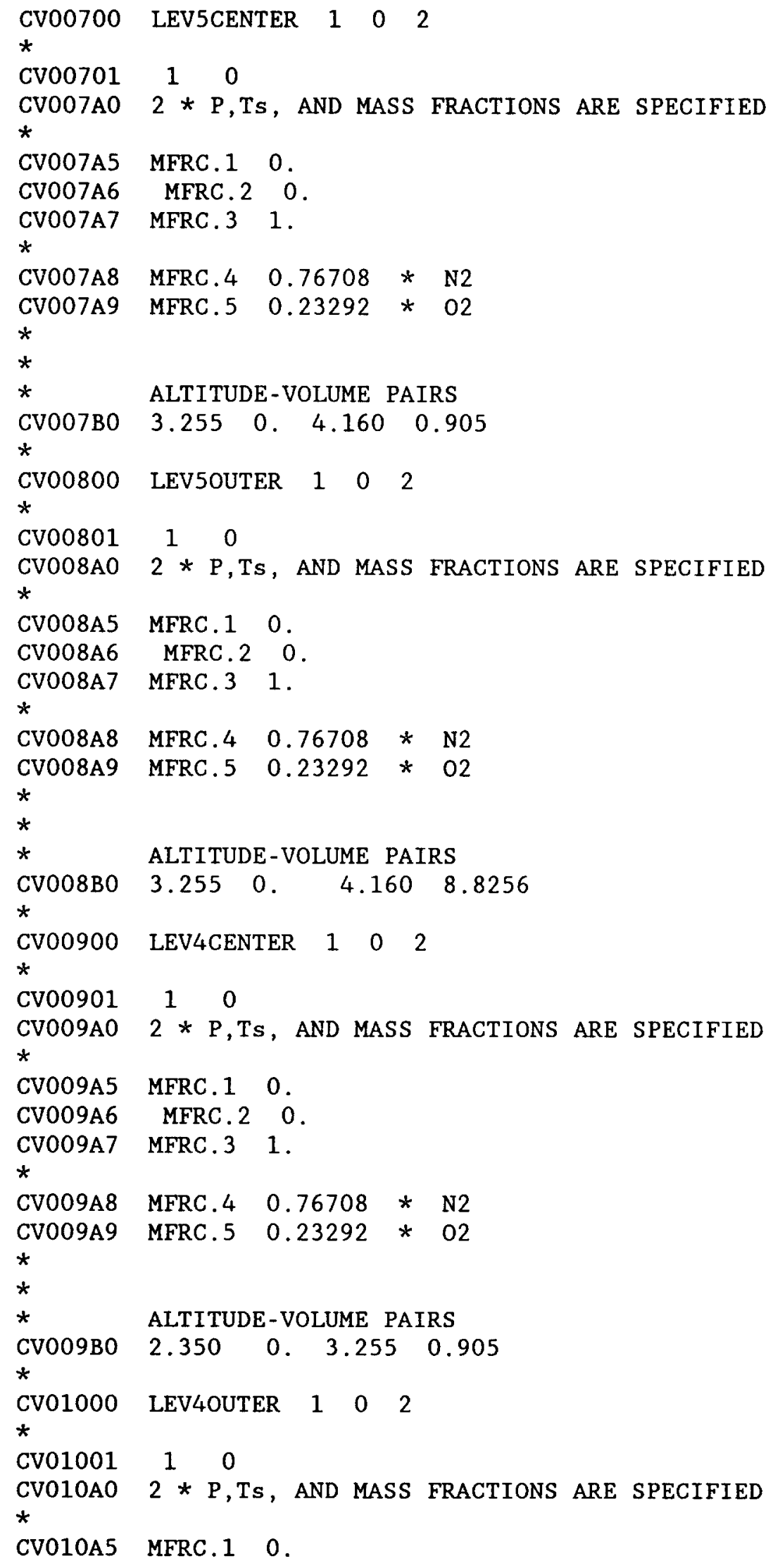




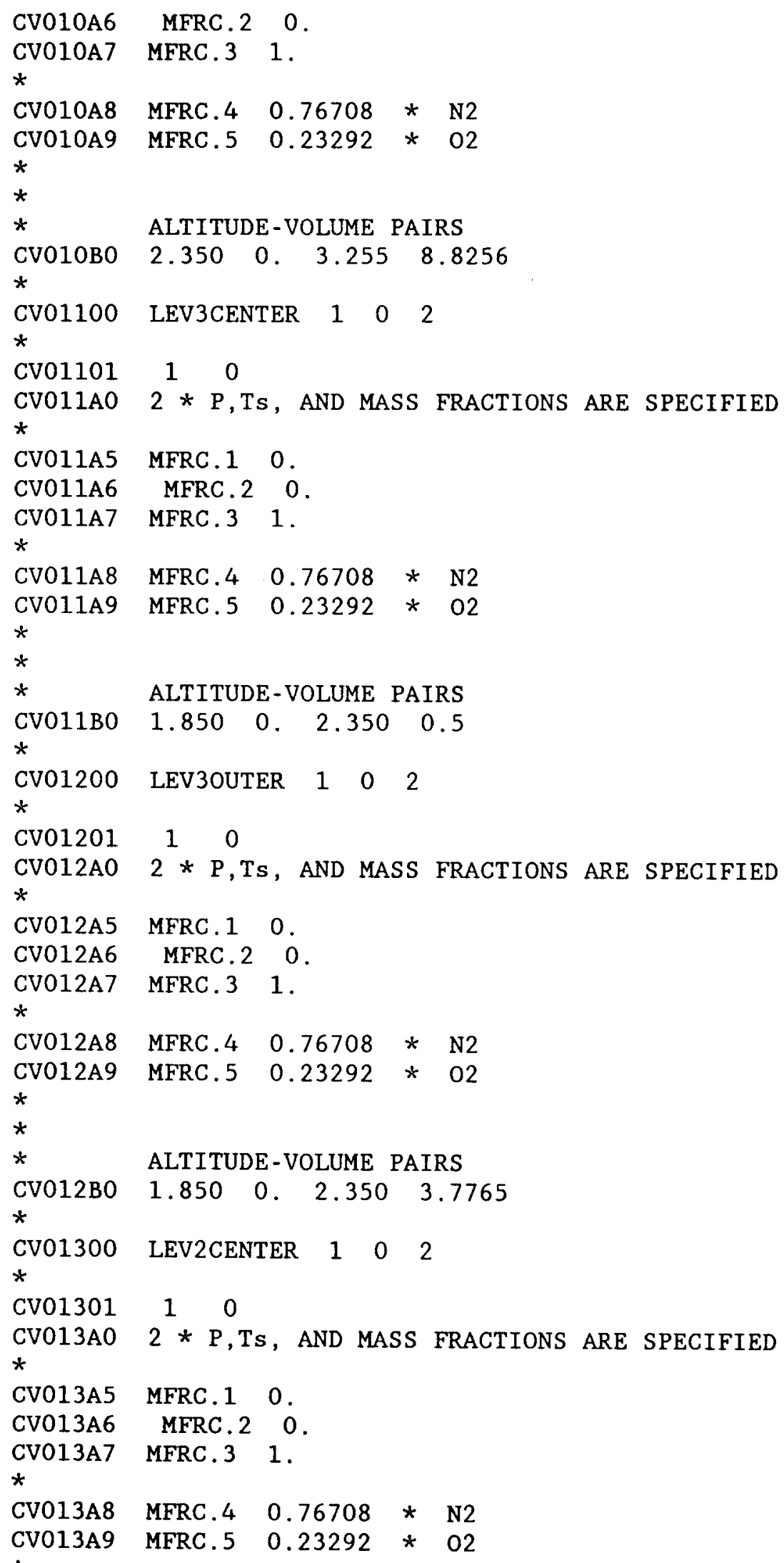




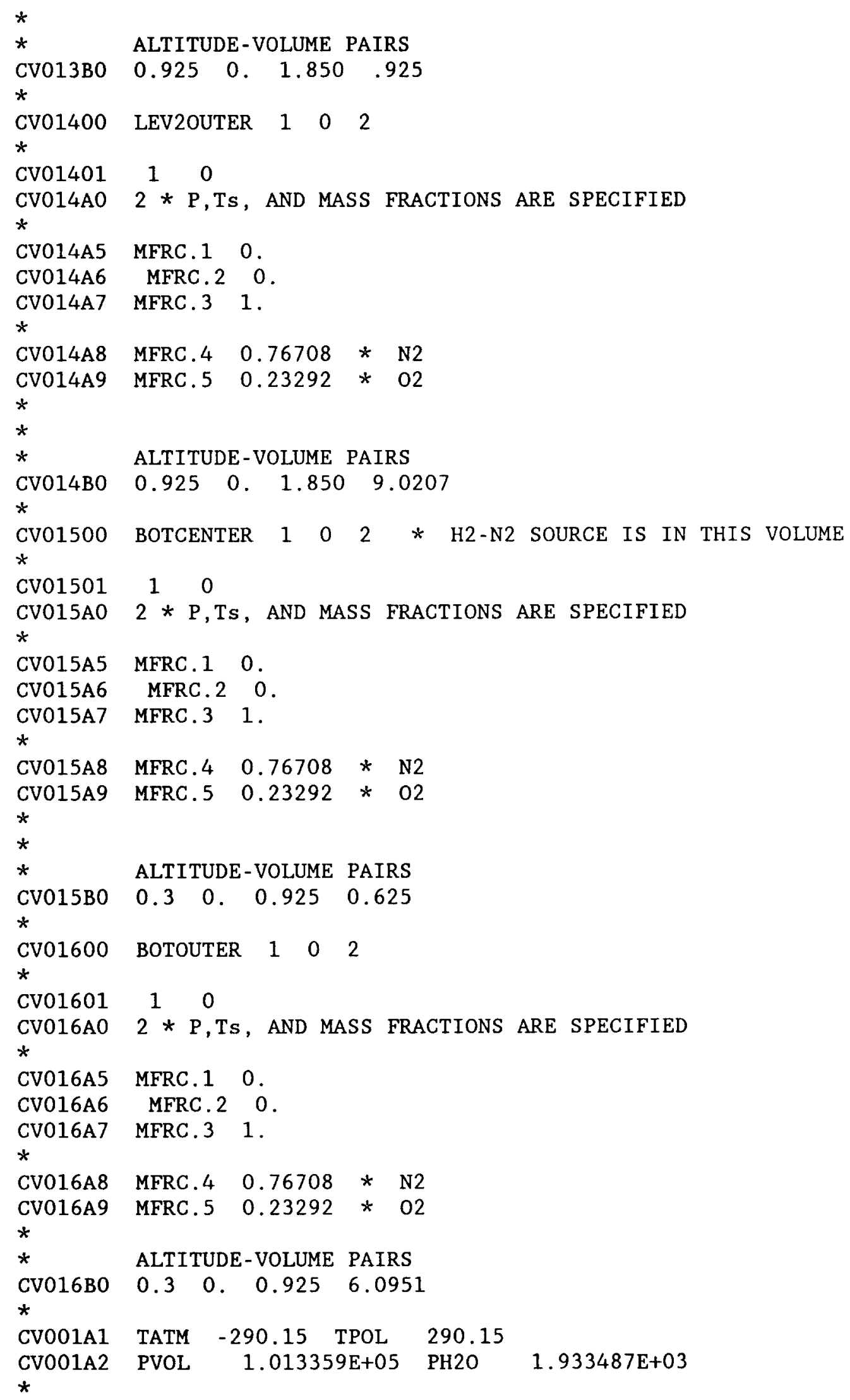




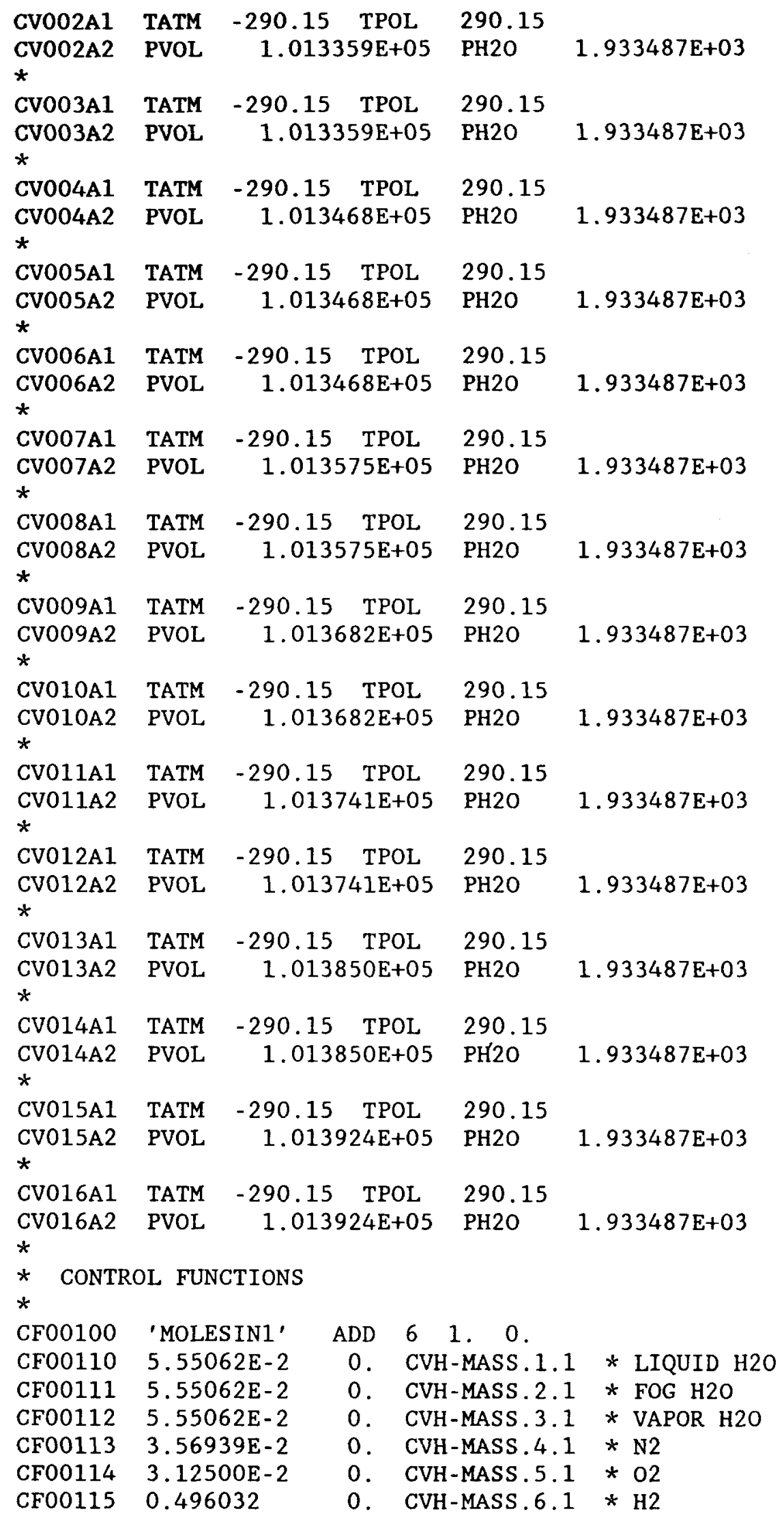




\begin{tabular}{|c|c|c|c|c|c|}
\hline CF00300 & 'MOLESIN2' & $\mathrm{ADD}$ & 0 . & & \\
\hline CF00310 & $5.55062 E-2$ & 0 . & CVH-MASS .1 .2 & * & LIQUID $\mathrm{H} 20$ \\
\hline CF00311 & $5.55062 E-2$ & 0 . & CVH-MASS .2 .2 & $\star$ & FOG $\mathrm{H} 2 \mathrm{O}$ \\
\hline CF00312 & $5.55062 E-2$ & 0 . & CVH-MASS .3 .2 & $\star$ & VAPOR H2O \\
\hline CF00313 & $3.56939 E-2$ & 0 . & CVH-MASS .4 .2 & * & N2 \\
\hline CF00314 & $3.12500 \mathrm{E}-2$ & 0 . & CVH-MASS .5 .2 & $\star *$ & 02 \\
\hline CF00315 & 0.496032 & 0 . & CVH-MASS .6 .2 & $\star$ & $\mathrm{H} 2$ \\
\hline CF00500 & 'MOLESIN3' & $\mathrm{ADD}$ & 61.0 & & \\
\hline CF00510 & $5.55062 E-2$ & 0 & CVH-MASS .1 .3 & $*$ & LIQUID $\mathrm{H} 20$ \\
\hline CF00511 & $5.55062 \mathrm{E}-2$ & 0 . & CVH-MASS .2 .3 & $*$ & FOG $\mathrm{H} 2 \mathrm{O}$ \\
\hline CF00512 & $5.55062 \mathrm{E}-2$ & 0 . & CVH-MASS .3 .3 & $*$ & VAPOR H2O \\
\hline CF00513 & $3.56939 E-2$ & 0 . & CVH-MASS .4 .3 & $\star$ & $\mathrm{N} 2$ \\
\hline CF00514 & $3.12500 \mathrm{E}-2$ & 0 . & CVH-MASS .5 .3 & * & 02 \\
\hline CF00515 & 0.496032 & 0 . & CVH-MASS .6 .3 & $\star$ & $\mathrm{H} 2$ \\
\hline CF00700 & 'MOLES IN4' & $\mathrm{ADD}$ & $\begin{array}{lll}6 & 1 .\end{array}$ & & \\
\hline CF00710 & $5.55062 \mathrm{E}-2$ & 0 . & CVH-MASS .1 .4 & * & LIQUID $\mathrm{H} 2 \mathrm{O}$ \\
\hline CF00711 & 5.55 & 0 . & CVH-MASS .2 .4 & $*$ & FOG $\mathrm{H} 2 \mathrm{O}$ \\
\hline CF00712 & $5.55062 E-2$ & 0 . & CVH-MASS .3 .4 & $*$ & VAPOR H2O \\
\hline CF00713 & 3.569 & 0 . & CVH-MASS .4 .4 & $\star$ & $\mathrm{N} 2$ \\
\hline CF00714 & 3.125 & 0 . & CVH-MASS .5 .4 & $*$ & 02 \\
\hline CF00715 & 0.496032 & 0 . & CVH-MASS .6 .4 & $*$ & H2 \\
\hline CF00900 & 'MOLESIN5' & ADD & 0. & & \\
\hline CF00910 & $5.55062 \mathrm{E}-2$ & 0. & CVH-MASS .1 .5 & $*$ & LIQUID $\mathrm{H} 2 \mathrm{O}$ \\
\hline CF00911 & $5.55062 \mathrm{E}-2$ & 0 . & CVH-MASS .2 .5 & $\star$ & FOG $\mathrm{H} 2 \mathrm{O}$ \\
\hline CF00912 & $5.55062 \mathrm{E}-2$ & 0 . & CVH-MASS .3 .5 & * & VAPOR H2O \\
\hline CF00913 & $3.56939 E-2$ & 0 . & CVH-MASS .4 .5 & * & $\mathrm{N} 2$ \\
\hline CF00914 & 3.125 & 0 . & CVH-MASS .5 .5 & $*$ & 02 \\
\hline CF00915 & 0.496032 & 0 . & CVH-MASS .6 .5 & * & $\mathrm{H} 2$ \\
\hline CF01100 & 'MOLESIN6' & ADD & $\begin{array}{lll}6 & 1.0 .\end{array}$ & & \\
\hline CFO & 5.550 & 0 . & CVH-MASS .1 .6 & * & LIQUID $\mathrm{H} 2 \mathrm{O}$ \\
\hline CF01111 & $5.55062 \mathrm{E}-2$ & 0 . & CVH-MASS .2 .6 & * & FOG $\mathrm{H} 2 \mathrm{O}$ \\
\hline CF01112 & $5.55062 E-2$ & 0 . & CVH-MASS .3 .6 & * & VAPOR H2O \\
\hline CF01113 & $3.56939 E-2$ & 0 . & CVH-MASS .4 .6 & * & $\mathrm{N} 2$ \\
\hline CF01114 & $3.12500 \mathrm{E}-2$ & 0 . & CVH-MASS .5 .6 & $*$ & 02 \\
\hline CF01115 & 0.496032 & 0. & CVH-MASS .6 .6 & $*$ & $\mathrm{H} 2$ \\
\hline CF01300 & 'MOLESIN7' & ADD & 0 . & & \\
\hline CF01310 & $5.55062 E-2$ & 0 . & CVH-MASS .1 .7 & * & LIQUID $\mathrm{H} 2 \mathrm{O}$ \\
\hline CF01311 & $5.55062 E-2$ & 0 . & CVH-MASS .2 .7 & $*$ & FOG $\mathrm{H} 2 \mathrm{O}$ \\
\hline CF01312 & $5.55062 E-2$ & 0 . & CVH-MASS .3 .7 & $\star$ & VAPOR H2O \\
\hline CF01313 & $3.56939 E-2$ & 0 . & CVH-MASS .4 .7 & * & N2 \\
\hline CF01314 & 3.12 & 0 . & CVH -MASS .5 .7 & $*$ & 02 \\
\hline CF01315 & 0.496032 & 0 . & CVH-MASS .6 .7 & $*$ & H2 \\
\hline CF01500 & 'MOLESIN8' & $\mathrm{ADD}$ & 61. & & \\
\hline CF01510 & 5.55 & 0 . & CVH-MASS .1 .8 & $*$ & LIQUID $\mathrm{H} 2 \mathrm{O}$ \\
\hline CF01511 & $5.55062 \mathrm{E}-2$ & 0 . & CVH-MASS .2 .8 & * & FOG $\mathrm{H} 2 \mathrm{O}$ \\
\hline CF01512 & $5.55062 \mathrm{E}-2$ & 0 . & CVH-MASS .3 .8 & * & VAPOR H2O \\
\hline CF01513 & $3.56939 E-2$ & 0 . & CVH-MASS .4 .8 & $*$ & N2 \\
\hline CF01514 & $3.12500 \mathrm{E}-2$ & 0 . & CVH-MASS .5 .8 & * & 02 \\
\hline CF01515 & 0.496032 & 0 . & CVH-MASS .6 .8 & $*$ & H2 \\
\hline CF01700 & 'MOLESIN9' & ADD & 61.0. & & \\
\hline CF01710 & $5.55062 \mathrm{E}-2$ & 0 . & CVH-MASS .1 .9 & * & LIQUID $\mathrm{H} 2 \mathrm{O}$ \\
\hline CF01711 & $5.55062 \mathrm{E}-2$ & 0 . & CVH-MASS .2 .9 & * & FOG $\mathrm{H} 2 \mathrm{O}$ \\
\hline CF01712 & $5.55062 \mathrm{E}-2$ & 0 . & CVH-MASS .3 .9 & * & VAPOR H2O \\
\hline CF01713 & $3.56939 \mathrm{E}-2$ & 0 . & CVH-MASS .4 .9 & $\star$ & N2 \\
\hline
\end{tabular}




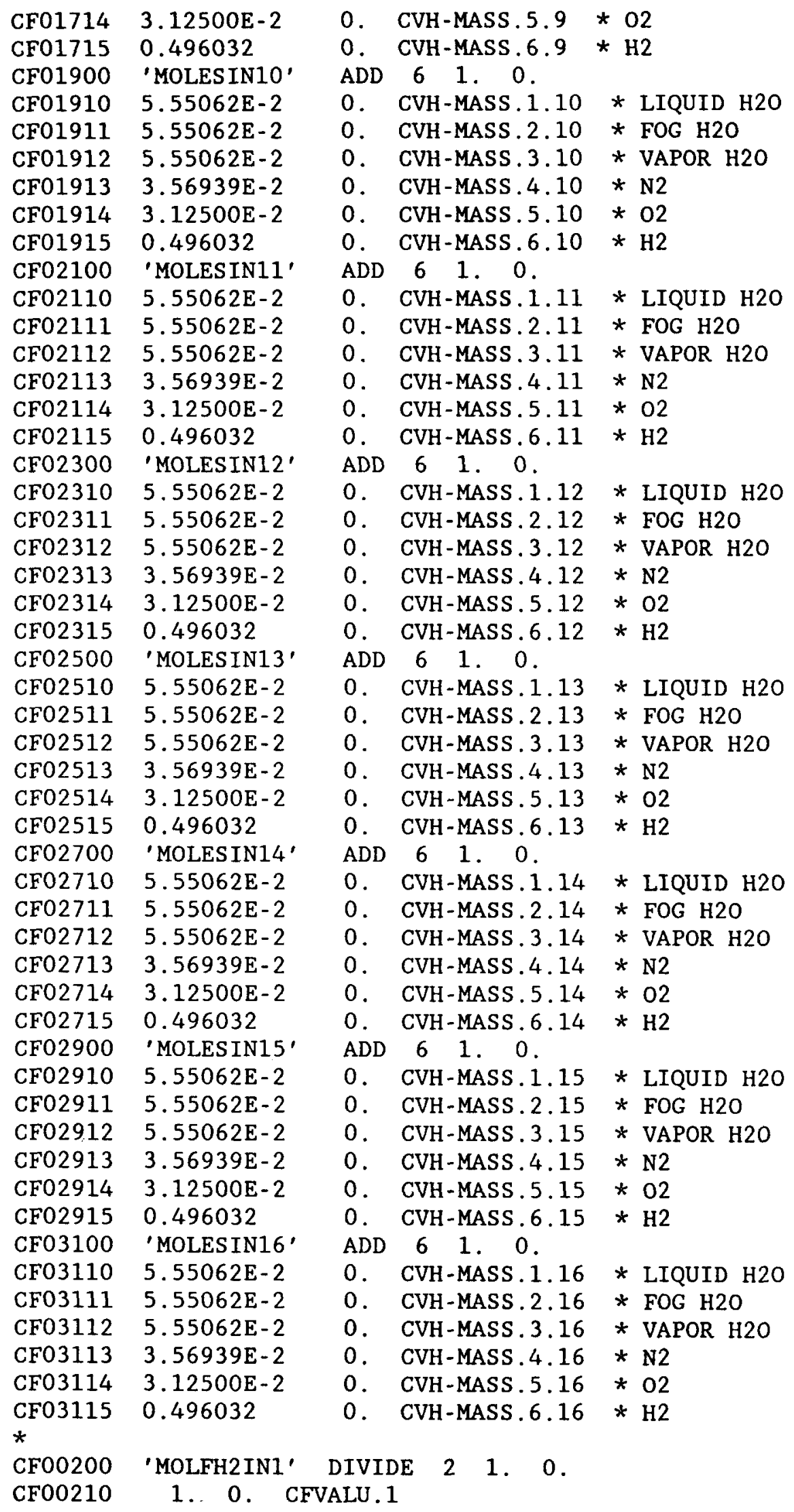




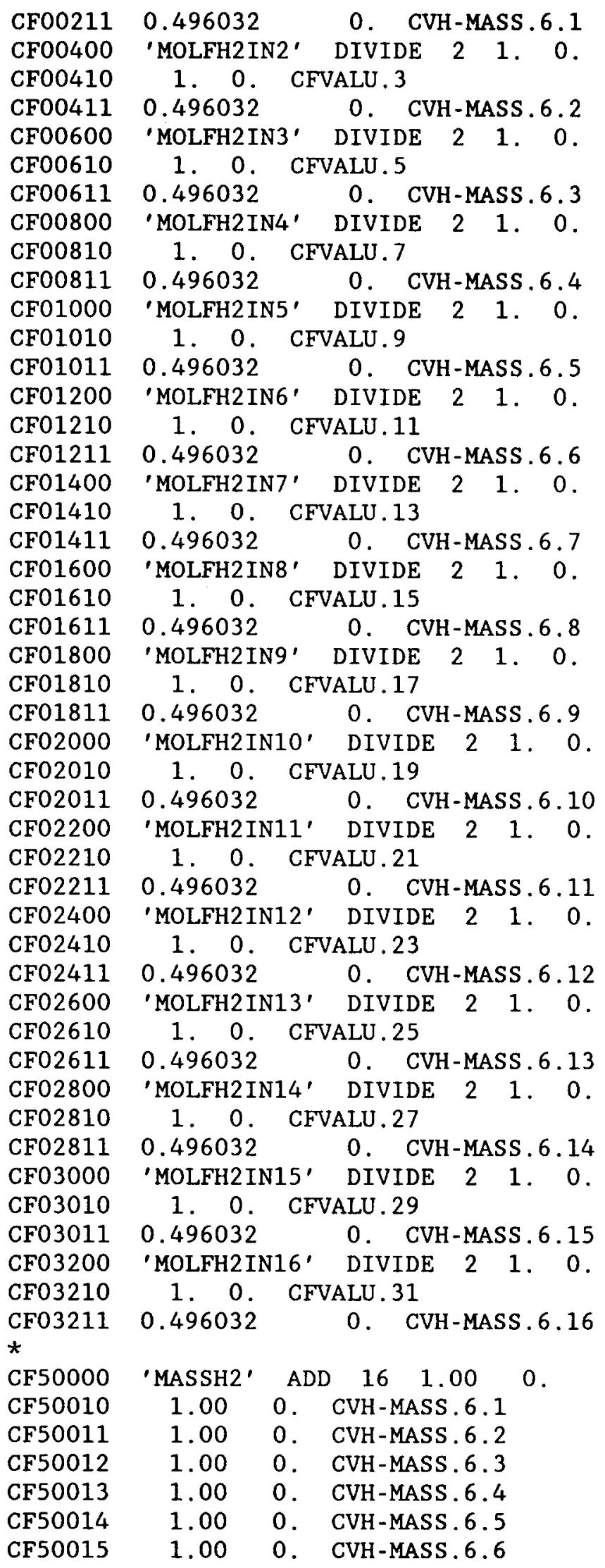




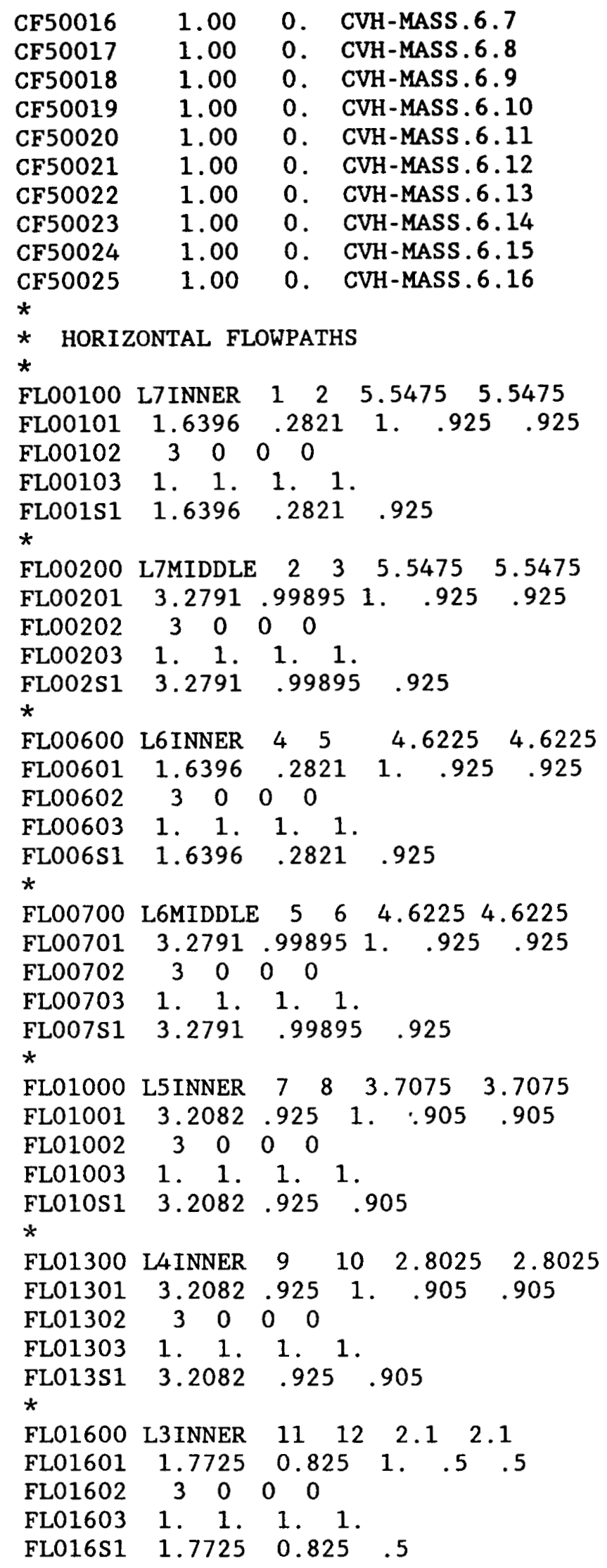




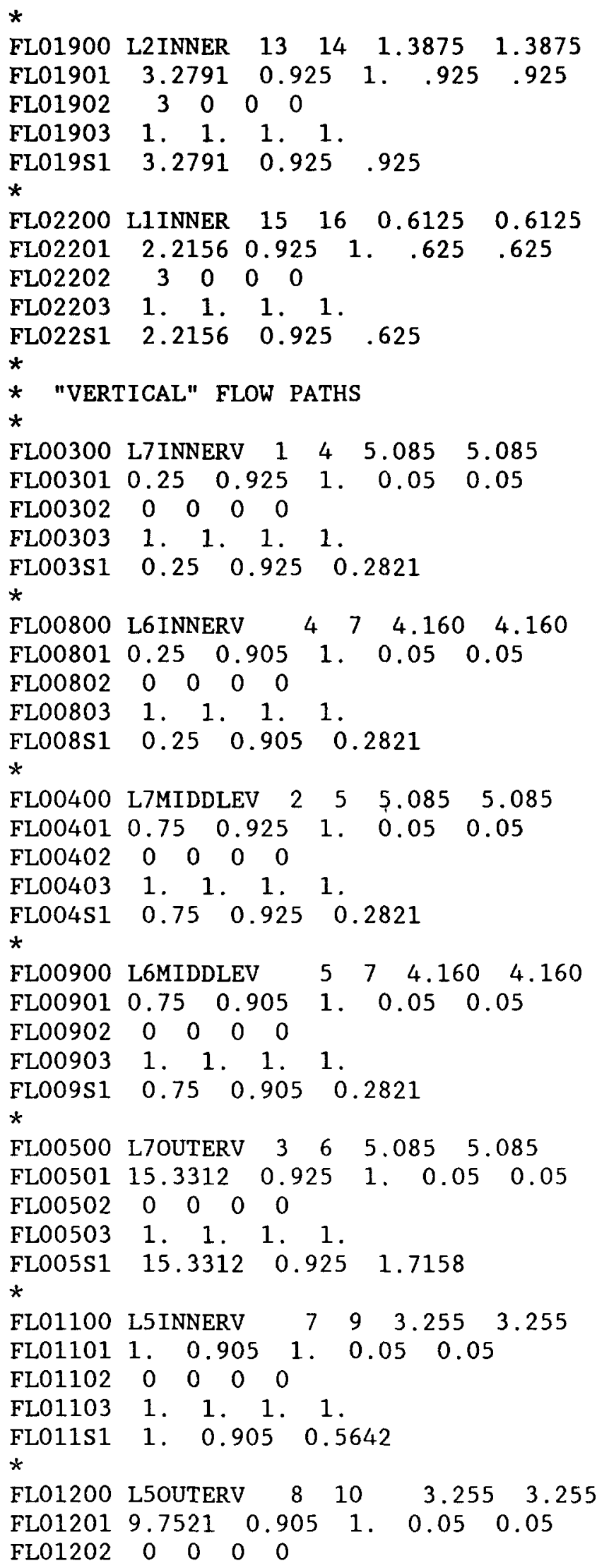




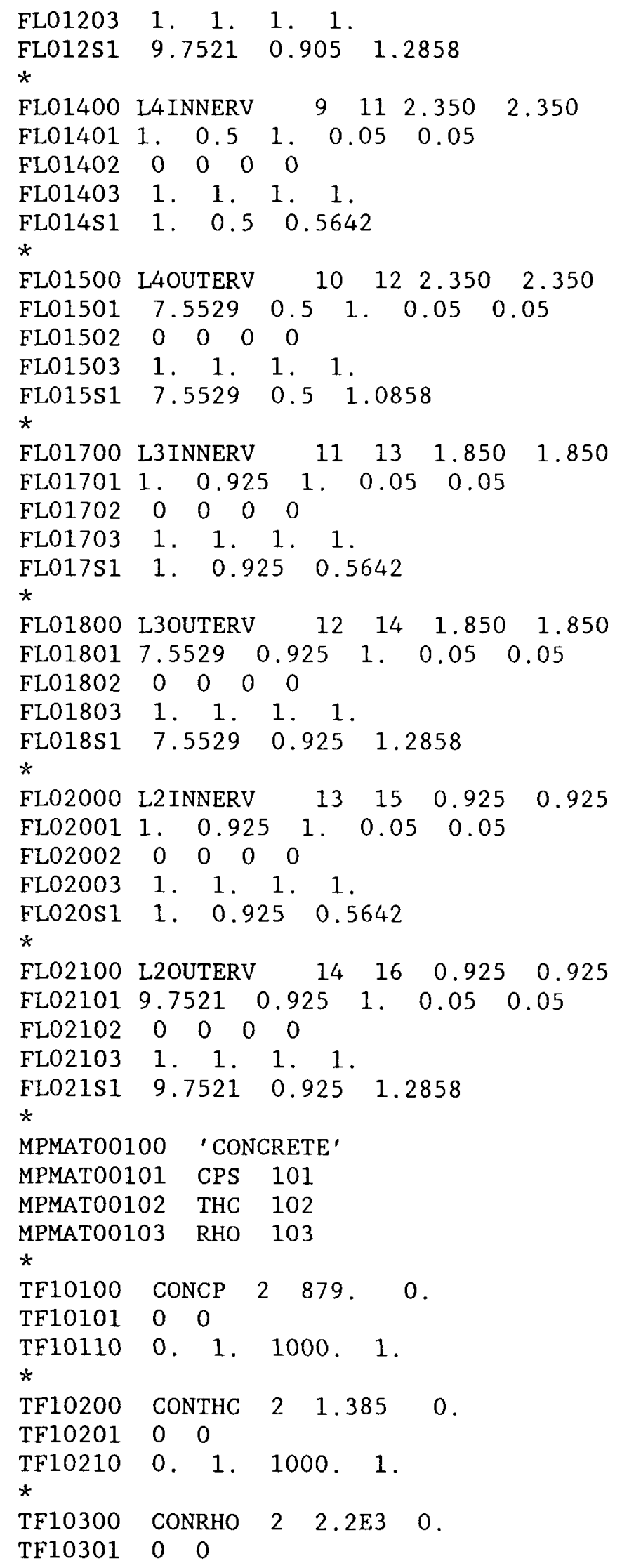




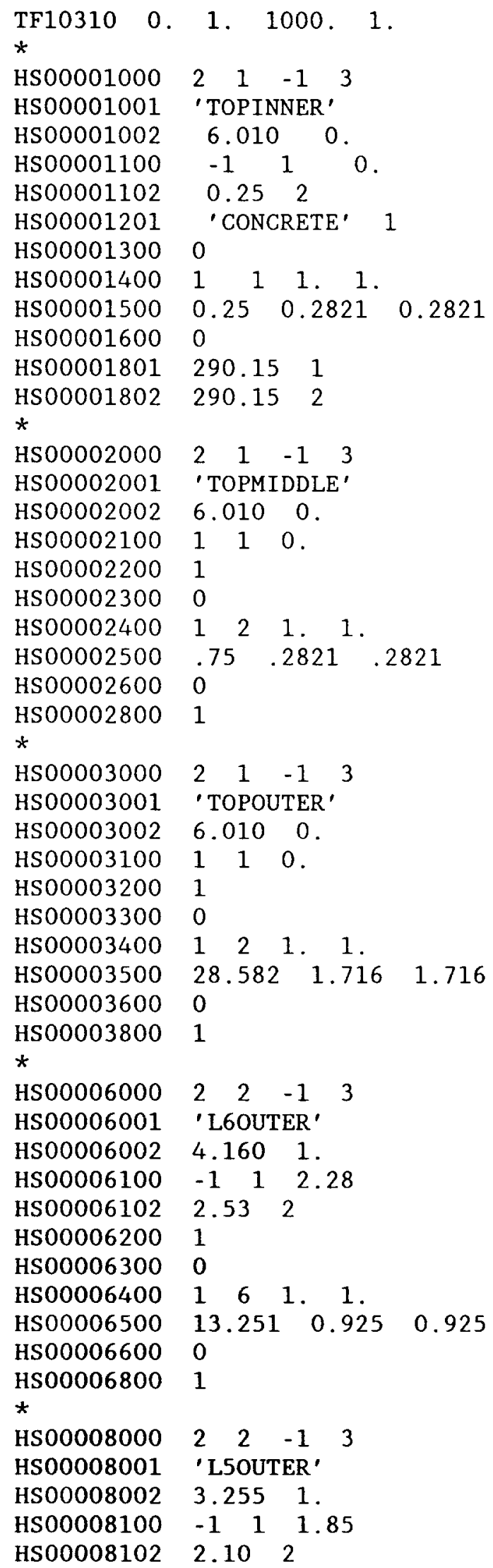




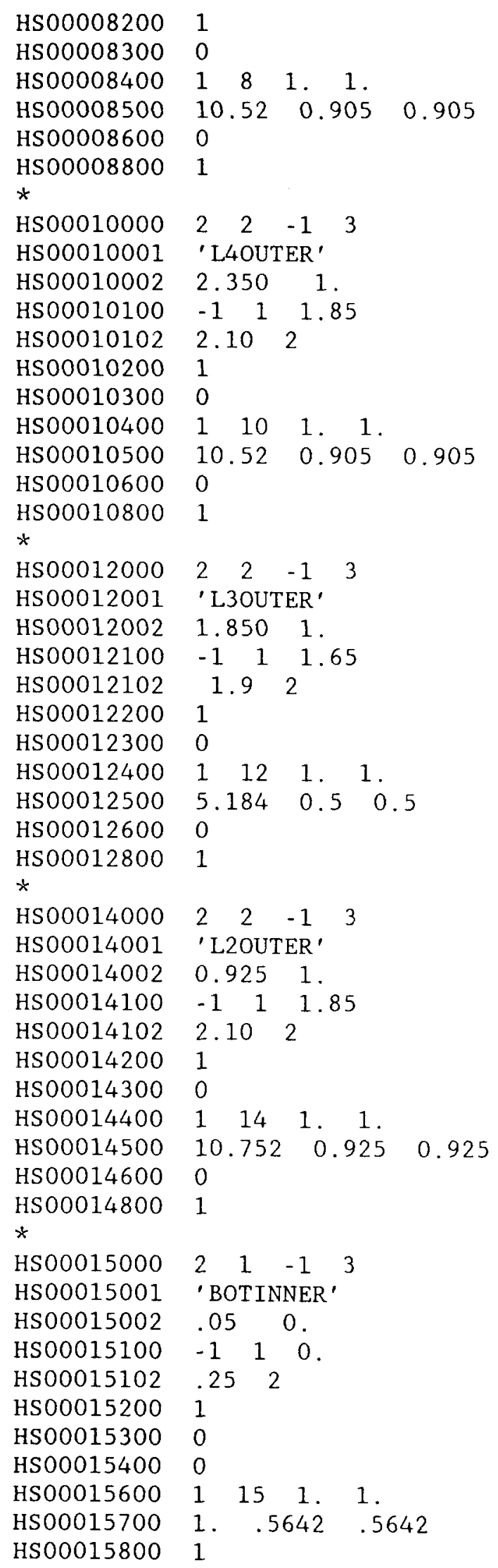




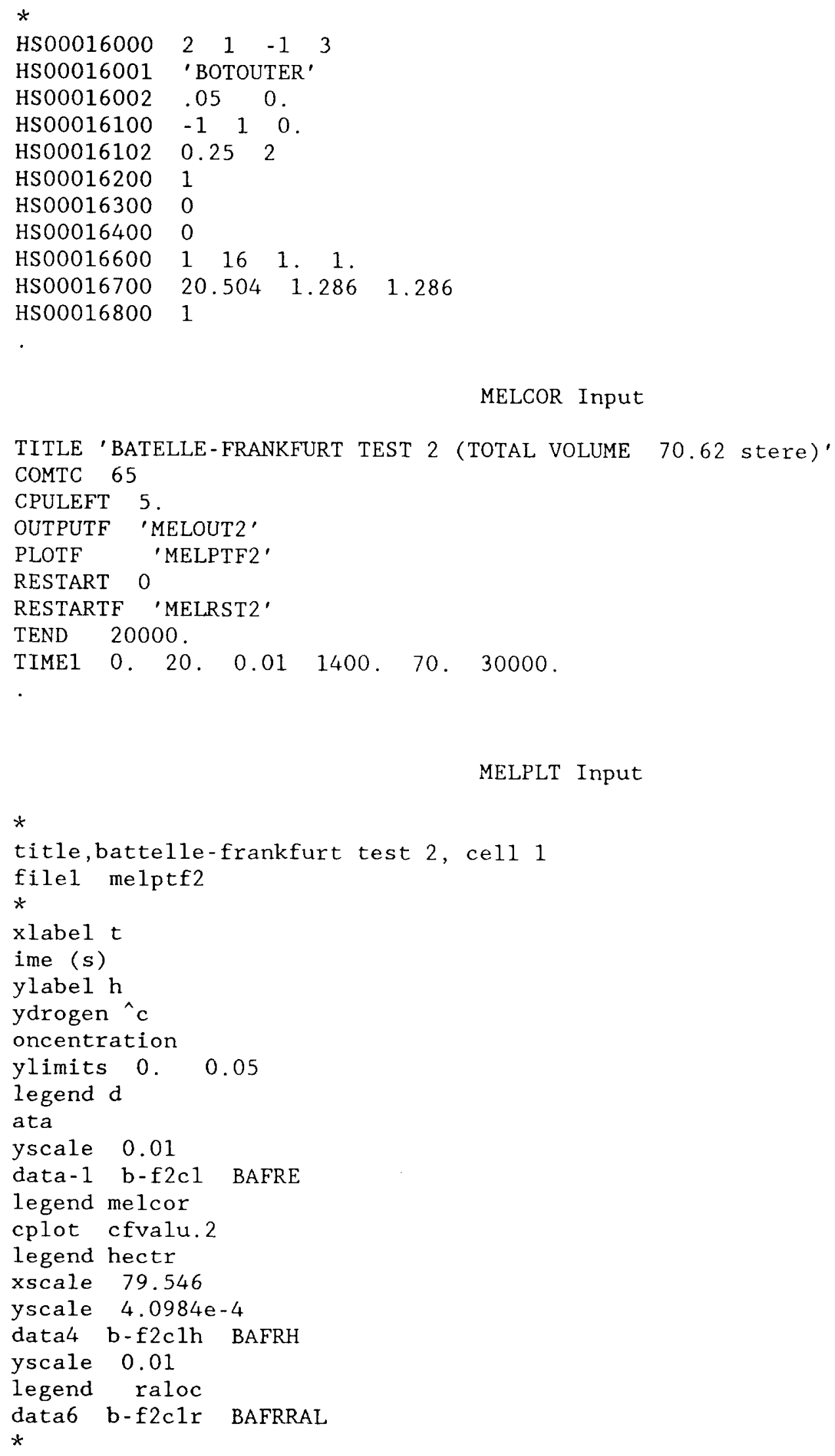

MELCOR Input 


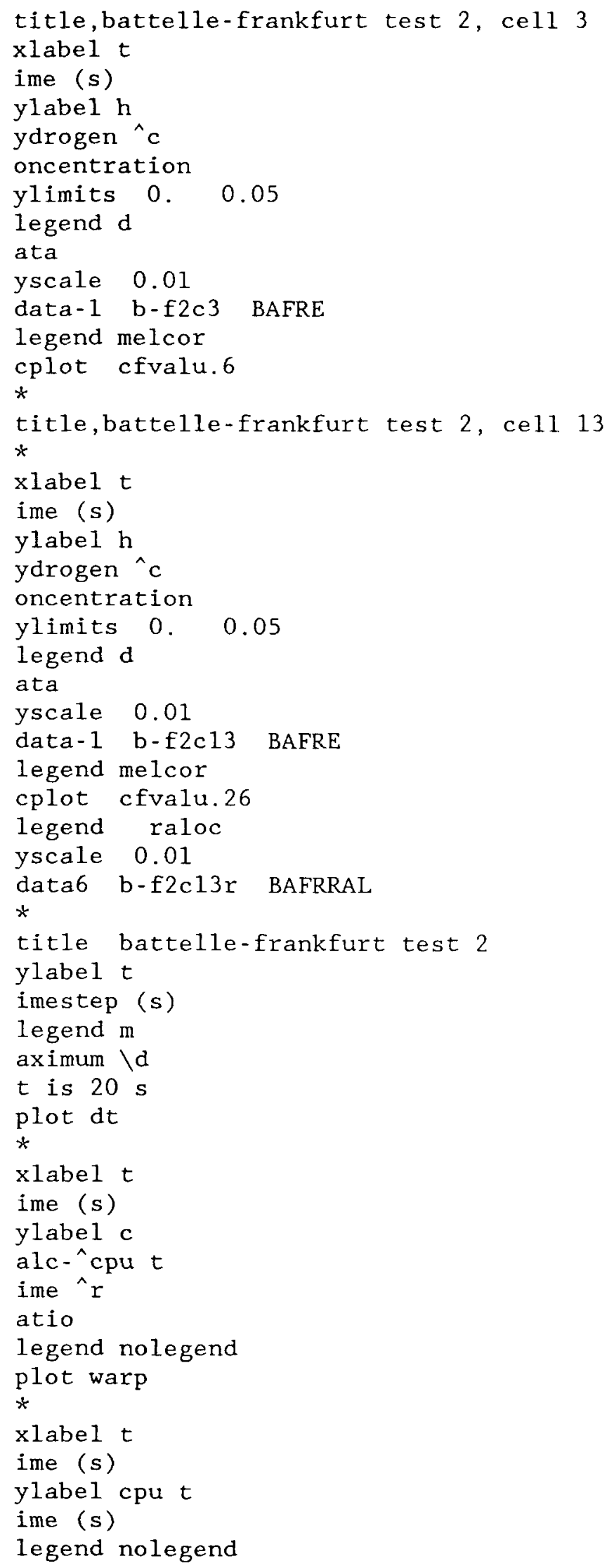




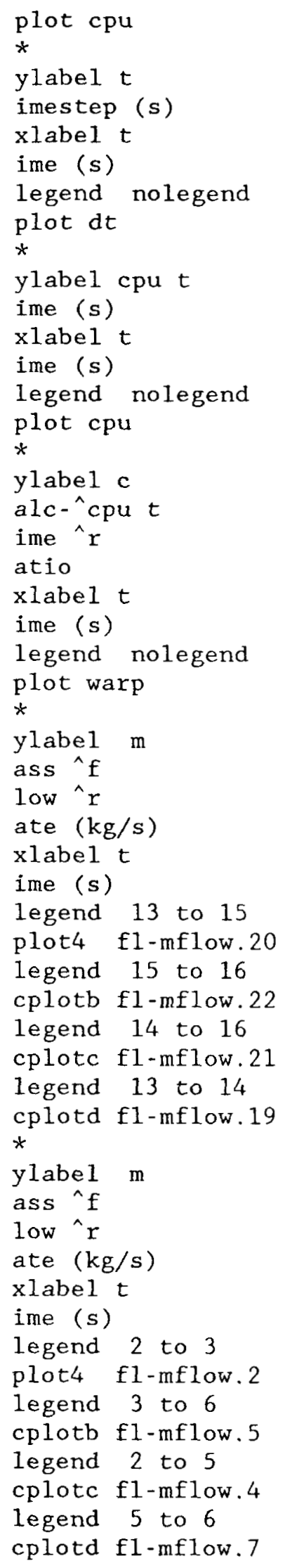




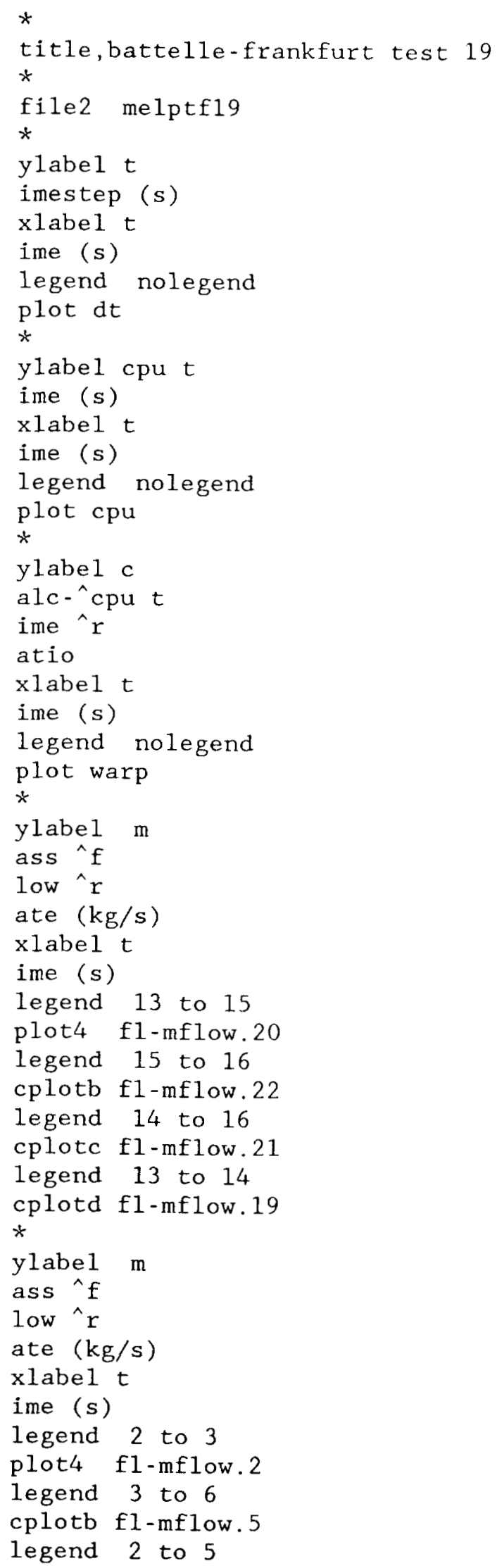




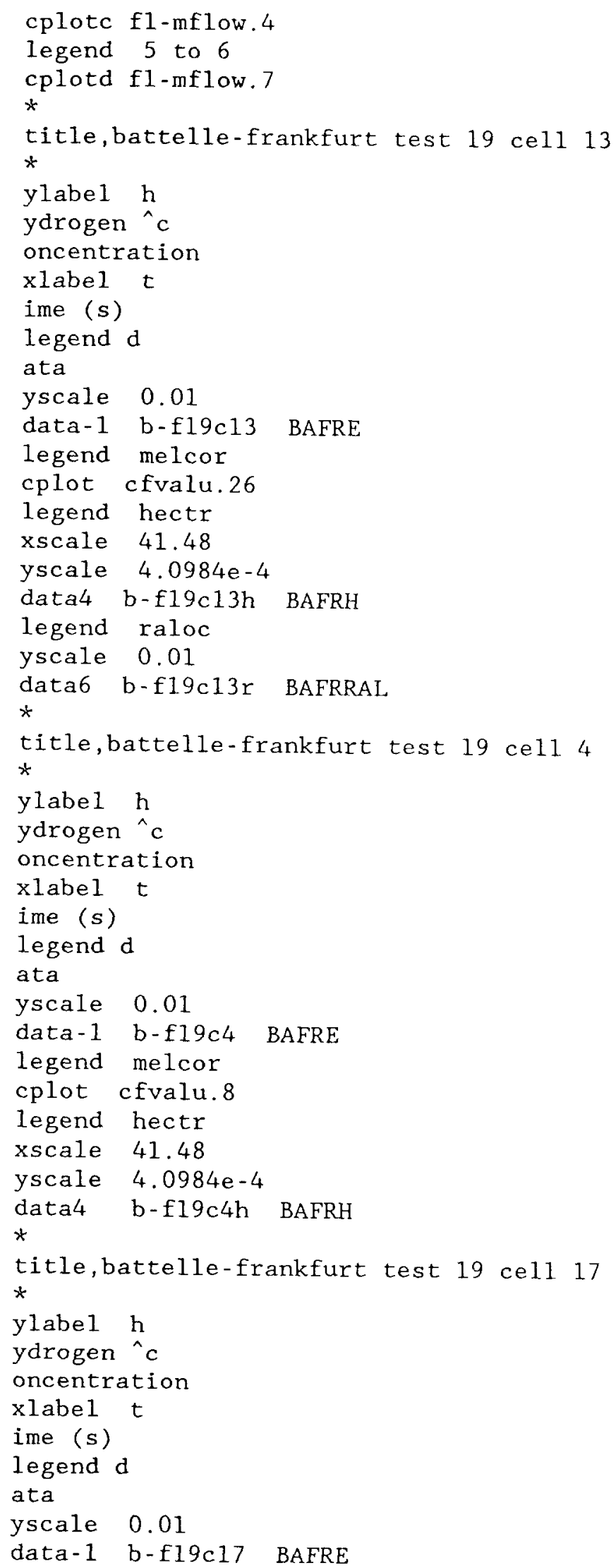




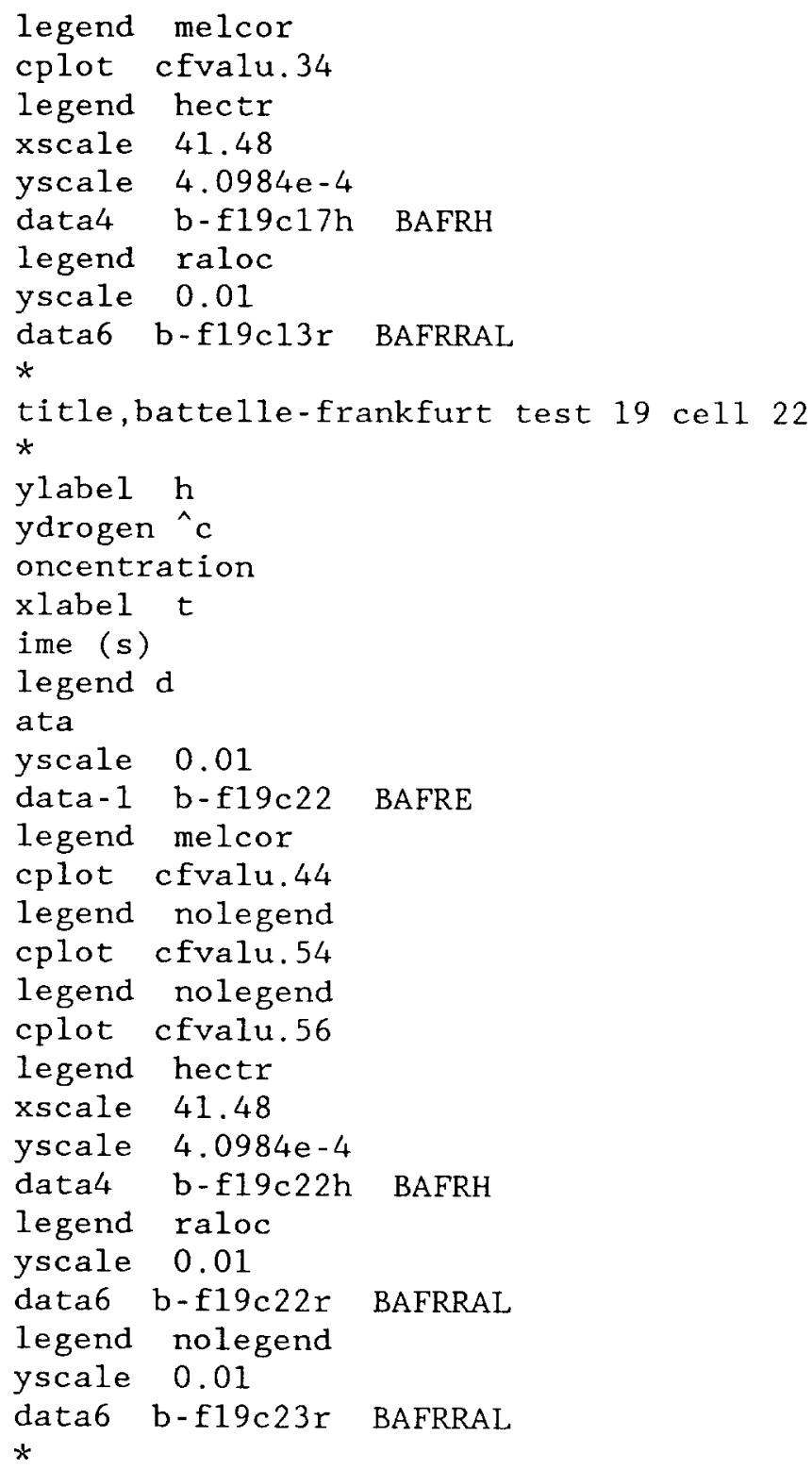

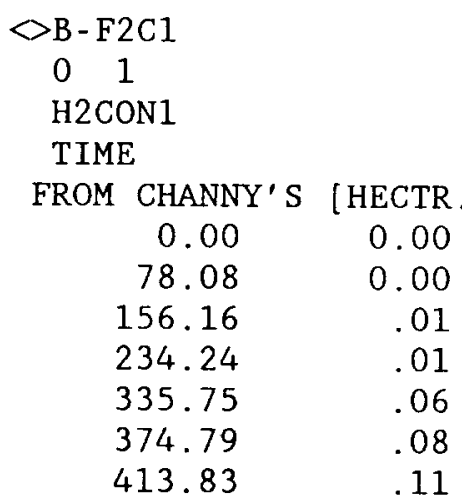




$\begin{array}{rr}452.87 & .14 \\ 530.95 & .16 \\ 554.38 & .14 \\ 609.04 & .11 \\ 671.50 & .12 \\ 671.50 & .15 \\ 671.50 & .20 \\ 726.16 & .20 \\ 827.66 & .19 \\ 929.17 & .19 \\ 991.63 & .20 \\ 1046.29 & .22 \\ 1124.37 & .26 \\ 1202.45 & .27 \\ 1288.34 & .31 \\ 1343.00 & .34 \\ 1460.12 & .37 \\ 1522.59 & .38 \\ 1561.63 & .38 \\ 1624.09 & .39 \\ 1717.79 & .40 \\ 1764.64 & .42 \\ 1819.30 & .47 \\ 1858.34 & .50 \\ 1936.42 & .49 \\ 1998.88 & .55 \\ 2061.35 & .54 \\ 2076.97 & .57 \\ 2139.43 & .61 \\ 2178.47 & .57 \\ 2217.51 & .59 \\ 2295.59 & .63 \\ 2319.02 & .66 \\ 2397.10 & .62 \\ 2436.14 & .62 \\ 2498.61 & .62 \\ 2514.22 & .65 \\ 2553.26 & .68 \\ 2631.34 & .70 \\ 2654.77 & .73 \\ 2732.85 & .75 \\ 2795.32 & .75 \\ 2873.40 & .77 \\ 2928.05 & .80 \\ 2974.90 & .82 \\ 3029.56 & .83 \\ 3107.64 & .85 \\ 3146.68 & .89 \\ 3209.15 & .91 \\ 3349.69 & .93 \\ 3388.73 & .97 \\ 3427.77 & .05 \\ 3505.86 & \\ 3583.94 & \end{array}$




$\begin{array}{ll}3662.02 & 1.09 \\ 3724.48 & 1.06 \\ 3724.48 & 1.12 \\ 3802.57 & 1.14 \\ 3865.03 & 1.16 \\ 3966.54 & 1.15 \\ 4005.58 & 1.17 \\ 4083.66 & 1.22 \\ 4122.70 & 1.24 \\ 4177.36 & 1.29 \\ 4200.78 & 1.31 \\ 4278.86 & 1.29 \\ 4278.86 & 1.34 \\ 4341.33 & 1.35 \\ 4419.41 & 1.39 \\ 4435.03 & 1.41 \\ 4481.87 & 1.45 \\ 4536.53 & 1.47 \\ 4599.00 & 1.49 \\ 4614.61 & 1.45 \\ 4653.65 & 1.40 \\ 4692.69 & 1.47 \\ 4739.54 & 1.51 \\ 4872.28 & 1.53 \\ 4895.71 & 1.57 \\ 4934.75 & 1.60 \\ 4973.79 & 1.63 \\ 5051.87 & 1.62 \\ 5090.91 & 1.60 \\ 5114.33 & 1.63\end{array}$

Note: This data file has been truncated here. For a more complete data set contact the editor of this report.

HECTR Data

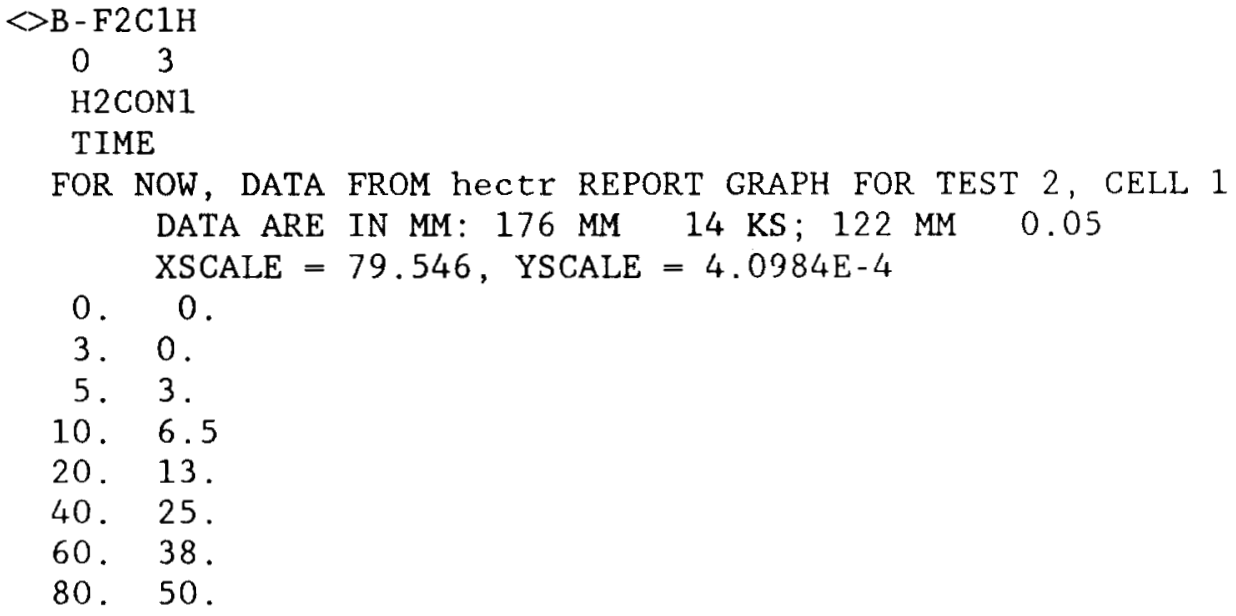


100. 63.

120. 74 .

140. 87.5

160. 99 .

171.8105 .

172.8103 .

173.5104 .

175.9104.

$-12345-12345$

$\triangle \mathrm{B}-\mathrm{F} 6 \mathrm{ClH}$

03

H2CON1

TIME

FOR NOW, DATA FROM hectr REPORT GRAPH FOR TEST 6, CELL 1 DATA ARE IN MM: $176 \mathrm{MM} 14 \mathrm{KS} ; 122 \mathrm{MM} 0.05$

0.0 . 0.

XSCALE $=79.546$, YSCALE $=4.0984 \mathrm{E}-4$

25. 0 .

30. .8

40. 1.5

45. 2 .

50. 3 .

55.4.

$60 . \quad 5.3$

65.6 .8

$70 . \quad 7.8$

75. 9 .

80. 10.7

85. $\quad 13.3$

$90 . \quad 17.2$

92.820 .

95.23 .

101.31 .

102.835 .

105. 35 .

108. 60 .

111. 75 .

112. 78 .

113. 80 .

115. 82.5

116. 84 .

117. 84.9

119. 86 .

121. 86.9

124.87.

128. 86.5

135. 85 .

140. 84.5

150. 82.9

155. 82.4

160.82 .

$161.5 \quad 81.5$

165. 77.5

167.75 . 
170. $\quad 72.5$

172. 71 .

$175 . \quad 69.4$

$-12345-12345$

$>\mathrm{B}-\mathrm{F} 6 \mathrm{C} 12 \mathrm{H}$

03

h $2 \operatorname{con} 12$

time

this may be hectr output digitized for test 6, cell 12

from channy's file bf6z12.dat

maybe heat structures

$\begin{array}{rr}0.000 & 0.0000 \\ 47.039 & 0.0000 \\ 78.039 & 0.0000 \\ 101.539 & 0.0000 \\ 119.039 & 0.0001 \\ 138.039 & 0.0005 \\ 175.539 & 0.0015 \\ 204.539 & 0.0023 \\ 238.039 & 0.0033 \\ 278.039 & 0.0044 \\ 312.039 & 0.0052 \\ 364.039 & 0.0062 \\ 423.539 & 0.0071 \\ 480.539 & 0.0082 \\ 537.039 & 0.0093 \\ 587.039 & 0.0104 \\ 640.539 & 0.0116 \\ 697.539 & 0.0127 \\ 735.039 & 0.0131 \\ 754.539 & 0.0131 \\ 771.039 & 0.0131 \\ 786.539 & 0.0130 \\ 801.039 & 0.0128 \\ 815.539 & 0.0124 \\ 833.539 & 0.0116 \\ 847.539 & 0.0110 \\ 860.539 & 0.0105\end{array}$

Note: This data file has been truncated here. For a more complete data set contact the editor of this report.

RALOC Data

$\triangle B$ B F 2 C $1 R$

01

H2CON1

TIME

FROM CHANNY'S R2Z1.DAT (RALOC) ALL ORDINATE VALUES ARE per centum

$+1.49864 \mathrm{E}+01,+1.67673 \mathrm{E}-02$

$+8.99183 \mathrm{E}+01,+1.67673 \mathrm{E}-02$

$+1.34877 \mathrm{E}+02,+4.35949 \mathrm{E}-02$ 


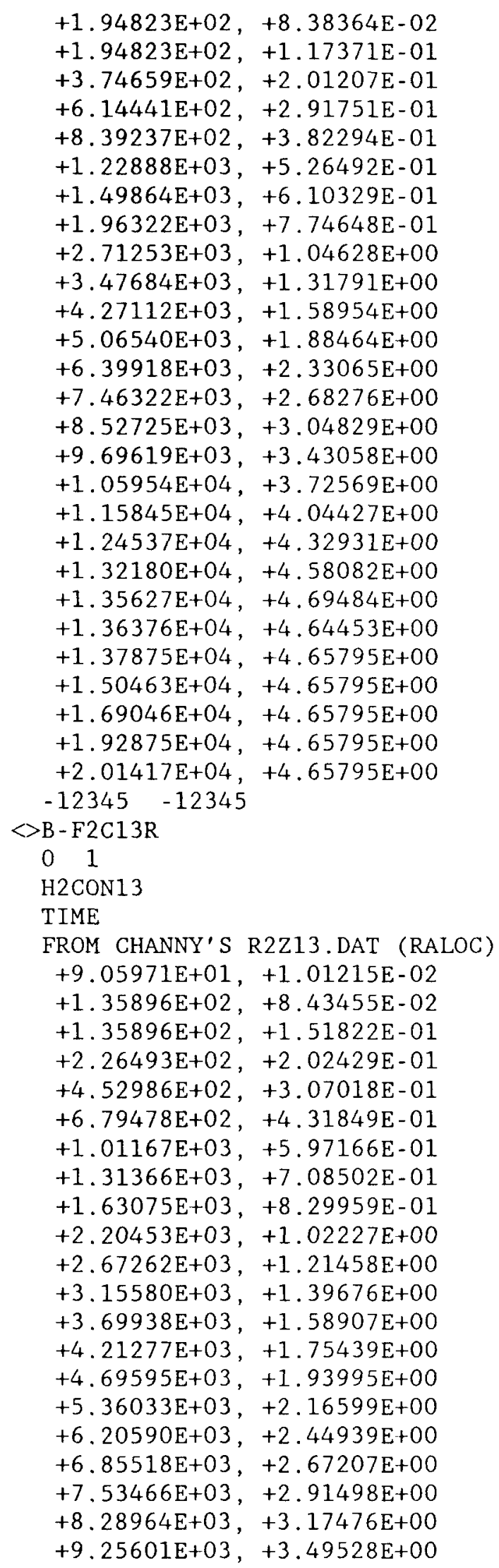




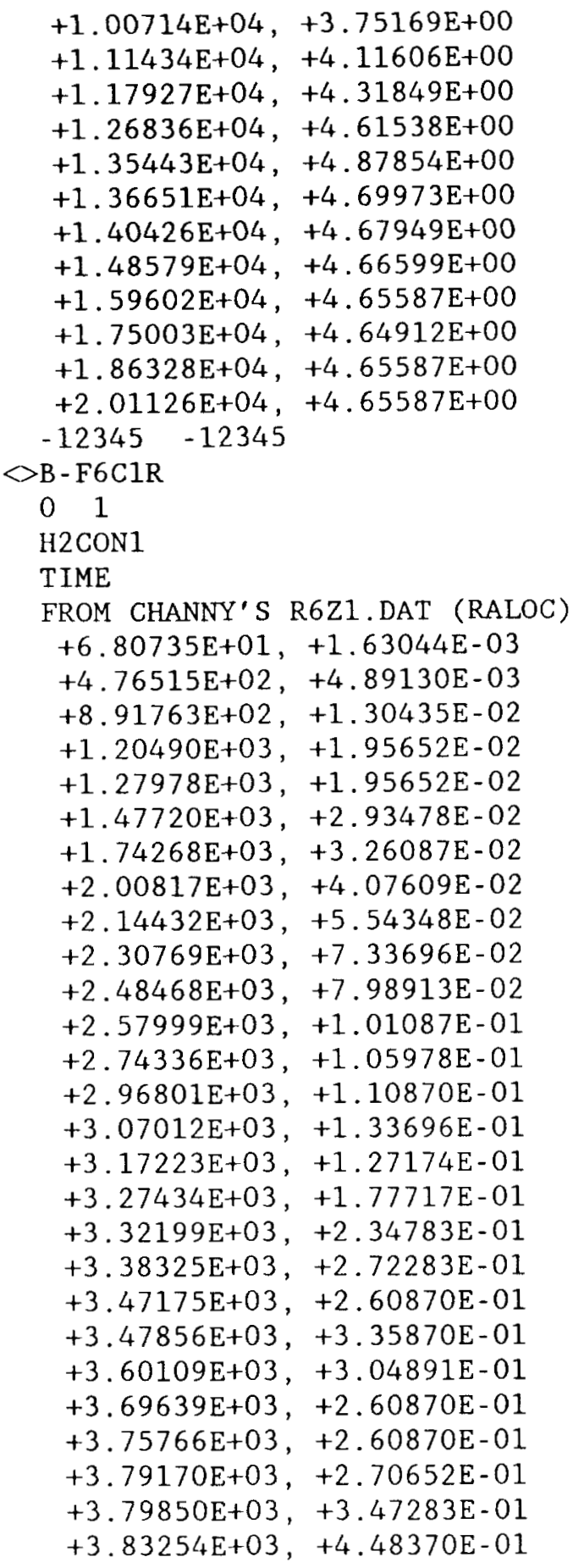

Note: This data file has been truncated here. For a more complete data set contact the editor of this report. 



\section{Appendix C}

Comparison Plots for MELCOR Standard Test Problems

Included in this appendix are the key plots for comparison for the MELCOR Standard Test problems. As mentioned in the preface, all of the results in this appendix were produced with the latest available version of the code, MELCOR 1.6.0. 


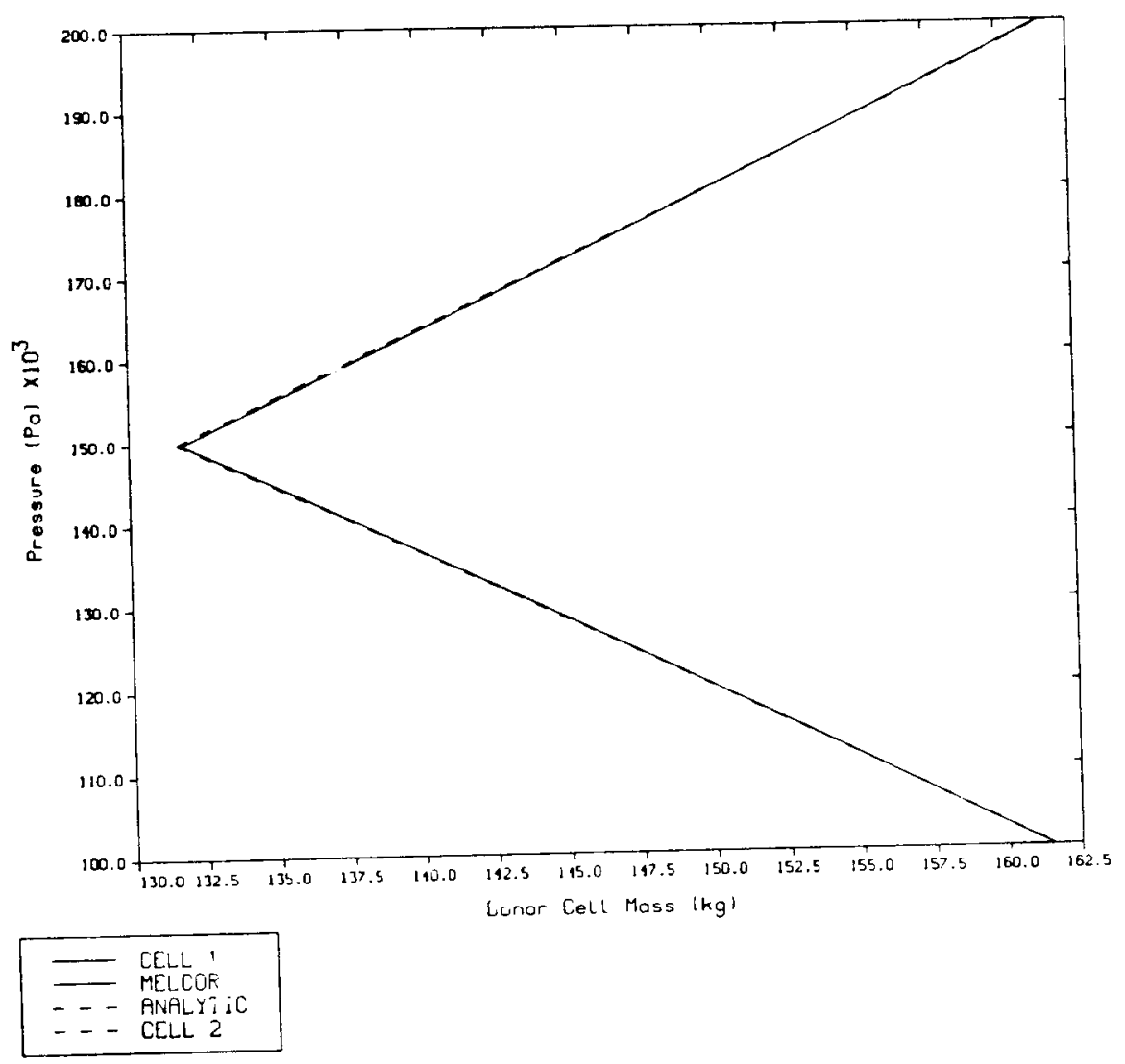

Figure C.1 Pressure versus time for both cells for ST001

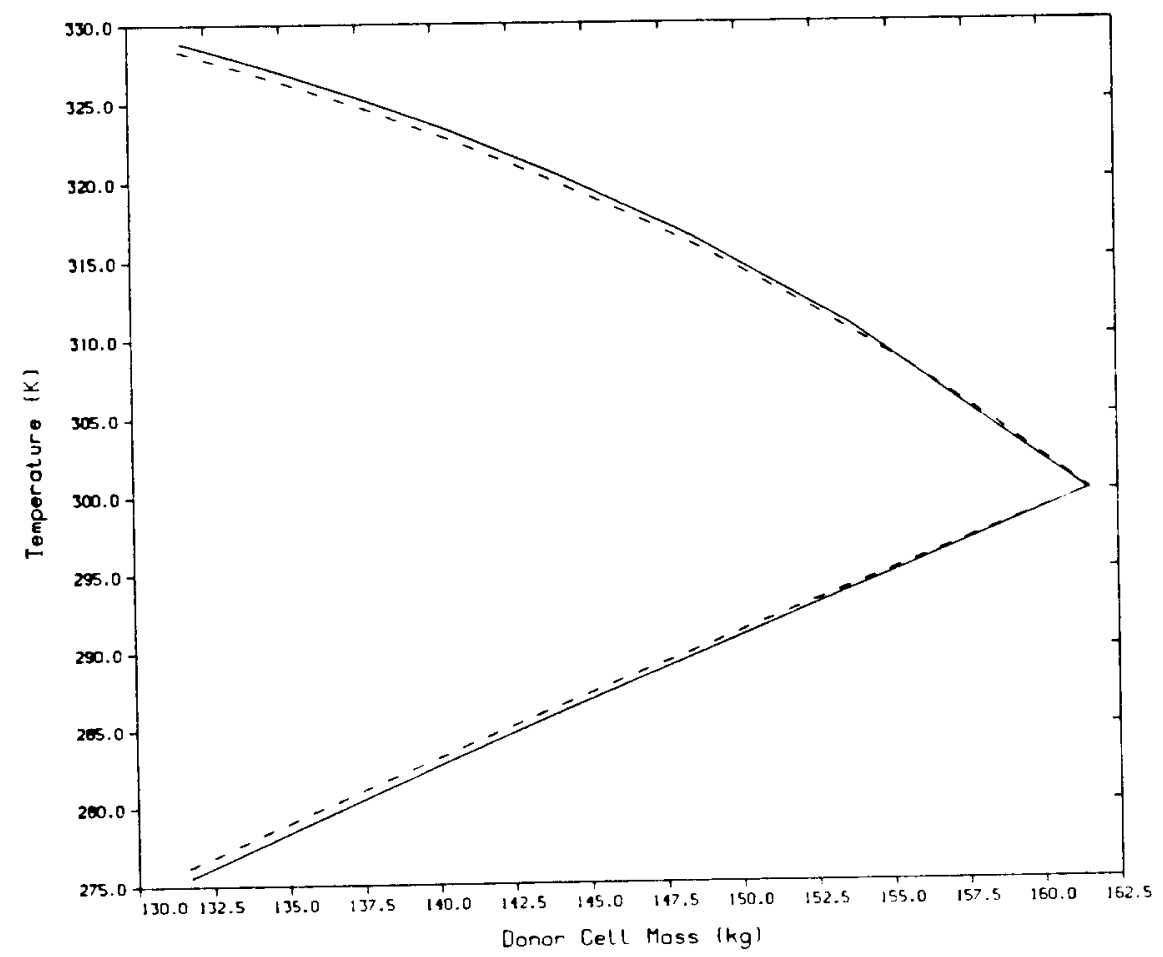

Figure C.2 Temperature versus time for both cells for ST001 C- 2 


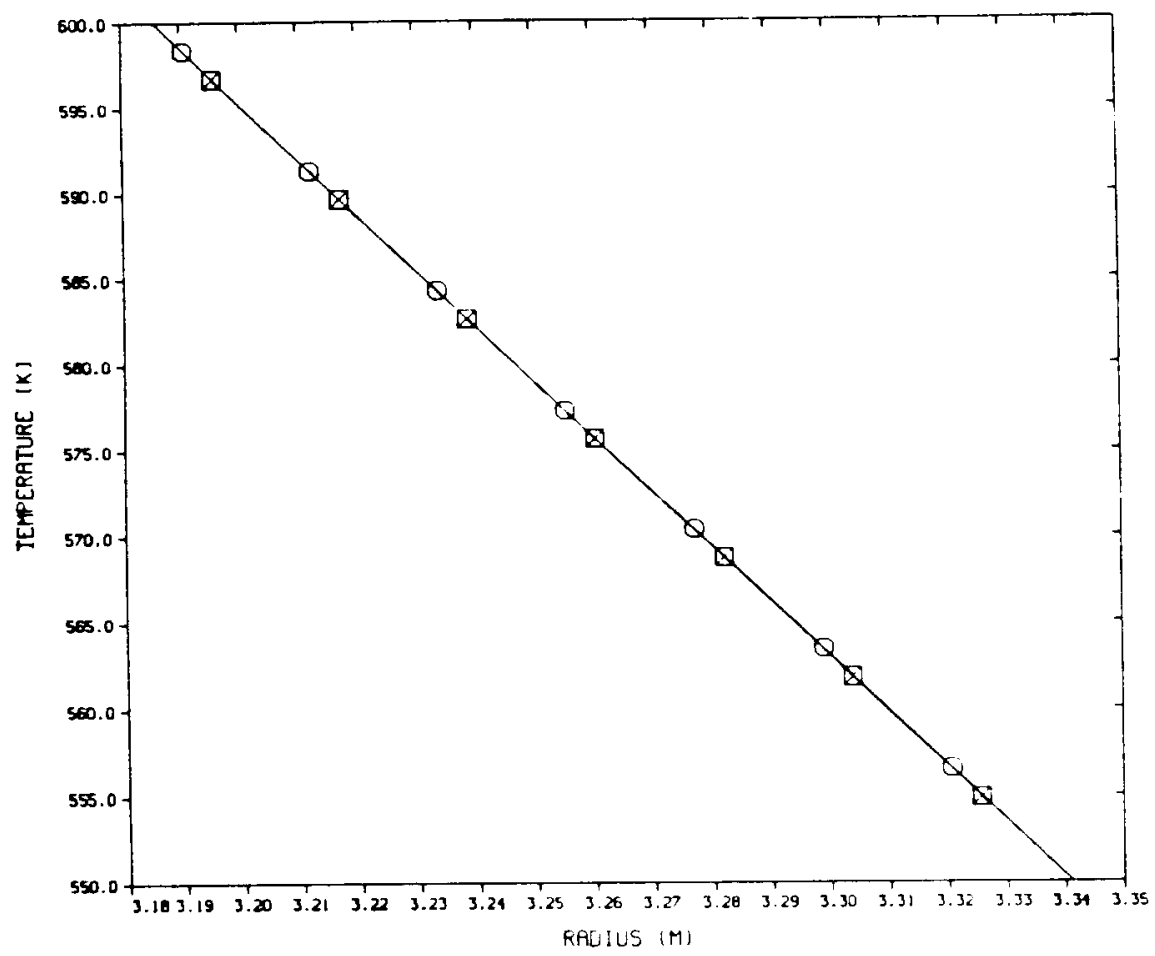

T-MELCOR-04
T-ANAL-04

Figure C.3. Temperature versus Radius for ST002

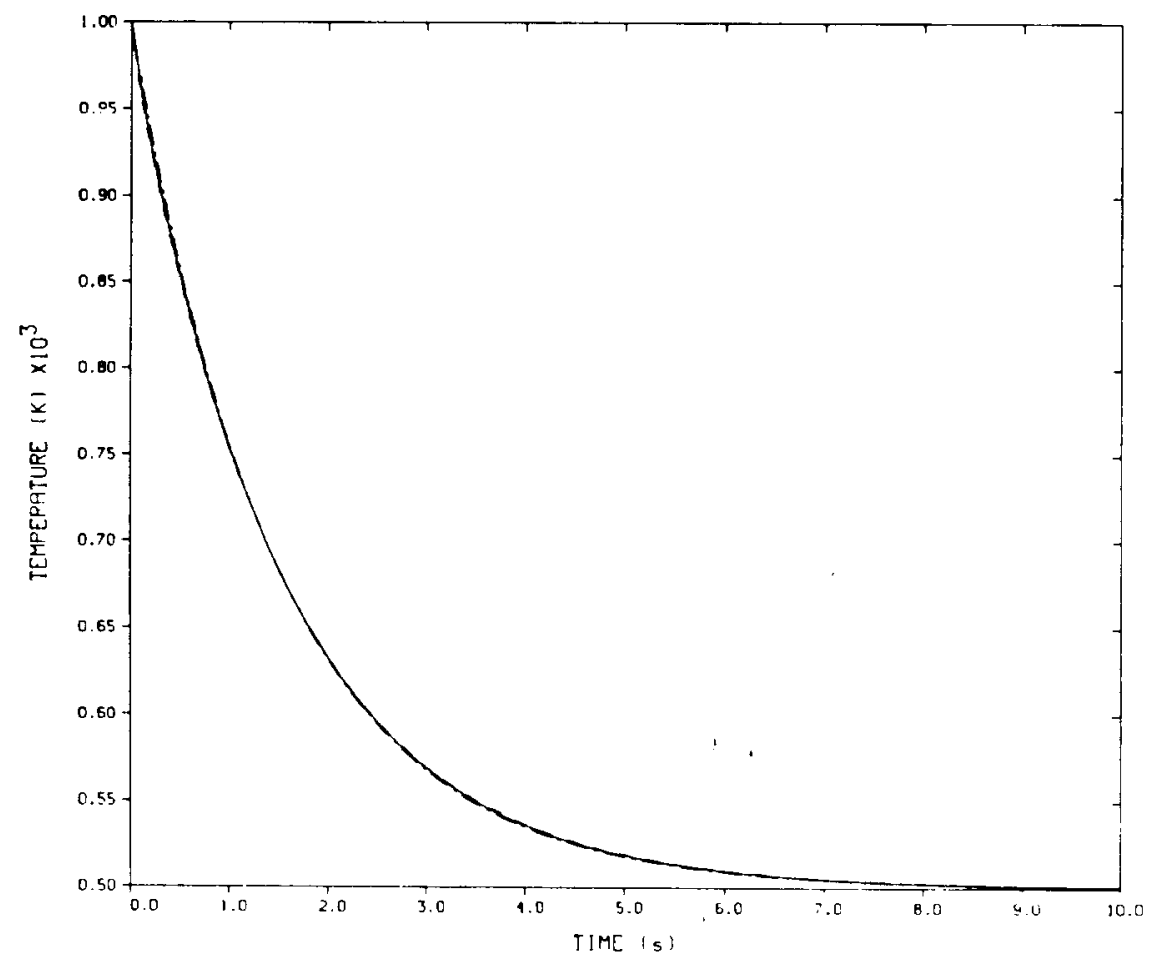

- - MCLCOR ICYLINOCRI
- - GNALYIIL SOLUTION

Figure C.4. Temperature versus Time for ST003

C- 3 

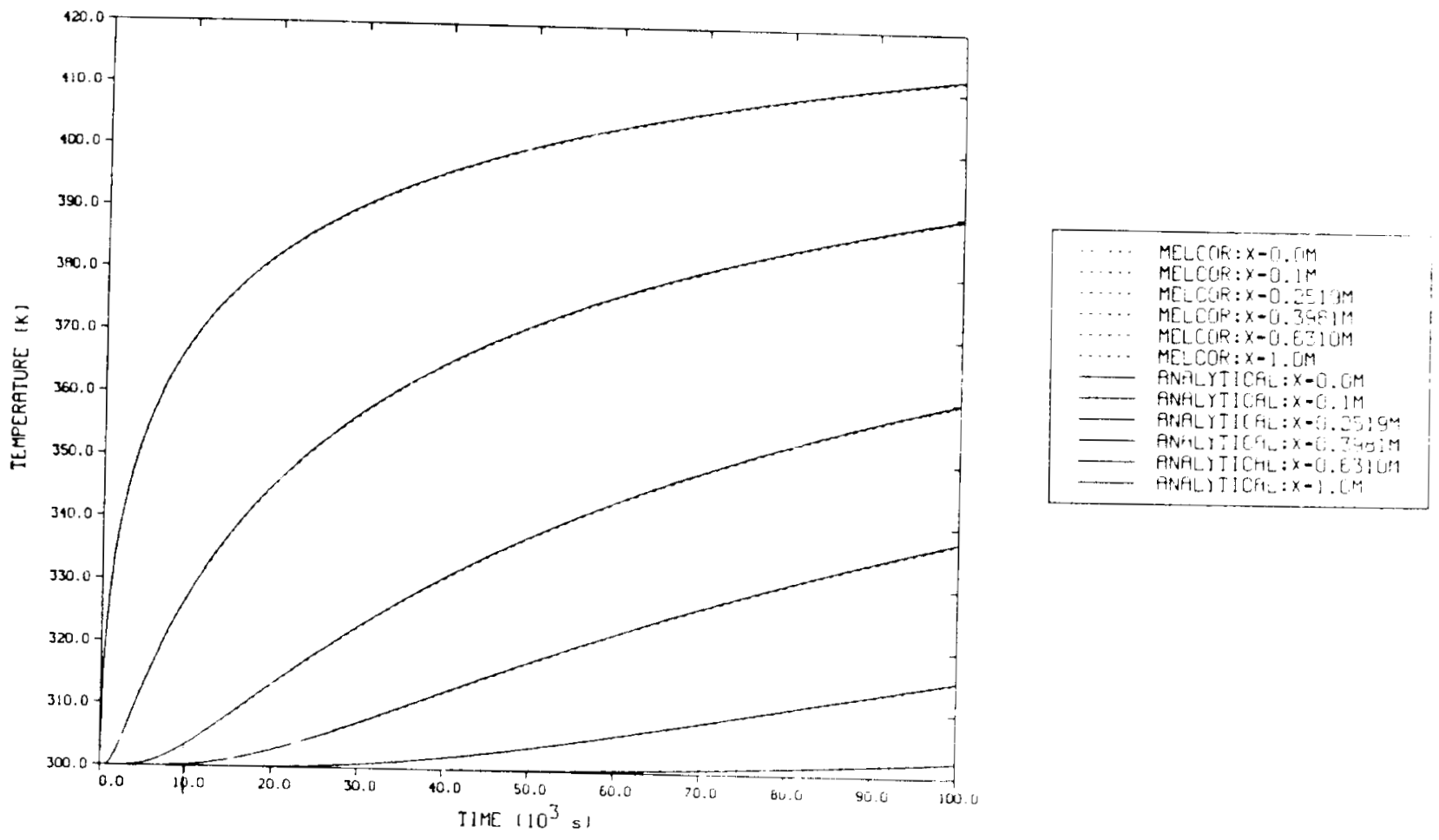

Figure C.5. Temperature versus Time within the structure for ST004A

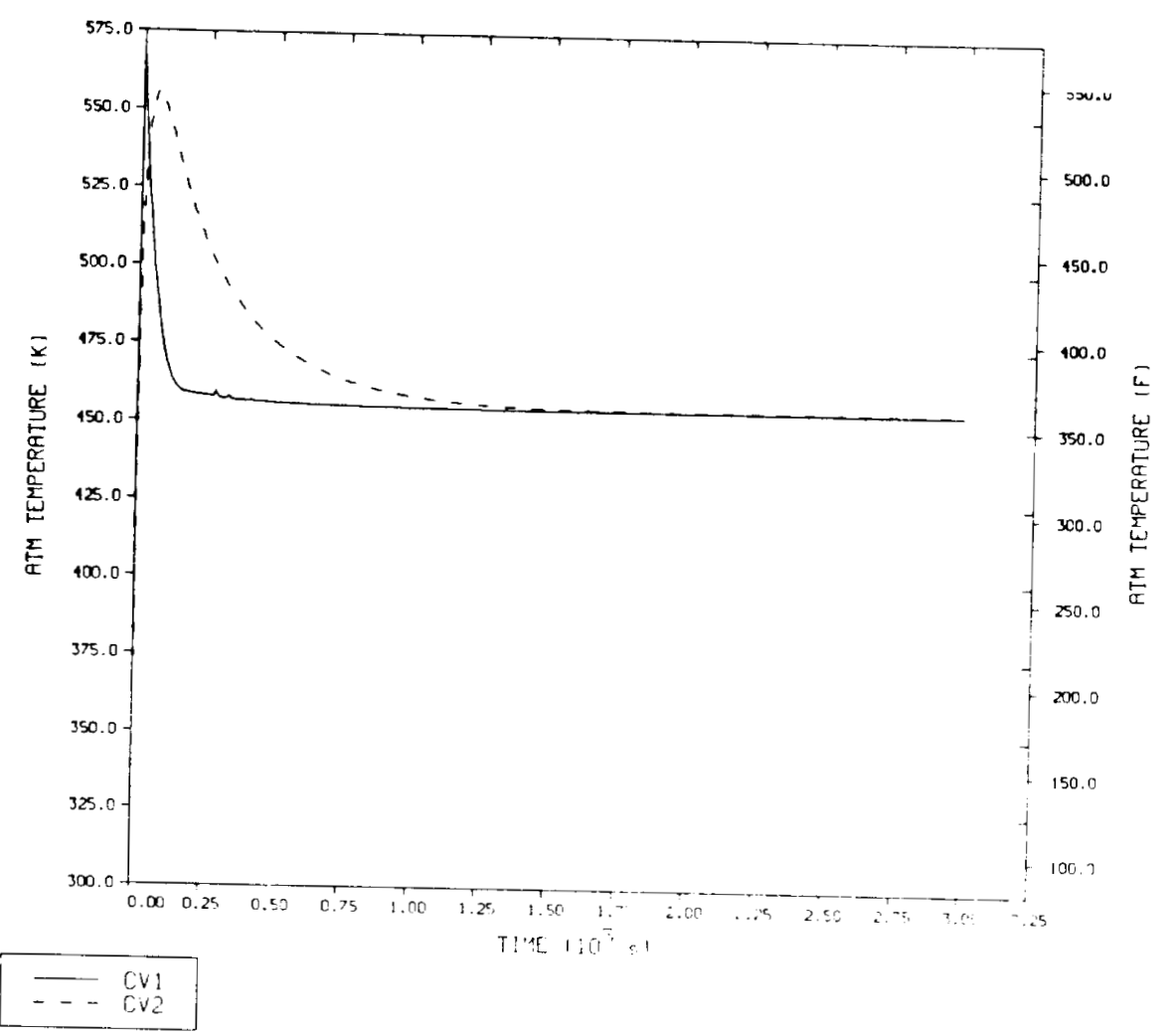

C.6. Temperature of Both Cells as a Function of Time for STO05

C -4 


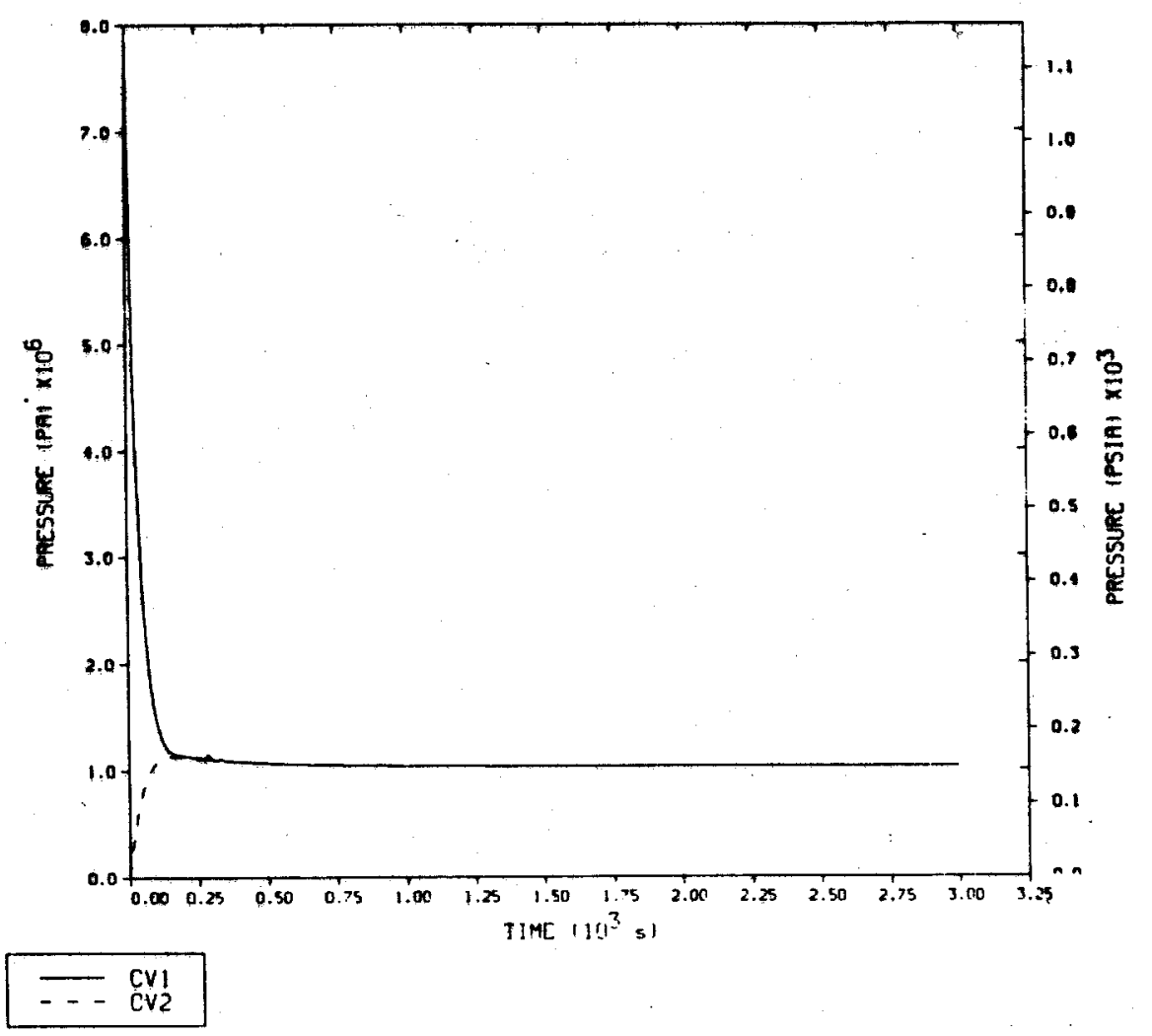

c.7. Pressure in Both Cells as a Function of Time for ST005

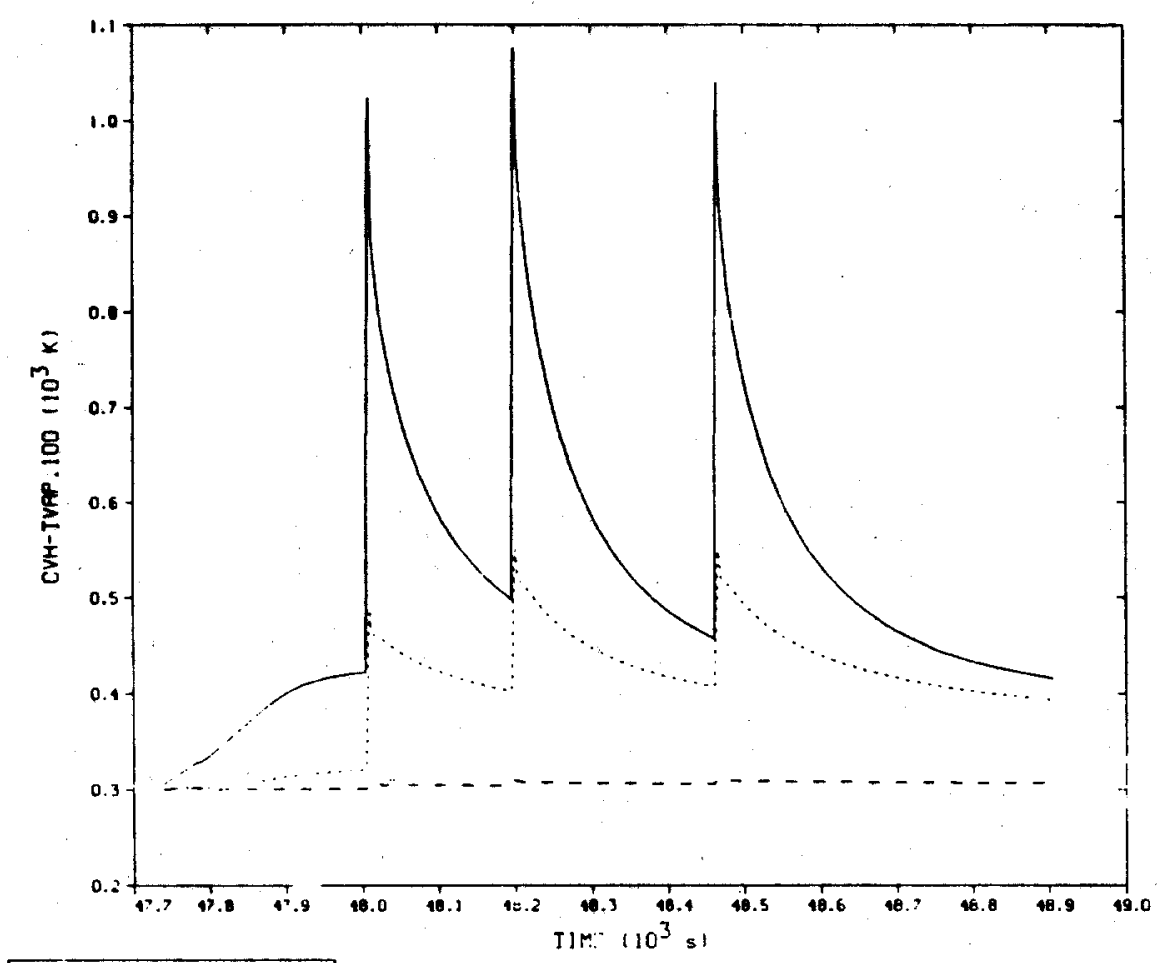

CVH-TVAF. 100
$\ldots \ldots$
CVH-TVAF. .200

- - CVH-TVIP. 300

C.8. Temperature versus Time for Control Volume 1 for ST006

C-5 


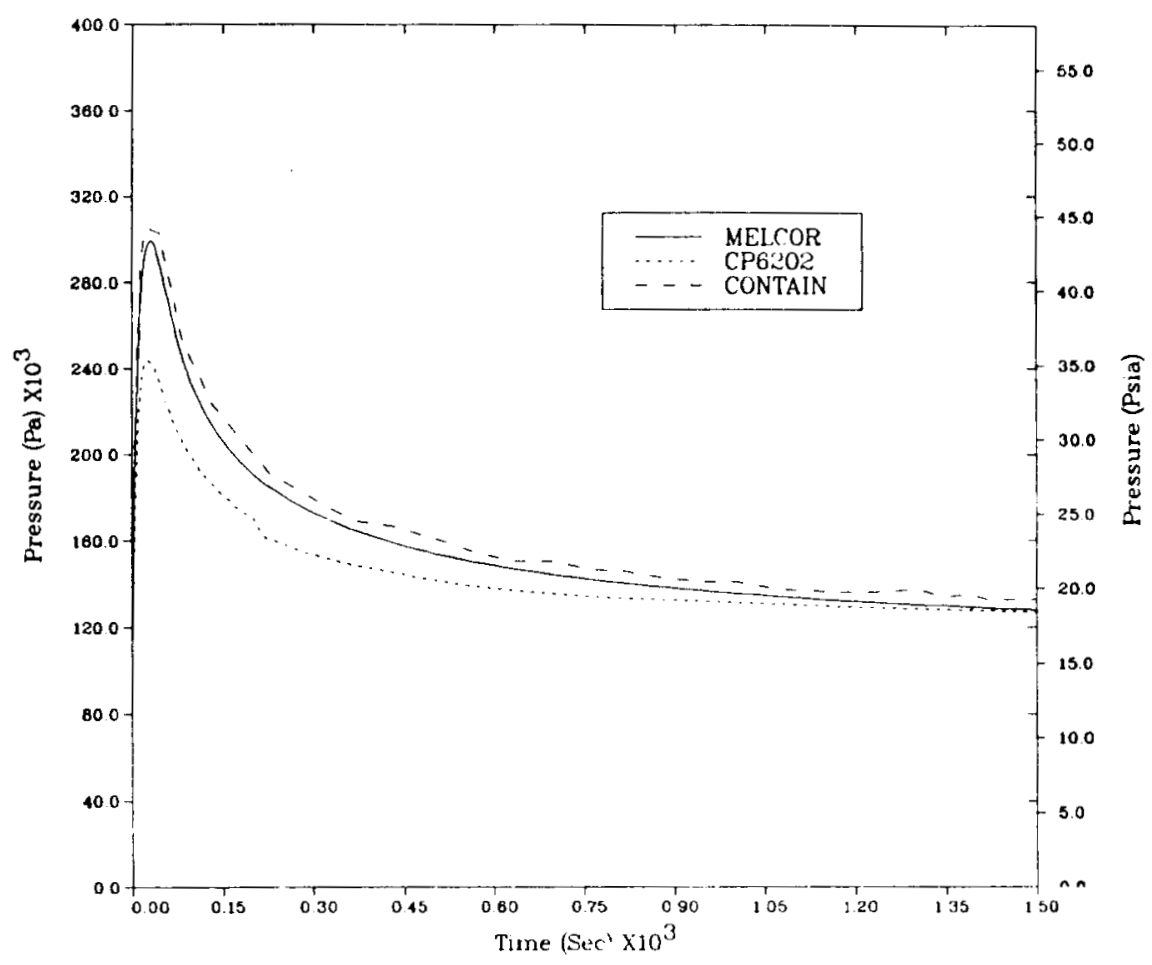

C.9. Containment Dome Pressure for ST007

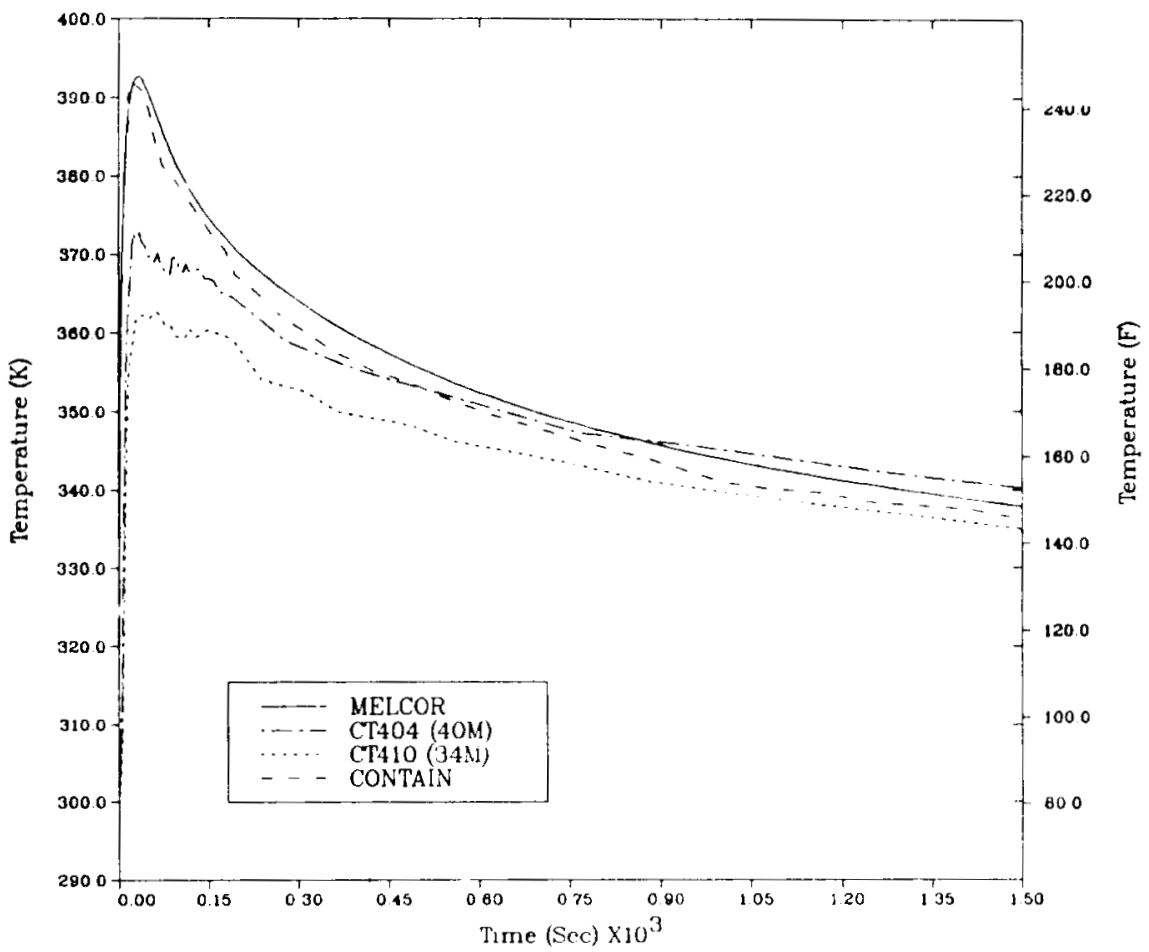

C.10. Containment Dome Temperature for ST007

$$
\text { C. } 6
$$




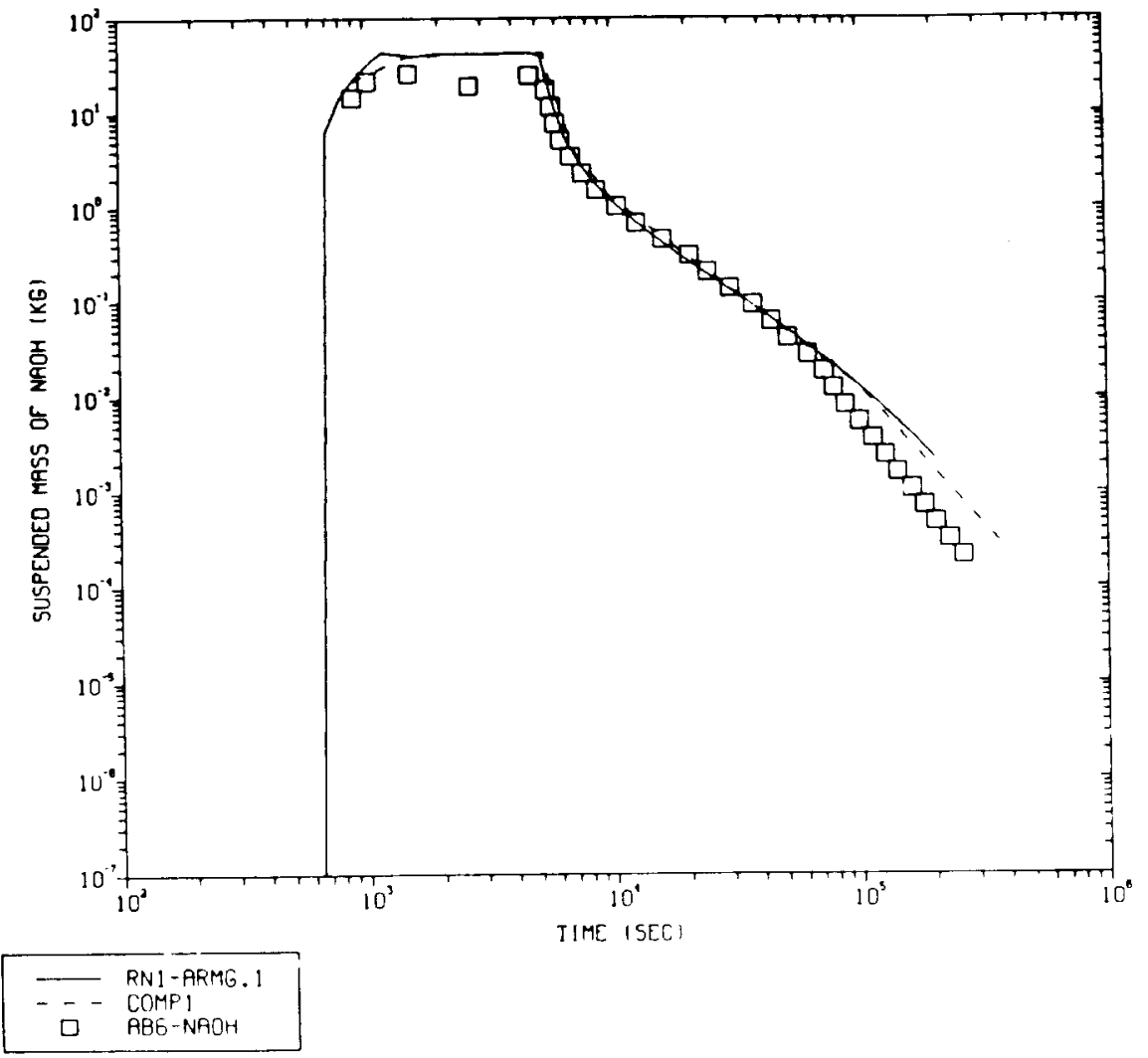

C.11. Suspended Mass of $\mathrm{NaOH}$ as a Function of Time for ST008

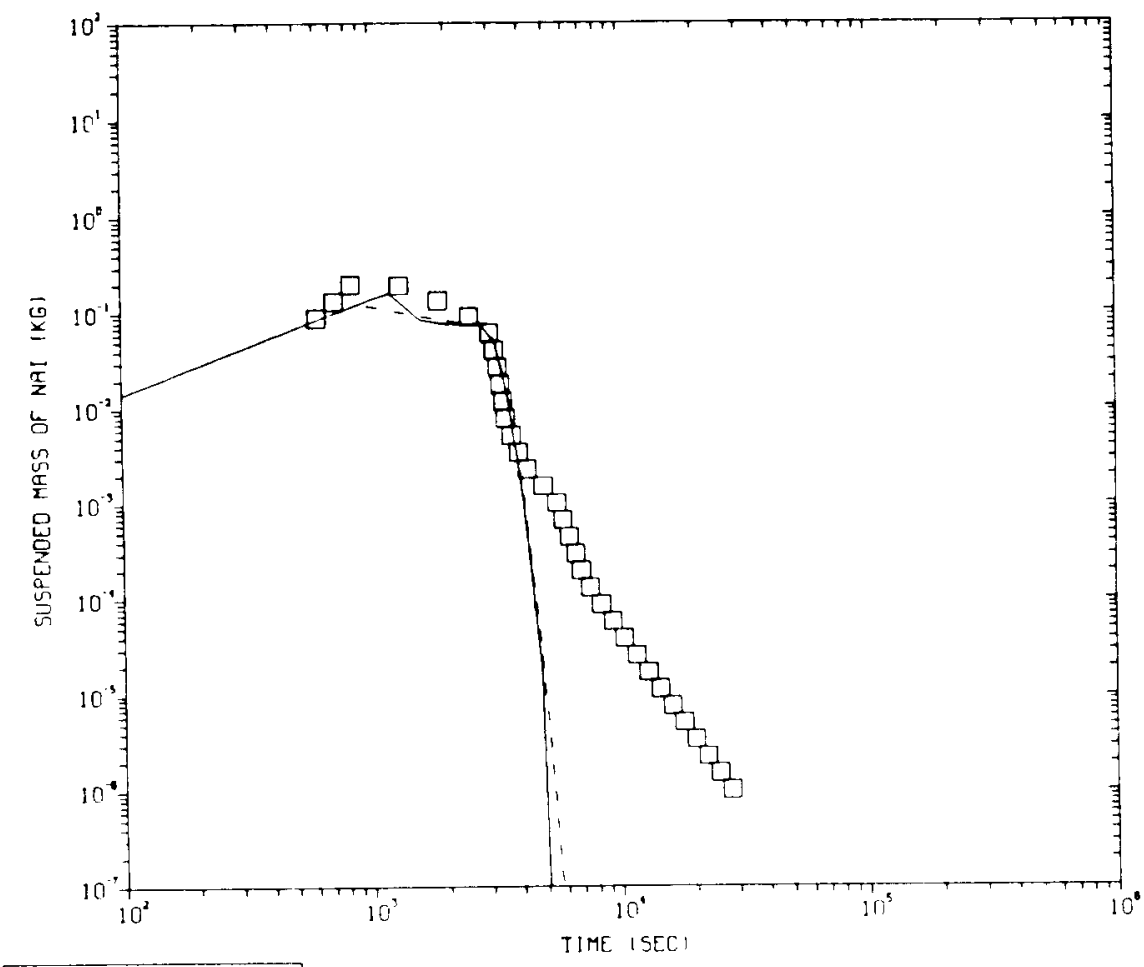

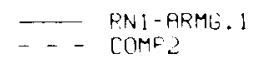

D ABG-NA:

C.12. Suspended Mass of NaI as a Function of Time for ST008 C -7 


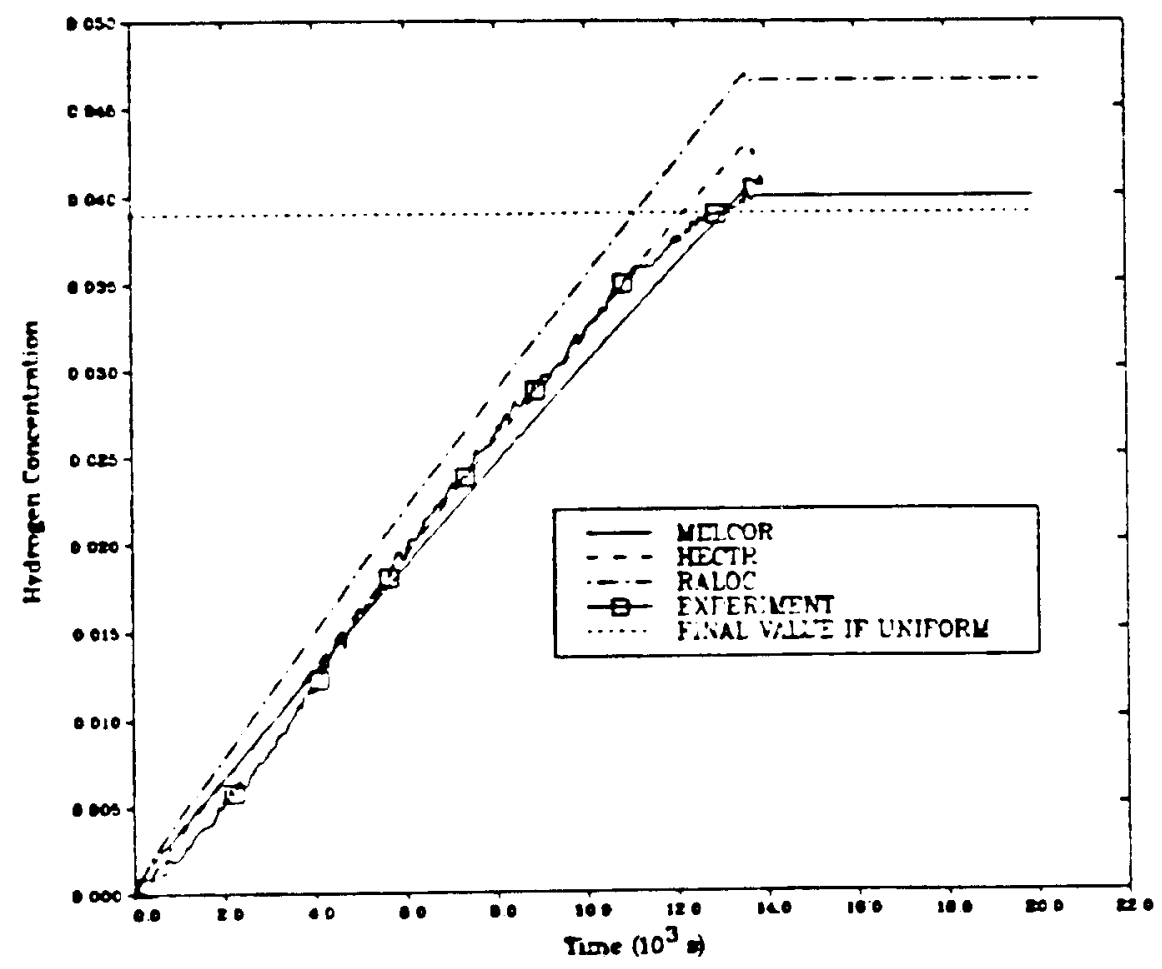

C.13. Hydrogen Concentration for Ce11 1 for Battelle-Frankfurt Test 2 (ST009)

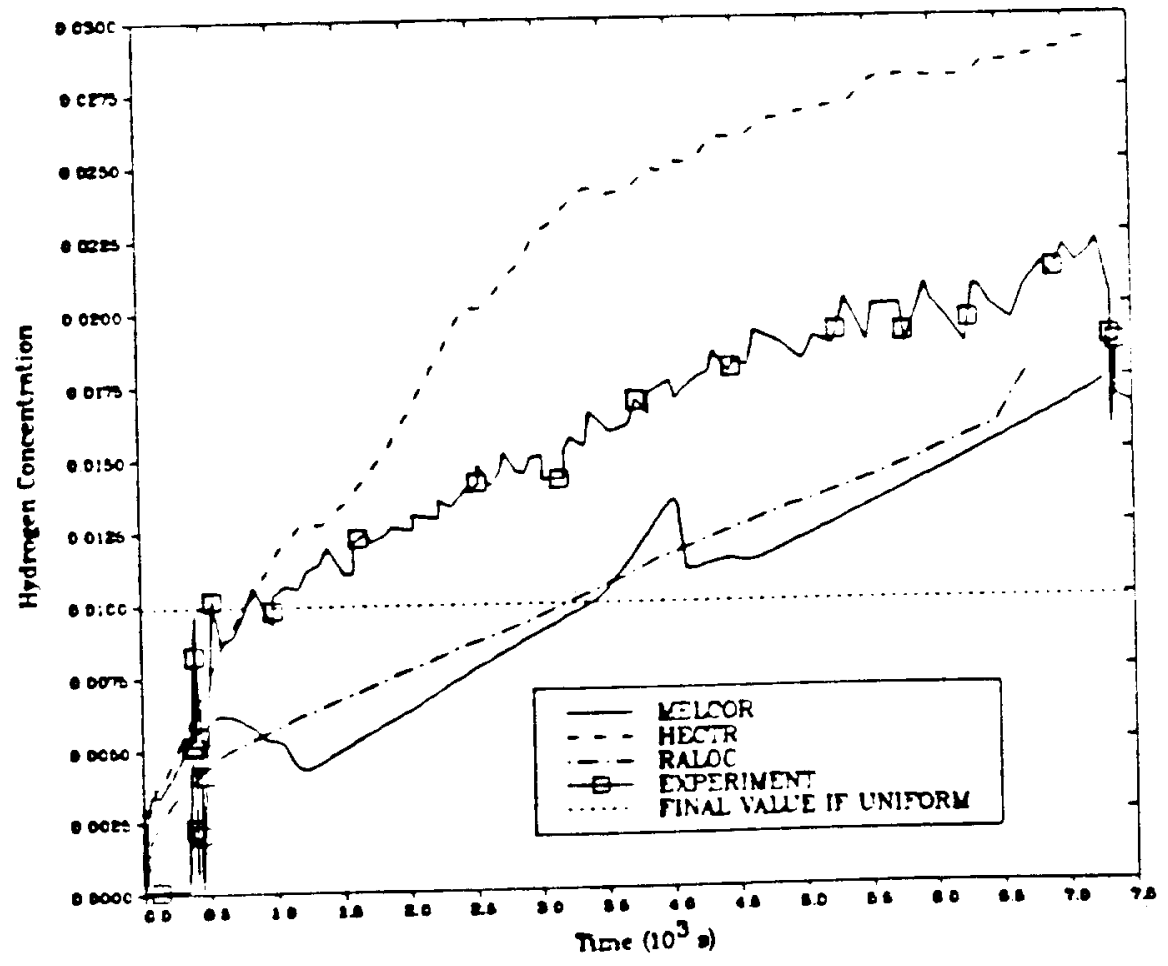

C.14. Hydrogen Concentration for Ce11 13 for Battelle-Frankfurt Test 19(ST009) C -8 


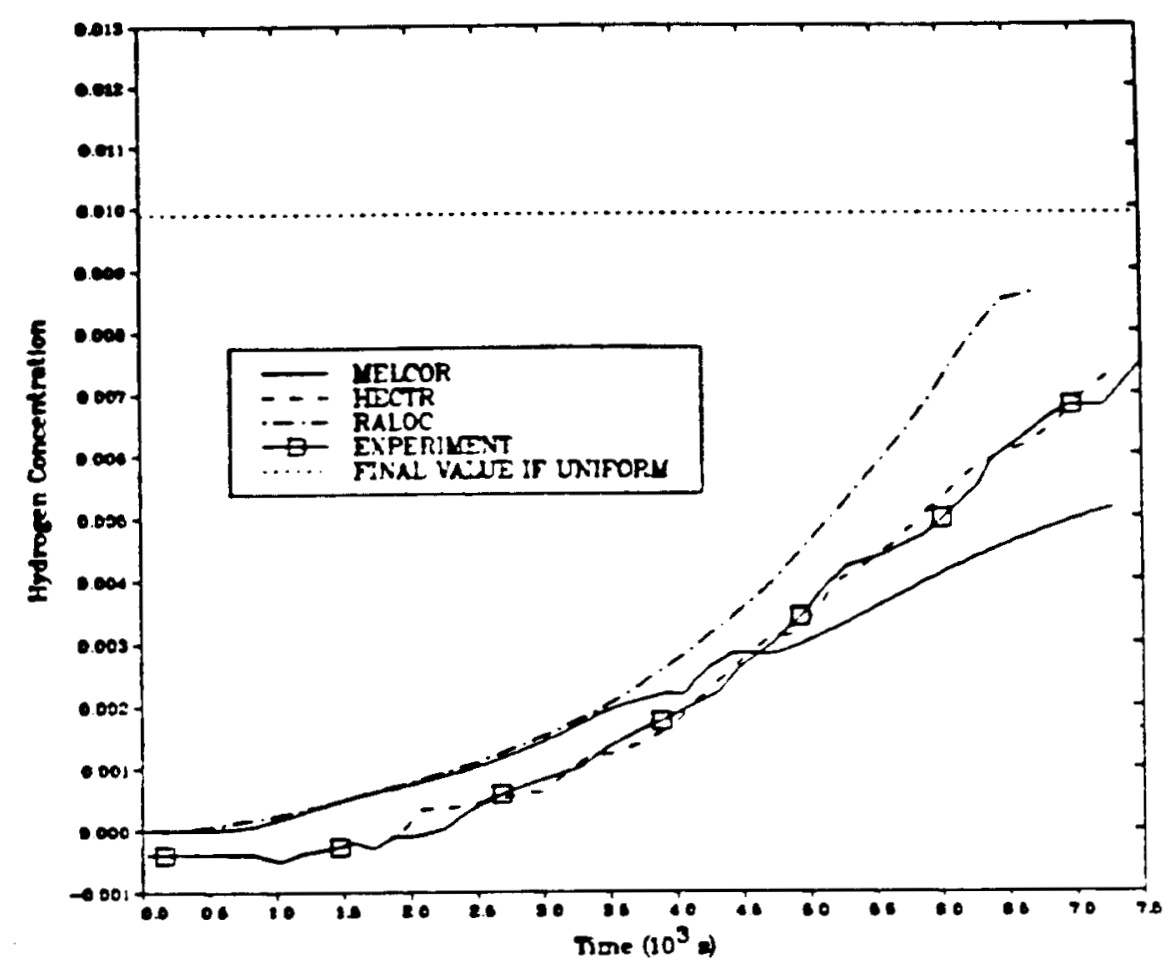

C.15. Hydrogen Concentration for Ce11 23 for Battelle-Frankfurt Test 19(ST009)

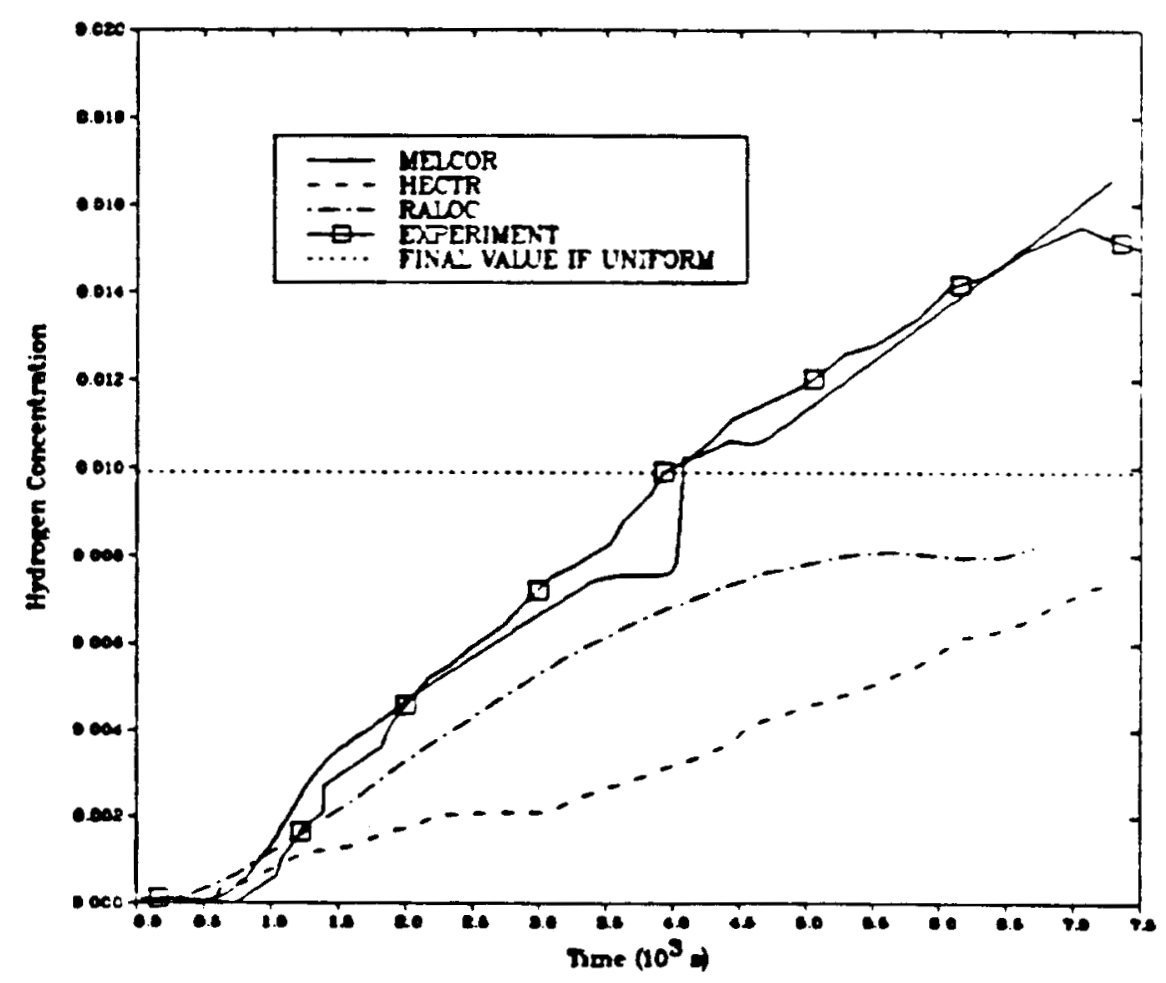

C.16. Hydrogen Concentration for Cel1 27 for Battelle-Frankfurt Test 19(ST009) C -9 

Distribution:

U.S. Government Printing Office Receiving Branch (Attn: NRC Stock)

8610 Cherry Lane

Laure 1, MD 20707

250 copies for R3

R. S. Denning

Battelle Columbus Laboratories

$505 \mathrm{King}$ Avenue

Columbus, $\mathrm{OH} 43201$

K. R. Perkins

Brookhaven National Laboratories

Building 130

Upton, NY 11973

M. S. Barents

EES (UK)

Granford ouse

16 Carfax

Horsham

West Sussex RH12UP

England

B. R. Sehgal

Electric Power Research Inst.

3412 Hillview Ave.

Palo Alto, CA 94304

J. A. Blackburn

Office of Nuclear Facility Safety

State of Illinois

Dept. of Nuclear Safety

1035 Outer Park Drive

Springfield, IL 62704

R. J. Dallman

INEL

P.O. Box 1625

Idaho Fal1s, ID 83401

K. C. Wagner

INEL

P.O. Box 1625

Idaho Falls, ID 83401

R. J. Barrett

Nuclear Regulatory Commission

Washington, DC 20555 
M. A. Cunningham

U. S. Nuclear Regulatory Commission

5650 Nicholson Lane

Rockville, MD 20852

R. O. Meyer

U. S. Nuclear Regulatory Commission

Washington, DC 20555

J. Mitche11

U. S. Nuclear Regulatory Commission

Washington, DC 20555

S. R. Greene

Oak Ridge National Laboratories

Building 9104-1, MS 1

Station 59, 9201-3

Y-12 Plant

Bear Creek Road

Oak Ridge, TN 37831

S. A. Hodge

Oak Ridge National Laboratories

Building 9104-1, MS1

Station 59, 9201-3

Y-12 Plant

Bear Creek Road

Oak Ridge, TN 37830

T. S. Kress

Oak Ridge National Laboratories

Building 91-4-1, MS1

Station 59, 9201-3

Y-12 Plant

Bear Creek Road

Oak Ridge, TN 37830

A. Torri

Pickard, Lowe \& Garrick

1421 Hymettus Ave.

La Condita, CA 92024

F. A. Koontz

Tennessee Valley Authority

$400 \mathrm{~W}$. Summit Hill Dr.

Knoxville, TN 37922

S. R. Kinnersly

Atomic Energy Establishment

Winfrith

Dorchester

Dorset DT28DH

England 


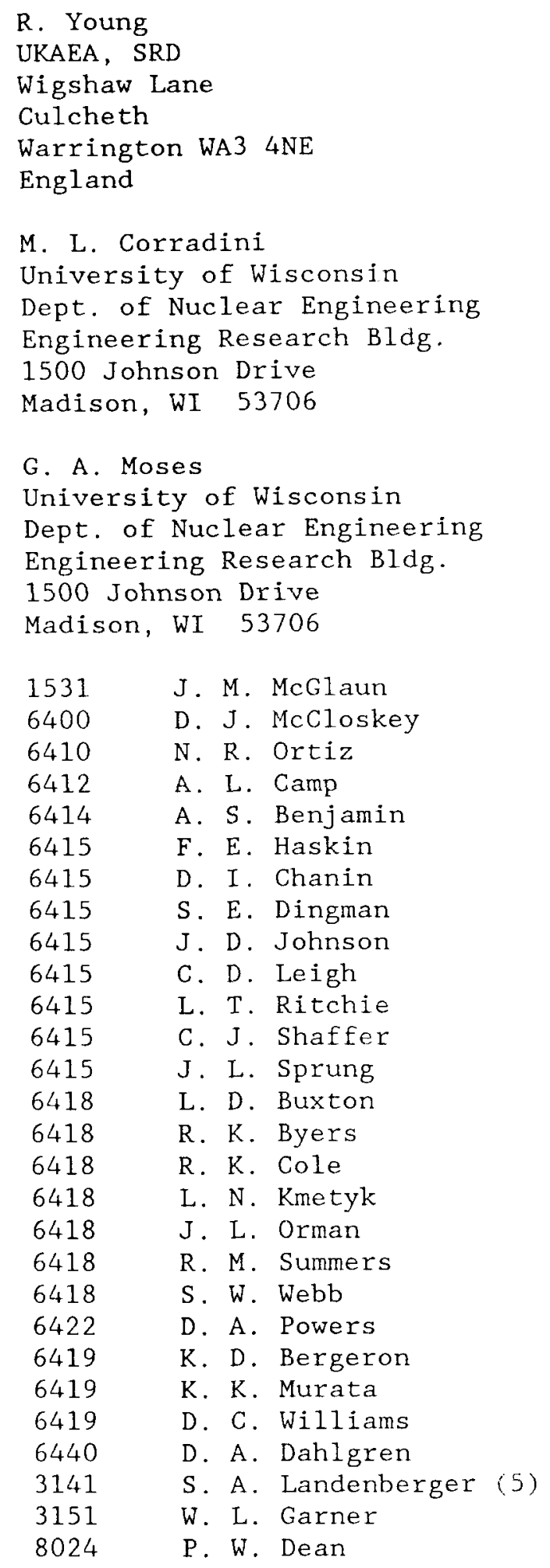




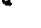




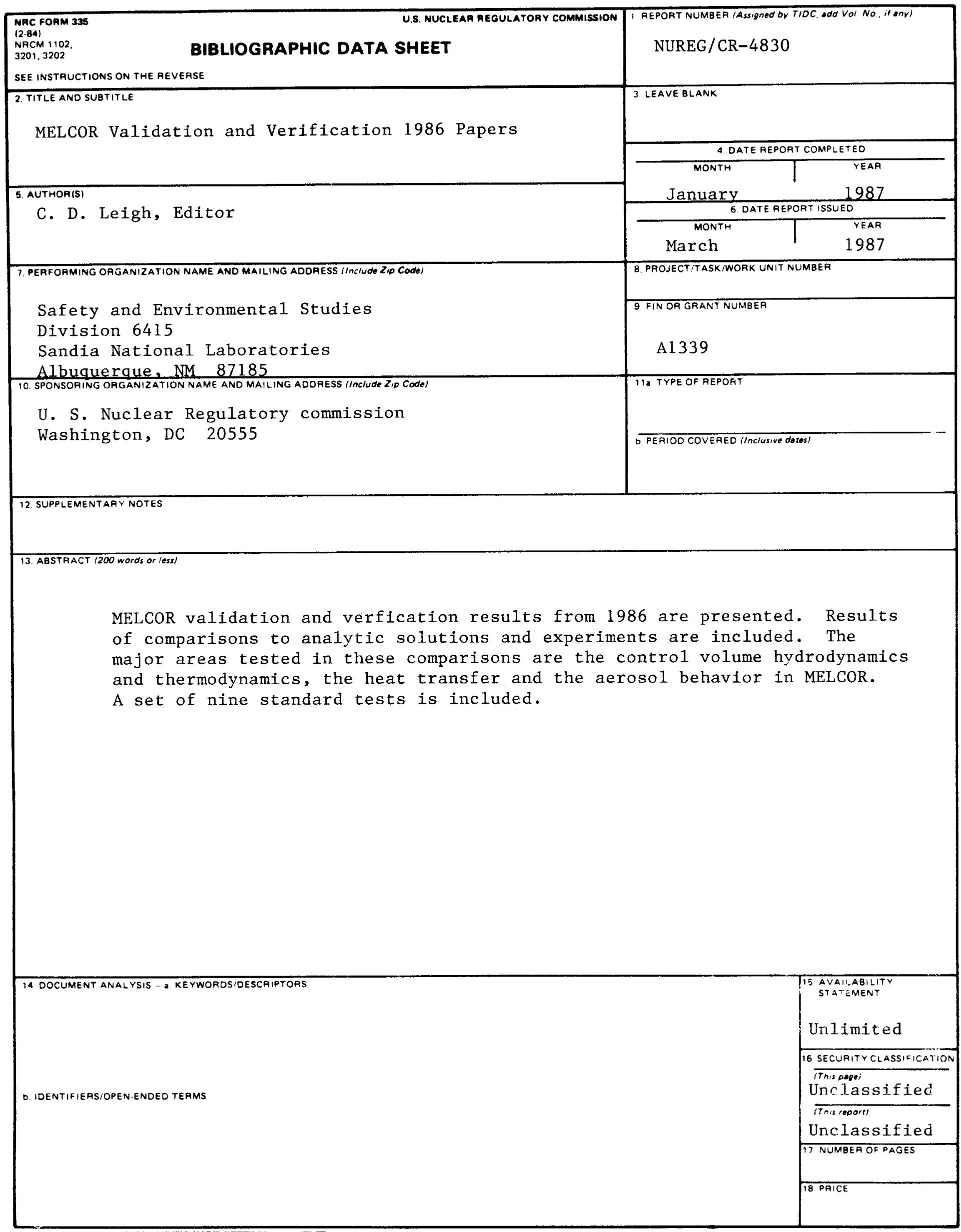

